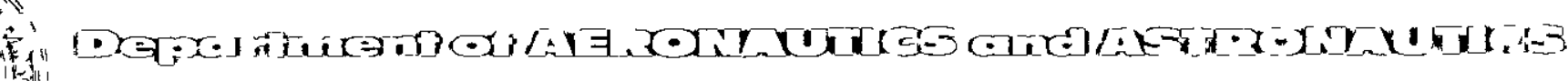

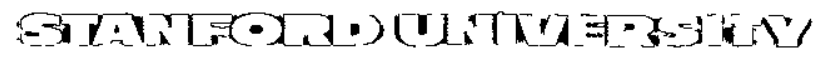

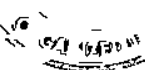

W. H. BoYKIN, JR.

I. FlügGE-LOTZ

\title{
ON THE HIGH-ACCURACY ATTITUDE CONTROL OF SATELLITES IN ELLIPTIC ORBITS
}

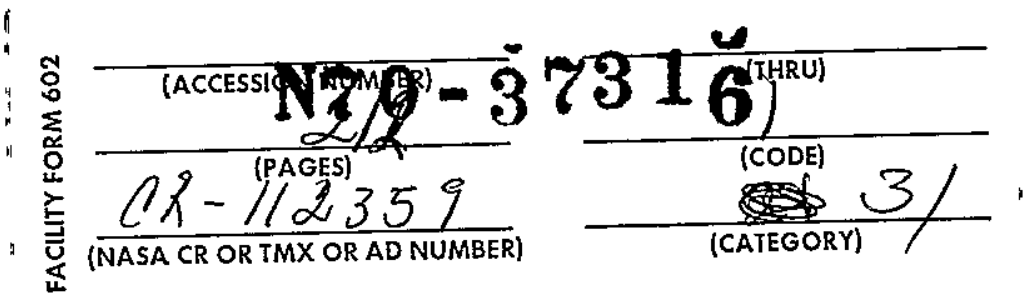

JULY

1967
Prepared for the National Aeronautics and Space Adminiștration Under Grant NsG 133-61
SUDAAR

NO 322 


\title{
Department of Aeronautzcs and Astronautics Stanford Unzversity Stanford, California
}

ON THE HIGH-ACCURACY ATTITUDE CONTROL OF SATETITTES IN ETIIPTIC ORBITS

\author{
by \\ W $\mathrm{H}$ Boykın, Jr \\ and \\ I Flugge-Iotz
}

SUDAAR NO 322

July 1967

This work was performed in association with research sponsored by the National Aeronautics and space Admunistration under Research Grant INsG-133-61 


\section{PRECEDING PAGE BLANK NOT FILMED.}

\section{ABSTRACT}

The goal of the Investigation was the development of a class of control systems which efficiently results in hlgh-accuracy ( $\leq 10^{-4}$ radiana) earth-pointing attıtude motions of sateliztes of different configurations in elliptic orbits. The earth-pointing orientation, $1 \mathrm{e}$, the orientation such that one body-fixed axis is parallel to the local vertical and another Is normal to the orbit plane, is required for the lifetimes of the satellites Gas jets provide the control torque

Innear differential equations with time-varying coefficients, which include terms for the gravity torque due to an oblate earth and terms for the aerodynamic torque, are used to describe the attitude motion when a satelizte is practically earth-pointing Nonlinear equations with timevaryıng coefficients are used to describe the attitude motion when acquisition of the earth-pointing motion from large, deviation angles $\left(\approx 80^{\circ}\right)$ is considered.

Pontryagın's Maxımum Princıple, the necessary conditıons for exact solutions of optimal bounded-phase-coordinate problems and guidelines obtained from the minumum-fuel station-keeping controls devised for single-axis systems are used in the development of the station-keeping part of the control system The acquisition part of the control system, developed here, results in acquisition of the earth-pointing motion from large angles in the time of one-quarter orbit with comparatively little fuel expenditures

The motions of the satellites with the developed station-keeping control systems are simulated on an analog computer, and, the performances of the systems are evaluated The nonlinear differential equations which Include the developed acquisition control systems with time delays are integrated by using a digltal computer The fuel expenditures and the times of acquisition obtained from these digital computer runs are compared with those for the satellite motions described approximately by Innear differential equations with the optimal controls obtained from the maxımum princıple 
The simulation studies together with the performance evaluations showed that the control systems are quite efflcient as well as reliable (The acquisition system is a back-up system to the station-keepıng system ) The overall control system, which is very simple to realize, is given in diagram form 


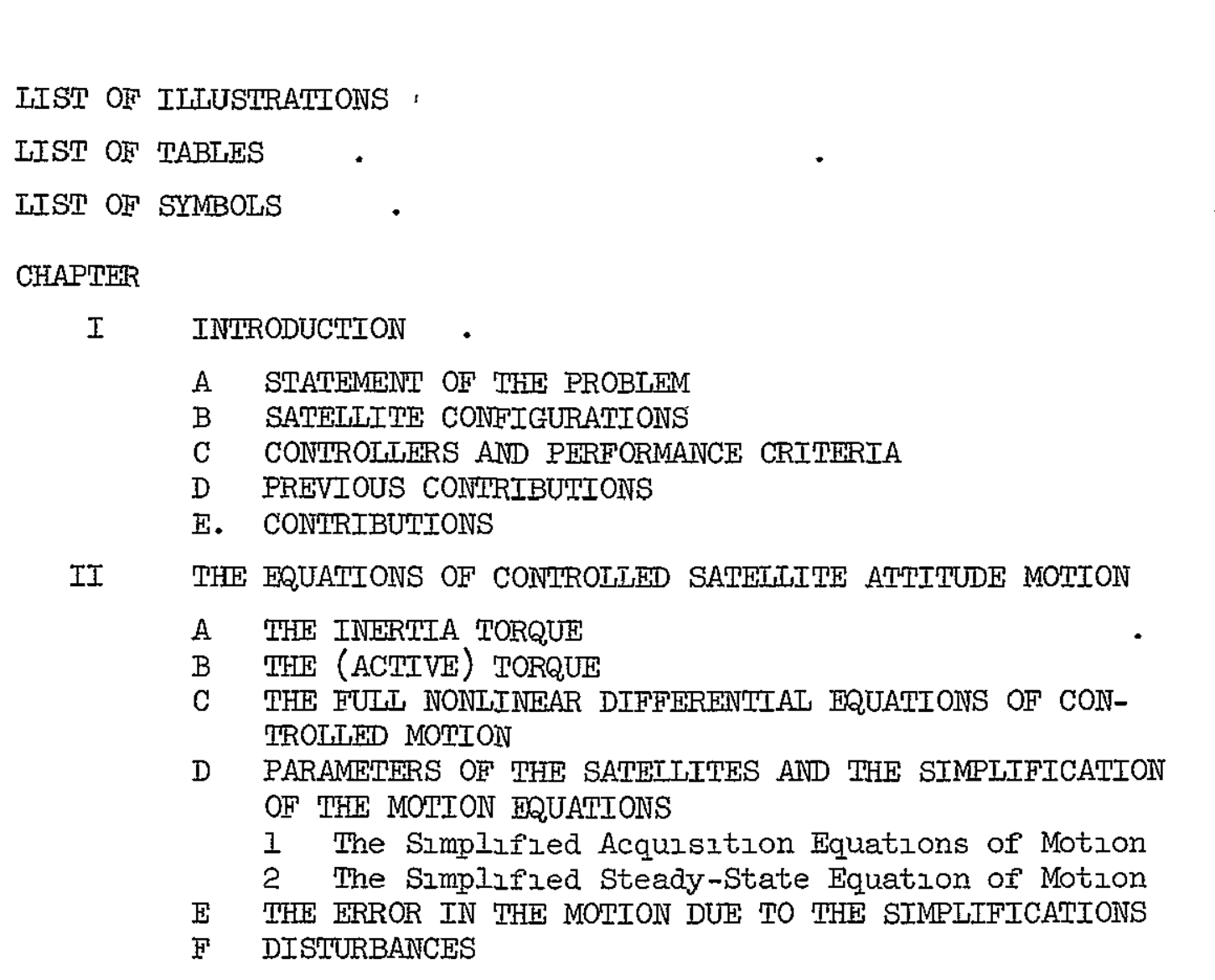

$x] 1$

X기그

Page

1

1

1

2

3

3

III THEORY OF THE CONTROL OF THE SATELIITES' ATTITEDES

A THE MOTION REQUIREMENTS IN TBRMS OF THE STATE OF THE PLANT

B SATISTACTORY PERFORMANVE AND THE COST

24

C THE OBJECTIVE

D MATHEMATICAL TOOIS USED FOR DETERMINING A CONTROL IAW

1 Pontryagın's Maxımum Princıple for Nonautonomous systems

2 Application to the Acquisition Problem

3 Application to Approximate Station-Keeping

4 Necessary Condztions for an Exact Solution (NCES) of the Station-Keeping Problem

IV DERIVATION OF STATION-KEEPING CONTROLS ILAWS

A THE APPROXIMATE SOLUTIONS - SPECIAI ORBITS 40

I A Station-Keeping Control Law Obtained From

$$
\begin{aligned}
& \text { PMP with } J=\int_{\tau_{0}}^{\tau_{f_{1}}}\left[f_{1}(x)+\left.\sum_{1}^{3}\right|_{1} \mid\right] \alpha \tau \\
& 2 \text { The Steady-State Motion Obtained from PMP for } \\
& x^{\prime \prime}=\mathrm{V} . \text {. }
\end{aligned}
$$


3 The Steady-State Motzon Obtained from PMP for $\mathrm{x}^{\prime \prime}+\mathrm{a}^{2} \mathrm{x}=\mathrm{v}, \mathrm{a}^{2}>0$

4 The Steady-State Motion Obtazned from PMP for $x^{\prime \prime}+a^{2} x=v, a^{2}<0$

B THE STATION-KEHEPING CONTROLS - GENERAL ORBITS

83

1 Station-Keeping Control of Satellites in a Maximum Gravitational Torque Orbit

2 Improvement of the Control Iaw of Part 1 , Section A

3 The Controls - Approximate Motions

4 The Controls - Station-Keeping Motions of the Satellites.

V DERIVATION OF ACQUISTTION CONTROL LAWS • • 104

A EXTENSTONS OF BUSCH ${ }^{2}$ S SOLUTION . . . 104

1 Via Phase Plane Techniques . . 104

2 Vıa Pontryagın's Maxımum Prıncıple. 108

$B$ ACQUISITION CONIROI IAWS WHICH PERFORM SATISFACTORILY

VI COMPLETE ATTITUDE CONTROL ARD PERFORMANCE EVALUATION

A ACQUISITION CONTROL COMPARED TO OPTIMAL (IINEAR)

ACQUISTTION CONIROL $\quad$ • . . .

B STATION-KEEPING CONTROI $\quad$ * $\quad 137$

I Comparison with Busch's Solutzon 137

2. Fuel Expenditure Per Orbit for Values of Various Parameters

C IMPERFECTIONS IN THE MODET AND THE ULTTMATE ABII,ITY TO EARTH-POINT

1 Nonrigidity of the Sateliztes. 145

2 Gas Jet Misalignment . 145

3 Sensors and Error 146

4 Others 146

VII CONCLUSION

REFHRENCES • • $\quad$ - $\quad$ - $\quad$ - $\quad 149$

APPENDIX $\quad$ Page

A THE GRAVITATIONAI TORQUE $\quad$ • 153

B TME AERODYNAMIC TORQUE $\quad$ - $\quad 159$

C THE PARAMETERS OF THE ORBIT AS FUNCTTONS OF TIME . . 164

D THE STATE-SPACE REGION OF STATION-KEEPING • $\quad 170$

E AN APPROXIMATE SOLUIION OF THE ADJOINT ERUATIONS 172

F DIGITAT AND ANTAIOG COMPUTER PROGRAMS 176 


\section{IIST OF IIUUSTRATIONS}

FIgure

Page

2.1 Principal Axes of Inertia, $I_{1}, I=1,2,3$, the Unit Vectors $\underline{n}_{1}, 1=1,2,3$, the Satellite $B$ and the Earth E.

31 A Simplified Diagram of the Controlled Attitude System.

3.2 The Functions $f_{1}, f_{2}, f_{e}$ and $f_{s}$ for $s_{2}=10^{-4}$.

41 Solution of Equations (4 3)-(4 6) for Satelizte (2) . 45

a Yaw Trajectory for $N_{1}=21 \times 10^{-4} \cdot N^{-4} \quad . \quad 45$

$b$ Yaw Adjolnt Variables for $n_{1}=10, n_{2}=20$. 45

c Roll Trajectory for $\mathrm{N}_{2}=7.1 \times 10^{-4}$. . . 46

d. Roll Adjoint Variables for $n_{3}=1.0, n_{4}=2.0$. 46

e Pitch Trajectory for $\mathrm{N}_{3}=206 \times 10^{-2}$. . 47

f. PItch Adjoint Variables for $n_{1}=20, n_{2}=4.0 \quad 48$

42 Solution of Equations (4.3)-(4.6) for Satellite (2). 54

a Yaw Trajectory for $\mathbb{N}_{1}=21 \times 10^{-4}$. . . . 54

b. Yaw Adjoint Varrables for $n_{1}=21, n_{2}=1.0 . .44$

c. Roll Trajectory for $\mathrm{N}_{2}=71 \times 10^{-4} \cdots 55$

d. Roll Adjolnt Varlables for $n_{3}=2.1, n_{4}=1.6$

e Pitch Trajectory for $\mathrm{N}_{3}=206 \times 10^{-2}$. . . 56

$f$ PItch Adjount Variables for $n_{1}=2.1, n_{2}=33$. 57

43 Typical Minımum Fuel Trajectories for System (4.13),

$\mathrm{N}_{2}=5 \times 10^{-4} \quad$. . . .

44 Nearly Minımum Fuel Boundary Encounter Trajectorıes for $\mathrm{x}^{\mathrm{n}}=\mathrm{v}, \mathrm{N}_{2}=50 \times 10^{-4}$

4.5 Adjoint Varıable in Backwards Tume Note: $p_{4}\left(\tau_{a}^{*}\right)>$. 10

46 A Free End Point Solution for $J$ with $f_{2}(x)$

a Phase Plane Trajectory . .

b Adjoznt Varıable 
47 Typıcal Minzmum Fuel Solutions for Systems (4.34),

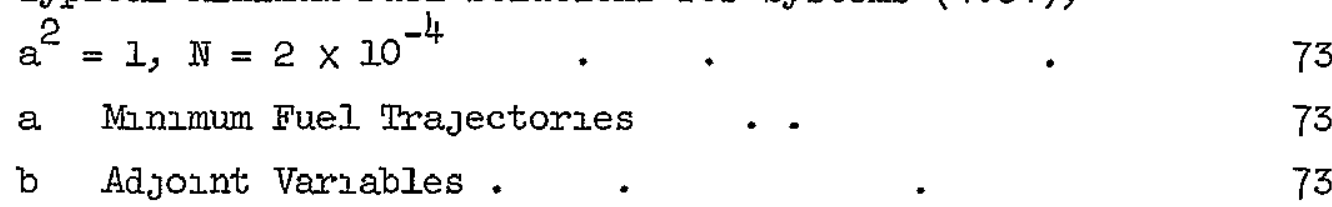

4.8 A Mnnmum Fuel Boundary Encounter Solution for System $(4.34)$

a Phase Plane Trajectories, $N=2 \times 10^{-4}, a^{2}=1 \quad 74$

b Adjoint Plane Trajectory . . 74

49 A Worst-Case Adjoint Solution Corresponding to Trajectory of Figure (4 8a), $n_{1}=103, n_{2}=-1$

410 Adjoznt Solutions.

411 Some Phase Plots of Solutions of Maximum Principle

Equations for $x^{\prime \prime}+a^{2} x=v, a^{2}=-1$

a Phase Plane Trajectories of $(434), \quad N=2 \times 10^{-i} \quad 79$

b. Phase Plane Plots of Adjolnt Varlables

79

412 Regions of Increase in Cost wath Increase in $\mathbb{N}$. 80

4.13 Iow Cost Control Laws and Trajectories, $\mathbb{N}=0$ 05, Tume Delay $=0.1 \mathrm{sec}$.

a A Iow Cost Control Law and Trajectory for a Realistic Case

b A Low Cost Control Law whlch Results in IIm]t Cycle Motion . .

414 A Single-Axıs Station-Keepıng Control Law .

4.15 The Control of Figure 414 Applied to $x^{\prime \prime}+a^{2}=v$, $\mathrm{a}^{2}=10, \mathrm{~N}=01, \mathrm{~d}=0$

4.16 The Control of Figure 414 Applied to $x^{\prime \prime}+a^{2} x=v$, $\mathrm{a}^{2}=-0.95, \mathrm{~N}=0.05, \mathrm{~d}=10^{-5}$. . . . 92

417 Station-Keeping Motion of Satellite (1)

a. Yaw Trajectory, $\mathbb{N}_{1}=001, t_{d}^{-}=0.5 \mathrm{sec}, t_{d}^{+}=125$ $\sec , d=4 \times 10^{-5^{1}}$ 
417 b. Roll Trajectory, $\mathrm{N}_{2}=0.01, \mathrm{t}_{\mathrm{a}}^{-}=0.5 \mathrm{sec}, \mathrm{t}_{\mathrm{d}}^{+}=1.0$ sec, $\mathrm{a}=4.0 \times 10^{-5} \ldots . . . . .93$

c Pitch Trajectory, $N_{3}=02, t_{d}^{\sim}=0.05 \mathrm{sec}, t_{d}^{+}=$ O O1 sec. $\mathrm{d}=25 \times 10^{-5} \ldots . . . . .94$

418 Statıon-Keepıng Motion of Satellite (2) . . . . . 95

a Yaw Trajectory, $\mathrm{N}_{1}=0.02, t_{\mathrm{d}}^{-}=0.5 \mathrm{sec}, \mathrm{t}_{\mathrm{d}}^{+}=1.25$ sec, $d=4 \times 10^{-5^{1}}$.........

b Rol1 Trajectory, $\mathrm{N}_{2}=002, t_{d}^{-}=0.5 \mathrm{sec}, t_{d}^{+}=10$ sec, $d=4 \times 10^{-5}$... ...

c Pitch Prajectory, $\mathbb{N}_{3}=0.03, t_{d}^{-}=02 \mathrm{sec}, t_{d}^{+}=$ $0.04 \mathrm{sec}, \mathrm{d}=25 \times 10^{-5}$.

4.19 Station-Keeping Motion of Satellite (3) . $\quad . \quad 96$

a Yaw Trajectory, $\mathrm{N}_{1}=0001, t_{\mathrm{d}}^{-}=05 \mathrm{sec}, \mathrm{t}_{\mathrm{d}}^{+}=1.25$ sec., $\mathrm{d}=2 \times 10^{-5^{1}}$. . . . . . . 97

b RoII Trajectory, $\mathrm{N}_{2}=0.001, \mathrm{t}_{\mathrm{d}}^{-}=0.5 \mathrm{sec}, \mathrm{t}_{\mathrm{d}}^{+}=$ $125 \mathrm{sec}, d=2 \times 10^{-5}$.

c Pitch Trajectory, $\mathrm{N}_{3}=0.03, \mathrm{t}_{\mathrm{d}}^{-}=0.2 \mathrm{sec}, \mathrm{t}_{\mathrm{d}}^{+}=$ $004 \mathrm{sec}, \mathrm{d}=25 \times 10^{-5}$

4.20 Station-Keepıng Motıon of Satellıte (4) . . . . . 99

a Yaw Trajectory, $N_{1}=001, t_{d}^{-}=05$ sec., $t_{d}^{+}=$ 125 sec., $\mathrm{d}=4 \times 10^{-5} \ldots \ldots \ldots$

b Roll Trajectory, $\mathrm{N}_{2}=0.01, \mathrm{t}_{\mathrm{d}}^{-}=0.5 \mathrm{sec}, \mathrm{t}_{\mathrm{d}}^{+}=$ $10 \mathrm{sec}, \mathrm{d}=4 \times 10^{-5}$

c Pitch Trajectory, $\mathrm{N}_{3}=0.12, \mathrm{t}_{\mathrm{d}}^{-}=02 \mathrm{sec}, \mathrm{t}_{\mathrm{d}}^{+}=$ $004 \mathrm{sec} . \mathrm{d}=2.5 \times 10^{-5}$

5.1 Swltching Curves of the Busch Control Iaw in the Yaw and Pltch Planes . . . . . . 106

52 Optimal (IInear) Acquisition Solutions . . 111

a Satellite $(1), J=8.19, \tau_{f} \tau_{0}=1.42, \theta_{0}=\pi / 4 . \quad 111$

b. Satellite (2), $J=8.92, \tau_{f}-\tau_{0}=132, \theta_{0}=\pi / 4 \quad 1.12$

c Satellite (3), $J=6.03, \tau_{f}-\tau_{0}=1.32, \theta_{0}=\pi / 4.113$

d. Satellite (4), $J=8.73, \tau_{f}-\tau_{0}=142, \theta_{0}=5 \pi / 4 \quad 114$ 
5.3 Suboptzmally Controlled Acquisition Motzon of Satellite

(1), $J=1266, \tau_{I}-\tau_{0}=142, \theta_{0}=\pi / 4 \quad 121$

a. Iarge Yaw Angles . 121

b Small Yaw Angles 121

c. Iarge Rol1 Angles - • 122

a Small Roll Angles . . . . . . 122

e Iarge Putch Angles . . . . . . . 123

$f \quad$ Small Patch Angles . . 123

5.4 Suboptimally Controlled Acquisition Motion of Satellite

(2), $J=9.07, \tau_{f}-\tau_{0}=169, \theta_{0}=\pi / 4 \quad 124$

a Iarge Yaw Angles $\quad$. . . . . . 124

b Small Yaw Angles . . . 124

c Iarge Roll Angles . . . . 125

d Small Roll Angles . . . . . . 125

e. Iarge Prtch Angles . • . 126

$f \quad$ Small Patch Angles . • . 126

5.5 Suboptimally Controlled Acquisition Motion of Satelilte

(3), $J=975, \tau_{f}-\tau_{0}=163, \theta_{0}=\pi / 4 . \quad . . \quad . \quad 127$

a Iarge Yaw Angles 127

b. Small Yaw Angles . $\quad$. . . 127

c Iarge Roll Angles . . 128

d. Small Roll Angles . . . . 128

e Large Pitch Angles . . . . . . 129

f. Small Pltch Angles . . . . 129

56 Suboptimally Controlled Acquisition Motion of Satellite (4), $J=837, \tau_{f}-\tau_{0}=169, \theta_{0}=7 \pi / 4 . . \quad 130$

a. Iarge Yaw Angles . . . 130

b. Small Yaw Angles . . 130

c Large Roll Angles . . 131

d. Small Roll Angles . . . . . . . . 131

e. Iarge Pıtch Angles . . . . . . . 132

f. Small Prtch Angles . . . . 132 
61 Block Diagram of the Complete Attitude Control System ... 135

6.2 Pitch Fuel Cost Per Orbit vs Eccentricity, $\mathrm{N}_{3}=0$ 035, $\mathrm{k}_{3}=099, \mathrm{~d}=0.140$

63 Roll-Yaw Fuel Cost for Varıous Values of $k_{1}$ and $k_{2}$, $\mathrm{N}_{1}=\mathrm{N}_{2}=0 \mathrm{01}, \mathrm{e}=005, \mathrm{\alpha}=3 \times 10^{-5} \cdot 14 \mathrm{l}$

64 Fuel Cost Per Orbit vs. Control Strength 143 a Roll-Yaw of Satellites (2) and (3) . 143 b Pitch of Satelizte (3) . . 143

65 Fuel Cost Per Orbit vs Size of the Region S - Satellite (2), $\mathrm{d}=20 \times 10^{-5}, \mathrm{~N}_{1}=\mathbb{N}_{2}=0 \mathrm{O}, \mathrm{N}_{3}=01 \quad 144$

A.I Unit Vectors and Parameters of the Orbit . 155

F I Solution of Approximate, Mnimum-Fuel Optimal, StationKeeping Equations $((43)$ and $(44))$ for Roll-Yaw

F 2 Solution of Approximate, Minımum-Fuel Optımal, StationKeepıng Equations $((45)$ and $(46))$ for PItch 180

F 3 Analog Program for Steady-State Roll-Yaw Motzon (Aero $\begin{array}{ll}\text { term added as required) } & 183\end{array}$

F 4 Analog Program for Steady-State Pitch Motion (Aero$\begin{array}{ll}\text { dynamıc torque term Is added as required) } & 185\end{array}$

F.5 Solution of Nonlinear Suboptimal Acquisition Equations $((214)-(52)) \quad \therefore \quad 187$

F 6 Solution of Optimal Iinear Acquisition Equation in Backward Time . . . . . . 190 


\section{TIIST OF TABLES}

TABLE

Page

21 Parameters of the Sateliltes and of Their Orbits

11

2.2 The Significant Torque Terms for Varıous Earth-Polnting Accuracies.

41 Fuel Expenditure for the Simulation Runs of Figure 4 17Figure 420

51 Modıfied Versions of Busch's Switching Curves

52 Slopes for the Stralght IIne Swltching Curves as Obtained from the Optimal (IInear) Solutions

53 The Parameters of the Control Iaw for the Inıtial Test 
IIST OF SYMBOLS

SYMBOI

a

A

B

B*

$\mathrm{C}_{\mathrm{D}}$

$c_{\delta}$

$c_{1}$

$\mathrm{C}_{1}$

CST

$c_{\theta}$

$c \theta$

$a$

$\delta$

$\Delta \tau+$

e

E

$\mathrm{E*}$

$\mathrm{f}^{1}$

f.

$F\left(\mathrm{x}_{I}\right)$

G

h

H

$I_{1}$
MEANING

Seml-major axis of elliptzc orbit

See equations (2.15)

RIgıd body satellite

Center of mass of $B$

Drag coefficient

Cosine function of $\delta$

Cosine function $\theta_{1}, 1=1,2,3$

Components of control torque

"Coast function" (see equation (4 2))

Cosine function of $\theta+\theta_{0}$

Cosine function of $\theta+\theta_{p}$

Distance between control switching lines (see

Figure 4 14)

Angle between earth's polar axis and the normal

to orbit plane (see Fugure A I)

see equation ( $\$ 7$ )

Eccentricity of orbut

10

Earth

Center of mass of $\mathrm{E}$

Functions representing right sides of equation of motion (see equation (3 1 ))

Functions of state which appear in some cost

functionals

32

Derıvatıve of $f_{1}$ with respect to $x_{1}$

42

Unıversal gravity constant

153

$h=r^{2} \theta$ for kepler orbit

10

Hamlltonlan functıon

29

Principal moments of Inertia, $1=1,2,3$

41

10

7

9

9


\{Oblateness coefficient (see Appendıx A)

(Cost functional or nondımensional fuel cost

K Constant in exponential atmospheric density law

Nondimensional inertia parameters, $1=1,2,3$

Components of distance vector from $B^{*}$ to center of aerodynamic pressure for $\underline{n}_{1}$

n Mean orbital rate 14.

NCES

"Necessary condıtions for exact solution"

Parameters in $f_{1}$

$\underline{n}$

Unlt vectors, $1=1,2,3$, parallel to princlpal axes

Maximum absolute value of $v_{I}$

Maxımum absolute value of $u_{1}$

104

Components of the satellite's angular velocity

See Figure A I

Adjoint vector $(n+1$ - dimensional)

Adjoint vector ( $\mathrm{n}$ - dimensional)

Distance from $\mathrm{E}^{*}$ to $\mathrm{B}^{*}$

Equatorial radıus of earth

Value of $r$ at perıgee

Atmospherıc density

Pa

Value of $\rho$ at apogee

Value of $\rho$ at perıgee 


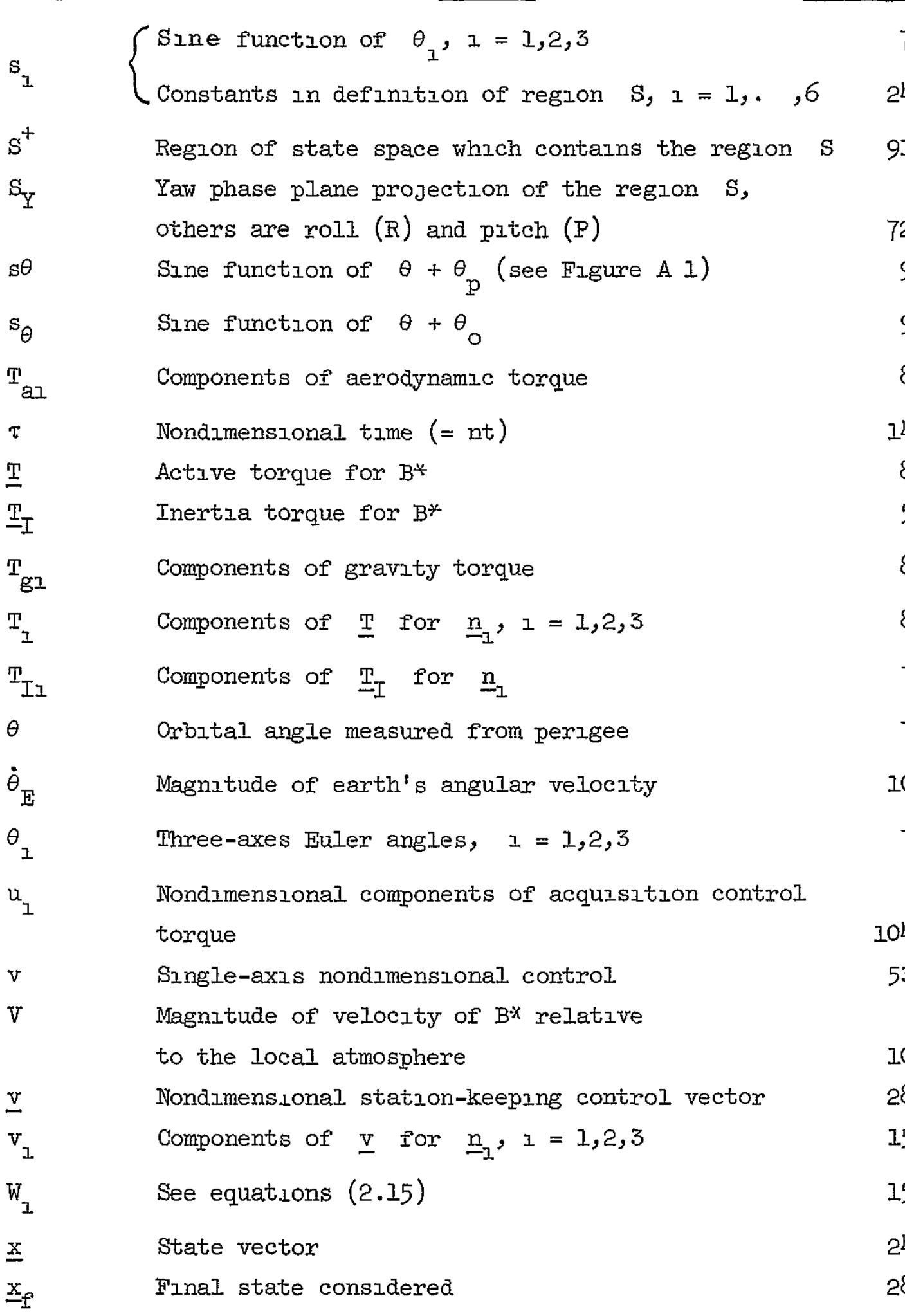


$\underset{x}{x}$

$\mathrm{x}_{1}$

$\mathrm{Y}_{\perp}$
Initial state considered

See equatıons (2 13)

$x_{1}$ scaled for analog computer to give one volt

when $x_{I}=10^{-4}$
28

14

183 


\section{INTRODUCTION}

\section{A. STATEMENT OF THE PROBIFM}

At thls time there are many planned artifical earth satellites which must perform tasks which require a given satellite-flxed line to be (nearly) parallel to the local vertical while the angles between every satellite-fixed Iine and tne orbit plane are (nearly) constant. This required orientation is called (near) earth-pointing Earth-pointing is not a natural satellite orientation so that control effort must be spent to keep the orientation (called station-keeping) once it has been acquired. The time interval of station-keeping for practical satellites ranges from minutes to years. In any case the controller, which causes the satellite to acquire the earth pointing attltude and keep It, must be effucient as well as reliable

The problem considered in this investigation is how to efficiently and reliably control a satellite's attitude motion so that it is very accurately earth-polntIng for a glven interval of time

\section{B SATEITITE CONFIGURATEONS}

Since attitude motion characteristics vary wldely with satellite configuration and since the efficiency of a given control varies with the characteristics of attıtude motıon, It, at first, seems necessary to consuder an almost irfunite variety of satellite configurations Lowever, upon further investigttion it is found that a few satelinte configurations exhibit a wide variety of attitude motions whose characteristics are basic characteristucs of a whole range of satellite configurations.

four configurations of sateliztes and tnelr orbits are considered. here Trese four configurations were chosen since they exhiblt a wide varlety of natural attitude motions and since they are similar to some future as well as some recent earth sateilites

Satellites (I) and (4) are simllar to some of today's "stable" scientific sateliztes $e \mathrm{~g}$, sateliztes of the Drbiting Geophysical Obse, vatory and the Turos serzes Satellite (4) Is such that aerodynamle forces significantly affect its attitude motion satellite (2) Is 
slmzlar to "unstable" manned and unmanned spacecraft whlch will be Inserted Into (nearly) circular earth parking orbits for transfer to orbits about other celestial bodies. Examples of such spacecraft are Apollo and Unmanned Mars Excursion Vehıcle Satelizte (3) is similar to future "unstable" mlitary applicatıons savellites

The orbits of the satellites are elliptlc, although for satelintes (2) and (3) the eccentricity is assumed to be only 0 ol. The orbits are not considered circular since sucn an assumption is generally a gross oversimplification and since the number of orbits a satelizte will complete before the aerodynamzc forces cause it to move on a trajectory back to earth increases with eccentricity (Breakwell and Koehler [4] have derived an expression for the number of orpits before decay This expression, whlch gives a lifetime of about 10,000 orbits (about 17 years) for an initial perıgee nelght of 200 miles and an initial eccentricity of 0.03 , has been experimentaliy verifiea )

\section{CONTROLTERS AND PERFORMANCE CRITERIA}

In recent years many devices which showed promise of controling tre attitude motion of sateliztes have been constructed, analyzed and to some extent applied with success These controllers are categorized according to tnelr subsystems whlch supply the control torques control torques are obtazned by devices such as gas jets, Ion propulsion units, three-axes-gyroscopes, v-gyroscopes, reaction wheels, reaction spheres, extendable pooms and magnetzc devices

Several investigators nave considered such devices in solving various acquisition and station-keeping problems For example, Horwitz [19] has considered pulse width modulation for fasrly hlgh accuracy control of highly Idealized attitude motion. Huston [20] considered the feasiblilty of employıng twan-gyroscopes for control, and, Schwartz [32] considered minimum energy acquisition using reaction wheel control Asymptotic stablizzation of the spin axis of a satellite in a circular orbit by magnetic control was considered by Wheeler [34] Haefner [15] and Nichol [28] each considered some of the general aspects of actitude control Although these solutions contribute to the solution of the problem at hand, none result in sufficient guidelines for the construction 
of a device which will efficiently and reliably control the attitude motion for high accuracy earth-polnting

Because of their simplicity and reliabllity, gas jets are considered In this investigation as the suppliers of control torque

The error in orientation for the high accuracy earth-pointing orientation is considered* to have priority over all other performances measures. However, for efficiency, the weight of the fuel spent for control must be as near minimal as is practicable (See Section B, Chapter III ) Another criterion used in the present investigation is the time limit for acquisition of the high accuracy earth-pointing orientation Since some satellites require rapid acquisition (e $g$, the acquisition of the Gemini-Agena to earth pointing before firing the agena rocket for changing orbit), the time of acquisition is limited to the time of onefourth of an orbit

D PREVIOUS CONTRIBUTIOINS

The present Investigation is a contınuation of the work at Stanford on the attrtude control of satellites Busch** [6] has developed a suboptimal minimum-fuel acquisition control law for a "stable" satellite in an elliptic orbit The use of this control law does not consistently result in acquisition to high accuracy earth-polnting unless the eccentricity of the orbit is very small However, Busch has Included a reaction wheel for improving the accuracy when the eccentricity is not small Although the reaction wheel must be slowed periodically by applyIng gas jet torque, Busch's controllex performs quzte well in stationkeeplng. The controller gives falrly high accuracy in earth-pointing, but the controller is not efficient whlle station-keeping

\footnotetext{
*After completing this work it came to our attention that $A$ E Pearson in his presentation on "Performance Maintainability in Precısion Attitude Control Systems" In J A C C preprints (Phıladelphia, 1967) discussed generalized performance measures for practical attitude control systems **AIso, see SUDAAR No 261 or $R \mathrm{E}$ Busch and I. Flügge-Lotz, "Attitude Control of a Satellite in an Elliptic Orbit", Journal of Spacecraft and Rockets, Vol 4, INo 4, 1967.
} 
Others who have Investigated certaln aspects of minimum-fuel attitude control are Flugge-Lotz and Marbach [13], Foy [14], Meditch [27], Athans [1], Cra.g and Flugge-Lotz [10] and Hales [16]

\section{E. CONIRTBUIIONS}

In Chapter II the equations of motions of rigld satellites in elliptic orbits about an oblate body with atmosphere are derived in terms of the "three-axes Euler angles" whlch for small angles are nearly the yaw, roll and pltch angles The effects of disturbances such as those due to solar radıatıon pressure, meteorolds, etc. are discussed A means of determining an upper bounds on the error due to simplifyzng the full nonlinear equations of controlled motion is given

In Chapter III the theory of the control of satelizte attitude motion Is discussed and its application justified

In Chapter IV a high-accuracy statıon-keepıng feedback control law Is developed The application of this control law to "unstable" as well as "stable" satellites results in very lıttle fuel expendıture The reliabllity and efficiency of the station-keeplng controller under adverse circumstances Is Investigated in Chapter VI where the overall system is dıscussed

Suboptimal acquisition control laws for the four sateliztes are developed In Chapter $V$ by extending Busch's results with the ald of phaseplane methods and Pontryagin's Maximum Principle.

It is assumed that sensors of attitude angles and their rates for such high accuracy will be avallable in the very near future 


\section{THE EQUATIONS OF CONTROIIED SATEIITTE ATTITUDE MOTION}

Satellite attitude motion is sultably described by a system of differential equations in which the dependent variables are the generalized coordinates of the satellite. Three of the generalized coordinates completely determine the attıtude of a rigld satelinte in some reference frame. The time-hustory of these three coordinates and their rates for some interval of time is called the attıtude motion in that time interval or more simply the motion

\section{A THE INERTIA TORQUE}

For a rigid* satellite, $B$, the inertıa torque for the mass center of $B, B^{*}$, Is well known. (See, for example, Kane [22].) If $\underline{n}_{1}$, $I=1,2,3$, are elements of a right-handed set of mutually perpendicular unit vectors which are parallel to principal axes of inertia of $B$ for $B^{*}$, say $I_{I}, I=1,2,3$, (see Flgure $2 I$ ) and If $I_{I}, I=1,2,3$, are the associated principal moments of inertia, then the inertia torque of $B$ for $B^{*}$ is given by

$$
\begin{aligned}
\underline{I}_{I} & =\left[\omega_{2} \omega_{3}\left(I_{2}-I_{3}\right)-\dot{\omega}_{1} I_{1}\right] \underline{n}_{1} \\
& +\left[\omega_{3} \omega_{1}\left(I_{3}-I_{1}\right)-\omega_{2} I_{2}\right] \underline{n}_{2} \\
& +\left[\omega_{1} \omega_{2}\left(I_{1}-I_{2}\right)-\omega_{3} I_{3} \underline{n}_{3},\right.
\end{aligned}
$$

where $\omega_{I}, I=1,2,3$, are the measure numbers of the angular velocity of $B$ in an inertial reference frame for the basis, $\underline{n}_{1}, 1=1,2,3$, and where the symbol ()$\equiv \alpha() / d t$

One orbit of the satellites considered very nearly lies in a plane In an ınertial space. (See Klng-Hele [23].). This plane, which contains the mass center, $\mathbb{F}^{*}$, of the earth, $E$, (together with the plane's normal) determines a sultable inertıal reference frame

\footnotetext{
* Causes of non-rigldity of the satellite and their effects on the controlled motion of the satellite and on the fuel cost are discussed in Section C of Chapter VI.
} 


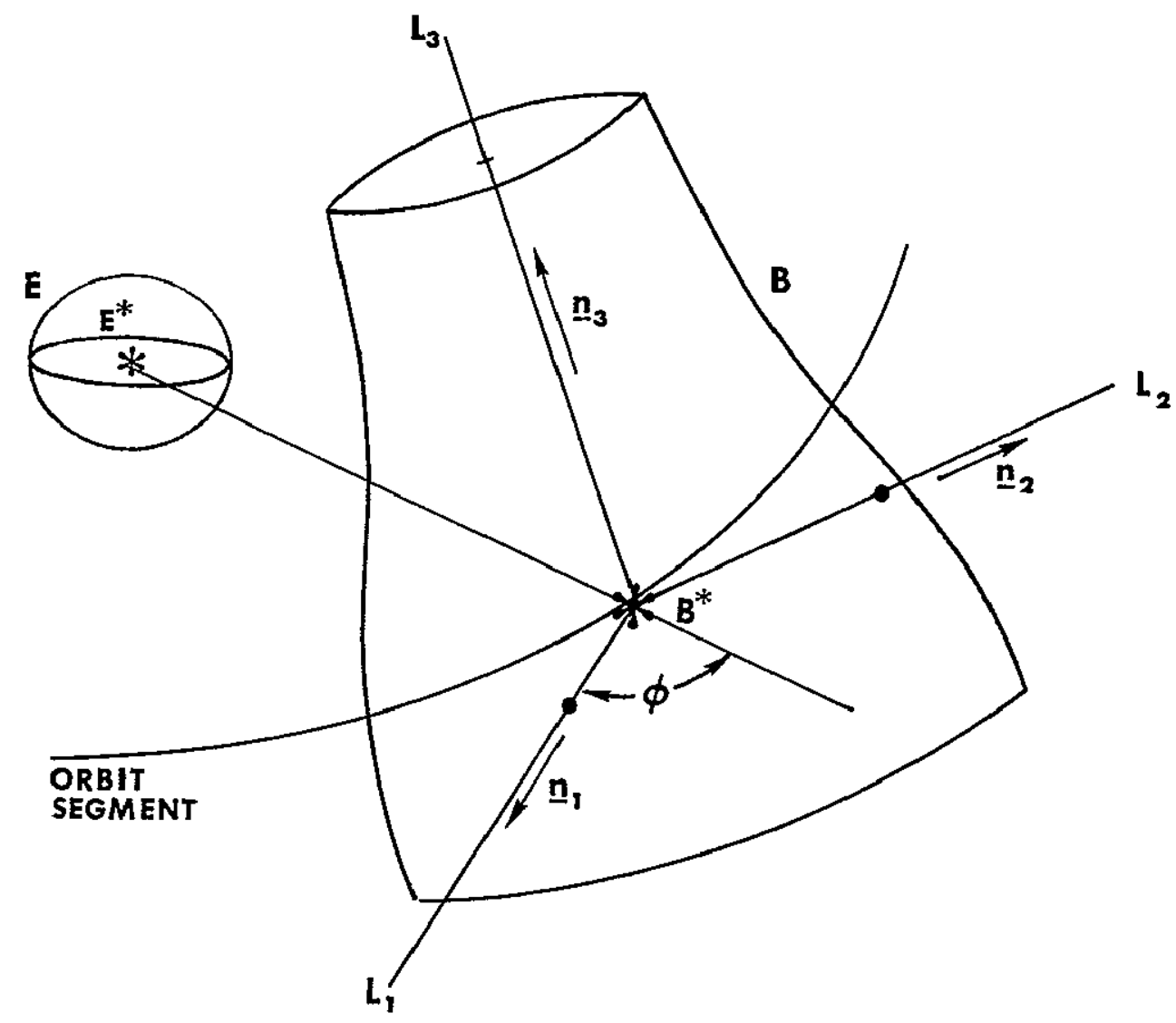

Figure 21 Principal Axes of Inertia, $I_{1}, 1=1,2,3$, the Unit Vectors $\underline{n}_{1}, 1=1,2,3$, the Satellite $B$ and the Earth E 
In terms of the "three-axes Euler angles", $\theta_{2}, 1=1,2,3, *$ (see Busch [6]) the measure numbers of $\mathbb{T}_{-}$, (2 I), for the basis $\underline{n}_{-1}$, $1=1,2,3$, are

$$
\begin{aligned}
T_{I 1} & =\left\{-\theta_{1} c_{2} c_{3}-\theta_{2} s_{3}+\theta_{1} \theta_{2} s_{2} c_{3}-\theta_{2} \theta_{3} c_{3}+\theta_{1} \theta_{3} c_{2} s_{3}\right. \\
- & \dot{\theta}\left[\theta_{1}\left(c_{1} s_{3}+s_{1} s_{2} c_{3}\right)-\theta_{2} c_{1} c_{2} c_{3}+\theta_{3}\left(s_{1} c_{3}+c_{1} s_{2} s_{3}\right)\right] \\
& \left.-\ddot{\theta}\left(s_{1} s_{3}-c_{1} s_{2} c_{3}\right)-k_{1} \omega_{2} \omega_{3}\right\} \times I_{1} \\
T_{I 2} & =\left\{-\theta_{2} c_{3}+\theta_{1} c_{2} s_{3}-\theta_{1} \theta_{2} s_{2} s_{3}+\theta_{2} \theta_{3} s_{3}+\theta_{1} \theta_{3} c_{2} c_{3}\right. \\
& -\theta\left[\theta_{1}\left(c_{1} c_{3}-s_{1} s_{2} s_{3}\right)+\theta_{2} c_{1} c_{2} s_{3}+\theta_{3}\left(c_{1} s_{2} c_{3}-s_{1} s_{3}\right)\right] \\
& \left.-\theta\left(s_{1} c_{3}+c_{1} s_{2} s_{3}\right)-k_{2} \omega_{3} \omega_{1}\right\} \times I_{2} \\
& =\left\{-\dot{\theta}_{3}-\theta_{1} s_{3}-\dot{\theta}_{1} \theta_{2} c_{2}+\dot{\theta}_{1}\left(\theta_{1} s_{1} c_{2}+\theta_{2} c_{1} s_{2}\right)\right. \\
& \left.-\dot{\theta}_{1} c_{2}-k_{3} \omega_{1} \omega_{2}\right\} \times I_{3}
\end{aligned}
$$

where $c_{1}=\cos \theta_{1}, s_{1}=\sin \theta_{1}, I=1,2,3$, and where

$$
\begin{aligned}
& \omega_{1}=\left(\theta s_{1}+\theta_{2}\right) s_{3}-\left(\theta c_{1} s_{2}-\theta_{1} c_{2}\right) c_{3} \\
& \omega_{2}=\left(\theta s_{1}+\theta_{2}\right) c_{3}+\left(\theta c_{1} s_{2}-\theta_{1} c_{2}\right) s_{3} \\
& \omega_{3}=\theta c_{1} c_{2}+\theta_{1} s_{2}+\theta_{3}
\end{aligned}
$$

The angle $\theta$ is defined in Appendix A (see Figure A I) and the inertia. parameters $\mathrm{k}_{1}, \mathrm{k}_{2}, \mathrm{k}_{3}$ are defined by

$$
k_{1}=\frac{I_{3}-I_{2}}{I_{1}}, \quad k_{2}=\frac{I_{1}-I_{3}}{I_{2}}, \quad k_{3}=\frac{I_{2}-I_{1}}{I_{3}} \text {. }
$$

When $\theta_{1}, 1=1,2,3$, are small, they can be considered as the yaw, roll and pitch angles, respectively 
The torque for $B^{*}$ is due to all contact and body forces acting on $B$ The body forces are due primarily to the gravitational attraction of the earth and other celestial bodies and the interaction of the satellite with the earth's magnetic field The contact forces are due primarily to the interaction of the satelizte with the earth's atmosphere and emissions from the sum, to collisions of the satellite with meteorolds and to the controls, for example gas jets

All of these forces were considered in the derivation of the torque for $B^{*}$ (See Section $F$ of this chapter.) However, the torque expression used in the derivation of the equations of motion is a result of considering only aerodynamic, control and earth gravitational forces This torque expression can be written as

$$
\underline{\underline{T}}=\sum_{1=1}^{3} \underline{T}_{1} \underline{\mathrm{n}}_{1}=\sum_{1=1}^{3}\left(\mathrm{~T}_{\mathrm{gl}}+\mathrm{T}_{\mathrm{al}}+\mathrm{C}_{1}\right)_{\underline{1}}
$$

where for the basis $\underline{n}_{1}, 1=1,2,3$, the measure numbers $C_{1}, 1=1,2,3$, are for the control torque vector, the measure numbers $T_{g 1}, 1=1,2,3$, are for the gravitational torque vector and the measure numbers $T_{a 1}$, $1=1,2,3$, are for the aerodynamic torque vector.

C. THE FULI NONLINEAR DIFEERENTIAT EQUATIONS OF CONTROTILDD MOTION If for each $\underline{n}_{1}, I=1,2,3$, the corresponding measure numbers of $I_{I}$ and $\underline{I}$ are divided by $I_{I}, I=1,2,3$, respectively, and summed to zero, then from (2.2a) $-(2 \mathrm{2c})$ and (2 5) the result is represented by three equations in $\theta_{1}, 1=1,2,3$ If these three equations are solved for $\theta_{1}, 1=1,2,3$, they give

$$
\begin{aligned}
\theta_{1} & =\left(\dot{\theta}_{1} \theta_{2} s_{2}-\theta_{2} \dot{\theta}_{3}-\dot{\theta}_{1} s_{1} s_{2}+\theta_{2} c_{1} c_{2}\right. \\
& -\dot{\theta}_{3} s_{1}+\theta c_{1} s_{2}+s_{3} k_{2} \omega_{3} \omega_{1}-c_{3} k_{1} \omega_{2} \omega_{3} \\
& \left.+c_{3} T_{1} / I_{1}-s_{3} T_{2} / I_{2}\right) / c_{2}
\end{aligned}
$$




$$
\begin{aligned}
\theta_{2} & =\theta_{1} \theta_{3} c_{2}-\theta_{1} c_{1}-\theta \theta_{3} c_{1} s_{2}-\dot{\theta}_{s_{1}} \\
& -c_{3} k_{2} \omega_{3} \omega_{1}-s_{3} k_{1} \omega_{2} \omega_{3} \\
& +c_{3} T_{2} / I_{2}-s_{3} T_{1} / I_{1} \\
\dot{\theta}_{3} & =-\dot{\theta}_{1} s_{2}-\dot{\theta}_{1} \theta_{2} c_{2}+\theta \theta_{1} s_{1} c_{2}+\theta \theta_{2} c_{1} s_{2} \\
& -\theta c_{1} c_{2}-k_{3} \omega_{1} \omega_{2}+T_{3} / I_{3}
\end{aligned}
$$

Equations (2.6a)-(2 6c) are the desired differential equations of motion in the dependent variables $\theta_{1}, 1=1,2,3$, and the independent variable $t$ If $\dot{\theta}$ and $\theta$ are known functions of $t$ and $T_{1}, 1=1,2,3$, are known function of $\theta_{1}, \dot{\theta}_{1}, 1=1,2,3$, and $t$. Except for $c_{1}$, $1=1,2,3$, which are to be determined in the following chapters as functions of $\theta_{1}, \dot{\theta}_{1}, I=1,2,3$, and $t$, the measure numbers $T_{1}$, $1=1,2,3$, are known functions of $\theta_{1}, \dot{\theta}_{1}, 1=1,2,3$, and $t$ Equations (B.II) wIth (B.3) and (B.IO) glve the desired relationships for T $T_{\text {al }}$, $1=1,2,3$, and Equations (A.8) with (A 9) and (A 10) give the desired relationships for $T_{g I}, 1=1,2,3$, if $r, r^{-2}, \mu / r^{3}, c_{\theta}$ and $s_{\theta}$ are known functions of time Equations (c 23)-(c 29) give $r, \mu / r^{3}, \theta, r^{-2}$, $\dot{\theta}, s_{\theta}$ and $c_{\theta}^{*}$ as functions of time.

The measure numbers of the torque as given by (2 5) can be written with the ald of Equations (A.8)-(A.10), (B.3), (B 10) and (B II) as

$$
\begin{aligned}
T_{1} & =G_{1}+\mu / r^{3}\left(I_{3}-I_{2}\right)\left\{-3 c_{2} s_{2} s_{3}\right. \\
& +J\left(r_{E} / r\right)^{2}\left[5\left(7 s_{\delta}^{2} s_{\theta}^{2}-1\right) c_{2} s_{2} s_{3}-2 s_{\delta} c_{\delta} c_{\theta} c_{1}^{2} c_{2} c_{3}\right. \\
& -2 s_{\delta}^{2} c_{\theta} s_{\theta} c_{1} s_{2} c_{3}+2 s_{\delta}^{2} c_{\theta} c_{1} s_{1} c_{2} c_{3} \\
& -2 c_{\delta}^{2} c_{1} s_{1} c_{2} c_{3}-8 c_{\delta} s_{\delta} c_{\theta} c_{1} c_{2}^{2} s_{3} \\
& \left.\left.+10 s_{\delta} c_{\delta} c_{\theta} c_{1} c_{2} s_{2}+\left(\text { THRMS IN } s_{1}^{2}, ., s_{1}^{4}\right)\right]\right\}
\end{aligned}
$$

(continued)

*If, of course, $\theta_{0}$ is replaced with $\theta_{p}$. 


$$
\begin{aligned}
& -\left(c_{D} / 2\right) \operatorname{SpV}\left\{\dot{r}\left(l_{2} s_{2}+b_{3} c_{2} s_{3}\right)\right. \\
& -r\left(\dot{\theta}-\theta_{E} c_{\delta}\right)\left[\ell_{2} s_{1} c_{2}+\ell_{3}\left(c_{1} c_{3}-s_{1} s_{2} s_{3}\right)\right] \\
& \left.+r \dot{\theta}_{E} s_{\delta} c_{\theta}\left[b_{2} c_{1} c_{3}-b_{3}\left(s_{1} c_{3}+c_{1} s_{2} s_{3}\right)\right]\right\} \\
& T_{2}=C_{2}+\mu / r^{3}\left(I_{1}-I_{3}\right)\left\{3 c_{2} s_{2} c_{3}+J\left(r_{E} / r\right)^{2}\left[5\left(1-7 s_{\delta}^{2} s_{\theta}^{2}\right) c_{2} s_{2} c_{3}\right.\right. \\
& -2 s_{\delta} c_{\delta} c_{\theta} c_{1}^{2} c_{2} s_{3}+2 c_{\delta}^{2} c_{1} c_{2} s_{2} c_{3}+8 s_{\delta} c_{\delta} s_{\theta} c_{1} c_{2}^{2} c_{3}-8 s_{\delta}^{2} s_{\theta} c_{\theta} s_{1} c_{2}^{2} c_{3} \\
& \left.\left.+18 s_{0}^{2} s_{\theta}^{2} c_{2} s_{2} c_{3}+\left(\text { TERMS IN } s_{1}^{2}, s_{1}^{3}\right)\right]\right\}-\left(c_{D} / 2\right) \text { Sp } V\left\{r\left(l_{3} c_{2} c_{3}-b_{1} s_{2}\right)\right. \\
& +r\left(\dot{\theta}-\theta_{E} c_{\delta}\right)\left[l_{3}\left(s_{1} s_{2} c_{3}+c_{1} s_{3}\right)+l_{1} s_{1} c_{2}\right] \\
& \left.+r \theta_{F} c_{\theta} s_{\delta}\left[b_{3}\left(s_{1} s_{3}-c_{1} s_{2} c_{3}\right)-b_{1} c_{1} c_{2}\right]\right\} \\
& T_{3}=C_{3}+\mu / x^{3}\left(I_{2}-I_{1}\right)\left(-3 c_{2}^{2} c_{3} s_{3}+J\left(x_{E} / r\right)^{2}\left[5\left(7 s_{0}^{2} s_{\theta}^{2}-1\right) c_{2}^{2} c_{3} s_{3}\right.\right. \\
& +8 s_{\delta}^{2} s_{\theta} c_{\theta} c_{1} c_{2} c_{3}^{2}+8 s_{\delta} c_{\delta} s_{\theta} s_{1} c_{2} c_{3}^{2}-18 s_{\delta}^{2} s_{\theta}^{2} c_{2}^{2} c_{3} s_{3} \\
& \left.\left.\left.-2 s_{\delta}^{2} c_{\theta}^{2} c_{1}^{2} c_{3} s_{3}+2 s_{\delta} c_{\delta} c_{\theta} c_{1}^{2} s_{2} c_{3}^{2}+\text { (TERMS IN } s_{1}^{2}, \quad, s_{1}^{5}\right)\right]\right\} \\
& -\left(c_{D} / 2\right) \operatorname{S\rho V}\left\{-r\left(l_{1} c_{2} s_{3}+l_{2} c_{2} c_{3}\right)\right. \\
& +r\left(\theta-\theta_{1} c_{\delta}\right)\left[b_{1}\left(c_{1} c_{3}-s_{1} s_{2} s_{3}\right)-b_{2}\left(s_{1} s_{2} c_{3}+c_{1} s_{3}\right)\right] \\
& \left.+r \theta_{E} c_{\theta} s_{\delta}\left[l_{1}\left(s_{1} c_{3}+c_{1} s_{2} s_{3}\right)-\ell_{2}\left(s_{1} s_{3}-c_{1} s_{2} c_{3}\right)\right]\right\}
\end{aligned}
$$

where

$$
\begin{aligned}
& \rho=\rho_{p} \exp \left[K\left(r-r_{p}\right)\right] \\
& V=(h / a)(I+2 e c \theta)^{I / 2}
\end{aligned}
$$

Equations (2.6a)-(2 6c) with Equations (2.3), (2.4), (2 7a)-(2 9) and with Equations (c.23)-(c.29) are the desired nonlinear differential 
equations of controlled motion This model of the controlled motion can be simplified without introducing significant error The simplifications strongly depend on the parameters of the satellite and on the mode (steady-state or acquisition) of motion

D PARAMETERS OF THE SATETITITES AND THE SIMPIICATION OF THE MOTION EQUATIONS

In the Introduction, Chapter $I$, the general configurations and the altitudes of the four satellites to be considered were discussed Here this discussion is translated into numbers for $I_{1}, I_{2}, I_{3}, k_{1}, k_{2}, k_{3}, e, a_{1}, \delta$, $\theta_{p}, \rho_{p}$, the helght of perigee ( $\left.p h\right)$ and the helght of apogee (ah) These numbers for the four satellites are given in Table (2 I) together with the a.r density at apogee, $\rho_{a}$

TABLE 21 PARAMETERS OF THE SATETIITES AND OF THEIR ORBITS

\begin{tabular}{|c|c|c|c|c|}
\hline Satellzte No & (1) & (2) & (3) & (4) \\
\hline $\begin{array}{c}I_{1} \\
I_{2} \\
I_{3} \\
\left(\text { slug }-f t^{2}\right) \\
\end{array}$ & $\begin{array}{l}230 \times 10^{5} \\
233 \times 10^{5} \\
236 \times 10^{5}\end{array}$ & $\begin{array}{l}115 \times 10^{5} \\
700 \times 10^{3} \\
121 \times 10^{5}\end{array}$ & $\begin{array}{l}700 \times 10^{3} \\
121 \times 10^{5} \\
115 \times 10^{5}\end{array}$ & $\begin{array}{l}143 \times 10^{4} \\
144 \times 10^{4} \\
145 \times 10^{4}\end{array}$ \\
\hline $\begin{array}{l}\mathrm{k}_{1} \\
\mathrm{k}_{2} \\
\mathrm{k}_{3}\end{array}$ & $\begin{array}{cc}0 & 01 \\
-0 & 03 \\
0 & 01\end{array}$ & $\begin{array}{r}099 \\
-086 \\
-089\end{array}$ & $\begin{array}{r}-086 \\
-089 \\
0.99\end{array}$ & $\begin{array}{cc}0 & 01 \\
-0 & 01 \\
0 & 01\end{array}$ \\
\hline $\mathrm{e}$ & 005 & 001 & 001 & 0.03 \\
\hline $\begin{array}{l}a(\text { mlles }) \\
p h \text { (mıles }) \\
a h(m i l e s)\end{array}$ & $\begin{array}{r}4480 \\
300 \\
745\end{array}$ & $\begin{array}{r}4500 \\
500 \\
585\end{array}$ & $\begin{array}{r}4500 \\
500 \\
585 \\
\end{array}$ & $\begin{array}{r}4260 \\
200 \\
460\end{array}$ \\
\hline $\begin{array}{l}\theta_{p}(\text { radıans }) \\
\delta(\text { radıans })\end{array}$ & \multicolumn{4}{|c|}{$\begin{array}{l}\text { varıable from } 0 \text { to } 2 \pi \\
\text { varıable from } 0 \text { to } \pi \text { if } 0 \leq \Omega \leq \pi\end{array}$} \\
\hline $\begin{array}{l}\rho_{p} \\
\rho_{a} \\
\left(\text { slugs } / f t^{3}\right)\end{array}$ & $\begin{array}{l}62 \times 10^{-15} \\
34 \times 10^{-18}\end{array}$ & $\begin{array}{l}16 \times 10^{-16} \\
47 \times 10^{-17}\end{array}$ & $\begin{array}{l}16 \times 10^{-16} \\
47 \times 10^{-17}\end{array}$ & $\begin{array}{l}40 \times 10^{-14} \\
37 \times 10^{-16}\end{array}$ \\
\hline
\end{tabular}


The orbits of the satellites are fixed by the values given for $a, e, \theta_{p}, \Omega$ and $\delta$ The shapes and compositzons of the sateliztes are not completely fixed by the values given for $I_{1}, I_{2}$ and $I_{3}$ and are even less fixed if values are only given for $k_{1}, 1=1,2,3$, (sınce common multiples of $I_{1}, I=1,2,3$, result in the same values of $k_{1}, I=1,2,3$ ) Typical configurations of the four satellites are as follows

(1) Nearly spherıcal with a welght of 60,000 Ibs, a maximum dimension of $14 \mathrm{ft}$ and a specific weight of $40 \mathrm{lbs} / \mathrm{ft}^{3}$

(2) Nearly circular cylindrical with a weight of 50,000 lbs, a helght of $30 \mathrm{ft}$., a mean diameter of $6 \mathrm{ft}$. and a specific weight of $60 \mathrm{lbs} / \mathrm{ft}^{3}$ The axıs of minımum moment of inertia is nearly tangent to the orbital path when in the earthpointing moder

(3) Similar to (2) except that its axis of minimum moment of inertia is nearly coincident with the local vertical when in the earth-pointing mode

(4) Nearly spherical with a welght of 10,000 Ibs, a maximum dimension of $9 \mathrm{ft}$. and a specific welght of $30 \mathrm{lbs} \cdot \mathrm{ft}^{3}$

The simplifications of the equations of motion are naturally divided by the regimes of $\left|\theta_{1}\right|, 1=1,2,3$, and the magnitudes of their compatible rates In the acquisition mode $\left|\theta_{I}\right|, I=1,2,3$, vary from about one radian down to $10^{-3}$ radians or less with most of the time of acquisition spent with $\left|\theta_{I}\right|, I=1,2,3$, assuming the larger values In the steady-state mode the motion will be controlled in a manner such that $\left|\theta_{1}\right|, I=1,2,3$, wIII be less than $10^{-3}$ radians In the following two parts of this section, Parts 1 and 2 , the equations of controlled motion are simplified for the two modes of motion. The reasons for the simplifications are the solution of the full nonlinear equations of controlled motion with the ald of a digital computer is extremely costly, the analog simulation of these equations (even after they have been Ilnearized in $\left.\theta_{1}, \dot{\theta}_{1}, 1=1,2,3\right)$ requires a greater number of operational amplifiers than Is avallable on the analog computer used (two pace IR-48 computers slaved together), and, finally, the error due to the simplificatıons is insignificant in the final results (see Chapter VI) 


\section{The Simplified Acquisition Equations of Motion}

For some satellites certaln terms in the nonlinear equations of controlled motion are insignificantly small when the controlled satellite is in the acquisition mode. These terms are less than one-one hundredth of the other terms in magnitude for all but about the last one-tenth of the time of acquisition, which is assumed to be the time of one-quarter of an orbit or less During the last one-tenth of the acquisition time all of the terms are of the order of $10^{-9}$ or less

For satellites (1), (2) and (3) the insignificant terms are those in equations $(27 \mathrm{a})-(27 \mathrm{c})$ with $C_{D}$ and $J$ as coefficients and some of those in equations $(26 a)-(26 c)$ and $(2.7 a)-(27 c)$ which are products of two or three of $s_{1}, \theta_{1}, 1=1,2,3$, and $\dot{\theta}$ The cost of the digital computer solution of the equations with the latter of the above InsIgniflcant terms included is not significantly greater than the cost of the solution without these terms If only those terms with $C_{D}$ and $J$ as coefficients are omitted, then the simplified acquisition equations of motion for satellites (1), (2) and (3) are

$$
\begin{aligned}
& \theta_{1}=\left(\theta_{1} \theta_{2} s_{2}-\theta_{2} \theta_{3}-\theta \theta_{1} s_{1} s_{2}+\theta_{2} c_{1} c_{2}-\theta \theta_{3_{1} s_{1}}+\dot{\theta} c_{1} s_{2}\right. \\
& +k_{2} s_{3} \omega_{3} \omega_{1}-k_{1} c_{3} \omega_{2} \omega_{3}+c_{3} c_{1}^{-} / I_{1}-3 k_{1}\left(\mu / r^{3}\right) c_{2} s_{2} c_{3} s_{3} \\
& \left.-s_{3} c_{2} / I_{2}-3 k_{2}\left(\mu / x^{3}\right) c_{2} s_{2} c_{3} s_{3}\right) / c_{2} \\
& \theta_{2}=\theta_{1} \theta_{3} c_{2}-\theta_{1} c_{1}-\theta_{3} c_{1} s_{2}-\theta_{s_{1}}-k_{2} c_{3} \omega_{3} \omega_{1}-k_{1} s_{3} \omega_{2} \omega_{3} \\
& +c_{3} \mathrm{C}_{2} / I_{2}+3 k_{2}\left(\mu / r^{3}\right) c_{2} s_{2} c_{3}^{2} \\
& -\mathrm{s}_{3} \mathrm{C}_{1} / I_{1}+3 \mathrm{k}_{1}\left(\mu / \mathrm{x}^{3}\right) c_{2} \mathrm{~s}_{2} \mathrm{~s}_{3}^{2} \\
& \theta_{3}=-\theta_{1} s_{2}-\ddot{\theta}_{1} \theta_{2} c_{2}+\dot{\theta}_{1_{1}} s_{1} c_{2}+\theta \theta_{2} c_{1} s_{2}-\dot{\theta} c_{1} c_{2}-k_{3} \omega_{1} \omega_{2} \\
& +\mathrm{C}_{3} / I_{3}-3 \mathrm{k}_{3}\left(\mu / \mathrm{r}^{3}\right) \mathrm{c}_{2}^{2} \mathrm{c}_{3} \mathrm{~s}_{3}
\end{aligned}
$$


where $\omega_{1}, I=1,2,3$, are given by (2.3) and $\mu / r^{3}, \dot{\theta}$ and $\theta$ are given by $(\mathrm{C} 24)$, (C 25) and (C 27) with $\theta_{0}$, the angle from perigee at $t=0$, added to nt

For satellite (4) the terms which are inslgnificant and will be omitted in the acquisition equations of motion are those which contain one of $J, C_{D} \dot{r}, C_{D} r \theta_{E}$ and $r \theta l_{I} s_{J} s_{k}, 1, J, k=1,2,3$, as factors In this case, if $\operatorname{Vr} \dot{\theta}$ is replaced by $\left(h^{2} / a^{2}\right)(1+2 e c \theta) \approx\left(h^{2} / a^{2}\right)[1+2 e \cos$ $\left.\left(\mathrm{nt}+\theta_{0}\right)\right]$ (see equations (B.10) and (C.29)), the simplified equatıons of motion are the same as (2 10a)-(2 10c) except that the terms

$$
\begin{aligned}
\operatorname{rhs}_{1} & =\left(c_{D} / 2\right) \operatorname{sp}\left(h^{2} / a^{2}\right)\left[1+2 e \cos \left(n t+\theta_{0}\right)\right] \\
& \times\left(c_{3} / I_{1} c_{2}\right)\left(l_{2} s_{1} c_{2}+b_{3} c_{1} c_{3}\right) \\
r h s_{2} & =0, \\
\operatorname{rhs}_{3} & =\left(c_{D} / 2 I_{3}\right) \operatorname{sp}\left(h^{2} / a^{2}\right)\left[1+2 e \cos \left(n t+\theta_{0}\right)\right] \\
& \times\left(b_{2} c_{1} s_{3}-b_{1} c_{1} c_{3}\right)
\end{aligned}
$$

are added to the right-hand sides of equations (2 10a), (2.10b) and (2 10c), respectively

If (C 23) Is substituted Into (B 2) and $\theta$ is assumed to be $\theta_{0}$ at $t=0$, then

$$
\rho=\rho_{p} \exp \left\{\operatorname{Ke}\left[\cos \left(n t+\theta_{0}\right)\right]\right\}
$$

A more convenient form of the simplified acquisition equations of motion is obtalned by letting $\tau=n t,()^{\prime}=a() / a \tau$

$$
x_{2 \times 1-1}=\theta_{1}, \quad x_{2 \times 1}=\theta_{1}^{t} \quad \text { for } 1=1,2,3
$$

With these substitutions and the substitution of (c 24), (c 25) and (C 27) into (2 10a)-(2 10c) the equations of motion for sateliltes (1), (2) and (3) becomes

$$
x_{1}^{i}=x_{2}
$$




$$
\begin{aligned}
x_{2}^{\prime}= & x_{2} x_{4} s_{2}-x_{4} x_{6}+A_{1}\left(x_{4} c_{1} c_{2}-x_{2} s_{1} s_{2}-x_{6} s_{1}\right)+A_{2} c_{1} s_{2} \\
& +k_{2} s_{3} W_{3} W_{1}-k_{1} c_{3} W_{2} W_{3}+c_{3} v_{1}-s_{3} v_{2} \\
& \left.-3 A_{3}\left(k_{1}+k_{2}\right) c_{2} s_{2} c_{3} s_{3}\right\} / c_{2} \\
x_{3}^{\prime} & =x_{4} \\
x_{4}^{\prime} & =x_{2} x_{6} c_{2}-A_{1}\left(x_{2} c_{1}+x_{6} c_{1} s_{2}\right)-A_{2} s_{1}-k_{2} c_{3} W_{1} W_{1}-k_{1} s_{3} W_{2} W_{3} \\
& +c_{3} v_{2}-s_{3} v_{1}+3 A_{3}\left(k_{2} c_{3}^{2}-k_{1} s_{3}^{2}\right) c_{2} s_{2} \\
x_{5}^{\prime} & =x_{6} \\
x_{6}^{\prime} & =-x_{2} x_{4} c_{2}-x_{2}^{\prime} s_{2}+A_{1}\left(x_{2} s_{1} c_{2}+x_{4} c_{1} s_{2}\right) \\
& -A_{2} c_{1} c_{2}-k_{3} W_{1} W_{3}+v_{3}-3 k_{3} A_{3} c_{2}^{2} c_{3} s_{3}
\end{aligned}
$$

where $v_{1}=C_{1} / n^{2} I_{1}, 1=1,2,3$,

$$
\begin{aligned}
& A_{1}=\dot{\theta} / n=\left[1+2 e \cos \left(\tau+\theta_{0}\right)\right] \\
& A_{2}=\dot{\theta} / n^{2}=-2 e\left[\sin \left(\tau+\theta_{0}\right)+5 e \cos \left(\tau+\theta_{0}\right) \sin \left(\tau+\theta_{0}\right)\right] \\
& A_{3}=\left(\mu / r^{3} n^{2}\right)=\left[1+3 e \cos \left(\tau+\theta_{0}\right)\right] \\
& W_{1}=\omega_{1} / n=x_{2} c_{2} c_{3}+x_{4} s_{3}+A_{1}\left(s_{1} s_{3}-c_{1} s_{2} c_{3}\right) \\
& W_{2}=\omega_{2} / n=x_{4} c_{3}-x_{2} c_{2} s_{3}+A_{1}\left(s_{1} c_{3}+c_{1} s_{2} s_{3}\right) \\
& W_{3}=\omega_{3} / n=x_{6}+x_{2} s_{2}+A_{1} c_{1} c_{2}
\end{aligned}
$$

The acquisition equations of motion for satelizte (4) are obtalned by adding

$$
\mathrm{RHS}_{1}=\operatorname{rhs}_{1} / \mathrm{n}^{2}=A_{4}\left(\ell_{2} \mathrm{~s}_{1} c_{2}+\ell_{3} c_{1} c_{3}\right)\left(c_{3} / I_{1} c_{2}\right)
$$




$$
\begin{aligned}
& \mathrm{RHS}_{2}=r h s_{2} / n^{2}=0 \\
& \mathrm{RHS}_{3}=r h s_{3} / n^{2}=A_{4}\left(\ell_{2} c_{1} s_{3}-\ell_{1} c_{1} c_{3}\right)\left(I_{3}^{-1}\right)
\end{aligned}
$$

where $A_{4}=\left(C_{D} \rho_{p} \operatorname{Sh}^{2} / 2 a^{2}\right)\left[I+2 e \cos \left(\tau+\theta_{0}\right)\right] \exp \left\{\operatorname{Ke}\left[\cos \left(\tau+\theta_{0}\right)-I\right]\right\}$ to the right-hand side of the second, fourth and sixth of equations (2 13), respectively. Equations (2.16) are obtained from equations (2 11a)(2 IIc) and (2 12)

\section{The Simplified Steady-State Equation of Motion}

High-accuracy earth-pointing motion or steady-state motion is defined to be motion such that $\left|x_{1}\right|<10^{-3}$ radians, $1=1,, 6$ (see equations (2 13)) (In the search for a steady-state control law, $1 \mathrm{e}$, for the functions $v_{1}=v_{1}\left(x_{1}, \ldots, x_{6}, \tau\right), 1=1,2,3$, It Is required that $\left|x_{1}\right| \leq 11 \times 10^{-4}$ radıans) In the steady-state mode the terms In the nonlinear equations of motion which contain products of some of $x_{I}, I=1, ., 6$, are InsIgnificantly small and can be omitted The terms in the earth oblateness part of the gravitation torque (terms with $J$ as a coefficient) cannot in general be neglected as was done in the acquisition equations. However, in the equation corresponding to the $\mathrm{T}_{3} \underline{n}_{3}$ component of the torque the oblateness terms can be neglected since for an entire orbit these terms are about one one-hundredth of the inertia torque term, $\dot{\theta}$ In the two equations corresponding to the $\mathbb{T}_{1} \underline{n}_{1}$ and $\mathbb{T}_{2} \underline{n}_{2}$ components of the torque the oblateness terms which are significant are of the same order of magnitude as the largest of the other terms for some orbits, but, these oblateness terms which are significant for some orbits are insignificant for other orbits (These significant oblateness terms are periodic with zero occuring at the time of colncldence of $B^{*}$ with a point of the earth's equitorial plane except in the case where the orbit is in the earth's equitorial plane and $a l l$ of the oblateness terms are zero.) It should be remarked that for greater earth-pointing accuracy, say an order of magnitude greater, some of the oblateness terms are the most significant terms in the equations corresponding to $T_{1} \underline{n}_{1}$ and $T_{2} \underline{n}_{2}$ for most orblts if the aerodynamic torque is insignificant. 
In the simplified steady-state equations of motion, which are written below, the significant oblateness terms are included; although, In some of the control law analysis the orbits are chosen so that these terms are zero. Before the equations are written it should be remarked that the "best" functions $v_{1}=v_{1}\left(x_{1}, \ldots, x_{6}, \tau\right), 1=1,2,3$, are such that $v_{1}$ are of the same order of magnitude as $x_{1}, 1=1, ., 6$, so that terms in the equations which are products of $v_{1}$ and $x_{1}$ are Insıgnificant.

If $s_{1}$ and $c_{1}$ are replaced by $x_{1}$ and 1 , respectively, then for satelilites $(1),(2)$ and (3) the simplified steady-state equations of motion are

$$
\begin{aligned}
x_{1}^{i} & =x_{2} \\
x_{2}^{\prime} & =-k_{1} A_{1}^{2} x_{1}+A_{2} x_{3}+K_{1} A_{1} x_{4}-2 k_{1} A_{3} J\left(r_{E} / r\right)^{2} s_{\delta} c_{\delta} c_{\theta}+v_{1} \\
x_{3}^{i} & =x_{4} \\
x_{4}^{i} & =-A_{2} x_{1}-K_{2} A_{1} x_{2}+k_{2}\left(3 A_{3}+A_{1}^{2}\right) x_{3} \\
& +8 k_{2} A_{3} J\left(r_{E} / r\right)^{2} s_{\delta} c_{\delta} s_{\theta}+v_{2} \\
x_{5}^{i} & =x_{6} \\
x_{6}^{t} & =-3 k_{3} A_{3} x_{5}-A_{2}+v_{3}
\end{aligned}
$$

where $K_{1}=1-k_{1}, K_{2}=1+k_{2}$ and $A_{1}, 1=1,2,3$, are given in (2.I5). For satellite (4) the simplified steady-state equations of motion are

$$
\begin{aligned}
& x_{1}^{\prime}=x_{2} \\
& x_{2}^{t}=K_{1} A_{1} x_{4}+\left(A_{4} / I_{1}\right) l_{3}+v_{1} \\
& x_{3}^{t}=x_{4}
\end{aligned}
$$

(contınued) 


$$
\begin{aligned}
& x_{4}^{2}=-K_{2} A_{1} x_{2}+8 k_{2} A_{3} J\left(r_{E} / r\right)^{2} s_{\delta} c_{\delta} s_{\theta}+v_{2}, \\
& x_{5}^{8}=x_{6} \\
& x_{6}^{8}=-A_{2}-A_{4} l_{1} / I_{3}+v_{3}
\end{aligned}
$$

where $A_{4}$ is the same as in $(2.16)$

E. TTHE ERROR IN THE MOTION DUE TO THE SIMPLIFICATIONS

An upper bound on the motion error due to the simplifications made In the equations of motion can be easily obtazned for sateliztes which are stable in the sense of DeBra [11]. Suppose that the full nonlinear equations of motion are written in matrix form as

$$
\underline{x}^{\prime}=A(\tau) \underline{x}+\underline{B}(\tau)+\underline{g}_{1}[\underline{x}, \underline{v}(\tau), \tau]+\underline{g}_{2}[\underline{x}, \underline{v}(\tau), \tau]
$$

where the transpose of $\underline{x}$ is given by $\underline{x}^{t}=\left(x_{1}, x_{2}, ., x_{6}\right), A(\tau)$ is a six-by-sıx periodically time-varyıng matrix, $B$ Is a six-by-three constant matrıx, $\mathrm{v}^{t}(\tau)=\left[\mathrm{v}_{1}(\tau),, \mathrm{v}_{3}(\tau)\right]$ Is the control vector which Is a known function of $\tau$ and the steady-state (or acquisition) solutions of (2.19), say $\varphi(\tau)$, for given initial conditions, $\varphi_{0}$, corresponding to $\tau, \underline{g}_{1}[\underline{x}, \underline{v}(\tau), \tau]$ is a vector function which contalns all of the forcing function (or nonlinear) terms retalned in the simplified steadystate (or acquisıtion) equations, and, $\underline{g}_{2}[\underline{x}, \underline{v}(\tau)]$ is a vector function which contalns all of the terms omitted in the sumplification Then the solution of (2.19) can be written as

$$
\begin{aligned}
\varphi(\tau) & =\Phi\left(\tau, \tau_{0}\right) \underline{\varphi}_{0}+\int_{\tau_{0}}^{\tau} \Phi(\tau, \lambda) \underline{B \underline{v}}(\lambda) d \lambda \\
& +\int_{\tau_{0}}^{\tau} \Phi(\tau, \lambda) \underline{g}_{1}[\underline{\varphi}(\lambda), \underline{v}(\lambda), \lambda] d \lambda \\
& +\int_{\tau}^{\tau} \Phi(\tau, \lambda) \underline{\underline{g}}_{2}[\underline{\varphi}(\lambda), \underline{v}(\lambda), \lambda] d \lambda
\end{aligned}
$$


where $\Phi\left(\tau, \tau_{0}\right)$ is the fundamental matrix of $\underline{x}^{i}=A(\tau) \underline{x}$.

If the norm is defined by

$$
|\underline{x}|=\sum_{I=1}^{6}\left|x_{I}\right| \text { and } \quad|\Phi|=\sum_{I, J=1}^{6}\left|\varphi_{I J}\right|
$$

where $\varphi_{I J}$ are elements of $\Phi$ and if $\varphi_{S}(\tau)$ is defined to be the solution of the simplified equations, then

$$
\left|\underline{\varphi}(\tau)-\underline{\varphi}_{S}(\tau)\right| \leq \int_{\tau_{0}}^{\tau}|\Phi(\tau, \lambda)|\left|\underline{g}_{2}[\underline{\varphi}(\lambda), \underline{v}(\lambda), \lambda]\right| d \lambda
$$

In the steady-state case since $g_{1}$ is a function of $\tau$ only in this case

DeBra has Investigated the motion of satellites in elliptic orbits about an oblate earth and has found for certain satellite conflgurations that the motion is "stable" Satellites which have such "stable" motion have the characteristic that $\max _{\lambda}\left|\Phi\left(\tau_{f}, \lambda\right)\right| \approx 20$ for $\tau_{0} \leq \lambda \leq \tau_{\text {f }}$ In the steady-state case, sInce $\underline{v}(\tau)$ Is such that $\left|\varphi_{I}(\tau)\right| \leq I I \times 10^{-4}$ for all $\tau$, the maximum value of $\left.\lg _{2}[\varphi(\tau), \underline{v}(\tau), \tau]\right|^{1}$ Is Iess than $10^{-8}$ Since the equations are periodic with perıod $2 \pi$, the equations for the steady-state case need be integrated only over the interval $\tau_{f}-\tau_{0}=2 \pi$. Thus, in this case $\left|\underline{\varphi}\left(\tau_{f}\right)-\varphi_{S}\left(\tau_{f}\right)\right|<126 \times 10^{-6}$ Since $\left|\varphi_{\text {SI }}\left(\tau_{f}\right)\right| \approx$ $10^{-4}, 1=1$, ,6, for most solutions obtalned (see chapters IV and VI), the error in $\varphi_{S I}(\tau)$ is generally less than $2 \%$ for satellites which are stable in the sense of DeBra Satellites (1) and (4), the roll and yaw motions of satellite (2) and the roll and pitch motions of satellite (3) are "stable"

Since the vector function $g_{1}$ is a function of $\underline{\varphi}(\tau)$ as well as of $\tau$ in the acquisition case, no meaningful upper bound on the error due to simplifynng the acquisition equations can be found with the above method However, Busch [6] found that there was little detectable error in his acquisition motion obtalned from his simplified equations, which were completely linearized.

"Busch compared the IInear acquisition solutions with the nonlinear solutions 


\section{DISTURBANCES}

Those Influences of the motzon (or those torques) which are not taken account of by the equations of motion are called disturbances The primary sources of possible disturbances are the sun, the earth's magnetıc field and meteorolds. (Other disturbances, e $g$, musalıgnment of gas Jets, are discussed in Chapter VI )

The torque for $B^{*}$ due to the sun's gravitational attraction of the satellite is no larger than $10^{-4}$ times the torque, $\underline{T}_{g}$, due to the gravitational attraction of the earth when the satellite is in the highaccuracy earth-pointing mode of motion This torque is, of course, very Insignificant when studying the motion for one orbit or less.

Emissions from the sun exert a pressure on the exposed part of the satellite's surface area. A torque for $B^{*}$ due to this pressure (usually called solar radiation pressure) can be quite significant Expressions for this torque have been dercved by McElvain [26] and Wheeler [34]. From these expressions It is concluded for the satellites considered here that the solar pressure torque is no larger than $10^{-3}$ times $\left|\underline{\mathrm{T}}_{\mathrm{g}}\right|$ when the satellite has large motion and a distance, $\mathrm{d}_{\mathrm{S}}$, between $\mathrm{B}^{*}$ and the center of solar pressure of 1 ft For high-accuracy earth-pointing motion the solar pressure torque can be as large as $\left|\underline{T}_{g}\right|$ if $d_{s}$ is of the order of I ft This torque can affect the form of the required steady-state control law and the cost of the control. However, since the solar torque is very similar to the aerodynamic torque in effect and since the aerodynamic torque is accounted for, the solar pressure torque per se is not considered further

The torque for $B^{*}$ due to the interaction of a satellite with the earth's magnetic field can have a significant effect on the motion Bandeen and Manger [2] have considered a model of the Tiros I satelilte for correlating data on the precession of the nearly earth-pointing spin axis. The model included the effect of the interaction with the earth's magnetic field To model this satellite Bandeen and Manger assumed that a curcular conductor with a one meter diameter was on board and carrying a current of one ampere. This model correlated well with the data recelved. The magnetic torque of this model was of the same order of 
magnitude as the earth's gravitational torque for an inaccuracy in earth-pointing of 01 radians However, since Tiros I was much less massive and extensive than the satellites considered here (with about the same asymmetry), the same magnetic torque is only about $10^{-2}$ times $\left|\underline{T}_{g}\right|$ for the same earth-pointing accuracy. If this same currentcarryıng coll were placed on the satellites consldered here, the magnetic. torque would be of the same order of magnitude as $\underline{\underline{T}}_{\mathrm{g}}$ when the satellites are In the hlgh-accuracy earth-polnting mode of motion.

For actual satellites in general it is difflcult to say what effect the torque due to the interaction of a satellite with the earth's magnetic field will have on the motion Part of this torque results from a residual component due to magnetization of some parts of the satelizte Since the magnetıc torque is considered to be no larger than the other torques and since by properly designing the satellzte this torque can be made quite small, it is considered hereafter only as an unknown disturbance of a certaln maximum amplitude which must be overcome by the . control

The forces and their torques due to collisions with meteorolds are considered to be extremely insignificant for nearly the entire lifetime of the satellite Christman and McMrllan [8] have concluded from measurements obtalned by the Fxplorer, Marlner and Pegasus satellites that the probabllity of no Impact by a meteorold with momentum of $6.67 \times 10^{-3} \mathrm{lb}-\mathrm{ft} / \mathrm{sec}$ is 099 and that for meteorolds with greater momentum Impact $I t$ Is even less. Usıng experımentally available data, Whipple [35] has estimated that meteorolds with speeds of $20,000 \mathrm{ft} / \mathrm{sec}$ and masses of $2 \times 10^{-12} \mathrm{Ib}$. WIII Impact. a satellite with a crosssectional area of twenty square feet about every 20 seconds at an altitude of 200 mlles. Whipple has also concluded that the frequency of Impact decreases log arithmetically with altitude and with increase in the mass of the meteorold

Cloutier [9] has found that the torque due to the forces exerted on a satellite by meteorold Impact can be as great or greater than the torque due to the earth's gravitational attraction but that this is generally a rarity A provision must be made for such rare occurances; and, this is done in Chapter IV. 
A summary of the most significant torques, which can be predicted with some certainty, is found in Table (2 2) In this table for various ranges of $\left|\theta_{1}\right|, 1=1,2,3$, the satellite numbers $((1)$ thru (4)) are placed under the torques and beside the component designation if for a particular satellite the component of the torque is significant A component of a torque is Insignificant if It is at least one order of magnitude less than corresponding components of other torques For satellite (I) some components of the totality of the torques in the table are shown as insignificant for some ranges of $\left|\theta_{1}\right|, 1=1,2,3$. The reason for this is that these components are insignificant compared to the corresponding components of the inertia torque, which is not included in the table.

The model used for determining the magnetic torque in Table 2.2 was the same as Bandeen and Manger used for Tiros I The expression used for the solar pressure torque of Table 22 was derıved by Wheeler. 
TABLE 22 THE SIGNIFICANT TORQUE TERMS FOR VARIOUS EARTH-POIINTING ACCURACIES

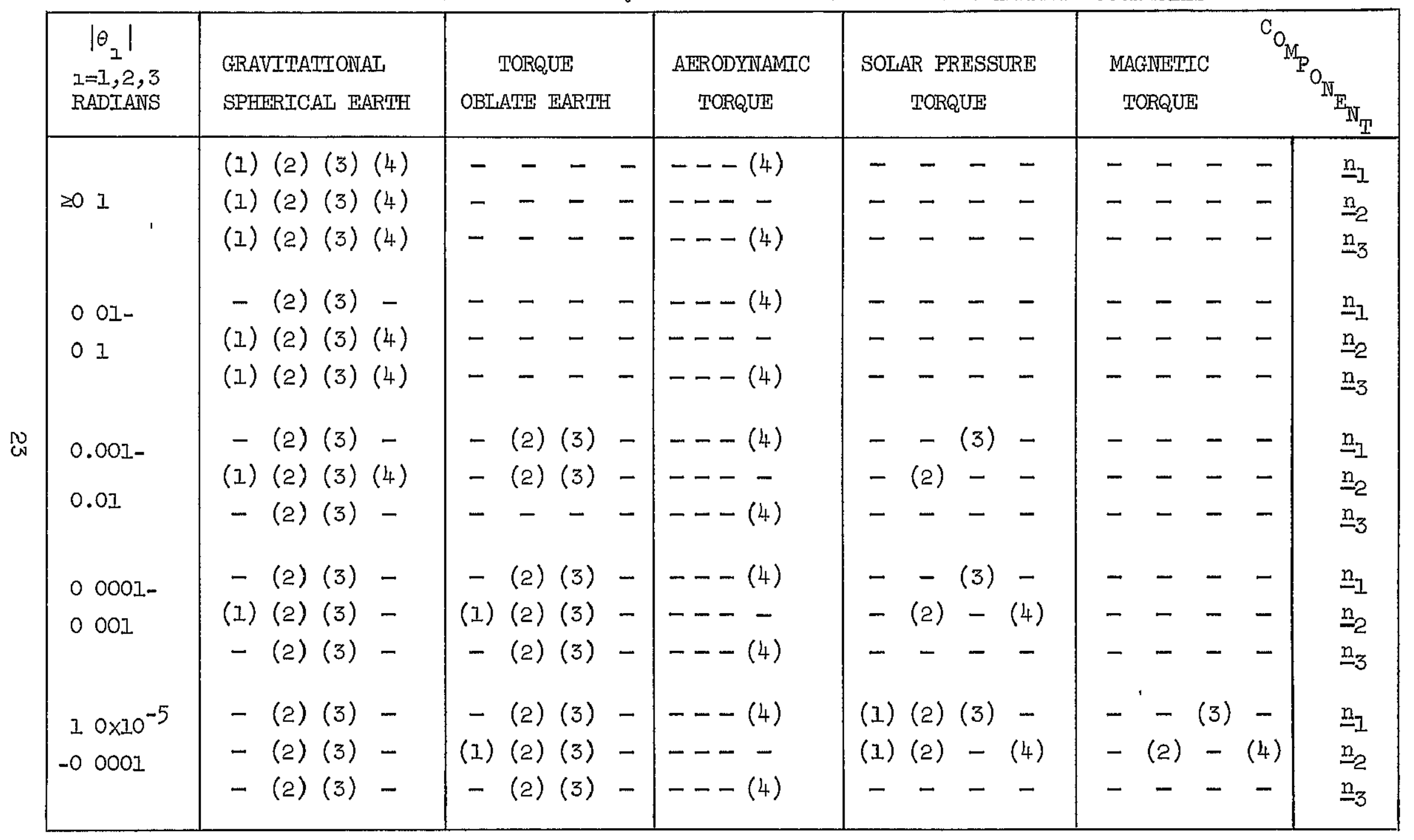




\section{THEORY OF THE CONTROL OF' THE SATELITTES' ATTITUDES}

\section{A THE MOTION REQUTREMENTS IN TERMS OF THE STATE OF THE PIANT}

In Chapter 1, Section A, the attitude motion requirements of the satellites were given in geometric terms Here, they will be given in an algebralc form

In Chapter II the differential equations of attıtude motion were derived in terms of the three-axes Euler angles, $\theta_{1}, \theta_{2}, \theta_{3}$, which define the orlentation of the satelilte with respect to the orbiting earthpointing reference frame On page 14 of Chapter II the three second-order differential equations of attitude motion were replaced with six first-

order differential equations by defining the vector $\underline{x}=\left(x_{1}, x_{2}, \quad, x_{6}\right)^{t}$ The state of the plant at some tıme, $\tau$, Is defined to be the sixdimensional vector $x(\tau)=\left[x_{1}(\tau), x_{2}(\tau),, x_{6}(\tau)\right]^{t}$ The state space $1 s$ the sıx-dimensional euclidian vector space, $X$, of which $x(\tau)$ is an element

High accuracy earth-polnting requires that $x_{1}, 1=1,2,1,6$, be kept less than or equal to given small positive numbers for the IIfetıme of the satellite. (See Appendix D) Iet $s_{1}, 1=1,2,6$, be these given* small positive numbers Then It is required that $x_{1} \leq s_{1}$, $I=1,2, \quad 6$ These Inequalities define a closed and bounded region, $S$, of the vector space $X$ which contanns the orıgın or zero vector

\section{B SATISFACTORY PERFORMANCE AND THE COST}

A satellite attitude controller (see Flgure 31 ) wl11 be sald to have satisfactory performance if acquisition to the region $S$ from $x_{1} \approx I 50$ $<\pi / 2,1=1,2, \quad 6$, can be accomplished with near minimum cost in less than the time of one quarter orbit and if the station-keeping part of the controller with near minumum cost for the Ilfetime of the satellite can keep the state space trajectory from departing the region $s$ by a signiflcant amount (except when large unaccounted for disturbances overpower the station-keeping part of the controller)

* See Chapter IV 


\section{CONTROLLER}

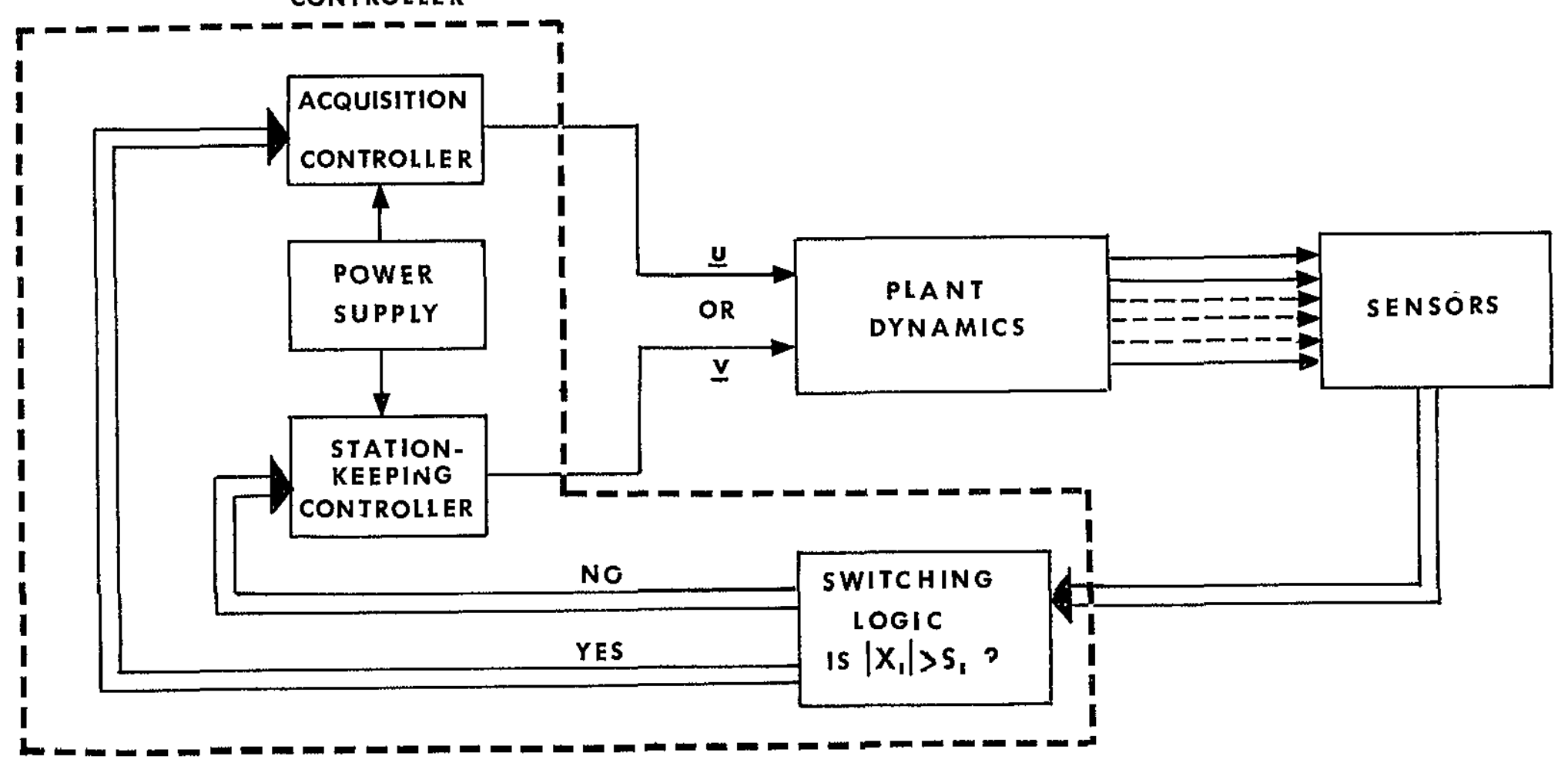

Figure 31 A Simplified Diagram of the Controlled Attitude System 
The cost of a satisfactorily performing satellite is ultimately a combination of the monetary cost and time costs of producing the satellite which performs the required mission. In this presentation it is assumed that except for the attıtude controller the satellite is of a given configuration and cost, so that, reductions in cost are obtainable only by reducing the cost of the controller

The cost of the controller is not just the cost of constructing the controller and operating it in orbit but includes the cost of placing the controller in orbut with the satellite. A heavy controller will require more power from the vehicle whlch orbits the satellite than a light controller

When the controller uses gas jets to provide the control torque, the welght of the fuel for the gas jets can Increase the cost even if Increases In the cost of orbiting the satellite are not considered For example, the increase in cost due to an increase in the weight of the fuel can result from expensive packaging caused by the increase in volume of the fuel contanner or from the increase in the cost of constructing the fuel contaıner which must withstand higher pressures if the volume is kept sma11

The feedback attitude controller will contain electronic computing elements and gas jet thrusters The number, sizes, weights and complexIties of these should be kept at a minımum for minimum overall cost It Is true that the use of off-the-shelf hardware components will reduce the cost if the weights and complexities of these components are not prohrbıtıve.

Thus, to reduce the cost of the attztude controller the welght of the controller should be reduced as much as possible compatible with Inexpensive off-the-shelf components and with the simplicity of the overall system

The power supply for a year or more of control is the heaviest component of the controller so that the welght of the power supply should be at the focus of attention. Other components are nearly fixed in weight by the state of the art except for the thrusters which generally decrease in size and welght with decrease in trust magnitudes It should be 
pointed out, however, that for very small thrust requirements hot gas or Ion thrusters are used and they require a weightly power supply for supplyzing heat

For a controller which utılızes gas jets for control the power supply consists of the fuel, which Is usually an inert gas, the fuel contalner, tubes for carrying the fuel to the thrusters and pressure regulating devices Except for the fuel, the components of the power supply are nearly standard in welght for all but high gas pressures By reducing the weight of the fuel, the gas pressure and/or volume wall be reduced Thus, the weight of the fuel will be at the focus of further attention

\section{THE OBJECTIVE}

In summary, the objective Is to determine a controller which wlll acquire the region $S$ of the state space within the one quarter orbit time limit from values of $x_{1}, 1=1,2,1,6$, of about 15 radians and whych will keep the state of the system within $S$ for the remaining lifetime of the satellite whlle using as little fuel as possible compatible wath costs due to the complexity of components and the development of new components

\section{MATHEMATICAI TOOIS USED FOR DETERMTIIING A CONTROI IAW}

Two basic approaches to solving the problem of determining a control law are

1) The application of mathematical results based on fundamental principles which apply to the minlmization problem

2) The simulation on an analog or digital computer of the plant with various controllers whych are determuned by theoretical knowledge of the behavior of the plant under the action of the controllers

In the mathematical theory the problem to be solved is one in the field of optimal control with inequality constraints on the state variables (the station-keepıng part) and without such constralnts (the acquisition part) 
Pontryagın's Maxımum Principle [29] and extensıons of it will be used as a mathematical ald in obtaining solutions to both the acquisition problem and the station-keepıng problem. For future use Pontryagın's Maximum Principle is stated below in the form which is applicable to both problems.

1. Pontryagın's Maxımum Prıncıple for Nonautonomous Systems

The maxımum prunciple gives necessary conditions for the solution of the optimal problem

Suppose the following are given

1) The differential equations of motion

$$
\underline{x}^{\prime}=\underline{\underline{f}}(\underline{x}, \underline{v}, \tau)
$$

where $\underline{x}=\left(x_{1}, \quad, x_{n}\right)^{t}$ and $\underline{f}=\left(\underline{r}^{1}, ., f^{n}\right)^{t}$. (For example, equation (3.1) can represent equations (2 14).)

2) An inctial point in the state space, say $\underline{x}_{0}$, which describes the motion at an initial time, ' ${ }_{0}$, after which the motion is considered to be under the influence of the control, $\underline{v}$ 3) A final point in the state space, say $x_{f}$, which describes the motion at the final instant of consideration, $\tau_{f}$ 4) The cost functional

$$
J=\int_{\tau_{0}}^{\tau} f^{O}[\underline{x}(\tau), \underline{v}(\tau)] d \tau
$$

Then the optimal problem is to fund the control $\underline{v}=\underline{v}(\tau)$, which Is at least as smooth as plecewise contınuous, that causes the motion to be given by $\underline{x}_{f}$ at $\tau_{f}$ and results in the minlmization of $J$

It should be pointed out that the maximum principle applies to problems in which the control is much less smooth than plecewise continuous However, there is no need to consıder a more general class of control since the control devices considered here are adequately described by piecewise continuous functions

The set $V$ Is defined as the set of all bounded plecewise continuous vector functions $\underline{v}=\underline{v}(\tau)$ The function $H[p(\tau), \underline{x}(\tau), \tau$, 
$V(\tau)]$, the Hamzltonıan, Is defined by

$$
H(\underline{p}, \underline{\underline{x}}, \tau, \underline{v})=\sum_{1=0}^{n} p_{1} f^{I}(\underline{x}, \underline{v}, \tau)
$$

where $p=\left(p_{0}, p_{1}, \quad, p_{n}\right)^{t}$ Is defined in detall below $H_{\max }(p, \underline{x}, \tau)$ Is given by

$$
\mathrm{H}_{\max }[p(\tau), \underline{x}(\tau), \tau]=\max _{\underline{v}(\tau) \in V} H[p(\tau), \underline{x}(\tau), \tau, \underline{v}(\tau)]
$$

where the maximuzation of $H$ on $\underline{v}(\tau)$ is with respect to $p(\tau)$, $x(\tau)$ and $\tau$

In order that $\mathrm{v}(\tau)$ yield a solution of the given optimal problem It is necessary that there exist a nonzero continuous vector function $p(\tau)=\left[p_{0}(\tau), p_{1}(\tau), ., p_{n}(\tau)\right]^{t}$ corresponding to the functions $\underline{\mathrm{v}}(\tau)$ and $\mathrm{x}(\tau)$ through equation $(31)$ and

$$
\mathrm{p}_{1}{ }^{\prime}=-\partial \mathrm{H} / \partial \mathrm{x}_{1}, \mathrm{I}=1, \mathrm{n}
$$

such that

(1) for all $\tau, \tau_{0} \leq \tau \leq \tau_{f}$, the function $\mathrm{H}[\mathrm{p}(\tau), \underline{x}(\tau), \tau, \underline{\mathrm{V}}]$ of the variable $\underline{v} \in V$ attains its maximum value at $\underline{v}=\underline{v}(\tau), 1 e$,

$$
H[p(\tau), \underline{x}(\tau), \tau, \underline{v}(\tau)]=H_{\max }[p(\tau), \underline{x}(\tau), \tau]
$$

where $H$ Is given by equation $\left(\begin{array}{ll}3 & 3\end{array}\right)$ and $H_{\max }$ is given by equation ( 34 ), (II) the function $p_{0}(\tau)$ is a nompositive constant

Thus Is a statement of Pontryagın's Maxımum Prıncıple (PMP) for nonautonomous systems. Pontryagin, et al [29] assume that $f^{\circ}(\underline{x}, \underline{v})$ and $\underline{f}(\underline{x}, \underline{v}, \tau)$ have continuous first derıvatives in $x$ in thelr proof of the maximum principle This restriction in the proof can be weakened so that the maxımum princıple applies to problems in whıch $\partial \mathrm{f}^{\circ}(\underline{x}(\tau)$, $v(\tau)) / \partial x_{1}$ Is only contınuous almost everywhere. Breakwell [3] glves a derivation in this case for autonomous systems in an early paper A slight extension of Halkin's work [17] results in a proof Rozonoer [30] gives a proof for optimal problems in whjch both $f^{\circ}(\underline{x}, \underline{v})$ and $\underline{f}(\underline{x}, \underline{v}, \tau)$ have continuous second derivatives in $x_{1}$ This proof can be modified so that 
It Is clear that PMP applies to problems which have $\mathrm{f}^{\circ}(\underline{\mathrm{x}}, \underline{\mathrm{v}})$ smooth only almost everywhere along $x(\tau), \tau_{0} \leq \tau \leq \tau_{f}$

The maximum principle as stated above can be extended to apply to the optimal station-keeping problem and to the optimal acquisition problem in the case acquisition to the region $S$ is required rather than the case were acquisition to the orıgin of the state space, $X$, Is required The applications of the maximum principle to these problems differ primarıly in the boundary conditions

Before the maximum principle is applied to an optimal problem there should be some certalnty that the results of the application will give correct information about the solution of the problem The maximum principle gives conditions which, if they are not satısfied, imply that the control is not optimal.

Suppose that there are many controls $\underline{v} \in V$ which take $\underline{x}_{0}$ to $\underline{x}_{f}$ and suppose that only one of these satisfies the maximum principle Then this one control Is the optimal control if an optimal control exists An optimal solution does not exist if the functional $J$ for the control $\underline{v} \in V$ whlch takes $\underline{x}_{0}$ to $\underline{x}_{f}$ whlle satısfycng the maximum principle is not a minimum. Otherwise, a solution to the optimal problem exists.

In the present Investıgatıon Pontryagın's Maxımum Prıncıple gives a complete set of relations for the determination of a control Even so and even if a solution exists, there is no guarantee that the control obtalned from the maximum princlple does not give a local minimum of $J$

In the IInearized acquisition problem an optimal solution exists for $\mathrm{V} \in \mathrm{V}$ and the functional $J$ does not have local minima, so that for a solution of the optimal IInearized acquisition problem, Pontragin's Maximum Principle gives sufficlency conditions. A proof of this can be found in Rozonoer [30] for the case when $\underline{f}(\underline{x}, \underline{v}, \tau)$ and $f^{\circ}(\underline{x}, \underline{v})$ have continuous first derivatives in $x$ which is true in the acquisition problem

In the application of the maximum principle to the approximate station-keeping problems, the function $f^{\circ}(\underline{x}, \underline{v})$ is either nonlinear or has derıvatıves in $x_{I}$ which are only almost everywhere continuous in $\underline{x}(\tau)$. In this case Rozonoex's proof of the sufficiency of the condztions 
of the maximum princıple does not hold. However, since the conditions of the maximum principle are necessary conditions and since they are sufficient to determine a unique motion, then they are sufficiency conditions for the optimal solution if an optimal solution exists In the case of the approxımate station-keepıng problems, the existence is concluded by direct reasoning

\section{Application to the Acquisition Problem}

Busch [6] has found a nearly optimal feedback control whlch will cause the motion to proceed from $\underline{x}_{0}$ to near zero for a "stable" satellite configuration For simplicity and reliability Busch's control law is a function of the state only The method Busch uses for determining a control law from the maximum principle is reverse-time integration, $1 . e$, once $\underline{v}=x(p, x, \tau)$ has been found from the maximization of the Hamiltonlan H (see equation $(34)$ ), the equations (3 I) and (3.5) are Integrated backwards from $p\left(\tau_{f}\right)$ and $\underline{x}_{f}$ to $\underline{x}_{0}$ and $p\left(\tau_{0}\right)$ The solutions $\underline{x}(\tau)$ and $p(\tau), \tau_{0} \leq \tau \leq \tau_{f}$, are then analyzed $\mathrm{ln}$ order that characterıstıcs of the solutions $\underline{x}(\tau)$ and $p(\tau)$ can be found which enable the control to be written as

$$
\underline{\mathrm{v}}=\underline{\mathrm{v}}(\underline{\mathrm{x}}, \underline{\tau})
$$

In the reverse time integration procedure $\tau$ is replaced with $\tau^{*}=\tau_{f}-\tau$ and $\underline{x}_{0}$ is determined by the choice of $p_{f}$ and the Interval of integration, $\tau_{f}-\tau$ (when $\underline{x}_{f}$ Is given)

In Chapter $V$ a solution to the problem of the optimal acquisition control of unstable sateliltes is given This solution is based on Busch's solution, the maximum principle and the Imposed time limit of acquisition

\section{Application to Approximate Statıon-Keepıng Problems}

Approximate solutions of the station-keepıng problem can be obtalned from PMP by takıng the cost functional to be of the form

$$
J=\int_{\tau_{0}}^{\tau_{f}}[f(\underline{x})+g(\underline{v})] d \tau
$$


where $g(\underline{v})$ Is scalar function of the control vector and $f(\underline{x}), a$ "penalty function", is a scalar function of the state vector.

Since the minimization of the weight of the fuel is required, $g(\underline{v})$ Is chosen as

$$
g(\underline{v})=\sum_{I=1}^{3}\left|v_{1}\right|
$$

The optimal control for the problem with the cost functional given by (3 7) with (3 8) and any $f(\underline{x})$ corresponds to the use of simple gas jets The "penalty function" Is chosen such that the control keeps $\underline{x}$ In or very near $S$ while using the least possible amount of fuel. If $f(\underline{x})$ Is chosen so that It 15 zero when $\underline{x}$ is in $S$, the functional (3.8) to be minımized becomes the minımum fuel functional while $x$ Is in $S$ Thus, It seems that the fuel expenditure should be a minlmum at least for those period when $\underline{x}$ is in $S$

Possible nonnegatıve functions which are zero when $x$ Is in $S$ are

$$
\begin{aligned}
& f_{1}(\underline{x})=\sum_{I=1}^{6} \begin{cases}0 & \text { if }\left|x_{1}\right| s_{1} \\
10^{n_{1}}\left(x_{1}-s_{1}\right) & \text { if } x_{1}>s_{1} \\
-10^{n}\left(x_{1}+s_{1}\right) & \text { if } x_{1}<-s_{1}\end{cases}
\end{aligned}
$$

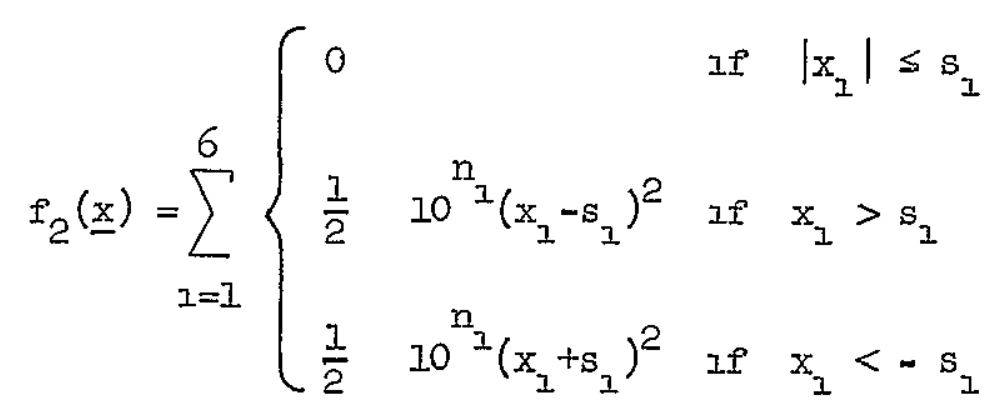




$$
f_{e}(\underline{x})=\sum_{I=1}^{6} \begin{cases}0 & \text { If }\left|x_{1}\right| \leq s_{1} \\ \exp \left[10^{n}\left(x_{I}-s_{1}\right)\right]-1 & \text { if } x_{1}>s_{I} \\ \exp \left[-10^{n}\left(x_{I}+s_{I}\right)\right]-I & \text { If } x_{1}<-s_{1}\end{cases}
$$

where $n_{I}, 1=1, \cdot, 6$, are numbers chosen so that $\underline{x}$ stays in or near S.

Functions similar to

$$
f_{S}(x)=\sum_{I=1}^{6} k_{1}\left|x_{1}\right| /\left(b_{1} \cdot s_{1}-\left|x_{1}\right|\right)
$$

where $k_{1}$ and $l_{1}$ (a number slightly greater than one) are chosen to keep $\underline{x}$ near $S$, are possible cholces Since they exhybit singular behavior as $\left|x_{I}\right| b_{I} \cdot s_{I}$, they result in the state stayıng very near the boundary of $S$ or in $S$ (depending on $l_{1}$ ), but, since they are not zero for $\underline{x}$ in $S$, fuel is wasted

For an Idea of the relative values of the functions given by equations $(39),(310),(3.11)$ and $(312)$ for values of $x_{1}$ see Figure 3.2.

Since In the station-keeping problem $\underline{x}_{0}$ and $\underline{x}_{f}$ are arbitrary to within being in $S$ or on the boundary of $S$, the boundary conditions on the variable $p(\tau)$ are somewhat better known in advance in the stationkeeping problem than in the acquisition problem

In Pontryagin, et al [29] and in Rozonoer [30] It Is shown that a necessary condition for an optimal solution is

$$
\underline{p}\left(\tau_{f}\right)=\left[p_{1}\left(\tau_{f}\right), \cdot, p_{n}\left(\tau_{f}\right)\right]^{t}=(0, \quad, 0)^{t}
$$

If $\underline{x}\left(\tau_{f}\right)$ Is (free) in the interior of $S$ or

$$
\underline{p}\left(\tau_{f}\right)=\left[\underline{p}_{1}\left(\tau_{f}\right), \quad, \underline{p}_{n}\left(\tau_{f}\right)\right]^{t}=-\mu \underline{b}\left(\underline{x}_{f}\right)
$$

If $\underline{x}\left(t_{f}\right)$ is (free) on the boundary of $s$ The vector $\underline{b}\left(\underline{x}_{f}\right)$ is the outer normal to the boundary of $S$ at $\underline{x}\left(\tau_{f}\right), \mu$ is a nonnegative constant 


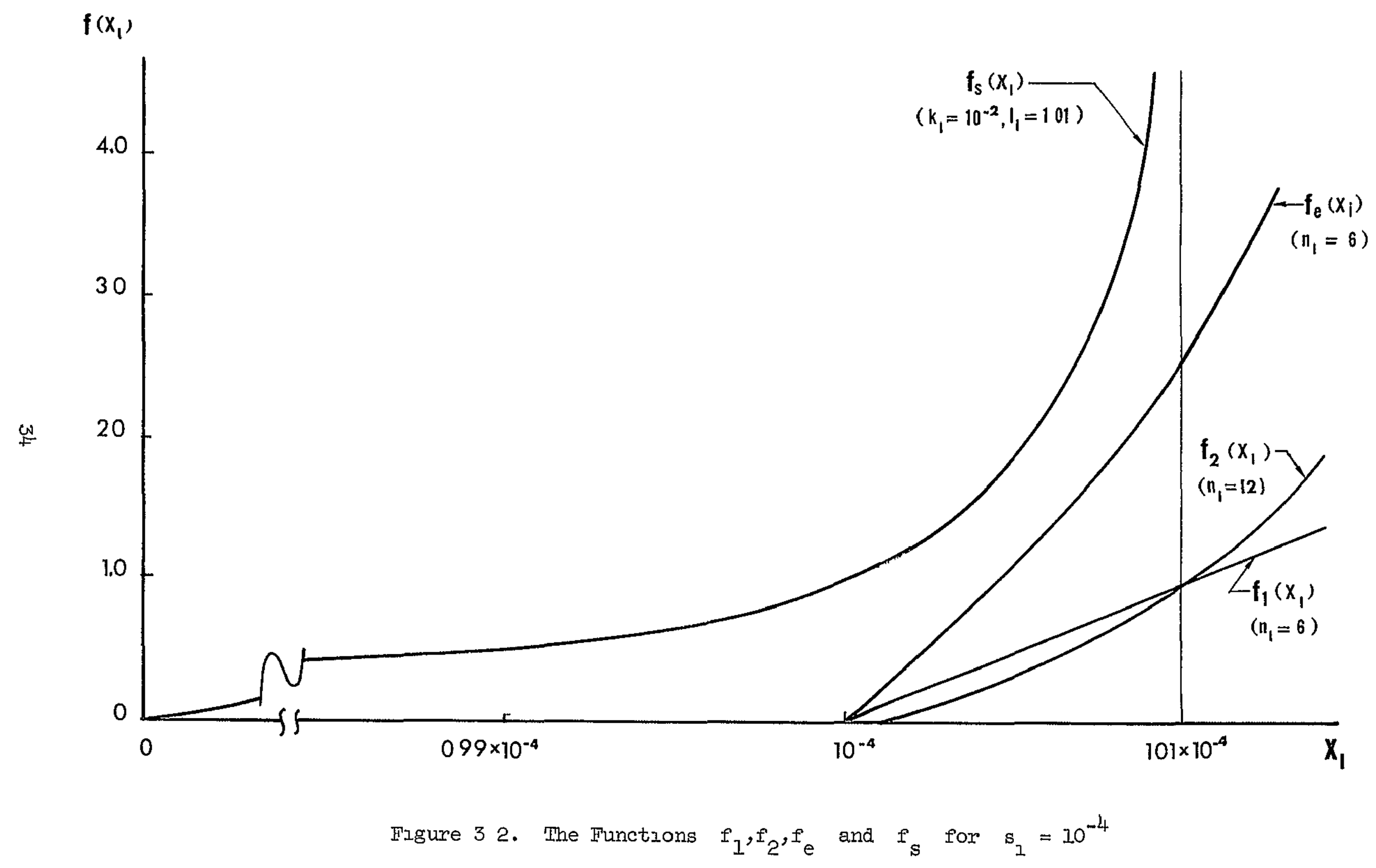


and $\mathrm{n}=6$ in the present investigation

The relation expressed by equation (3 14) Is called the transversality condition Since $S$ is defined by $\left|x_{1}\right| \leq s_{1}, 1=1, \quad, 6$, equation ( 314 ) can be written as

$$
p_{1}\left(\tau_{f}\right)=-\mu \operatorname{sgn}\left[x_{1}\left(\tau_{f}\right)\right], I=1, \quad, 6
$$

The maximum principle requires that $p_{0}$ be a nonpositive constant Rozonoer has shown that if $p_{0}=-\lambda$, then a necessary condition Is $\lambda>0$ Since $H$ Is homogeneous in $p_{1}, 1=1,6$, the maxımınization of $H$ Is Independent of $\lambda$ For convenience choose $\lambda=1$

The inztial value $\underline{\underline{p}}\left(\tau_{0}\right)$ Is in general not known If $\underline{x}\left(\tau_{0}\right)$ is required to be on the boundary of $s$, then $\underline{p}\left(\tau_{0}\right)$ must satısfy a condition similar to that given in equation (3 14) Otherwise, $\underline{p}\left(\tau_{0}\right)$ is unknown Since $\underline{x}\left(\tau_{0}\right)$ is not required to be on the boundary of $s$, the transversality conditıon for $\underline{x}\left(\tau_{0}\right)$ ls not applıed

It should be noted that the boundary conditions given by equation (3 14) do not apply when $x$ Is on a "cornex" of $S$, $I$ e, a point on the boundary of $S$ at which two of $\left|x_{2}\right|, 1=1,4$, or both of $\left|x_{5}\right|$ and $\left|\mathrm{x}_{6}\right|$ are equal to the corresponding numbers $s_{1}$ This follows from the fact that the normal to the boundary of $S$ Is not defined at a "corner" If this should present a problem, the "corner" can be smoothed out by constructing a sultably smoothe "surface" In the "corner" between the faces of the polyhedron in the six dimensional space (If these surfaces are small enough, no physlcally measurable changes in the boundary wIll occur )

The above boundary conditions and the cost functionals given by (3 7)-(3 11) are used In Chapter IV with the maximum principle to determine approximate solutions of the steady-state problem

Similar approximate methods of solution for linear, minimum time problems with restructed phase coordinates has been developed by Iee [24] and by Russell [31] Iee applies the method to the minzmum time acquisıtion problem of a $1 / \mathrm{s}^{2}$ plant with bounded phase coordinates 
4 Necessary Conditions for an Exact Solution (NCES) of the Statıon-Keepıng Problem

Several investigators have to some extent developed exact solutıons to the bounded phase coordinate optımal control problem Bryson, Denham and Dreyfus [5] have found necessary conditions for solving problems in which the control is a scalar and certaln smoothness assumptions must hold Chang [7] and RusselI [31] are concerned with sufficiency conditions for solving the linear, minimum time acquisition problem with bounded phase coordınates. Pontryagin, et al [29] devote their Chapter VI to obtaining necessary conditions for the solution of the optimal control problem with restricted phase coordinates These necessary conditions, which are discussed in this section, will be used in the derivation of the station-keeping control law in Chapter IV

Since the control function $\underline{v}(\tau)$ Is plecewise smooth (discontinuities of the first $k I n d)$ and since the other terms in the right hand slde of the differential equations of motion are smooth, there exists only a finite number of points in time at which the trajectory, $x(\tau)$, Is on the boundary and either $\underline{x}\left(\tau^{-}\right)$or $\underline{x}\left(\tau^{+}\right)$or both are not on the boundary If $x(\tau)$ is the state at such a point in time $\tau$ and if both $\underline{x}\left(\tau^{-}\right)$and $\underline{x}\left(\tau^{+}\right)$are in the Interior of $S$ or one is on the boundary of $\mathrm{S}$, then the point $\underline{x}(\tau)$ Is called a junction point of the trajectory of course, there are only a finite number of junction points

In the derivation of the necessary conditions for an optimal trajectory with restricted states it is assumed that. (I) the optimal trajectory has only a finite number of junction points, (2) the optimal trajectory lies either entirely in $S$ or on the boundary of $S$, and, (3) the parts of the optimal trajectory which Ile on the boundary of $S$ for a finite interval of time must be "regular"

The boundary of the region $S$ must be somewhat "regular" or smooth, I e, if $s(\underline{x})=0$ describes the boundary of $s$, then grad $s(\underline{x})$ must be continuous and not vanish for any $\underline{x}$ in the boundary of $s$ In the station-keeping problem with $s$ defined by $\left|x_{1}\right| \leq s_{1}$, $I=1,2, \quad, 6$, this is not the case unless the "corners" of $S$ are avolded when the trajectory colncldes with the boundary of $S$ By 
surtably "smoothıng" the "corners" (see p 35 of this section) this mathematzcal difficulty is overcome In Chapter IV the NCES are applied to several approximate single-axis satellite motıons by replacing the "non-regular" boundaries of a phase-plane projection of $S$ with appropriate "regular" boundarzes These "regular" boundaries are section of known optimal trajectories which must exıst and deviate from the phaseplane projection of $\mathrm{S}$ (for bounded $\mathrm{v}$ ) by some small allowable amount In Chapter VI of Pontryagın, et al, the concept of regularity Is used in the derivation of necessary conditions for optimality of those parts of the trajectory (If any) which lie entirely on the boundary of $S$ It should be noted that Pontryagin, et al derived these necessary conditions under the assumption that each of $f^{\circ}(\underline{x}, \underline{v})$ and $\underline{f}(\underline{x}, \underline{v}, \tau)$ have contınuous first derıvatıves in both $\underline{x}$ and $\underline{v}$ If $i t$ is assumed that $f^{0}(\underline{x}, \underline{v})$ has only contınuous furst derıvatıves $i n \underline{x}$ and not in $\underline{v}$ then a weaker set of necessary conditions are obtained These weaker conditions are the same as Theorem 22 of Pontryagın, et al, except that $\partial H / \partial v$ does not exist everywere along the trajectory which colncides with the boundary

If there exists an optimal trajectory whych lies in the region S, It is possible that part of this trajector lies entirely in the Interior of $S$ These parts of the optimal trajectory must satisfy the conditions of the maximum principle

If the regular optimal trajectory contains only a finzte number of junction points, then an adalional condition on the function $\underline{p}(\tau)$ at the Junction time can be derived Pontryagin, et al, call this condition the Jump condition The Jump condition is satisfied if one of the two following conditions is satisfied

$$
\begin{aligned}
& \underline{\underline{p}}\left(\tau^{+}\right)=\underline{\underline{p}}\left(\tau^{-}\right)+\mu \operatorname{grad} \mathrm{s}[\underline{\underline{x}}(\tau)] \\
& \underline{\underline{p}}\left(\tau^{+}\right)=\underline{\underline{p}}\left(\tau^{-}\right)+\mu \operatorname{grad} \mathrm{s}[\underline{x}(\tau)]=0, \quad \mu \neq 0
\end{aligned}
$$

where $\mu$ is a number to be determined

(In the station-keepıng problem the region $S$ has corners In a note in Chapter VI of Pontryagin, et al, (page 310) It is pointed out that Jump conditions completely analogous to those of equations (3 15) 
must be satisfied at the transition point from one smooth part of the boundary of $S$ to another )

The necessary condztions for an exact solution of the stationkeepıng problem can be summarized as follows. The condztions of the maximum principle must be satısfied by each part of the regular optimal trajectory which lies in the interior of the region $S$ The conditions of Theorem 22 of Pontryagin, et al, must be satısfied by those parts of the optimal trajectory which lie entirely on the boundary of $S$ The jump condition must be satisfied at a junction point

The above necessary conditions are, generally, insufficient to determine the optimal control Without any conditions other than those above the search for the optimal control must, usually, be carried out In a large dimension parameter space Parameters of this space Include the number of junction points, the number of the parts of the trajectory which lie on the boundary, the boundary conditions $p\left(\tau_{0}\right)$ and $p\left(\tau_{f}\right)$ and the number $\mu$

In the next chapter the above necessary conditions will be used In a search for a control law for the station-keeping problem This search WIll also be alded by the optimal solutions to the several approxımate statıon-keepıng problems 


\section{DERIVATION OF STATION-KEEPING CONIROLS ILAWS}

The attitude motion of a satellite in the steady-state mode of controlled motion is to be such that.

1) The initial instant of station-keeping, $\tau$, is arbitrary, I $e, \tau_{0}$ Is the time at which the satelizte Is at an arbitrary point in its orbit,

2) The motıon at time $\tau_{0}$ Is arbitrary to wathın $\underline{x}\left(\tau_{0}\right)$ being in the region $S$ of the state space,

3) The motion after $\tau_{0}$ and until some given final time $\tau_{f}$ must be the result of a control $\mathrm{v}(\tau), \tau_{0} \leq \tau \leq \tau_{f}$, which keeps $\underline{x}(\tau), \tau_{0}<\tau \leq \tau_{f}$ from departing the region $S$ and which uses as little fuel as possible

In the application of the theory of the previous chapter to the search for station-keeping control laws, it is convenient to take $\tau_{0}=0$, $\tau_{f}=2 \pi$ and (In elther $\left(2\right.$ 17) or $\left(2\right.$ 18)) $\theta_{0}=0$ This can be done without loss of generality since $(1) \underline{x}\left(\tau_{0}\right)$ and $\underline{x}\left(\tau_{f}\right)$ are arbitrary to within their being in $S\left(\underline{x}\left(\tau_{0}\right)\right.$ can be the final state of an acquisıtion trajectory or the final state of a previously considered station-keeping trajectory), (2) The equations of motion are periodic with a period of $2 \pi$ radians, and, (3) In the lifetime of a typical satelizte the boundary of $S$ Is encountered many thousands of times and the region $S$ IS nearly covered by the state-space trajectory (see Part 1 of Section A)

The region $s$ was defined to within the numbers $s_{1}, 1=1,6$, In Section $A$ of Chapter III If $s_{1}, 1=1, ., 6$, are greater than about $10^{-2}$, the simplified steady-state equations of motion do not give a suztable description of the motion The lower limits on $s_{1}, 1=1,1,6$, are fixed by the state-of-the-art in the construction of sensors and controllers whlch have very small gas jet thrust and/or time delays Hereafter, the numbers $s_{1}, 1=1,6$, are assumed to be $10^{-4}$ unless otherwise specified 
A THE APPROXIMATE SOLUTIONS - SPECIAL ORBITS

In this section several approximate solutions will be presented They are approximate solutions to the problem of determining a control which will keep the state of a satelilte's attıtude motion in the region $S$ while minimizing the fuel used

The approximate solutions are approximations in the sense that the state space trajectories are allowed to exist the region $S$ by a small distance (compared to the maximum dimension of $s$ ) and in the sense that Integral constraints on the states are used to limit the motion If the Integral constraint Is given by

$$
\left.0 \leq \int_{\tau_{0}}^{\tau} f \underline{x}(\tau)\right] d \tau \leq A
$$

where $A$ is a given (perhaps small) positive number and $f(\underline{x})$ Is given by (3.9) or (3 10) or (3 11), then this optimal problem is equivalent to the optimal problem of Part 3, Section D of Chapter III The problems are equivalent in the sense that their solutions (as obtazned from the maximum principle) are the same

In this section the equations of motion are assumed to be given by (2.17) with the angle $\delta$ elther zero or $\pi / 2$ radians These values correspond to satellites in nearly equatorial or nearly polar orbits, respectively They are used initially (Part l) to simplify the analysis although the results do not depend on $\delta$ In Parts 2-4 these orbits, I.e, these values of $\delta$ are assumed so that equilibrium points exist

In Parts 2, 3 and 4 of this section the equations of motion are approximated further The "stable" single-axıs motions of the satellites are approxımated by $x^{\prime}+a^{2} x=v$, and, the "unstable" single-axis motions are approxımated by $x^{\prime \prime}=v$ and $x^{\prime \prime}+a^{2} x=v$ with $a^{2}<0$ The study of these simple motions results in characteristzcs of a suboptimal minimum-fuel station-keepıng control as well as a check on the methods of Part 1 
1 A Statıon-Keepıng Control Iaw Obtalned From PMP with

$$
J=\int_{\tau}^{\tau} f\left(\tau_{I}(\underline{x})+\sum_{I}^{3}\left|v_{I}\right|\right] d \tau
$$

The Hamlitonian for the system of equations (2 17) with $\delta=0$ or $\delta=\pi / 2$ can be written as

$$
\begin{aligned}
H= & p_{2} v_{1}+p_{4} v_{2}+p_{6} v_{3}-\left|v_{1}\right|-\left|v_{2}\right|-\left|v_{3}\right|+\text { (terms which do not } \\
& \text { contann } \left.v_{1}, 1=1,2,3\right)
\end{aligned}
$$

sInce as was seen in Chapter III $p_{0}$ can be taken as -I

The control $\mathrm{V}$ cannot be optimal unless lt maximlzes $\mathrm{H}$ for all values of $p, \underline{x}$ and $\tau$ Thus, from ( 411$)$ the optimal control for bounded $v_{I}$ must be the "coast function" of $p$ given by

$$
v_{1}=\operatorname{CST}\left(p_{2 \times 1}\right)=\left\{\begin{array}{ll}
0 & \text { if }\left|p_{2 \times 1}\right|<1 \\
N_{I} \operatorname{SGN}\left(p_{2 \times 1}\right) & , \text { if }\left|p_{2 \times 1}\right| \geq 1
\end{array} \quad 1=1,2,3\right.
$$

where $\mathbb{N}_{1}, I=1,2,3$, are glven positıve numbers and $\operatorname{SGN}(g)=(\mathrm{g}) /|(\mathrm{g})|$

Since the last two equations of (2 17), the pitch equations, are not coupled to the first four of (2 17), the yaw-roll equations, the controlled pitch motion can be solved for independently of the yaw-roll motion These equations (for the cases when $\delta \approx 0$ or $\delta \approx \pi / 2$ ) with the corresponding equatıons for the adjount variables as determined from (35) can be written in backwards times by lettıng $\tau *=2 \pi-\tau$ as follows

yaw-rol1

$$
\begin{aligned}
& { }^{\prime} x_{1}=-x_{2} \\
& { }^{\prime} x_{2}=k_{1} A_{1}^{2} x_{1}+A_{2} x_{3}-K_{1} A_{1} x_{4}-v_{1} \\
& { }^{\prime} x_{3}=-x_{4} \\
& { }^{\prime} x_{4}=-A_{2} x_{1}+K_{2} A_{1} x_{2}-k_{2}\left(3 A_{3}+A_{1}^{2}\right) x_{3}-v_{2}
\end{aligned}
$$




$$
\begin{aligned}
& { }^{\prime} p_{1}=-F\left(x_{1}\right)-k_{1} A_{1}^{2} p_{2}+A_{2} p_{4} \\
& { }^{\prime} p_{2}=F\left(x_{2}\right)+p_{1}-K_{2} A_{1} p_{4} \\
& { }^{t} p_{3}=-F\left(x_{3}\right)-A_{2} p_{2}+k_{2}\left(3 A_{3}+A_{1}^{2}\right) p_{4} \\
& { }^{\prime} p_{4}=F\left(x_{4}\right)+K_{1} A_{1} p_{2}+p_{3}
\end{aligned}
$$

pltch

$$
\begin{aligned}
& { }^{3} x_{5}=-x_{6} \\
& { }^{\prime} x_{6}=3 k_{3} A_{3} x_{5}-A_{2}-v_{3} \\
& { }^{\prime} p_{5}=-F\left(x_{5}\right)-3 k_{3} A_{3} p_{6} \\
& { }^{\prime} p_{6}=F\left(x_{6}\right)+p_{5}
\end{aligned}
$$

where ${ }^{\prime}()=a() / d \tau *$, the functions $A_{1}, A_{2}$ and $A_{3}$ are the same as In (2 15) but with $\tau$ replaced by $\tau^{*}$ and

$$
F\left(x_{1}\right)=\partial f_{1}(\underline{x}) / \partial x_{1}=\left\{\begin{array}{cll}
0, & \text { If } & \left|x_{1}\right| \leq 10^{-4} \\
10^{n_{1}}, & \text { If } & x_{1}>10^{-4}, 1=1, \\
-10^{n_{1}}, & \text { If } & x_{1}<-10^{-4}
\end{array}\right.
$$

Equations (4 3)-(4.6) with $(42)$ and the boundary conditions given by $(313),\left(3.14^{\prime}\right)$ and $\underline{x}\left(\tau_{0}^{*}\right)=\underline{x}\left(\tau_{f}\right)$ are sufficient for determınıng the controlled motion, $\underline{x}\left(\tau^{*}\right)$, the adjoint variables $\underline{p}\left(\tau^{*}\right)$ and, hence the control $\underline{v}\left(\tau^{*}\right)$ for $\tau_{0}^{*} \leq \tau^{*} \leq \tau_{f}^{*}$ These solutions can be used to determne the optimal feedback control law for this problem or at least characteristics of the optimal feedback control law which can be used in the construction of a minimum-fuel suboptimal feedback control law

Although the differential equations are plecewise IInear, it is not practical to invest a great deal of time in a search for their exact solution since the coefficients are time-varying To determine the feedback control law It is only necessary to determine the values of $\underline{x}\left(\tau^{*}\right)$ and $\tau^{*}$ at which the adjolnt variables assume the values of +1 or -1 
Thus, the solution of the equations with the ald of a high-speed computer Is perhaps the most logical approach to determinlng the feedback control law

After a thorough investigation the hope of using the analog computer for solving the above equations was abandoned The reason for this was that some of the computer variables, $1 \mathrm{e}$, the scaled dependent variables, are generally $10^{4}$ times the other computer variables, so that, It was Impossible to obtaln an accurate and therefore meaningful solution with this computer

The equations can be solved accuarately enough with a digltal computer A Kutta-Merson integration routine was programmed as an AIGOI procedure on the Burroughs $B 5500$ computer The Kutta-Merson procedure used was a modified version of the Stanford Computation Center KuttaMerson procedure These modifications, the additions of an absolute error bound and a stepsıze-cuttıng limıter, were made to the procedure to reduce the computation time The modifications did not affect the accuracy in less than the fifth significant figure in the test runs made A further reduction in the computation time is accomplished by scaling the equations so that the dependent variables are more nearly the same size A IIsting of the program used for integrating the equations is given in Appendix $F$

Several computer solutions of the yaw-roll equations and of the pitch equations were needed to determine the "best" values of $n_{I}$, $I=1, \quad 6$, in the penalty function and $\mathrm{IN}_{1}, 1=1,2,3$ (These "best" values are the values which result in the fuel cost being as small as possible whlle the control keeps $\left.\left|\mathrm{x}_{1}\right| \leq 11 \times 10^{-4}, 1=1, \quad, 6\right)$

The inltial cholce of values for $n_{1}$ and $\mathbb{N}_{1}$ was made in the following way The possible cholces on $\mathbb{N}_{1}$ lie 1 a a range from the smallest values with which control wlll be malntalned at all tImes up to the largest values which cause changes in the motion to occur too rapidly In practice the smaller values are the logical ones to choose since with large $\mathbb{N}_{1}$ the inherient imperfections in the controller can cause unsatIsfactory motion and wasted fuel The smallest possible values of $\mathrm{N}_{1}$ such that control could always be manntained, even if $\left|x_{1}\right|, 1=1,1,6$, grew to values as large as $20 \times 10^{-4}$, where chosen For satellite (2), 
for example, these values are $N_{1}=21 \times 10^{-4}, N_{2}=71 \times 10^{-4}$ and $\mathbb{N}_{3}=206 \times 10^{-2}$

The possible values of $n_{1}$ are the real numbers from the cost functional for this problem It can be seen that its minimum for intervals of time when $x$ is not $i n$ $S$ is the result of minimizing the part which Is a functional of $\underline{x}$ if

$$
\sum_{1=1}^{4} \pm 10^{n}\left(x_{1} \mp 10^{-4}\right)>\sum_{I}^{2} N_{1}
$$

and

$$
\sum_{1=5}^{6} \pm 10^{n}\left(x_{1} \mp 10^{-4}\right)>N_{3}
$$

If It Is desıred to keep $\left|\mathrm{x}_{1}\right| \leq 11 \times 10^{-4}$, then possible "best" values of $n_{1}$ for satellite (2) are $n_{1}=10, n_{2}=20, n_{3}=10, n_{4}=20$, $n_{5}=20$ and $n_{6}=40$ In the choice of these numbers nearly twice the weight was placed on the parts for $x_{2}, x_{4}$ and $x_{6}$ since these varıables change more rapldly than $x_{1}, x_{3}$ and $x_{5}$

The results of a computer solution of the equations for satellite (2) with the above values of $n_{I}$ and $\mathbb{N}_{I}$ are gIven $I$ graphlcal form in Figure 41 From this solution it is obvious that the above values of $n_{1}$ and $\mathbb{N}_{1}$ are not the "best" values Even though this solution exhIbIts characteristıcs which ald both the search for the "best" values of $n_{I}$ and $\mathbb{N}_{1}$ and the search for the feedback control law, the cost (In computer time) of continuing this method wathout other ands is prohibitıve

An approximate solution of the adjoint equations of this problem for arbitrary $\underline{x}(\tau)$ can be ootalned so that an optimal feedback control law for this problem can be written in terms of $n_{1}$ This approximate solution can be used as an ald in the search for the "best" values of $n_{I}$ and $\mathbb{N}_{1}$ and as a guzdeline in the search for nearly optimal and practical feedback controllers of the attıtude motions of satellites The approximate solution, which is derıved in Appendix $\mathrm{E}$, Is 


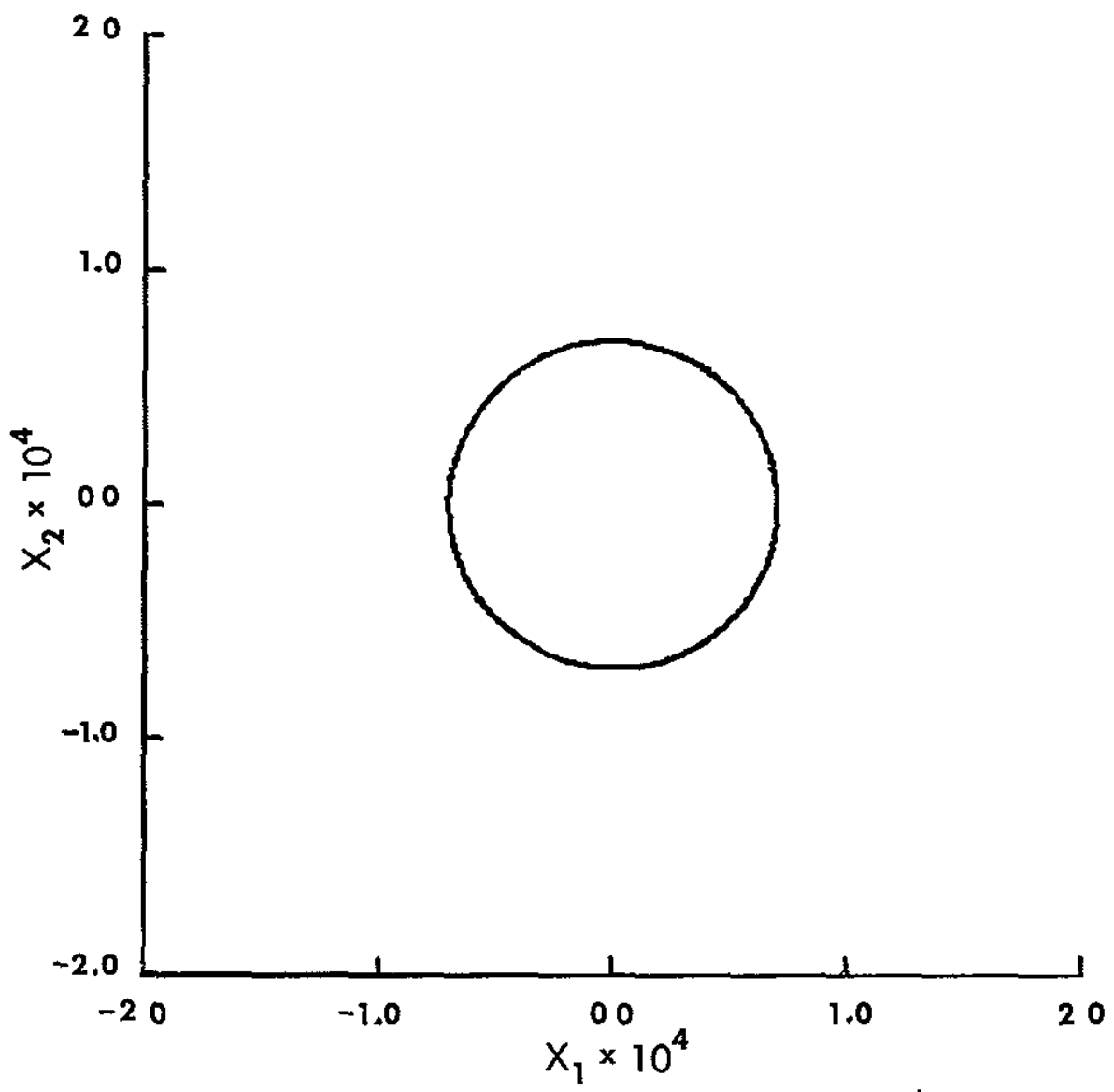

a Yaw Trajectory for $\mathbb{N}_{1}=21 \times 10^{-4}$
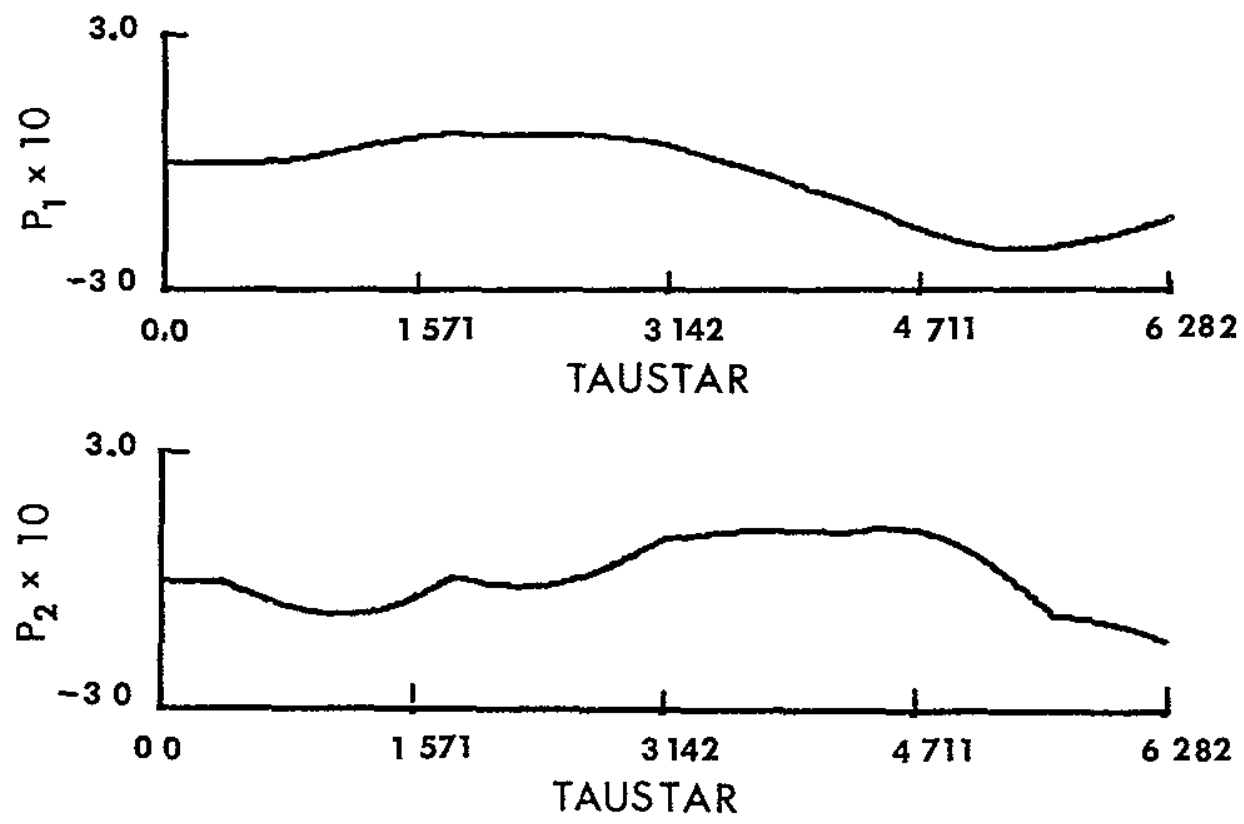

b. Yaw Adjount Varıables for $n_{1}=10, n_{2}=20$

Figure 41 Solution of Equations (4 3)-(4 6) for Satellite (2) 


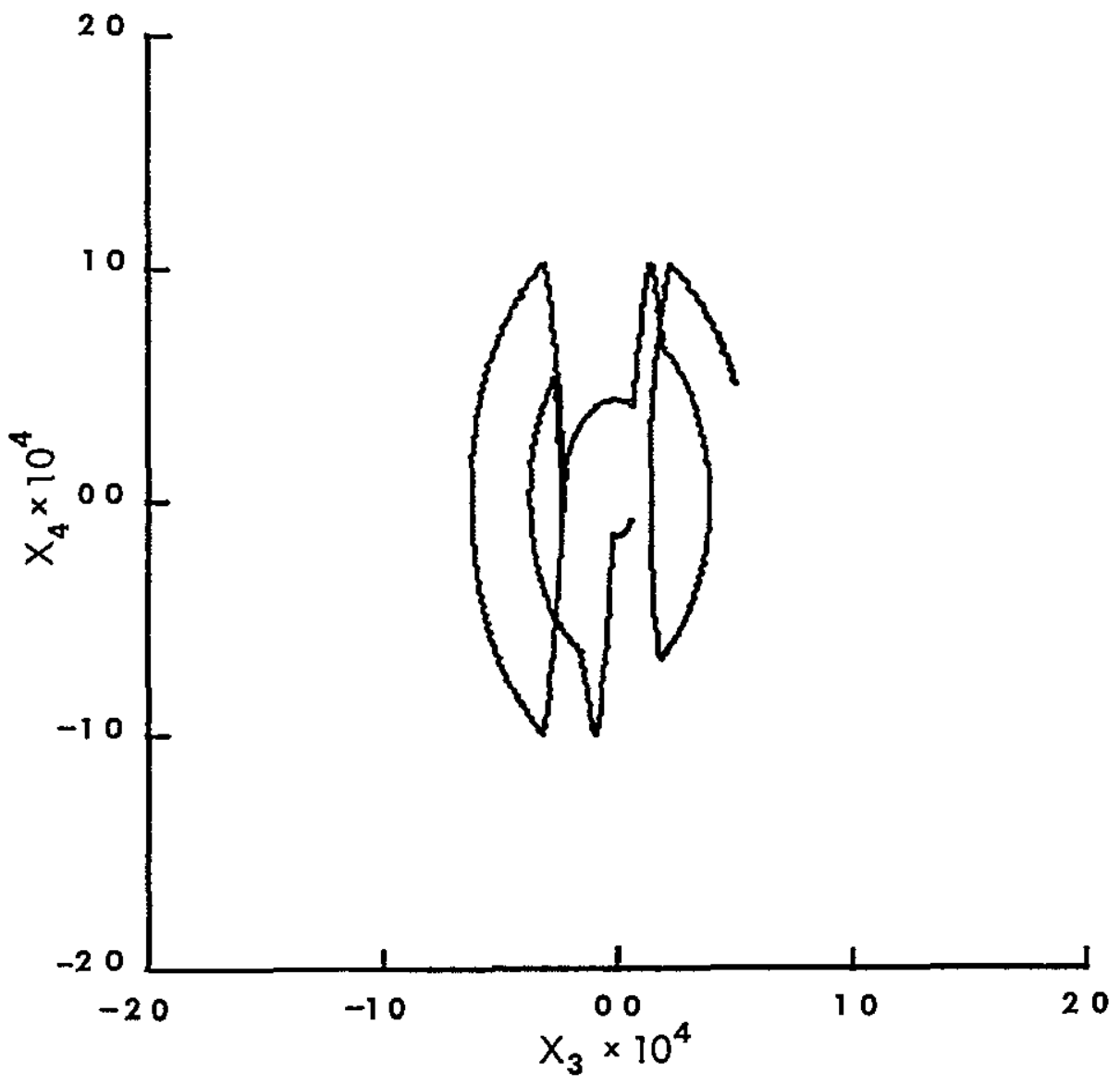

c Rol1 Trajectory for $\mathrm{N}_{2}=71 \times 10^{-4}$
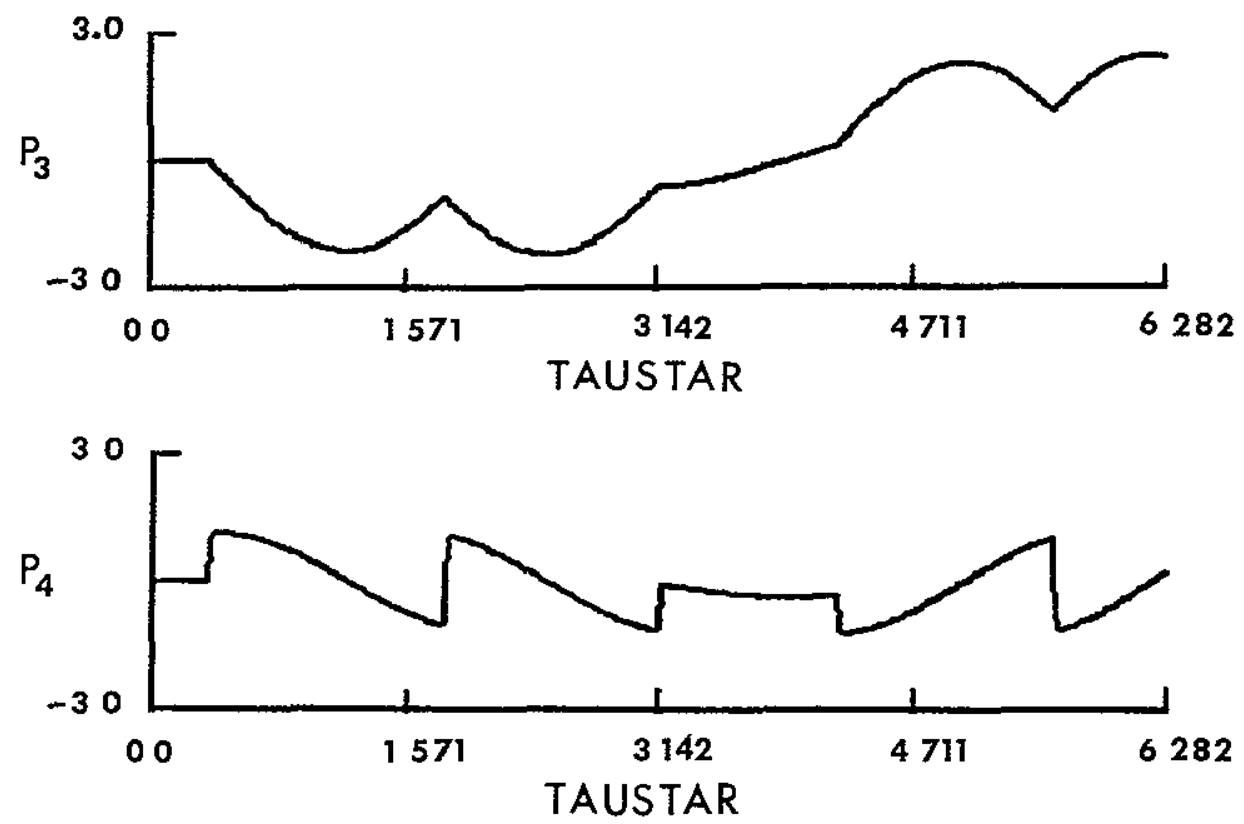

d. Roll Adjount Varıables for $n_{3}=10, n_{4}=20$

Figure 41 Continued 

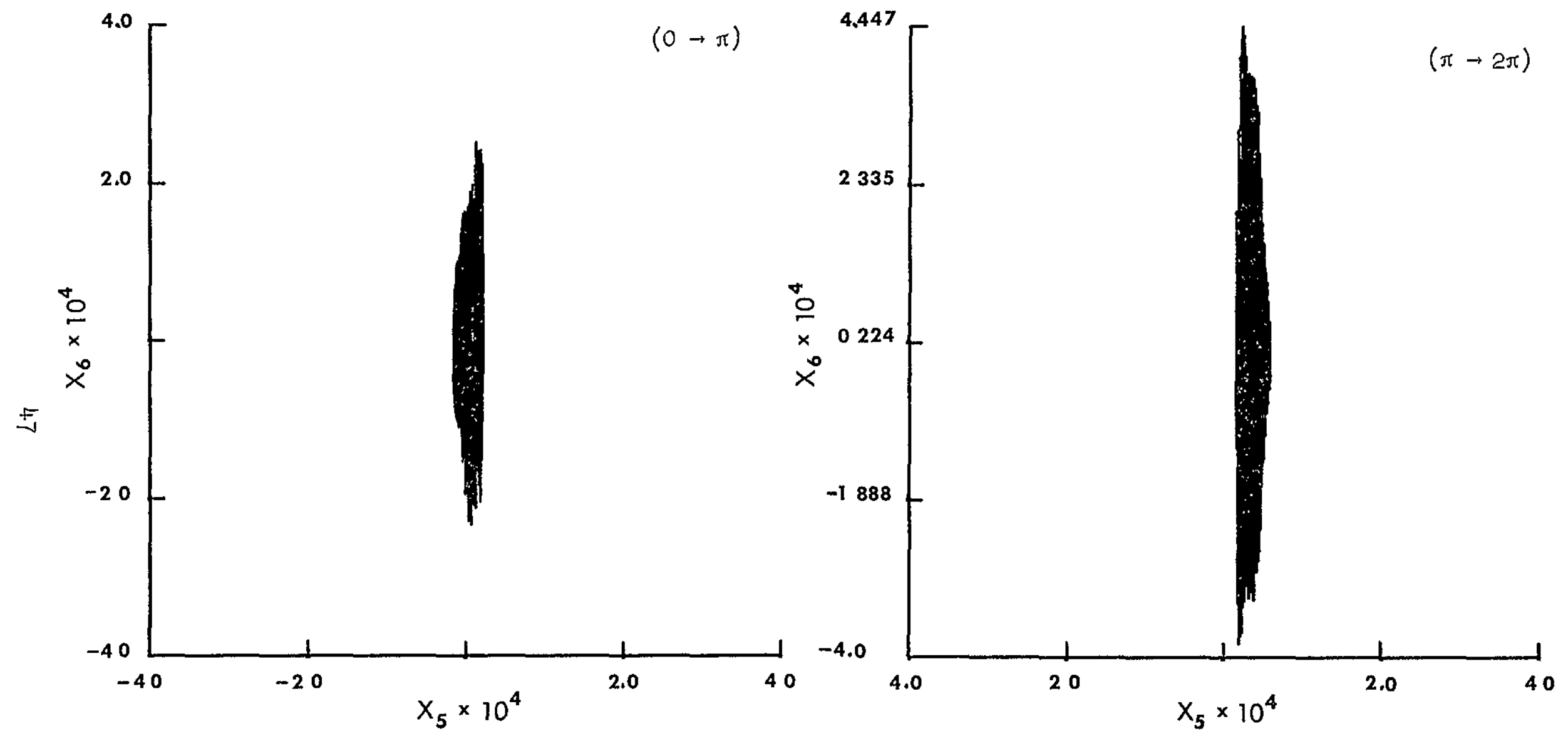

e Putch Trajectory for $\mathrm{N}_{3}=206 \times 10^{-2}$

Figure 41 Continued 

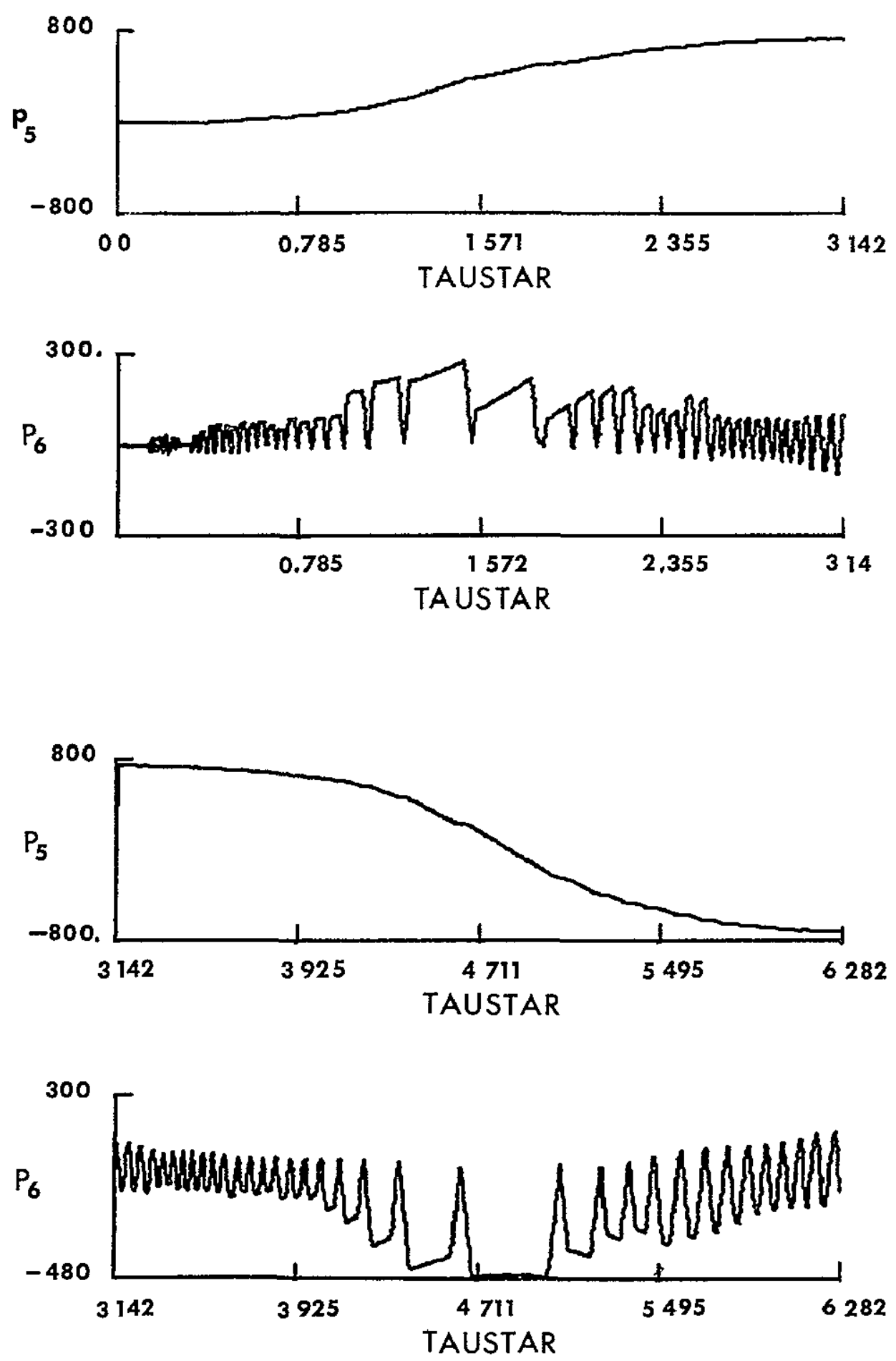

$f \quad$ Pitch Adjoint Varıables for $n_{1}=20, n_{2}=40$

Figure 41 Continued 


$$
\begin{aligned}
& p_{1}\left(\tau^{*}\right)=p_{1 e}\left\{1-\left[\left(B_{3}-B_{4}\right)+\left(\omega_{1}^{2}+\omega_{2}^{2}\right)\right]\left(\Delta \tau^{*}\right)^{2}\right\} \\
& -p_{2 e}\left[B_{1} \Delta \tau^{*}+B_{4} B_{5}\left(\Delta \tau^{*}\right)^{2}\right]-p_{3 e^{3}} B_{5}\left(\Delta \tau^{*}\right)^{2}-p_{4 e^{[}}\left[B_{5} \Delta \tau^{*}\right. \\
& \left.-\mathrm{B}_{1} \mathrm{~B}_{2}\left(\Delta \tau^{*}\right)^{2}\right]-\mathrm{F}\left(\mathrm{x}_{1}\right) \Delta \tau_{1}^{*}-\mathrm{F}\left(\mathrm{x}_{2}\right) \mathrm{B}_{1}\left(\Delta \tau_{2}^{*}\right)^{2}-F\left(\mathrm{x}_{4}\right) \mathrm{B}_{5}\left(\Delta \tau_{4}^{*}\right)^{2}
\end{aligned}
$$

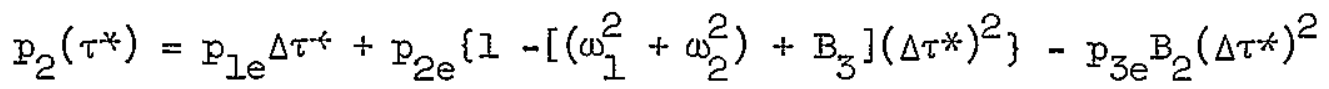

$$
\begin{aligned}
& -\underline{p}_{4 e}\left[B_{2} \Delta \tau \pi+B_{5}\left(\Delta \tau^{*}\right)^{2}\right]-F\left(x_{1}\right)\left(\Delta \tau_{1}^{*}\right)^{2}-F\left(x_{4}\right) B_{2}\left(\Delta \tau \tau_{4}^{*}\right)^{2}+F\left(x_{2}\right) \Delta \tau_{2}^{*} \\
& p_{3}\left(\tau^{*}\right)=p_{1} e_{5}(\Delta \tau *)^{2}+p_{2 e}\left[B_{5} \Delta \tau *+B_{3} B_{4}(\Delta \tau *)^{2}\right]+p_{3 e}\left\{1-\left[\left(\omega_{1}^{2}-\omega_{2}^{2}\right)\right.\right. \\
& \left.\left.+\left(B_{1}+B_{2}\right)\right]\left(\Delta \tau^{*}\right)^{2}\right\}-p_{4 e}\left[B_{3} \Delta \tau+B_{2} B_{5}(\Delta \tau *)^{2}\right] \\
& +F\left(x_{2}\right) B_{5}(\Delta \tau \underset{2}{*})^{2}-F\left(x_{3}\right) \Delta \tau *_{3}^{*}-F\left(x_{4}\right) B_{3}\left(\Delta \tau_{4}^{*}\right)^{2} \\
& p_{4}\left(\tau^{*}\right)=p_{1 e^{-}} B_{4}(\Delta \tau)^{2}+p_{2 e}\left[B_{4} \Delta \tau^{*}+B_{5}(\Delta \tau *)^{2}\right] \\
& \left.+p_{3 e} \Delta \tau+p_{4 e}\left\{I-\left[\left(\omega_{1}^{2}+\omega_{2}^{2}\right)+B_{1}\right]\left(\Delta \tau^{*}\right)^{2}\right\}+F\left(x_{2}\right) B_{4}(\Delta \tau)^{*}\right)^{2} \\
& -F\left(x_{3}\right)\left(\Delta \tau_{3}\right)^{2}+F\left(x_{4}\right) \Delta \tau_{4}^{*} \\
& p_{5}\left(\tau^{*}\right)=p_{5 e}\left[1-B_{6}\left(\Delta \tau^{*}\right)^{2}\right]-p_{6} e_{6} \Delta \tau^{*}-F\left(x_{5}\right) \Delta \tau_{5}^{*}-F\left(x_{6}\right) B_{6}(\Delta \tau /)^{2} \\
& p_{6}\left(\tau^{*}\right)=p_{5 e^{\Delta \tau *}+p_{6}}\left[1-B_{6}\left(\Delta \tau^{*}\right)^{2}\right]-F\left(x_{5}\right)\left(\Delta \tau \frac{*}{5}\right)^{2}+F\left(x_{6}\right) \Delta \tau \frac{*}{6}
\end{aligned}
$$

where $\omega_{1}, \omega_{2}, \Delta \tau^{*}, \Delta \tau_{1}^{*}, B_{1}$ and $p_{1 e^{\prime}} 1=1, \quad 6$, are as defined in Appendıx $\mathrm{E}$

In equations $(48)$ and $(49)$ all of $B_{1}, 1=1,6$, are periodic (with a period of $2 \pi$ ) and except for $B_{5}$ they are nearly constant The averages (over the tIme of one orbit) of $B_{1}, 1=1,4,4,6$, were substituted into the above equations $B_{5}$ was considered constant in the time between boundary encounters with its value taken as the value 
at the time of the previous boundary encounter (Its average value was not used since its average over the time of one orbit is zero) The approximate values for $p_{1}(\tau *), 1=1,1,6$, which are given by equations (4 8) and (4 9) were compared with the "exact" values obtanned from digital computer solutions

Equations (4 3)-(4 6) were solved with the ald of the digital computer for several sets of values of $n_{1}, 1=1,2,6$, and several initial conditions (some of $\underline{x}\left(\tau_{0}\right)$ in the interior of $S$ and some on the boundary of $s)$ The time of solution was $\tau_{f}^{*}-\tau_{0}^{*}=628 \approx 2 \pi$ and the solution was printed out at intervals of $\tau^{+}$of 0 ol The motzons considered were the roll-yaw motions of satellites (1) and (2) and the pitch motions of satelizte (3) The control strength used was $\mathrm{N}_{1}=$ $21 \times 10^{-4}, N_{2}=71 \times 10^{-4}$ and $N_{3}=206 \times 10^{-2}$ These "exact" solutıons for $p_{1}\left(\tau^{*}\right), 1=1,6$, were compared with the approximate values given by equations ( 4 ) and ( 49 ) for as many as ten Intervals of time per solution as follows Each solution of $x_{1}(\tau *), 1=1, \quad, 6$, was applied through $F\left(x_{1}\right)$ to equations (4 8) and (4 9) The inltial conditions on $p_{1 e}, 1=1, \quad, 6$, were the same as $p_{1}\left(\tau_{0}^{*}\right), 1=1,1,6$ After the inltial tıme $\tau_{0}^{*}$ the values of $p_{1 e^{\prime}} 1=1,1,6$, were taken to be the values of $p_{1}\left(\tau^{*}\right), 1=1, ., 6$, at the time the proper (yaw, roll or pltch) trajectory projection reentered the proper projection of s. These new values of $p_{1 e}$ were retalned until the trajectory exlted and reentered $S$ agann

In most cases the comparison of the approximate solutions with the "exact" solutions showed that the approximate solutions differed from the exact solutions only in the third significant figure In other cases the difference was only in the fourth significant figure Therefore, if (4 8) and (4 9) are substituted Into (4 2), the result is a time-varyıng feedback control law which is consıdered optımal for the present problem This control law can be implemented in a controller, but, the devices needed to determine if $x_{1}$ Is exiting $S$ or entering $S$ when $\left|x_{1}\right|=$ $10^{-4}$ may be complicated and can be unreliable Timers, which are activated when $x_{1}, I=1,, 6$, exıt $s$ and reenter $s$ are also needed to generate $\Delta \tau_{1}^{*}, 1=1,, 6$, and $\Delta \tau^{*}$ Thus, even if this 
control law is the optimal minimum fuel control law with best values of $\mathrm{n}_{1}$ and $\mathrm{N}_{1}$ for the above satellites, It might not be the least costly control law to implement in practice More is sald about this in Section B

Estimates of the "best" values of $n_{1}$ and $\mathbb{N}_{1}$ for the satellites can be obtanned with the ald of $(48)$ and $(49)$ If the control is off and $\underline{x}\left(\tau^{*}\right)$ Is exıtıng $s$, the time $1 t$ takes for $\left|x_{1}\left(\tau^{*}\right)\right|, 1=1, \quad, 6$, to increase from $10^{-4}$ to $11 \times 10^{-4}$ is generally small enough, so that, If $\operatorname{NRS}_{1}, 1=1,6$, is the no-control right hand side of the equations, (4 3) and (4 5), for ${ }^{\prime} x_{1}, 1=1,6$, then

$$
\Delta x_{I} \approx\left(N_{1} S_{1}\right) \tau_{I}^{*} \quad I=1, \cdot, 6
$$

Is a satısfactory approximation

During those periods of time when the control is off, $\left|p_{1}\left(\tau^{*}\right)\right|$, $1=2,4,6$, must be less then unity For the control to turn on so that $\left|\mathrm{x}_{1}\left(\tau^{*}\right)\right|, 1=1,, 6$, do not increase to values greater than $11 \times 10^{-4}$, the values of the corresponding $\left|p_{1}\left(\tau^{*}\right)\right|, 1=2,4,6$, must be unity or greater at the tIme when $\left|x_{1}\left(\tau^{*}\right)\right|=11 \times 10^{-4}$ Since In (4 8) and (4 9) $p_{1 e}, 1=1, \quad 6$, are nearly perıodic with an average over one orblt of nearly zero (see Figure 4 Ib, for example) a first approximation is

$$
\begin{aligned}
& p_{2}\left(\tau^{*}\right) \approx F\left(x_{2}\right) \Delta \tau_{2}^{*}-F\left(x_{1}\right)\left(\Delta \tau_{1}^{*}\right)^{2} \\
& p_{4}\left(\tau^{*}\right) \approx F\left(x_{4}\right) \Delta \tau_{4}^{*}-F\left(x_{3}\right)\left(\Delta \tau_{3}^{*}\right)^{2} \\
& p_{6}\left(\tau^{*}\right) \approx F\left(x_{6}\right) \Delta \tau_{6}^{*}-F\left(x_{5}\right)\left(\Delta \tau_{5}^{*}\right)^{2}
\end{aligned}
$$

so that for $\left|p_{I}\left(\tau^{*}\right)\right|$ to grow to unity in the time interval $\Delta \tau^{*}$ in whIch $\left|\Delta \mathrm{x}_{1}\right|$ grows to $10^{-5}, \mathrm{I}_{\mathrm{I}},\left|\mathrm{x}_{1}\left(\tau^{*}\right)\right|$ Increases from $10^{-4^{7}}$ to $11 \times 10^{-4^{1}}$, It must be true (as seen from $(410)$ and (4 11)) that

$$
\begin{aligned}
& 10^{n_{1}}=F\left(x_{1}\right) \approx\left(\Delta_{1}^{*}\right)^{-1} \approx \mathbb{N R S}_{1} / 10^{-5}, \quad I=2,4,6 \\
& 10^{n_{I}}=F\left(x_{1}\right) \approx\left(\Delta \tau_{1}^{*}\right)^{-2} \approx\left(\operatorname{NRS}_{1} / 10^{-5}\right)^{2}, \quad I=1,3,5
\end{aligned}
$$


Equations (4 12) can be used to determine an estimate of the "best" values for $n_{1}, 1=1, ., 6$ In (4 12) the largest possible values for $\mathbb{N R S}_{I}$ should be used since smaller values result in $n_{I}$ which are too small to keep $\left|x_{1}\right| \leq 1.1 \times 10^{-4}$ For satellite (2), for example, the largest posslble values of $\mathrm{NRS}_{1}$ for $\left|\mathrm{x}_{1}\right| \leq 11 \times 10^{-4}$ are $\mathrm{NRS}_{1}=11 \times 10^{-4}, \mathrm{NRS}_{2}=113 \times 10^{-4}, \mathrm{NRS}_{3}=1.1 \times 10^{-4}, \mathrm{NRS}_{4}=$ $369 \times 10^{-4}, \quad \operatorname{NRS}_{5}=11 \times 10^{-4}$ and $\operatorname{NRRS}_{6}=2.06 \times 10^{-1}$ WIth these values It is found from (4 12) that $n_{1}=2.1, n_{2}=10, n_{3}=21$, $n_{4}=16, n_{5}=2.1$ and $n_{6}=3.3$

From several digltal computer solutions obtalned with the above estimates of the best values of $n_{1}$ and with several sets of values of $\mathfrak{N}_{1}$, It was found that some of $\left|x_{1}\right|, 1=1, ., 6$, grew to values as large as $60 \times 10^{-4}$, which, of course, Is too large Also, from the solutions It was found that for $\mathbb{N}_{1}$ and $\mathbb{N}_{2}$ nelther the largest nor the smallest of the values tried were best and for $\mathbb{N}_{3}$ the smallest value was best. A detalled examnation of this result with the and of $(42),(43),(45),(4.8)$ and $(49)$ proved to explain the effects of $n_{I}$ and $N_{I}$ on the solutions and offered new values of $n_{I}$ and $N_{I}$ to be tested (Thls detalled examınation is not glven here since it is long and tedious with many numbers and since simllar examınations are given in Parts 2 and 3 ) Whth the newly offered values of $n_{I}$ and $N_{I}$ digltal computer solutions were obtalned It was found that the requirement for the "best" values was satısfied by Increasıing $n_{1}, 1=2,4,6$, by about one over the above estimated values As expected, the accuracy of earthpointing Improved and the fuel cost increased to the maximum value, which was for no control-off intervals, with increasing $n_{1}$ Also, it was found that both the fuel cost and the earth-polntIng accuracy generally Increased with Increases in $N_{I}$ above their "best" values for values of $\mathbb{N}_{1}$ less than about $0 I$ For values of $\mathbb{N}_{I}$ of 01 or more the fuel cost still Increased with Increases in $N_{I}$ but the accuracy of earthpointing dropped off sharply Values of $\mathrm{N}_{1}$ which were smaller than the "best" values resulted in the control being on so much longer that the fuel cost was generally higher The "best" values of $n_{I}$ and $N_{I}$ resulted In the pitch axis control staying on about $95 \%$ of the time whlle the roll-yaw control was on about $33 \%$ of the time 
In summary the main result of this part is the time-varying feedback control law given by $\left(\begin{array}{ll}4 & 2\end{array}\right)$ together with (4 8) and (4 9) The control law is optimal in the sense that it was obtained from the sufficlent conditions of the maximum principle for the cost functional

$$
J=\int_{\tau}^{\tau} \sum_{1}^{3}\left|v_{1}\right| d \tau
$$

and the Integral constrant on the states

$$
\int_{\tau_{0}}^{\tau} f_{1}[x(\tau)] d \tau \leq A
$$

Other results of this part are (a) a not-too-expensive method has been devised for determining the "best" values of the control law parameters $n_{I}$ and $N_{I},(b)$ the effects of varying the parameters $n_{1}$ and $N_{I}$ from their "best" values was glven, and, (c) satellite (2) has the smallest unit fuel cost with the above control Figure (4 2) shows yaw, roll and putch projections of a state space trajectory of satellite (2) for the time of one orbit with the above control and the "best" values of $\mathrm{n}_{1}$ and $\mathrm{N}_{1}$

The optimal control of this part is not necessarly minimum fuel optimal Indeed, it is not difficult to exhiblt several controls which keep $\underline{x}$ in $S$ and use less fuel Since It Is very difficult and expensive computer-tıme to apply the NCES to the full three-axes satellite control problem and since a basis for fuel cost comparison is needed, simple single-axis control problems are now investigated

2 The Steady-State Motıon Obtained From PMP for $x^{\prime \prime}=v$

$$
\begin{aligned}
& \text { In } x^{\prime \prime}=v \text { let } x=x_{3}, x^{\prime}=x_{4} \text { and } v=v_{2} \text { Then } \\
& x_{3}^{\prime}=x_{4} \\
& x_{4}^{\prime}=v_{2}
\end{aligned}
$$




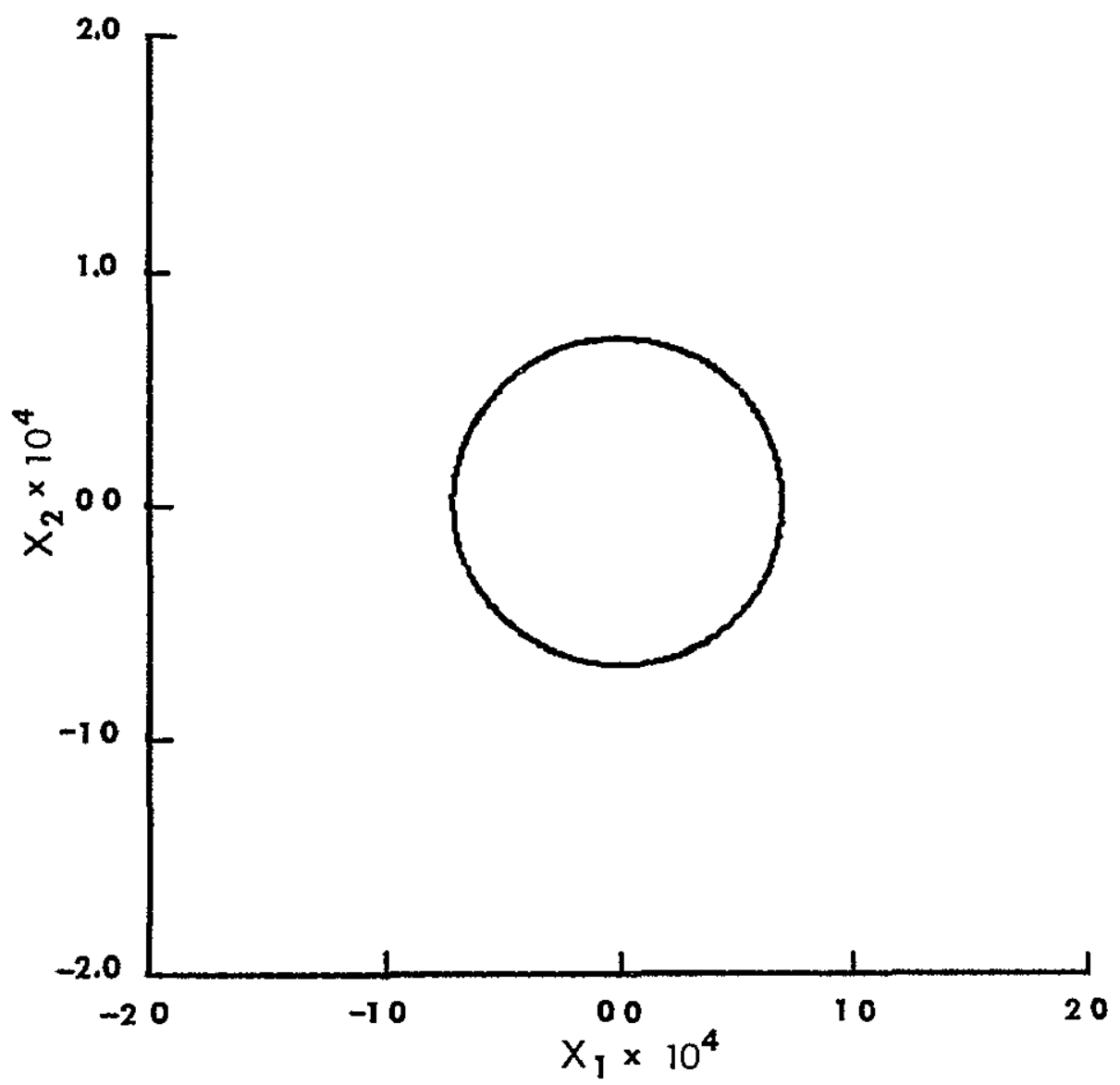

a Yaw Trajectory for $\mathrm{N}_{1}=21 \times 10^{-4}$
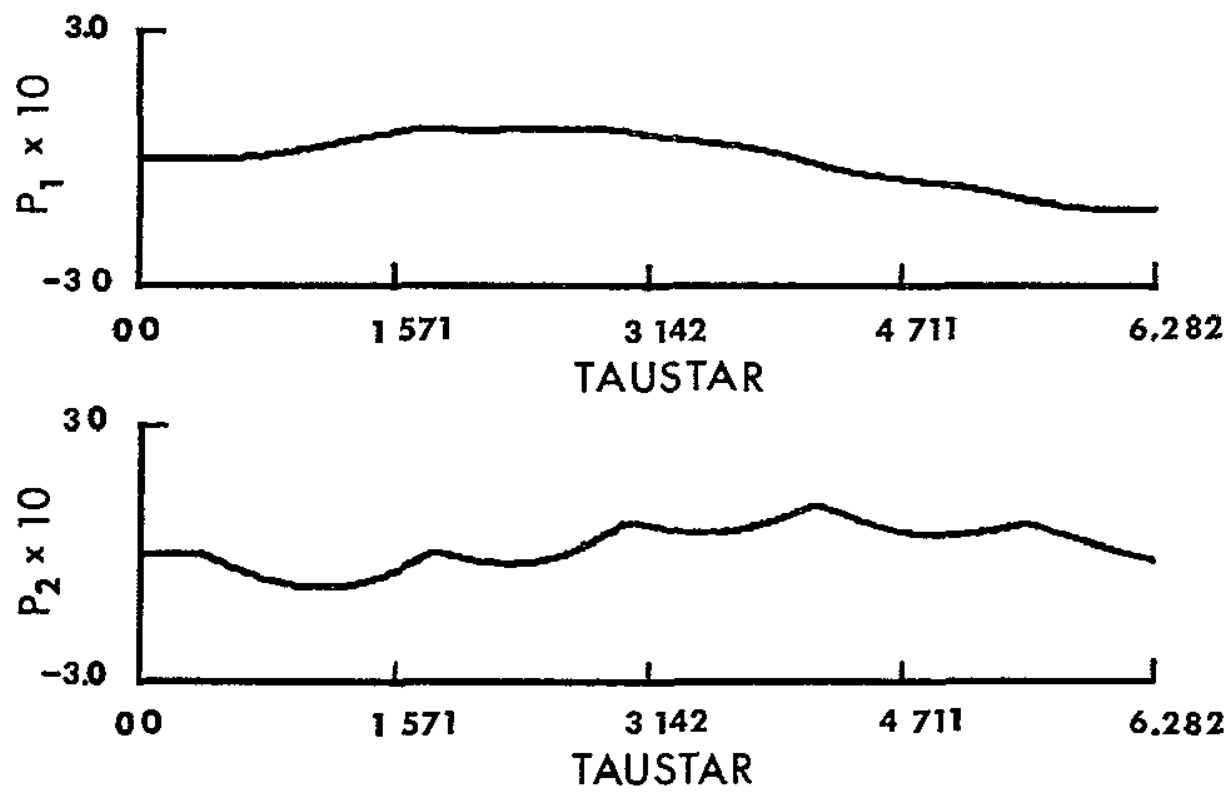

b Yaw Adjount Varıables for $n_{1}=21, n_{2}=1.0$

Figure 42 Solution of Equations (4 3)-(4 6) for Satelilte (2) 


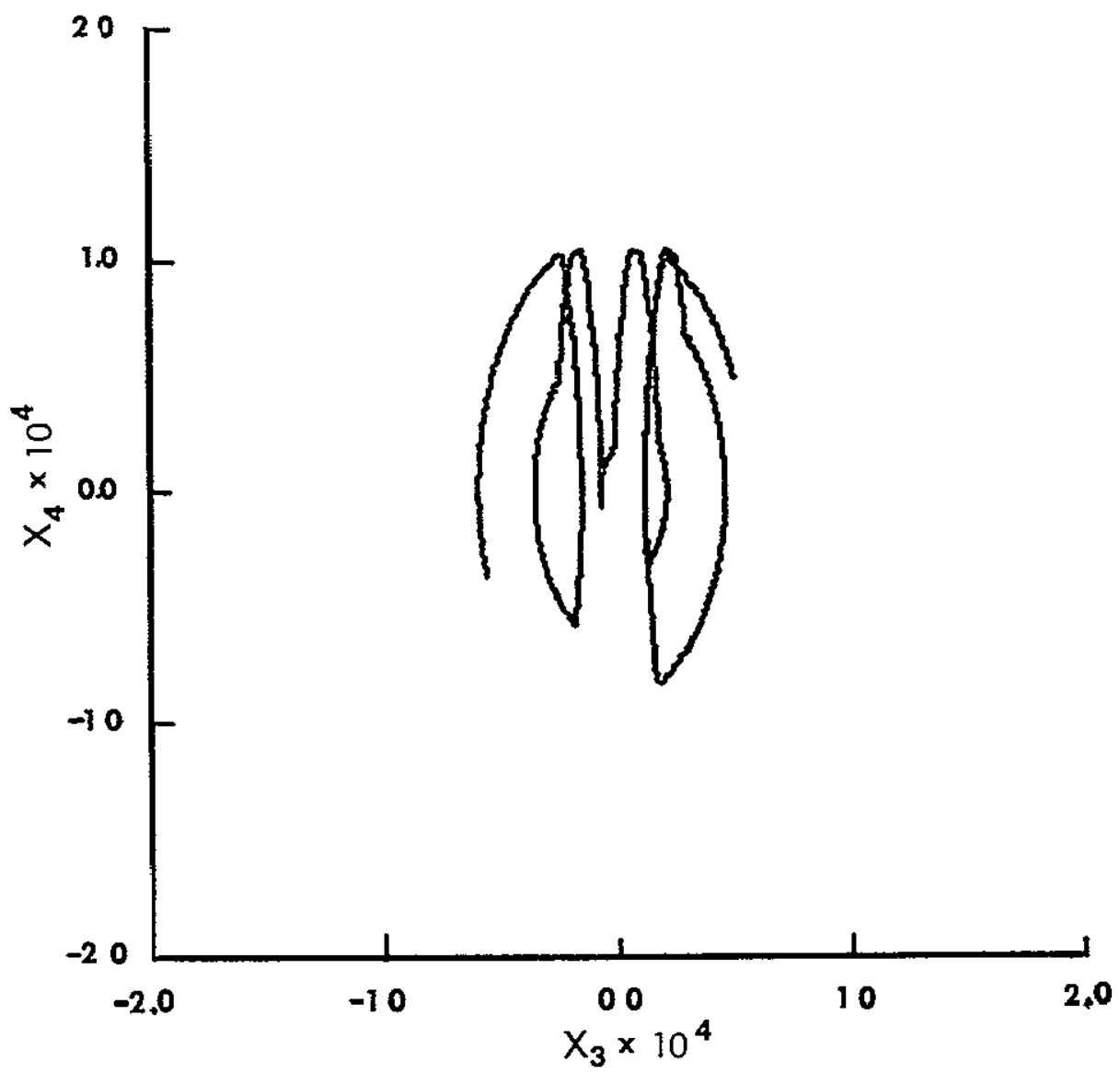

c Roll Trajectory for $\mathrm{N}_{2}=71 \times 10^{-4}$
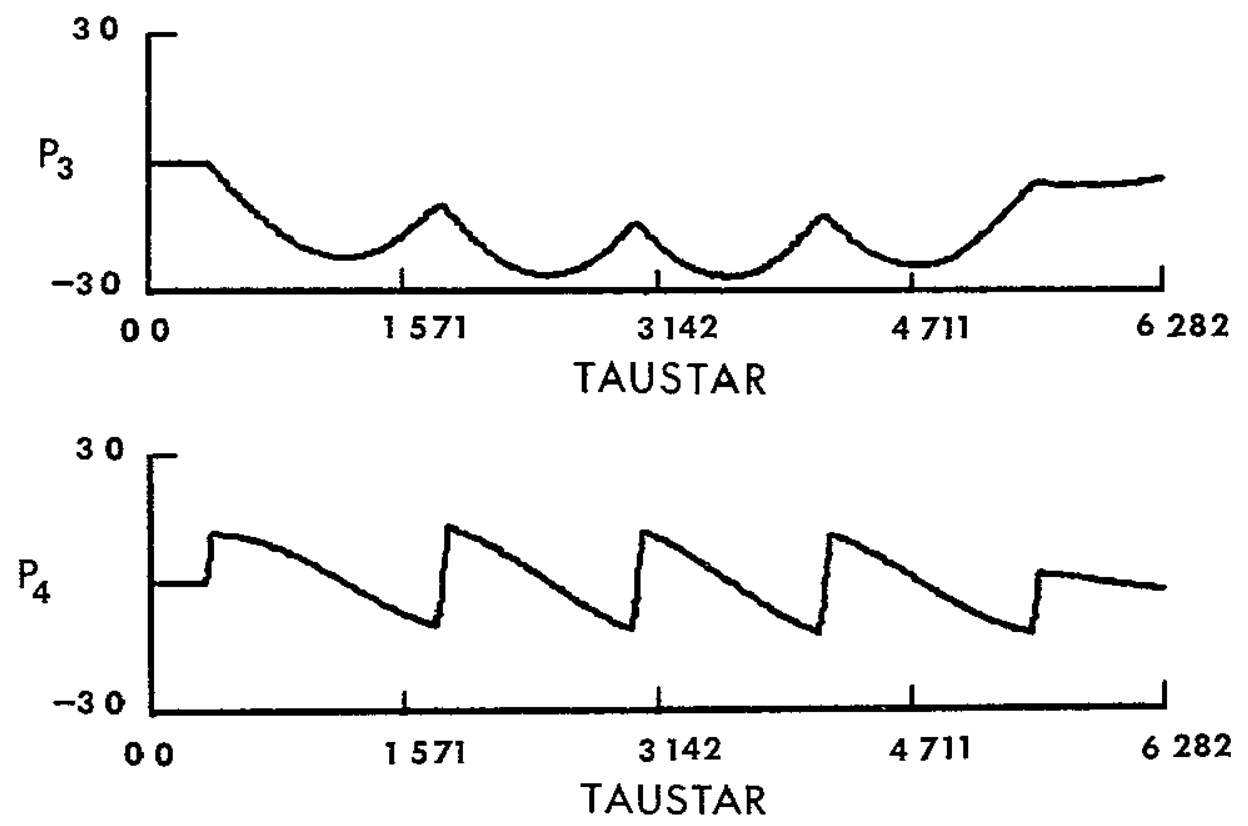

d. Roll Adjoint Varıables for $n_{3}=21, n_{4}=16$

Figure 42 Continued 


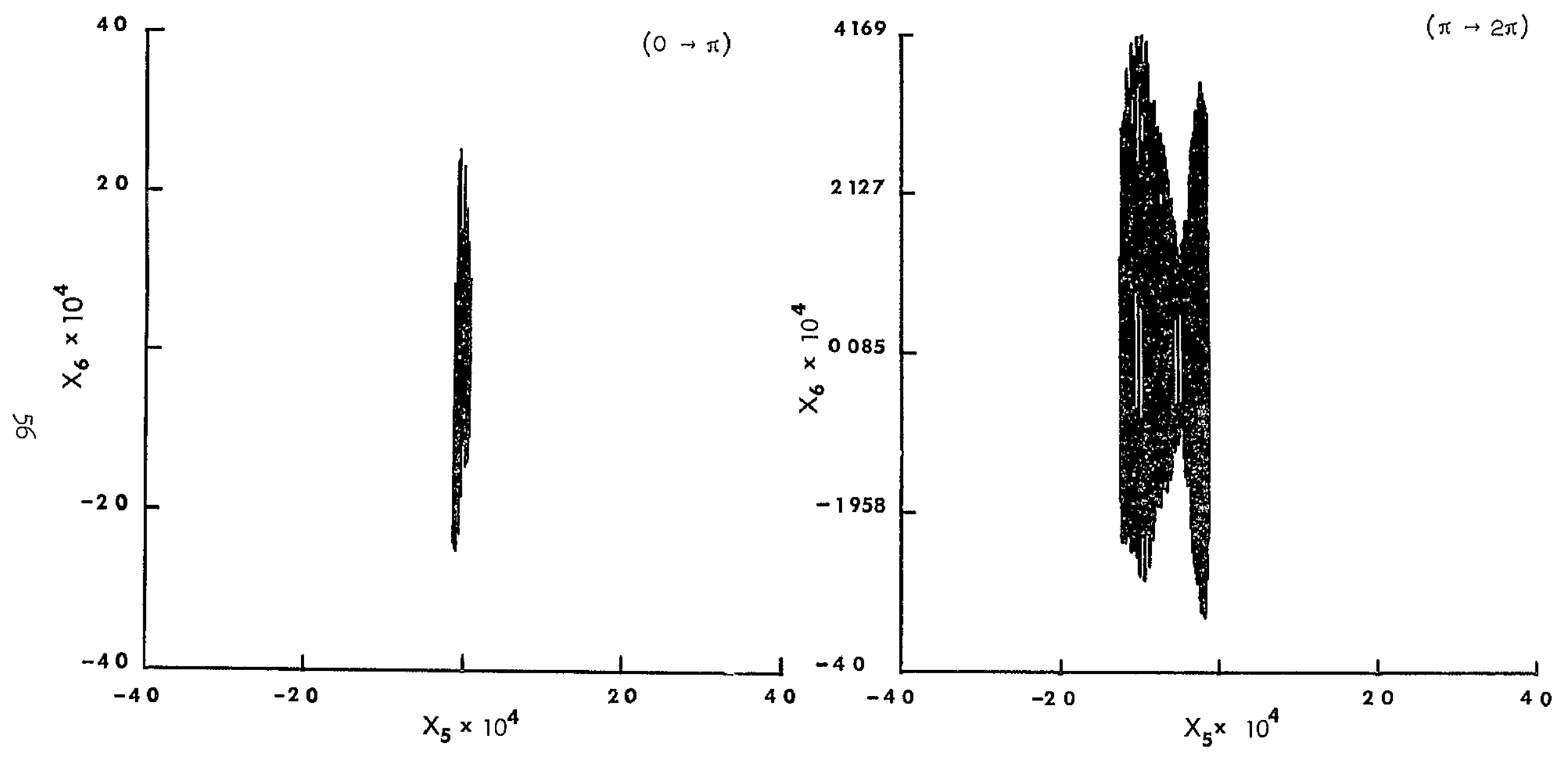

e Prtch Trajectory for $\mathbb{N}_{3}=206 \times 10^{-2}$

Figure 42 Continued 

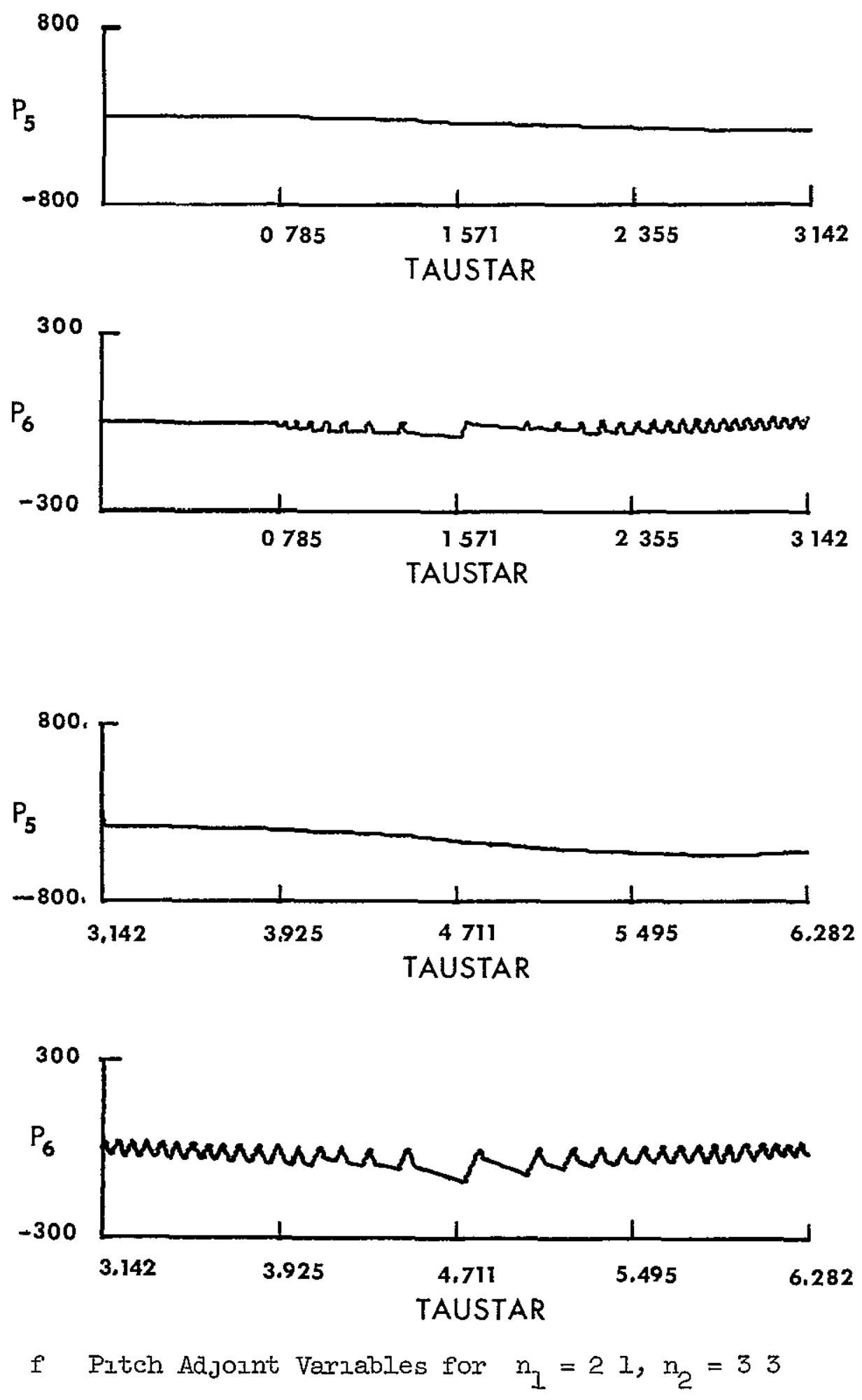

Figure 42 Continued 
is equivalent to $x^{\prime \prime}=v$ For some intervals of time, equations (4 13) approximately describe the roll motion of satellites if they are nearly symmetric (such that $\mathrm{k}_{2} \approx 0$ ), If they are not significantly affected either by the earths atmosphere or the disturbances mentioned in Chapter II and if they are controlled such that $x_{1}=0,1=1,2,5,6$ of course, no such controlling of a satellite's motzon is practicable at this time However, if $\mathrm{v}_{2}$ is a "coast functıon" wIth magnıtude $\mathrm{N}_{2} \geqslant 0 \mathrm{OI}$, equation (4 13) adequately describes both the roll and yaw motions during those time intervals when the control is $\pm \mathrm{N}_{2}$ In any case, for the purpose of comparing the two mathematical methods (approximate and exact), it is worthwhle to study the controlled motzon of the simple plant described by (4 13)

By studying the possible controls and motions which satisfy the NCES (see Part 4, Section D, Chapter III), controls which perform satısfactorly are obtalned and given below (These controls are compared later to the controls obtalned from PMP with

$$
J=\int_{\tau_{0}}^{\tau}\left[f_{\underline{I}}(\underline{x})+|v|\right] d \tau
$$

for the motion described by (4 13), 1 e , the approximate method )

Whlle the phase-plane trajectory is in the interior of $S_{R}$, the roll phase-plane projection of $\mathrm{S}$, the condltions of PMP must be satisfied They are (4 13) and

$$
\begin{aligned}
& p_{3}^{\prime}=0 \\
& p_{4}^{\prime}=-p_{3} \\
& v_{2}=N_{2} \operatorname{CST}\left(p_{4}\right)
\end{aligned}
$$

The parts of the trajectories which colncıde with the parts of the boundary of $S_{R}$ given by $x_{4}= \pm 10^{-4}$ are "regular" For a given value of $\mathrm{N}_{2}(<\infty)$, trajectories which begin in the shaded regions of $S_{R}$ In Figure ( 43 ) must exıt $S_{R}$ In acquirıng equilıbrium points, namely those points such that $x_{4}=0$ These trajectories do not satisfy the 


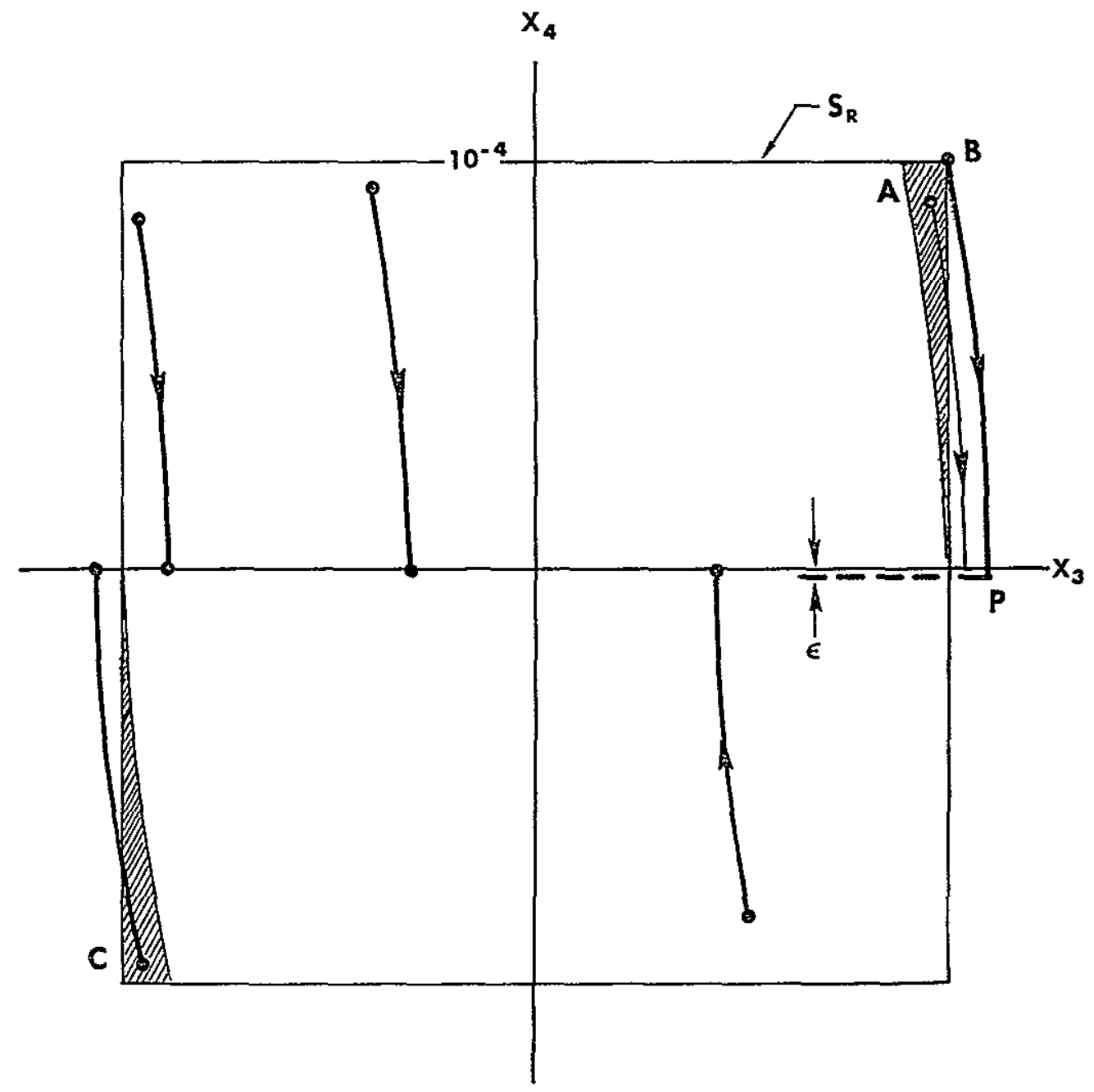

Fıgure 43 Typıcal Mınımum Fuel Trajectorıes for System (4 13), $N_{2}=5 \times 10^{-4}$ 
NCES unless the vertical parts of the boundary of $\mathrm{S}_{\mathrm{R}}$ are replaced by segments of parabolic curves (control-on trajectories) The control-on parts of the trajectorles "A", "B" and "C" In FIgure ( 4 3) are such curves The trajectories are "regular" All trajectorles in Figure (4.3) except " $B$ " acquire the part of the line $x_{4}=0$ in or sufficiently near $\mathrm{S}_{\mathrm{R}}$ In this case the transversality condition (3 14) with $\underline{b}\left(\underline{x}_{\mathrm{f}}\right)$ perpendicular to the $x_{3}$-axis is applied Trajectory " $B$ " Is not precisely a mınımum fuel trajectory except in the limlt as $\epsilon \rightarrow 0$ However, $\epsilon \neq 0$ Is more practical since Imperfections such as tIme delays, thresholds, etc, (see Flugge-Iotz [12]) are always present in the controller, and, for comparison of the NCES with the approximate method, this is an Interesting case when $\underline{x}_{f}$ is free in the interior of $S$ The value of $\mathrm{N}_{2}$ used in Figure 43 is the smallest value which results in $\left|\mathrm{x}_{I}\right| \leq$ $I I \times 10^{-4}, I=3,4$, (a $10 \%$ error In the maximum error) regardless of the initial point in $S_{R}$ The "Jump condition" (3 15) Is applied at "P" Since the time required to reach $\mathrm{x}_{4}\left(\tau_{f}\right)=0$ in $\mathrm{S}_{\mathrm{R}}$ (or a point sultably near so that no future control effort is required for the remaining part of the satellite's lifetime) Is not important, the usual "bang-cost-bang" control, I e, $\pm \mathbb{N}_{2} \rightarrow 0 \rightarrow \mp \mathbb{N}_{2}$, does not result in a minimum fuel expendlture (see, for example, Marbach [25] whereln the acquisition time is given)

Now consider the controls and resulting motions obtained from PMP with

$$
J=\int_{\tau_{f}}^{\tau_{0}}\left[f_{I}(\underline{x})+|v|\right] d \tau
$$

for $x^{\prime \prime}=v$ and for varıous tzmes of consideration and compare them with the controls and resulting motions obtained from the NCES

As in Part 1 of this section, the equations of the maximum principle for this problem can be written in backwards time as

$$
\begin{aligned}
& { }^{\prime} x_{3}=-x_{4} \\
& { }^{\prime} x_{4}=-v
\end{aligned}
$$




$$
\begin{aligned}
& { }^{t} p_{3}=-F\left(x_{3}\right) \\
& { }^{t} p_{4}=F\left(x_{4}\right)+p_{3} \\
& v=N \operatorname{CST}\left(p_{3}\right)
\end{aligned}
$$

These equations can be solved in a plecewise manner.

The piecewise solution of $(416)$ for intervals of $\tau^{*}$ over

whIch $\mathrm{v}\left(\tau^{*}\right)$ Is constant Is given by

$$
\begin{aligned}
& x_{3}\left(\tau^{*}\right)=\left\{\begin{array}{r}
+\mathbb{N} \\
0 \\
-N
\end{array}\right\} \tau^{2}-x_{40} \tau *+x_{30} \\
& x_{4}(\tau *)=\left\{\begin{array}{r}
-\mathbb{N} \\
0 \\
+N
\end{array}\right\} \tau *+x_{40}
\end{aligned}
$$

where $\tau^{*}$ Is measured from the last time of control swltching, $\tau_{S}^{*}$, or from the Initıal tıme, $\tau_{0}^{*}$, and $x_{30}=x_{3}\left(\tau_{1}^{*}\right), x_{40}=x_{4}(\tau *), I=0, s$ If equations (4 17) are solved for the same Intervals of $\tau^{*}$ as the plecewise solution of the adjoint variables given in Part 1 and in Appendix E, the result is

$$
\begin{aligned}
& \mathrm{p}_{3}\left(\tau^{*}\right)=\mathrm{p}_{3 e}-\mathrm{F}\left(\mathrm{x}_{3}\right) \Delta \tau_{3}^{*} \\
& \mathrm{p}_{4}\left(\tau^{*}\right)=\mathrm{p}_{4 \mathrm{e}}+\mathrm{p}_{3 \mathrm{e}} \Delta \tau^{*}+\mathrm{F}\left(\mathrm{x}_{4}\right) \Delta \tau_{4}^{*}-\mathrm{F}\left(\mathrm{x}_{3}\right)\left(\Delta \tau_{3}^{*}\right)^{2} / 2
\end{aligned}
$$

(Notice that when $x \in S$ equations (4 20) are just the backwards time solution of $(414)$ and that $(4$ 18) and $(4$ 15) are the same for any $\left.f_{1}(x)\right)$

With the proper initial conditions equations (4 19) and (4 20) can be used together with ( 4 18) to construct optImal controls and optImal trajectories If the boundary of $S$ is not encountered by the trajectory, which in foreward time goes from a free initial point to a fixed final point on the $x_{3}$-axis $\left(\left|x_{4}\left(\tau_{f}\right)\right| \leq 10^{-4}\right)$, the optimal control results in a trajectory which is typically any of those in Figure 43 except the ones which cross the boundary of $S_{R}$ This is easily verufled 
with (4 18)-(4 20), since $F\left(x_{1}\right) \equiv 0, p_{1 e}=p_{1}\left(\tau_{0}^{*}\right)=p_{1}\left(\tau_{f}\right), 1=3,4$, and $p_{I}\left(\tau_{f}\right)$ Is elther completely arbitrary (If $\underline{x}\left(\tau_{f}\right)$ is a given point and $\underline{x}\left(\tau_{0}\right)$ Is freely chosen) or such that the transversality condition Is satisfied (If $\underline{x}\left(\tau_{f}\right)$ Is any point of $x_{4}\left(\tau_{f}\right)=0$ and $\left|x_{3}\left(\tau_{f}\right)\right| \leq 10^{-4}$ ) If the initial point of the trajectory is so near the parts of the boundary of $S_{R}$ given by $x_{3}= \pm 10^{-4}$ that an exceedingly large control is needed to keep the trajectory in the interlor of $S_{R}$, the trajectory is allowed to exit $S_{R}$ by a sultably small amount As before the trajectories are limıted by $\left|x_{1}\right| \leq 11 \times 10^{-4}, 1=3,4$ The value of $\mathrm{N}_{2}$ used in applying the NCES, namely $\mathrm{N}_{2}=50 \times 10^{-4}$, Is used here

If the proper final conditions (Initial conditions in backwards time) are imposed by the adjount varıables and if the "best" value of $\mathrm{n}_{3}$ Is used, equations $(4$ 18)-(4 20) give boundary encounter trajectories whlch are precisely the same as trajectory " $B$ " of Flgure 43 whlch was obtalned from the NCES, see Part 4, Section D, Chapter III Figure 44 shows two such phase-plane trajectories Figure 4.5 shows a plot of $\mathrm{p}_{4}\left(\tau^{*}\right)$ for one of the trajectorzes as obtanned from both the NCES and (4 20) The curve in Figure 45 which is obtained from (4 20) Is unique only for given $p_{3}\left(\tau_{0}^{*}\right)$ and $p_{4}\left(\tau_{0}^{*}\right)$ This curve is only required to pass through the points $\left(\tau_{\mathrm{b}}^{*},+1\right)$ and $\left(\tau_{\mathrm{d}}^{*},-1\right)$ Thus, the parameters, $p_{3}\left(\tau_{0}^{*}\right), p_{4}\left(\tau_{0}^{*}\right)$ and $n_{3}$, can be varied somewhat without affecting the control, $v_{2}\left(\tau^{*}\right)$, or the resulting trajectory. The values of these parameters used in constructing Figure 45 are $p_{3}\left(\tau_{0}^{*}\right)=-020, p_{4}\left(\tau_{0}^{*}\right)=$ 1.004 and $n_{3}=042$ For convenzence $p_{4}\left(\tau_{c}^{*}\right)$ was chosen to be zero so that the "best" value of $n_{3}$ was the same as obtalned from the method of estimation of Part 1

From the above Investigation It Is apparent that the approximate solution, equations (4 18)-(4 20), gives the same results as the exact solution, if It is required that the final point of the trajectory be a point of the $x_{3}$-axis in $S_{R}$ It is not difficult to see that the two solutions also agree precisely in the case that the final point, $\left[x_{3}\left(\tau_{f}\right)\right.$, $x_{4}\left(\tau_{f}\right)$, Is free in $S_{R}$ if $S_{R}$ Is exited only once (As in Part $I$ the free ( In $\left.S_{R}\right)$ final point requires $p_{3}\left(\tau_{f}\right)=p_{4}\left(\tau_{f}\right)=0$ ) 


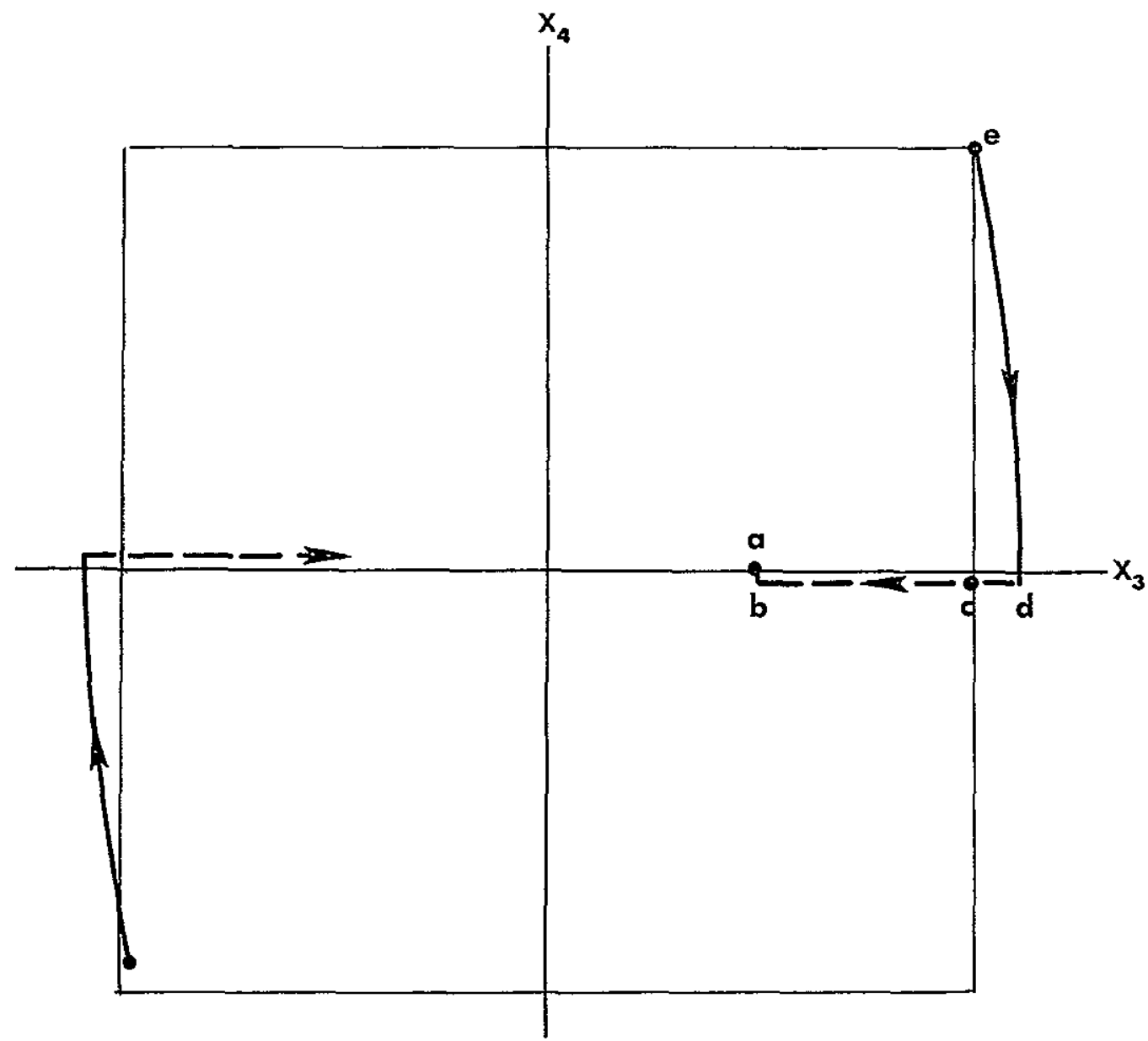

Figure 44 Nearly Minmum Fuel Boundary Encounter Trajectories for $\mathrm{x}^{\mathrm{n}}=\mathrm{v}, \mathrm{NN}_{2}=50 \times 10^{-4}$

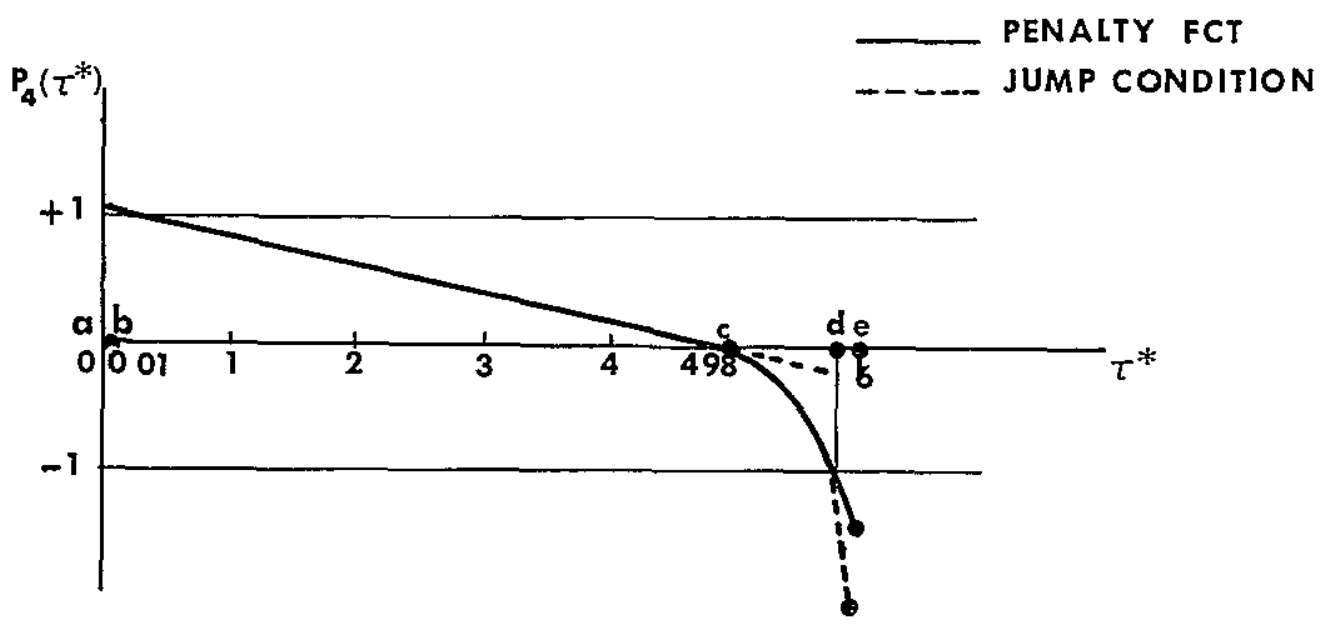

Figure 45 Adjoint Varıable in Backwards Time. Note $p_{4}\left(\tau_{a}^{*}\right)>10$ 
If the approxlmate solution is carried out for $\tau_{\hat{f}}^{*}-\tau_{0}^{*}$ which Is sufficiently large for two or more exits of $S_{R}$, It becomes clear that regardless of the values of $n_{3}, n_{4}$ and $\mathbb{N}$ used the approximate solution has a fuel cost which is larger than the fuel cost of the exact minimum fuel solution The approximate solution can be made better by changing the values of $n_{3}$ and $n_{4}$ before each exit or $s_{R}$ or by applyzng the solution in a plecewise manner with the jump condition. These methods of Improving the approximate solutions with more than one exzt of $S_{R}$ are, generally, not satisfactory since they make the conditions of the approximate solution as difficult to apply correctly as the NCES An alternative to these methods is the use of functions other than $f_{1}(\underline{x})$ in the integral constraint on the states The functions $f_{2}(x)$ and $f_{e}(\underline{x})$ given by $(3.10)$ and $(311)$ are the same as $f_{I}(\underline{x})$ when $\underline{x} \in S$ so that they result in the same satisfactory solutions if the trajectory remains in the interior of $S$ If the trajectory exits the region $S$ more than once in the time interval of consideration, the use of $f_{2}(x)$ Instead of $f_{I}(\underline{x})$ results in a reduction in fuel cost ThIs is true since the derivatıve of $f_{2}(\underline{x})$ (which appears in the adjoint solution) Is smaller near the boundary of $S$ than the derıvatıve of $f_{1}(x)$ so that the fuel cost carries more welght over the trajectory when $f_{2}(\underline{x})$ Is used than when $f_{1}(\underline{x})$ Is used

A free final point solution of the approximate problem with $f_{2}(x)$ used in the integral constraint is given below The steps leading to this solution are very simllar to steps leading to the solutions (with $f_{I}(x)$ used) glven above with the several types of boundary condltions For completeness these steps are given in detall

The equations of the maxumum principle for this problem in backwards time are

$$
\begin{aligned}
{ }^{t} x_{3} & =-x_{4} \\
{ }^{t} x_{4} & =-v \\
{ }^{\prime} p_{3} & =-\left\{\begin{array}{lll}
10^{n}\left(x_{3}-10^{-4}\right), & \text { if } x_{3}>10^{-4} \\
0 \quad & \text { if }\left|x_{3}\right| \leq 10^{-4}
\end{array}\right\}
\end{aligned}
$$




$$
\begin{aligned}
& \left(10^{n_{3}}\left(x_{3}+10^{-4}\right) \text {, if } x_{3}<-10^{-4}\right) \\
& p_{4}=p_{3}+\left\{\begin{array}{ccc}
10^{n}\left(x_{4}-10^{-4}\right), & \text { If } & x_{4}>10^{-4} \\
0 & , \text { if } & \left|x_{4}\right| \leq 10^{-4} \\
10^{n / 4}\left(x_{4}+10^{-4}\right), & \text { If } & x_{4}<-10^{-4}
\end{array}\right\} \\
& \mathrm{v}=\mathbb{N} \operatorname{CST}\left(\mathrm{p}_{4}\right)
\end{aligned}
$$

Equations (4.21) are the same as (4 16) and their solution is the same as (4 19) Equation (4 23) Is Identical to (4.18). If the "If" parts of the statements which define the functions in brackets in (4 22) are assumed but not written, the solution of (4 22) can be written as

$$
\begin{aligned}
& p_{3}(\tau *)=-\frac{10^{n_{3}}}{2}\left\{\begin{array}{l}
2\left(x_{30}-10^{-4}\right) \tau *-x_{40} \tau^{2}+v *^{3} / 3 \\
0 \\
2\left(x_{30}+10^{-4}\right) \tau *-x_{40} \tau *^{2}+v \tau^{3} / 3
\end{array}\right\}+p_{3 e} \\
& p_{4}(\tau *)=-\frac{10^{n}}{2}\left\{\begin{array}{l}
\left(x_{30}-10^{-4}\right) \tau *^{2}-x_{40} \tau^{3} / 3+v \tau *^{4} / 12 \\
0 \\
\left(x_{30}+10^{-4}\right) \tau *^{2}-x_{40} \tau *^{3} / 3+v \tau *^{4} / 12
\end{array}\right\} \\
& +p_{4 e}+p_{3 e} \tau^{*} \\
& +10^{n_{4}} \tau^{*}\left\{\begin{array}{l}
x_{40}-10^{-4}-v \tau^{*} / 2 \\
0 \\
x_{40}+10^{-4}-v * * / 2
\end{array}\right\}
\end{aligned}
$$

where $\tau^{*}, \mathrm{x}_{30}$ and $\mathrm{x}_{4,0}$ are Inıtıalızed at each tıme of encounter with the boundary as well as at each time a switch in control occurs

Suppose that the initial point is given by $\left[x_{3}\left(\tau_{0}^{*}\right), x_{4}\left(\tau_{0}^{*}\right)\right]=$ $\left(-5 \times 10^{-5}, 10^{-5}\right)$ and in forward time is a free funal point In this 
case $p_{3 e}=p_{3}\left(\tau_{0}^{*}\right)=0$ and $p_{4 e}=p_{4}\left(\tau_{0}^{*}\right)=0$ Untıl the boundary of $S$ is encountered (point " 1 " in Figure $46 \mathrm{a}$ ), sat at $\tau_{1}^{*}$, the solutions $(4$ 19), (4 23), (4.24) and $(4.25)$ give

$$
\begin{aligned}
& x_{3}\left(\tau^{*}\right)=x_{30}-x_{40} \tau^{*}-5 \times 10^{-5}-10^{-5} \tau^{*} \\
& x_{4}\left(\tau^{*}\right)=x_{40}=10^{-5} \\
& v=0 \\
& p_{3}\left(\tau^{*}\right)=0 \\
& p_{4}\left(\tau^{*}\right)=0
\end{aligned}
$$

From the first equation of $(426)$ the time of encounter with $x_{3}\left(\tau^{*}\right)=-10^{-4}$ is found to be $\tau_{1}^{*}=5$ since $x_{3}, x_{4}, p_{3}$ and $p_{4}$ are contınuous, they have the same values at $\left(\tau_{1}^{*}\right)^{+}$as at $\left(\tau_{1}^{*}\right)^{-}$Thus, until the control turns on, say at $\tau_{2}^{*}$, the solution is

$$
\begin{aligned}
& x_{3}\left(\tau^{*}\right)=x_{30}-x_{40} \tau^{*}=-10^{-4}-10^{-5} \tau^{*} \\
& x_{4}\left(\tau^{*}\right)=x_{40}=10^{-5} \\
& v\left(\tau^{*}\right)=0 \\
& p_{3}\left(\tau^{*}\right)=-10^{n_{3} / 2\left\{-x_{40} \tau *^{2}\right\}=10^{n^{-5}} \tau *^{2} / 2} \\
& p_{4}\left(\tau^{*}\right)=-10^{n_{3} / 2\left\{-x_{40} \tau^{3} / 4\right\}=10^{n_{3}-5} \tau *^{3} / 8}
\end{aligned}
$$


WIth $N=5 \times 10^{-4}$ the allowable error will not be exceeded, 1.e, $\left|x_{3}\right| \leq 11 \times 10^{-4}$, if the control turns on when $x_{3}=-108 x$ $10^{-4}$ From the first equation of $(427)$ with $x_{3}(\tau *)=-108 \times 10^{-4}$ It Is found that $\tau_{2}^{*}=08$ (measured from $\tau_{1}^{*}$ ) For the control to turn on at $\tau_{2}^{*}, p_{4}$ must grow to uncty at $\tau_{2}^{*}$. Thus, from the last equation of (4.27) the "best" value of $n_{3}$ Is found to be $n_{3}=62$ from the fourth equation of $(427)$ It Is found that $p_{3}\left(\tau_{2}^{*}\right)=5.0$ Thus, for the next part (from point " 2 " In Figure $46 \mathrm{a}$ ), of the calculation $x_{30}=$ $-108 \times 10^{-4}, x_{40}=10^{-5}, p_{3 e}=50, p_{4 e}=10$ and $v=N=5 \times 10^{-4}$ UntII the boundary of $S$ Is again encountered (polnt " 3 " In Figure 4 6a), say at $\tau \frac{*}{3}$, the solution is

$$
\begin{aligned}
& x_{3}\left(\tau^{*}\right)=N \tau^{2}-x_{40} \tau^{*}+x_{30}=5 \times 10^{-4} \tau^{*}+10^{-5} \tau^{*}-108 \times 10^{-4} \\
& x_{4}\left(\tau^{*}\right)=-11 \tau^{*}+x_{40}=-5 \times 10^{-4} \tau *+10^{-5} \\
& v\left(\tau^{*}\right)=N \\
& p_{3}(\tau *)=-10^{n} 3 / 2\left\{2\left(x_{30}+10^{-4}\right) \tau *-x_{40} \tau *^{2}+v \tau^{2} / 2\right\}+p_{3 e} \\
& =50+125 \tau *+78 \tau^{*}-130.0 \tau *^{3} \\
& p_{4}\left(\tau^{*}\right)=-10^{n^{3}} / 2\left\{\left(x_{30}+10^{-4}\right) \tau^{2}-x_{40} \tau^{*^{3}} / 3+v \tau^{*} / 12\right\}+p_{4 e}+p_{3 e} \tau^{*} \\
& =10+50 \tau *+625 \tau t^{2}+26 \tau *^{3}-325 \tau *^{4}
\end{aligned}
$$

The time of reentry is found from the first equation of (4 28) to be $\tau_{3}^{*}=0126$, since $x_{3}\left(\tau_{3}^{*}\right)=-10^{-4}$ From $(4.28)$ with $\tau_{3}^{*}=0126$, the inctial values for the next part of the calculation are found to be $\mathrm{x}_{40}=-530 \times 10^{-5}, \mathrm{p}_{3 \mathrm{e}}=643, \mathrm{p}_{4 \mathrm{e}}=173$ and $\mathrm{v}=\mathbb{N}$ The next part of the solution is such that $p_{4}\left(\tau^{*}\right)$ continues to increase so that the control stays on and druves the trajectory to the boundary agasn Thus, untıI the boundary Is encountered again (point "4" In Figure 4 6a), say at $\tau_{4}^{*}$, the solution is 


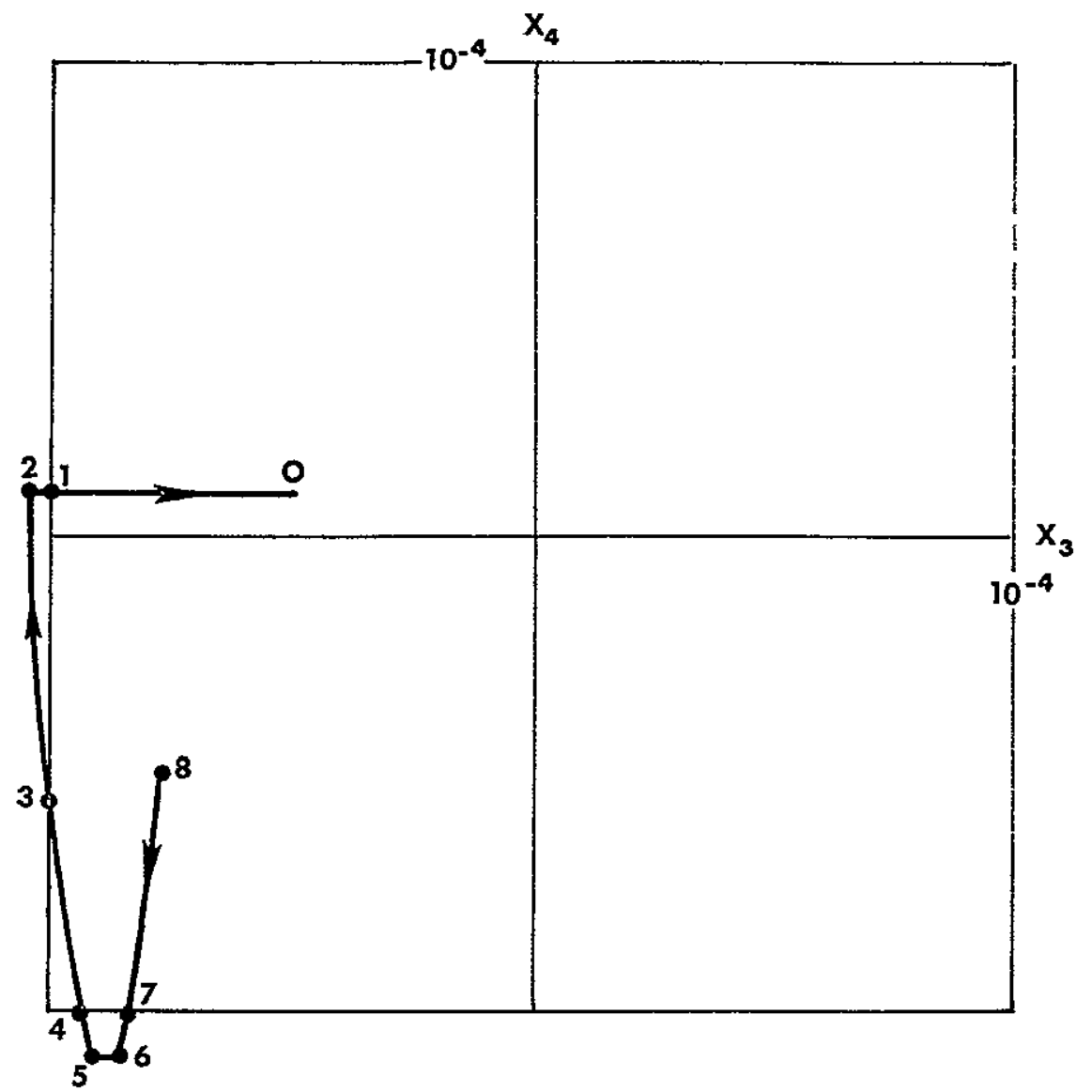

a. Phase Plane Trajectory

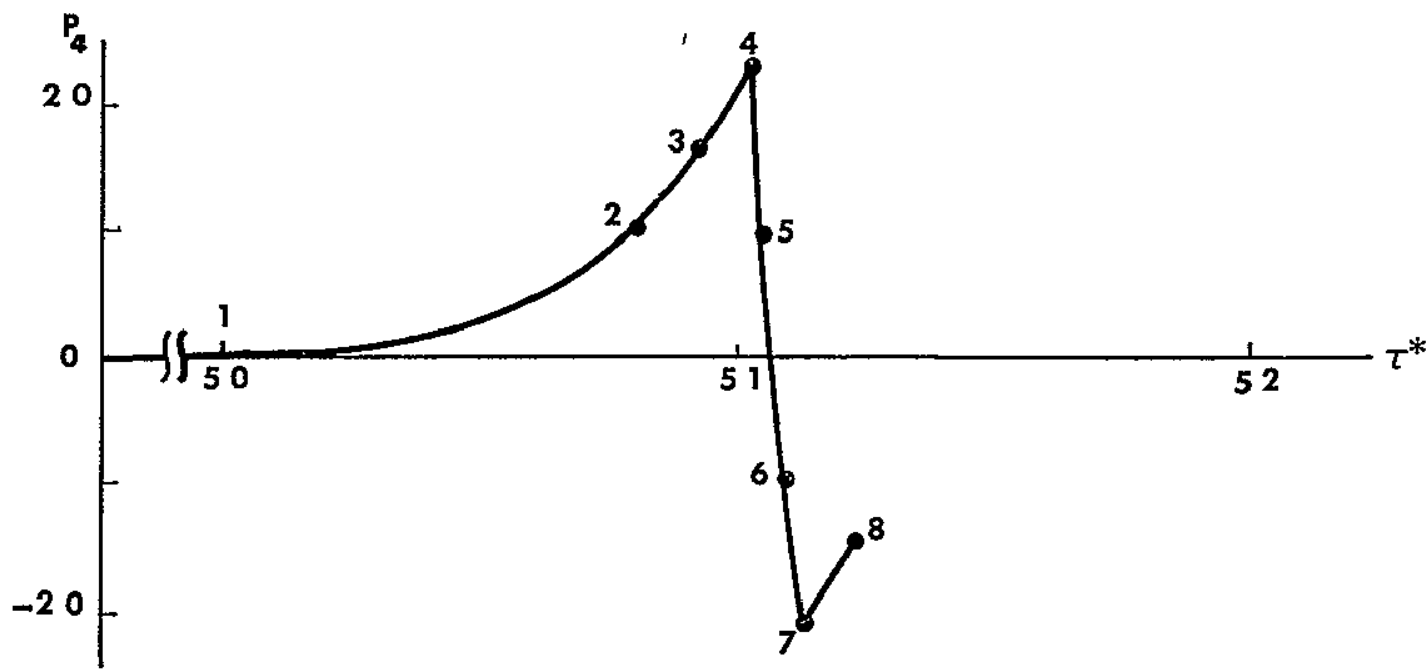

b Adjoint Varıable

Figure 4.6 A Free End Point Solution for $J$ with $f_{2}(\underline{x})$ 


$$
\begin{aligned}
& \mathrm{x}_{3}\left(\tau^{*}\right)=\mathrm{N} \tau^{*^{2}}-\mathrm{x}_{40} \tau^{*}+\mathrm{x}_{30} \\
&=5 \times 10^{-4} \tau^{2}+53 \times 10^{-5} \tau^{*}-10^{-4} \\
& \mathrm{x}_{4}\left(\tau^{*}\right)=-\mathrm{N} \tau^{*}+\mathrm{x}_{40}=-5 \times 10^{-4} \tau^{*}-53 \times 10^{-5} \\
& \mathrm{v}=\mathrm{N} \\
& \mathrm{p}_{3}\left(\tau^{*}\right)=\mathrm{p}_{3 e}=643 \\
& \mathrm{p}_{4}\left(\tau^{*}\right)=\mathrm{p}_{4 \mathrm{e}}+\mathrm{p}_{3 \mathrm{e}^{*}}=173+643 \tau^{*}
\end{aligned}
$$

The time of exit, $\tau_{4}^{*}$, Is found from the second of (4 29) to be $\tau_{4}^{*}=0094$ since $x_{4}\left(\tau_{4}^{*}\right)=-10^{-4}$ From $(429)$ wath $\tau_{4}^{*}=0094$ the Initial values for the next part are found to be $x_{30}=-91 \times 10^{-5}$, $p_{3 e}=643, p_{4 e}=233$ and $v=\mathbb{N}$ The next part of the solution continues until the control switches, say at $\tau \frac{*}{5}$, and Is

$$
\begin{aligned}
x_{3}\left(\tau^{*}\right) & =5 \times 10^{-4} \tau^{*}+10^{-4} \tau^{*}-91 \times 10^{-5} \\
x_{4}\left(\tau^{*}\right) & =-5 \times 10^{-4} \tau^{*}-10^{-4} \\
p_{3}\left(\tau^{*}\right) & =p_{3 e} \\
p_{4}(\tau *) & =p_{4 e}+p_{3 e} \tau^{*}+10^{n_{4}} \tau+\left\{x_{40}+10^{-4}-v \tau^{*} / 2\right\} \\
& =233+6.43 \tau^{*}+10^{n_{4}} \tau *\left\{-5 \times 10^{-4} \tau * / 2\right\}
\end{aligned}
$$

The control switches to zero when $p_{4}(\tau)=10$ and the trajectory becomes parallel to the $x_{3}$-axis Since it is required that $\left|x_{4}\left(\tau^{*}\right)\right| \leq$ $1.1 \times 10^{-4}$, the control switch must occur no later than $\tau_{5}^{*}=002$ Thus, from the last equation of (4.30), It is found that $n_{4} \geq 71$ is required If $n_{4}=71$ and $\tau_{5}^{*}=002$ are used in $(430)$, the initial values for the next step are found to be $x_{30}=-888 \times 10^{-5}, x_{40}=-11 \times 10^{-4}$, $p_{3 e}=643, p_{4 e}=10$ and $v=0$ The solution for the next part (from the point " 5 " In Figure $46 \mathrm{a}$ ), Is 


$$
\begin{aligned}
& x_{3}\left(\tau^{*}\right)=x_{30}-x_{40} \tau^{*}=-880 \times 10^{-5}+11 \times 10^{-4} \tau^{*} \\
& x_{4}\left(\tau^{*}\right)=x_{40}=-11 \times 10^{-4} \\
& p_{3}\left(\tau^{*}\right)=p_{3 e}=643 \\
& p_{4}\left(\tau^{*}\right)=p_{4 e}+p_{3 e} \tau^{*}+10^{n_{4}} \tau *\left\{x_{40}+10^{-4}\right\}=10-1186 \tau^{*}
\end{aligned}
$$

This solution is for the time interval ( $\tau_{5}^{*}, \tau_{6}^{*}$ ] where $\tau_{6}^{*}$ is the time when the control switches from zero to $\mathrm{V}=-\mathbb{N}$ This switch in the control occurs when $p_{4}\left(\tau \frac{t}{6}\right)=-1$ Thus, from the last equation of $(431)$ It Is found that $\tau_{6}=0017$ The initial values for the next step can be found from (4 3I) with $\tau_{6}=0.17$ They are $x_{30}=-869 \times 10^{-5}$, $x_{40}=-1.1 \times 10^{-4}, p_{3 e}=6.43, p_{4 e}=-10$ and $v=-N$ Thus, the solution for the next step, which is until $\tau_{7}^{*}$ at which time the trajectory reenters $\mathrm{S}$, Is

$$
\begin{aligned}
& x_{3}(\tau *)=-N \tau^{2}-x_{40} \tau *+x_{30}=-5 \times 10^{-4} \tau *^{2}+11 \times 10^{-4} \tau^{*} \\
& -869 \times 10^{-5} \\
& \mathrm{x}_{4}(\tau *)=N \tau *+\mathrm{x}_{40}=5 \times 10^{-4} \tau *-11 \times 10^{-4} \\
& p_{3}(\tau *)=p_{3 e}=6.43 \\
& p_{4}(\tau *)=p_{4 e}+p_{3 e} \tau^{*}+10^{n_{4}} \tau *\left\{x_{40}+10^{-4}+N \tau * / 2\right\} \\
& =-10-118 \tau *+3120 \tau *^{2}
\end{aligned}
$$

The time $\tau_{I_{4}}^{*}$ can be found from the second equation of ( $\left.\begin{array}{ll}42 & 32\end{array}\right)$ since $x_{4}(\tau *)=-10^{-4}$ It 1 s $\tau_{7}^{*}=0$ 02 The Inıtial values of the next (and final) step can be found from ( 432$)$ with $\tau_{7}^{*}=002$ They are $x_{30}=-84 \times 10^{-5}, x_{40}=-10^{-4}, p_{3 e}=643, p_{4 e}=-212$ and $v=-N$ The solution for the last step which Is until t is

$$
x_{3}(\tau *)=-5 \times 10^{-4} \tau *^{2}+10^{-4} \tau *-8.4 \times 10^{-5}
$$

(continued) 


$$
\begin{aligned}
& x_{4}(\tau *)=5 \times 10^{-4} \tau *-10^{-4} \\
& p_{3}(\tau *)=643 \\
& p_{4}(\tau *)=-2.12+643 \tau *
\end{aligned}
$$

The final time $\tau_{t}^{*}=\tau_{1}^{*}+\cdot+\tau_{8}^{*}$ is chosen so that the trajectory begins (In forward time) in $\mathrm{S}$ The solution is given in graphical form in Figure 46

In summary the main results of this part are (1) minimum fuel controls for the single-axis motion of sateliztes if the motion is described by $x=v$, (2) the demonstration of the fact that the solutions obtalned from PMP with

$$
J=\int_{\tau_{0}}^{\tau}(\underline{f}(\underline{x})+|v|) d \tau
$$

$\left(f(\underline{x})=f_{1}(\underline{x}), f_{2}(\underline{x}), \cdot, f_{e}(\underline{x})\right)$ are minimum fuel solutions if the boundary of $S$ is exited no more than once, (3) the use of smooth functions like $f_{2}(\underline{x})$ results in less control effort than the plecewise smooth function $f_{I}(\underline{x})$ if more than one exıt of $S$ occurs

3 The Steady-State Motion Obtained from PMP for $x^{n}+a^{2} x=v$, $a^{2}>0$

The equation $x^{\prime \prime}+a^{2} x=v$ describes a stable system if $a^{2}>0$ If the pitch motion is controlled so that $\left|x_{1}(\tau)\right| \leq 11 \times 10^{-4}, 1=5,6$, and If the satellıte has inertia properties such that $k_{1} \approx 1$ and $k_{2} \approx-1$ (Ilke satellite (2), for example), then both the roll motion and the yaw motion are very nearly described by $x^{\prime \prime}+a^{2} x=v$ with $a^{2}>0$ If the eccentricity of orbıt is less than $5 \times 10^{-6}, \mathrm{k}_{3} \approx 1$ and the yaw-rolI motion Is controlled so that $\left|x_{1}(\tau)\right| \leq 11 \times 10^{-4}, 1=1$, ,4, then the pitch motion is also very nearly described by $x^{\prime \prime}+a^{2} x=v$ Thus, the application of the theory of Chapter III to

$$
\begin{aligned}
& x_{1}^{\prime}=x_{2} \\
& x_{2}^{\prime}=-a^{2} x_{1}+v
\end{aligned}
$$


leads to useful information about the theory and the required control In this part of Section $A$, the requirements on the control and the methods of analysis are the same as in Part 2 of Section $A$

First consider the necessary conditions for exact solutions (NCES) of Part 4, Section D of Chapter III WhIle the state-space trajectory is in the interzor of $S$ the condıtıons of PMP, 1.e, (4 34) and

$$
\begin{aligned}
& p_{1}^{\prime}=a^{2} p_{2} \\
& p_{2}^{\prime}=-p_{1} \\
& v=N \operatorname{CST}\left(p_{2}\right)
\end{aligned}
$$

must be satisfied with the proper boundary conditions

Three representatıves minumum fuel phase plane trajectorles which do not encounter the boundary are shown In Figure $47 \mathrm{a}$. These trajectorıes, denoted by $A, B$ and $C$, are the results of applyng PMP wath three different sets of Initial conditions on $\left(x_{1}, x_{2}\right)$ and $\left(p_{1}, p_{2}\right)$ The circular region, $\Gamma$, which Is just inside the yaw projection of $S, S_{Y}$, Is the region to be acquired if inztially (after acquisıtion to $S$ ) the trajectory is not already in $\Gamma$ The region $\Gamma$ was chosen to be acquired since once it is acquired no future control effort is needed to keep the trajectory in $S_{Y}$ (In the absence of detrimental disturbances) Also, less fuel is needed to acquire $\Gamma$ (from within $S_{Y}$ ) than any other circular region in $S_{Y}$ The final points, $P$, of the trajectories, $A, B$ and $C$, correspond to the final time of consideration, namely $\tau_{f}$. For trajectory $A$ the final point Is fixed The final point of trajectory $B$ is free so that $p_{1}\left(\tau_{f}\right)=$ $p_{2}\left(\tau_{f}\right)=0$. The trajectory $C$ acquires the boundary of $\Gamma$ so that the transversalıty condıtıon applies

There are points in $S_{Y}$ from which $\Gamma$ cannot be acquired without encountering the boundary of $S_{Y}$ A typical case is shown in Figure 48 The final point of the trajectory is fixed so that $p_{1}\left(\tau_{f}\right), 1=1,2$, are entirely unknown a priorl. The jump condition is applied at the junction point denoted by the number " 3 " (Those parts of the boundary of $S_{Y}$ which are vertical IInes are replaced by arcs of circles about $( \pm N, 0)$. In Figure $48 \mathrm{a}$ the normal to the boundary at the junction point makes an 


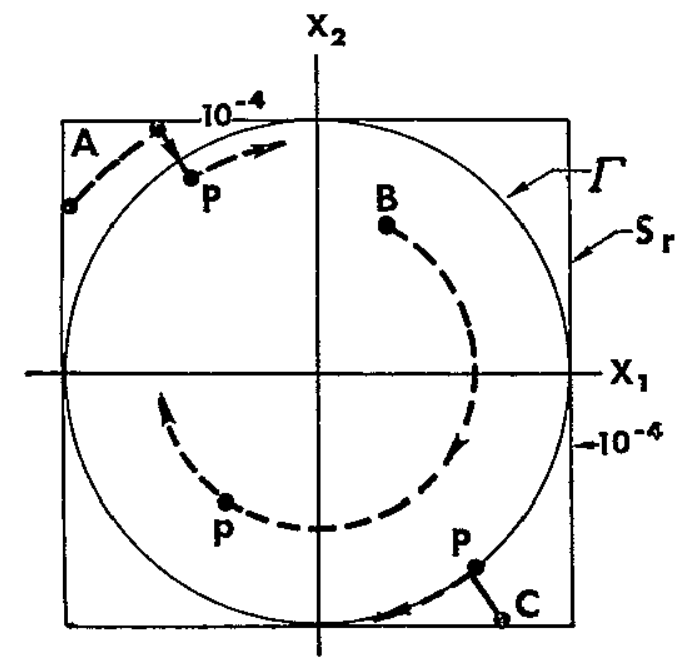

a Minimum Fuel Trajectorıes
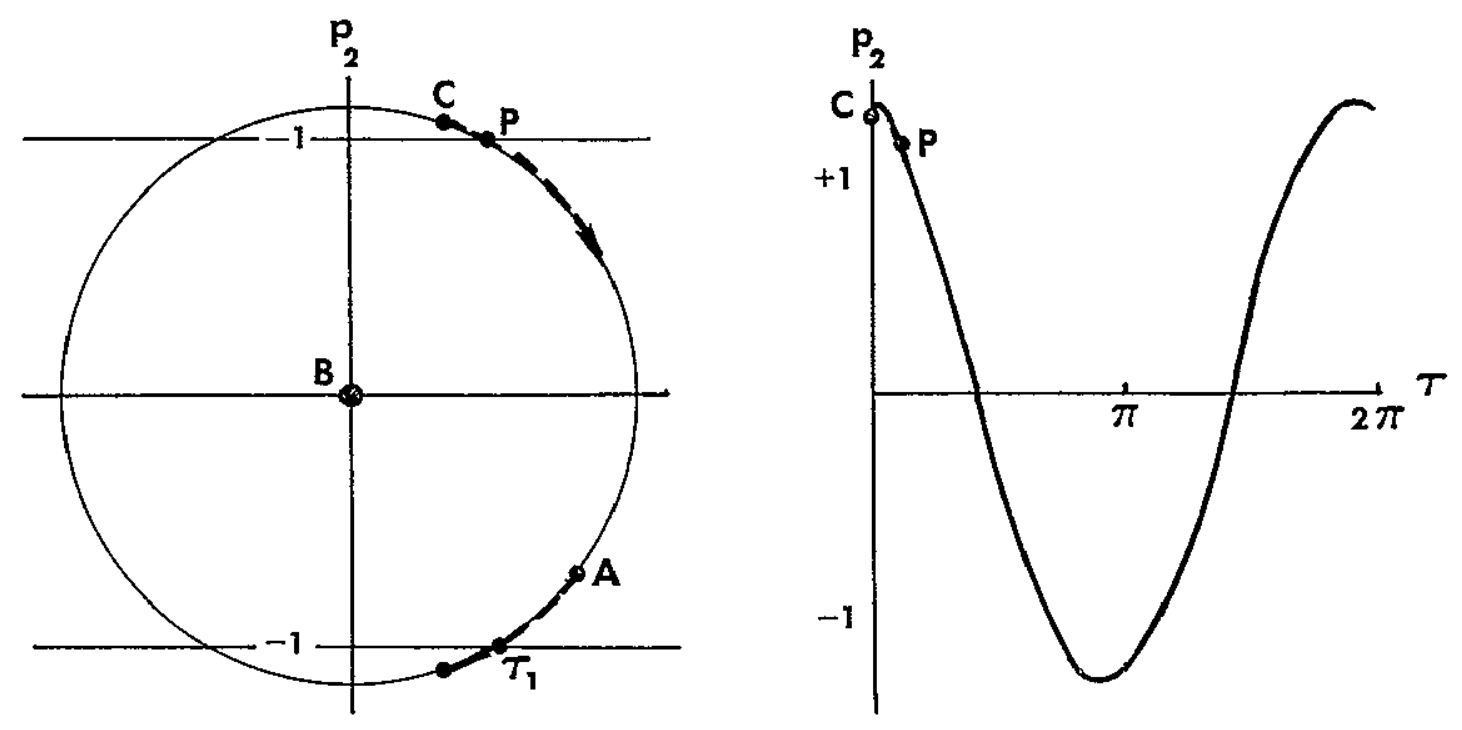

b Adjoint Varıables

Fingure 47 Typıcal Minımum Fuel Solutions for System $(434), a^{2}=1$, $\mathbb{N}=2 \times 10^{-4}$ 


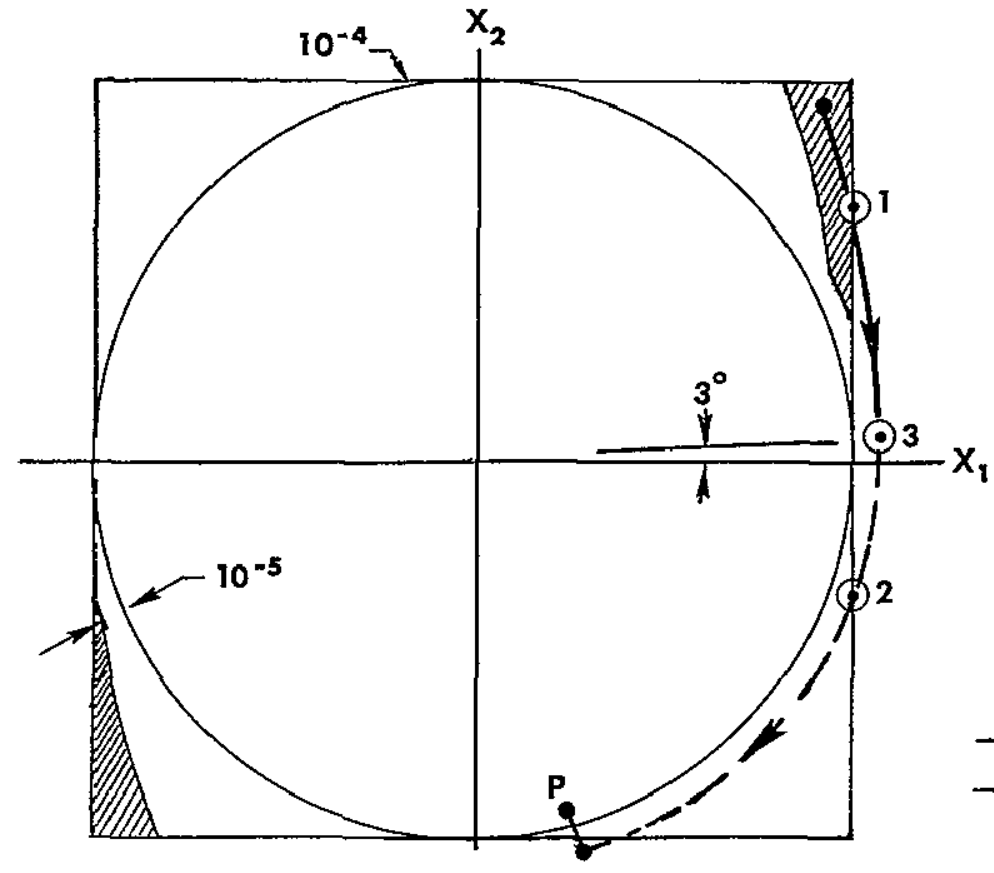

a Phase Plane Trajectory, $N=2 \times 10^{-4}, a^{2}=1$

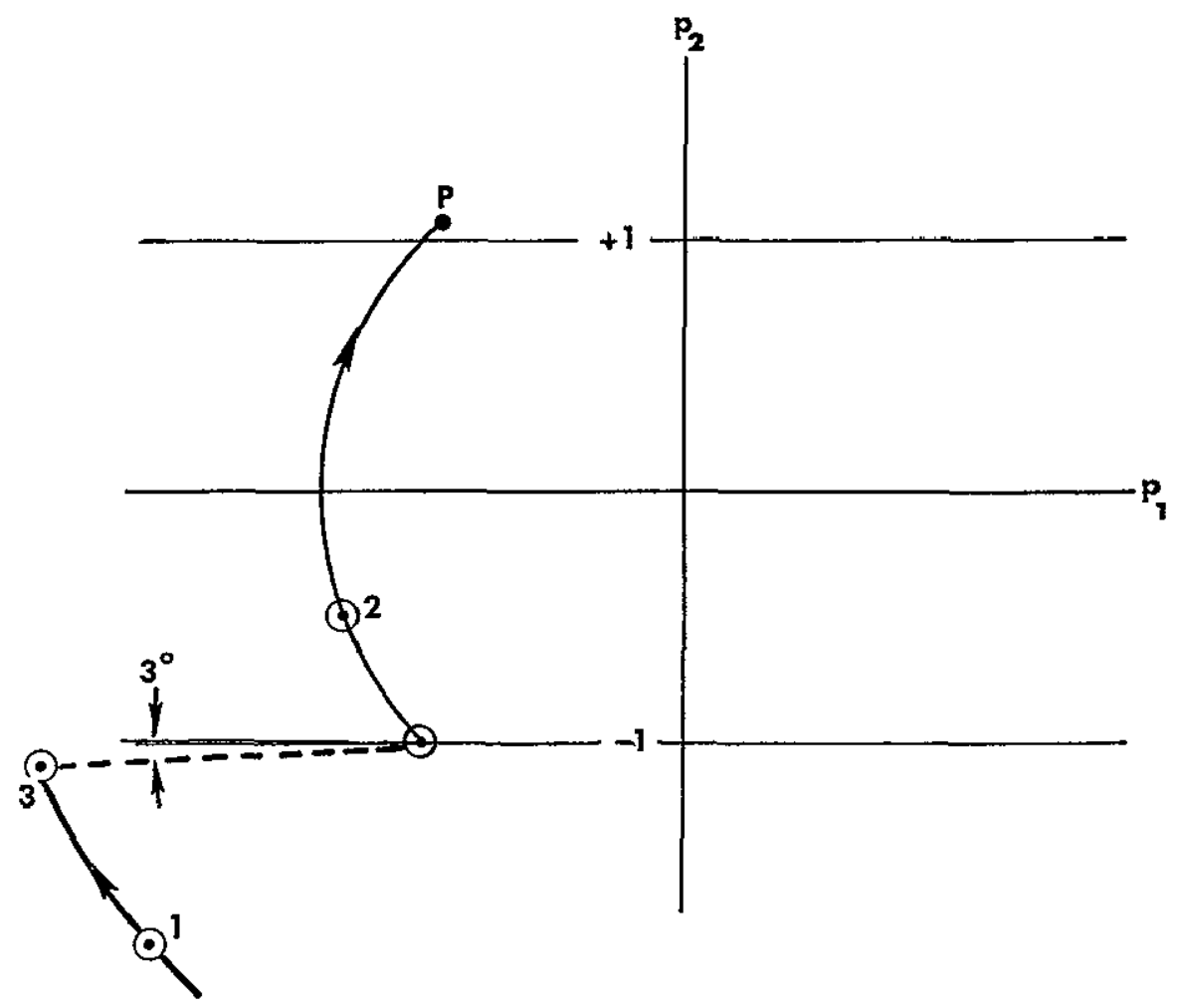

b Adjoint Plane Trajectory

Figure 48 A Mnnzmum Fuel Boundary Encounter Solution for System (4 34) 
angle of $3^{\circ}$ with the $x_{1}$-axls, so that, In Flgure $48 \mathrm{~b}$ the "jump" In $\left(p_{1}, p_{2}\right)$ at "3" Is at an angle of $3^{\circ}$ whth the $p_{1}$-axis In this applycation the Jump condition constant is negative. The normals to the vertical boundary lines at the boundary points " 1 " and " 2 " are parallel to the $x_{1}$-axns.

The part of the trajectory in Figure $48 \mathrm{a}$ whych begins at the Junction point " 3 " and ends at the flxed final point $P$ is part of the optimal trajectory from " 3 " to the origin for acquisition times greater

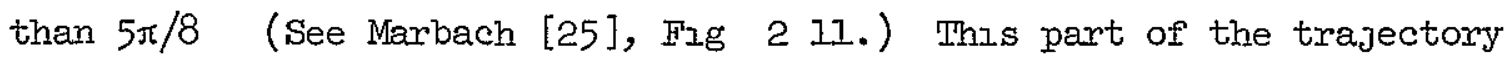
Is minimum-fuel optimal since it is part of an optimal trajectory The time of acquisition $(>5 \pi / 8)$ is taken as large as possible since the fuel cost decreases with increase in acquisıtion time (See Marbach's FIg 215 )

$$
\text { For } x^{\prime \prime}+a^{2} x=v \text { as for } x^{\prime \prime}=v \text { in Part } 2 \text { it can easily be }
$$
seen that the optimal (minimum fuel) controls obtalned from the NCES with the Jump conditions applied at boundary encounter points are the same as the optimal controls obtalned from PMP with

$$
\left.J=\int_{\tau_{0}}^{\tau} f \underline{f}(\underline{x})+|v|\right] d \tau
$$

The equations of the maxımum princıple for

$$
J=\int_{\tau_{0}}^{\tau}[f(\underline{x})+|v|] d \tau
$$

In backwards tıme are

$$
\begin{aligned}
& { }^{\mathrm{t}} \mathrm{x}_{1}=-\mathrm{x}_{2} \\
& { }^{\mathrm{t}} \mathrm{x}_{2}=a^{2} \mathrm{x}_{1}-\mathrm{v} \\
& { }^{\mathrm{t}} \mathrm{p}_{1}=-F\left(\mathrm{x}_{1}\right)-\mathrm{a}^{2} \mathrm{p}_{2} \\
& { }^{\mathrm{i}} \mathrm{p}_{2}=F\left(\mathrm{x}_{2}\right)+\mathrm{p}_{1}
\end{aligned}
$$




$$
\mathrm{v}=\mathbb{N} \operatorname{CST}\left(\mathrm{p}_{2}\right)
$$

As in forward time the solution of (4 37) Is a parametric representation of the equation of a circle in the $\left(x_{1}, x_{2}\right)$-plane The center of the circle on the $x_{1}$-axis at $x_{1}=v(v= \pm N$ or zero $)$ The trajectory proceeds in a counter-clockwise sense with increasing $\tau^{*}$ The piecewise solution of $(438)$ can be obtalned by the method of AppendIx $E$ and Is

$$
\begin{aligned}
& p_{1}\left(\tau^{*}\right)=p_{1 e} \cos \left(a \Delta \tau^{*}\right)-p_{2 e^{a} \sin \left(a \Delta \tau^{*}\right)}-F\left(x_{1}\right) a^{-1} \sin \left(a \Delta \tau_{1}^{*}\right) \\
& -F\left(x_{2}\right)\left[1-\cos \left(a \Delta \tau_{2}^{*}\right)\right]
\end{aligned}
$$

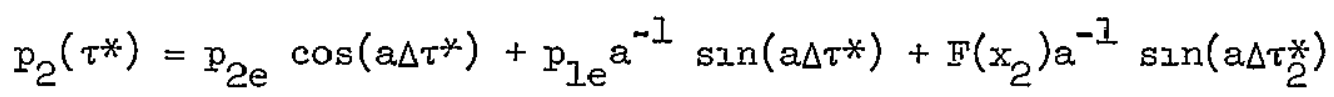

$$
\begin{aligned}
& -F\left(x_{1}\right) a^{-2}\left[1-\cos \left(a \Delta \tau_{1}^{+}\right)\right]
\end{aligned}
$$

Figure 49 shows a graph of a solution of (4 38) as obtalned from (4 40) This solution corresponds to the solution of (4 37) shown In Figure $48 \mathrm{a}$ in forward time (as indicated by the arrows) As before In Part 1 and Part 2 of this section, the values of $n_{1}$ and $n_{2}$ depend on the initial values of the adjount variables. The initial values of $p_{1}$ and $p_{2}$ used In the solution shown In Figure 49 are a worst case cholce Although Figure 49 shows a worst case, there is still some resemblance to the curve of Flgure $48 \mathrm{~b}$, which is obtained from the IVCES, If differences in scaling are accounted for If the initial (backward tIme) value of $p_{1}$ Is made more negative, the solution (4 40) of the adjoint equations whlch corresponds to the trajectory of (4 $8 a$ ) agrees perfectly with the curve in Figuxe if $8 \mathrm{~b}$ for all except about one-fourth of the time of consideration The difference in the curves is due to the mechanism which causes the change in the adjoint variables on encounterıng a boundary For comparison purposes Figure 410 shows a solution obtalned from (4 40) which mostly agrees with the "Jump" solution The above example, which show excellent agreement in the solutions obtalned from the NCES and from PMP with 


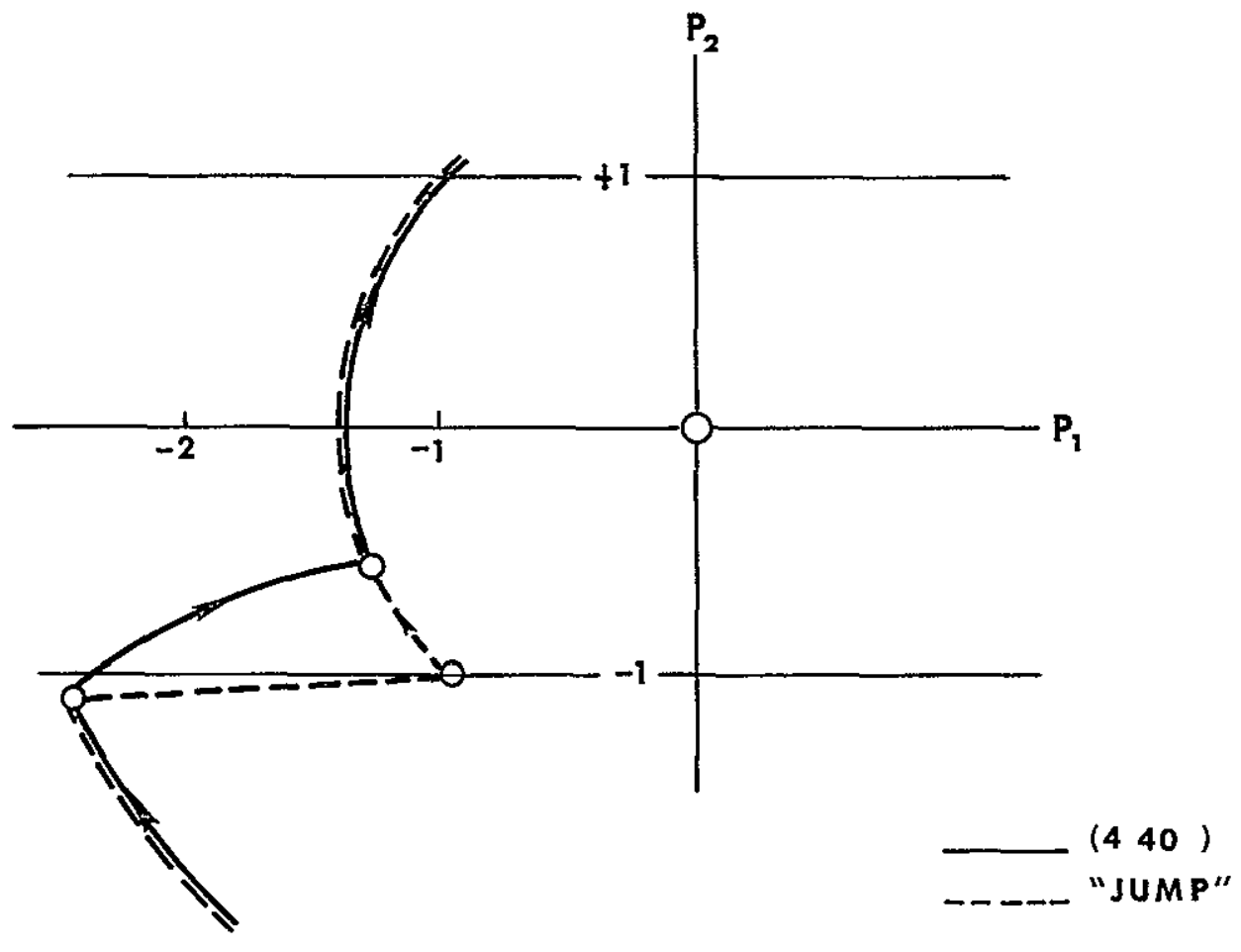

Figure 49 A Worst Case Adjount Solution Corresponding to Trajectory of Figure (4 8a), $n_{1}=103, n_{2}=-1$

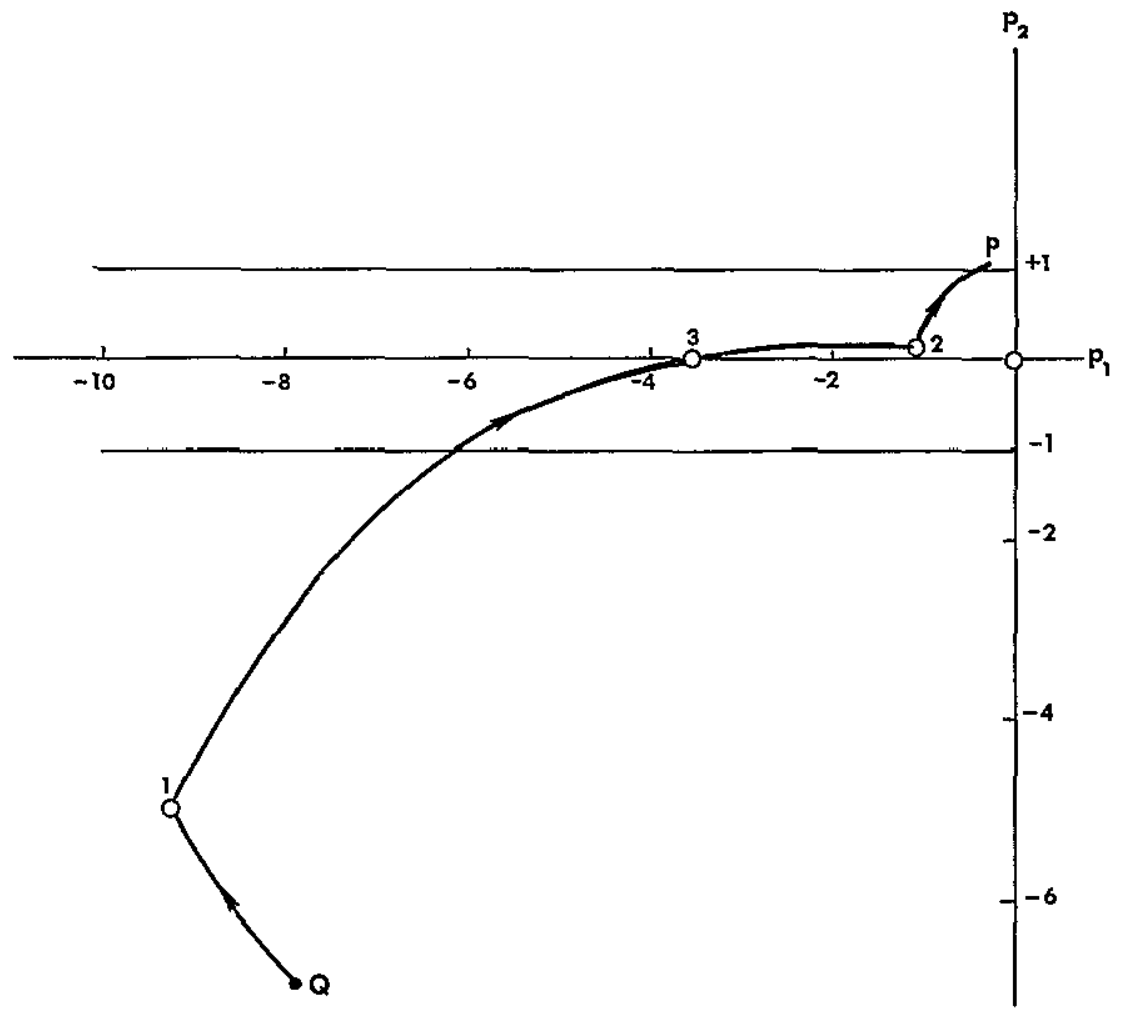

Figure 410 Adjoint Solutions 


$$
J=\int_{\tau_{0}}^{\tau}\left[f_{I}(\underline{x})+|v|\right] d \tau
$$

are representatıve of all optimal solutıons which must (for a given value of $\mathbb{N}$ ) exit the region $S_{Y}$ (by more than some small allowable amount) once and only once The main reason this generalization can be made is the fact that the parameters $n_{1}, n_{2}$ and $\mu$ are freely chosen

4. The Steady-State Motion Obtalned From PMP for $x^{\prime \prime}+a^{2} x=v$, $a^{2}<0$

The equation $x^{\prime \prime}+a^{2} x=v$ with $a^{2}<0$ gives an accurate description of the yaw motion of satellite (3) for practıcal time intervals If the roll and pltch motions are sultably controlled This equation also describes the putch motzon of satellite (2) near apogee and perigee if the yaw and roll motions are sultably controlled

The equations of the maximum principle for this part are the same as in Part 3 except that here $a^{2}<0$ [See (4 34)-(4 36)] Figure 4.11 shows some phase plane plots of solutions of $(434)$ and $(435)$ for $a^{2}=-1$ The curves are hyperbolıc

Ideally, I.e, in the absence of disturbances and Imperfections in the controller, the best control is the minimum-fuel control which acquires the IIne $P Q$ In Figure 4 Ila (If the IIne $P Q$ Is acquired in this Ideal case, no future control effort Is required, since once $P Q$ Is acquired the trajectory moves very slowly along $P Q$ to zero ) Since the transversality condition must hold at the final time, which is free, the minimum-fuel control which acquires the line $P Q$ must be on ( $\pm N$ ) all of the time of acquisition (See Figure $411 \mathrm{~b}$ ) Therefore, in this Ideal case the control must be $-\mathbb{N}$ above $P Q$ and must be $+\mathbb{N}$ below $P Q$

The magnitude of the control used in constructing Figure $411 \mathrm{a}$ Is too small For two reasons $\mathbb{N}$ should be larger They are (1) the error In $x_{1}(\tau)$ grows to undesirably large values, $1 \mathrm{e},\left|\mathrm{x}_{1}(\tau)\right|>$ $1.1 \times 10^{-4}$, If inıtıally both $x_{1}$ and $x_{2}$ are near $10^{-4}$ or $-10^{-4}$, (2) for most of $S_{Y}$ the cost of acquiring the line $P Q$ decreases with Increase in $\mathbb{N}$ until the cost is the same as for $x^{\prime \prime}=V$ in acquiring the same IIne ThIs last reason Is easily valldated by conslderıng the 


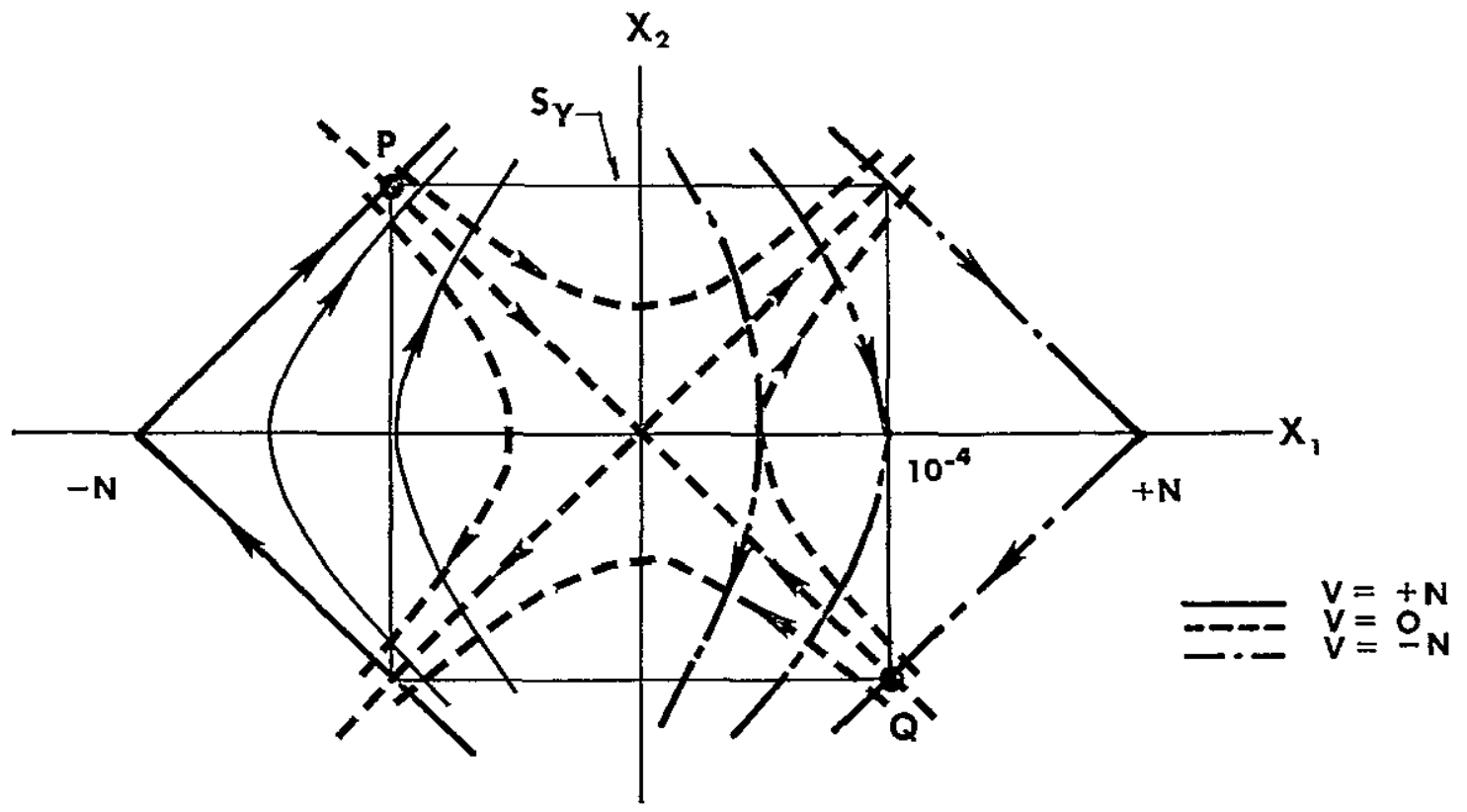

a Phase Plane Trajectories of $(434), N=2 \times 10^{-4}$

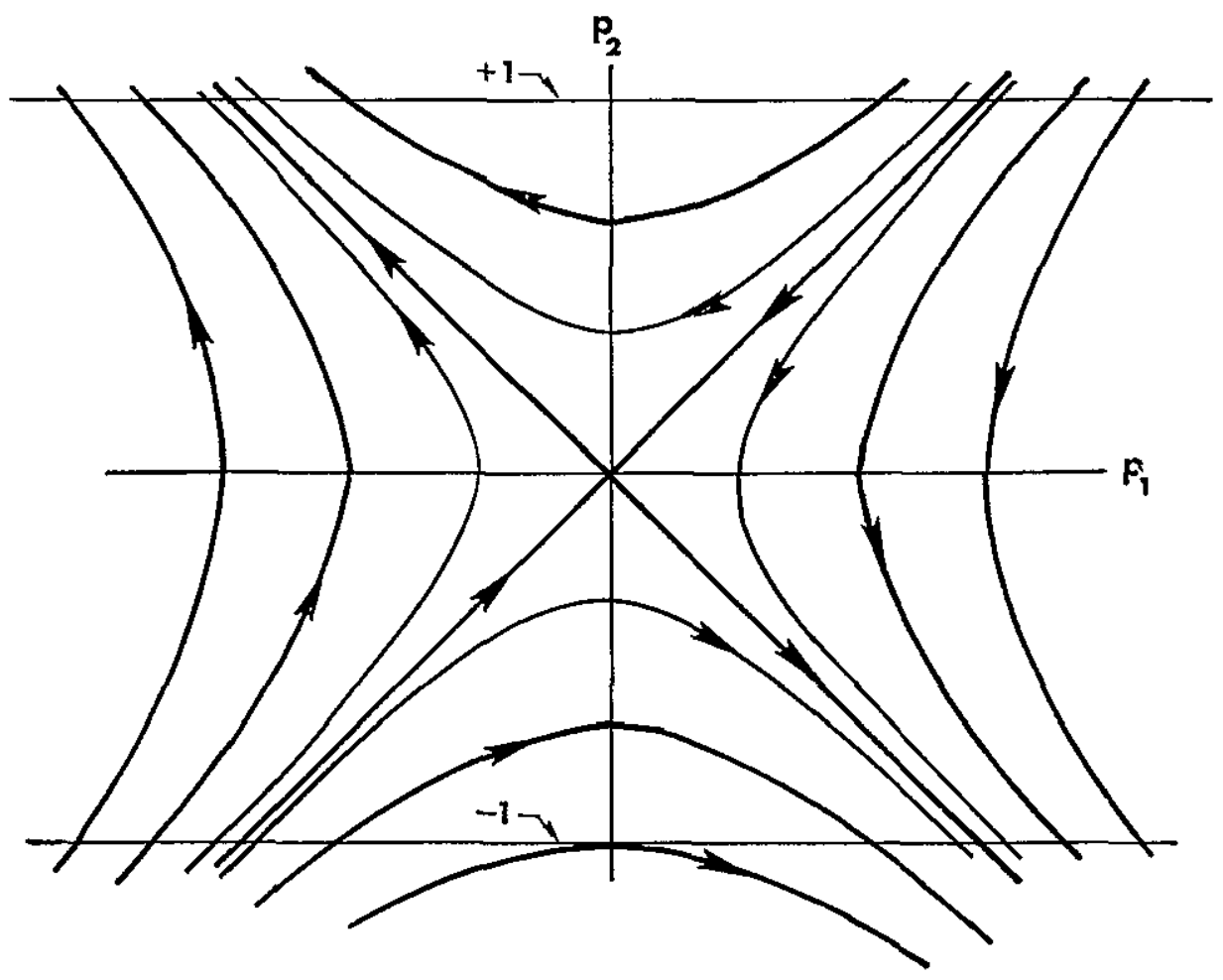

b Phase Plane Plots of Adjoint Variables

Flgure 411 Some Phase Plots of Solutıons of Maximum Princıple Equations for $x^{\prime \prime}+a^{2} x=v, a^{2}=-1$ 
time integral of the last of the system equations (equations (4 34))

$$
\pm x_{2}=\widetilde{x}_{1} \Delta \tau \pm \mathbb{N} \Delta \tau
$$

where $\widetilde{x}_{1}$ is the mean value (of the integral mean value theorem) for the time interval $\Delta \tau, \Delta x_{2}>0$ and $\mathbb{N}>0$

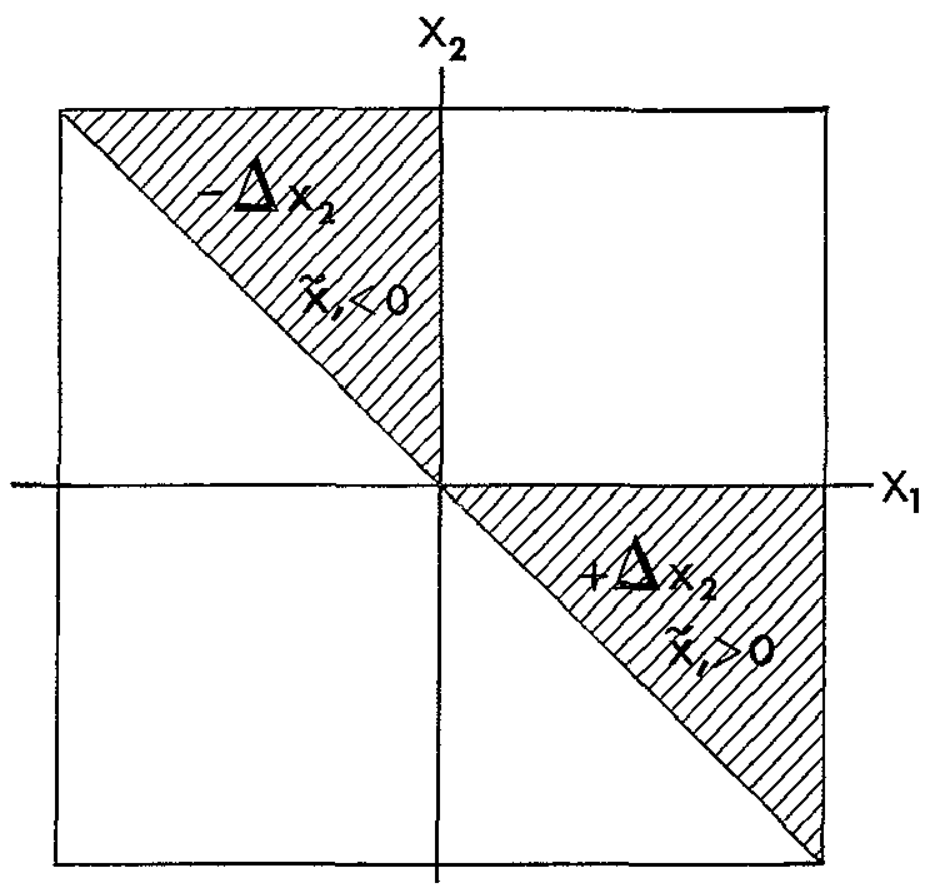

Figure 4 I2 Regions of Increase in Cost With Increase in N If (4 4I) Is solved for $\pm N \Delta \tau$, whose magnitude is the cost, the result Is

$$
\pm J= \pm N \Delta \tau= \pm \Delta x_{2}-\widetilde{x}_{1} \Delta \tau
$$

As $N$ Increases the value of $\tilde{x}_{1}$ approaches the InItial value of $x_{I}$ (Even for small $N$, say $N=2 \times 10^{-4}$, the change in $x_{1}$ is small compared to $\Delta \mathrm{x}_{2}$ for most inztial conditions and time intervals see Figure $4 \mathrm{Ila}$ ) Since the time interval required for $\mathrm{x}_{2}$ to change by a given amount decreases with Increase in $N$, It Is easıly seen from (4 42) that the cost decreases with increase in $\mathbb{N}$ whenever the change in $x_{2}$ Is positive or negatıve) and $\tilde{x}_{1}$ is negative (or positive) In the 
IImzt $J=\Delta x_{2} \quad$ In the shaded reglons of Figure 412 the cost is less than $\Delta x_{2}$ for bounded $\mathbb{N}$ and in the limit $J=\Delta x_{2}$

In the more realistic case in which imperfections in the controller and disturbances of the motion are present, the IIne $P Q$ cannot be precısely obtalned, and, even if It could be acquired, the control effort is not exactly a minimum The disturbances of the motion are mostly due to the coupling with the motion about other axes, the periodic oblateness part of the earth's gravitational torque and (rarely appearıng) meteorolds These disturbances can be small enough for the trajectories, which are never nearer than about $10^{-6}$ to the diagonal no-dzsturbances trajectories, to remaln nearly hyperbollc In this case the control law described by Figure $4 \mathrm{IJa}$ Is very conservative with respect to cost (With $\mathrm{N}=4 \times 10^{-4}$ the control Is on only about one-seventh of the time of one orbit ) The trajectory in Figure 4 l3a is realistic in the sense that a time delay of $01 \mathrm{sec}$ Is assumed in the controller and a small amplitude $\left(\approx 10^{-6}\right)$ sinusoldal disturbance is assumed to affect the motion of the system descrubed by equations (4 34) wath $a^{2}=-1$ The cost of the limat cycle motion of Figure $413 \mathrm{~b}$ is about ten times smaller than the cost of the controlled motion of Figure $413 \mathrm{a}$ However, the limut cycle motion requires sensors (of the state varıables) which give one order of magnitude greater accuracy If the two triangular control-on regions in $S_{Y}$ whlch contain part of the $x_{1}$-axıs are replaced with control-off regions, the control effort is not significantly increased unless a large, but rare, disturbance causes the trajectory to acquire a polnt near $x_{2}=0, x_{1}= \pm 10^{-4}$ This simplification of the control logic can result in a lower overall controller cost even though it can cause an Increase In control effort (See Section B)

As in Part 2 and Part 3, the solution of the optimal problem with

$$
J=\int_{\tau_{0}}^{\tau}\left[f_{1}(\underline{x})+|v|\right] d \tau
$$

IS precisely the same as the solution obtalned from the NCES except for the discrepancies in the adjount variables which occur during the time when the state trajectory 1 s outside of $S_{Y}$ The adjount variables for 


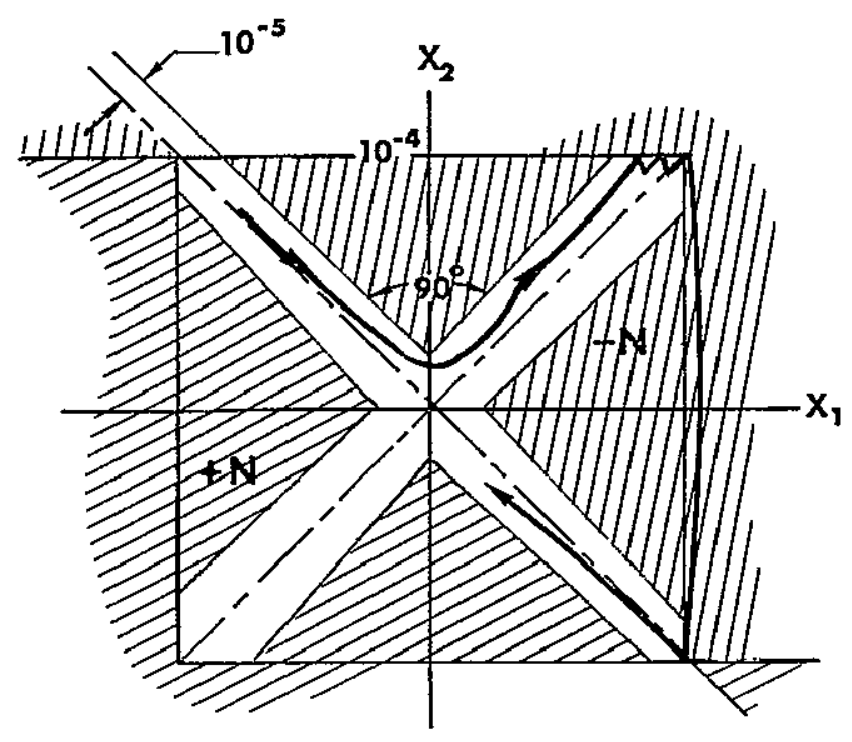

a. A Iow Cost Control Iaw and Trajectory for a Realistıc Case

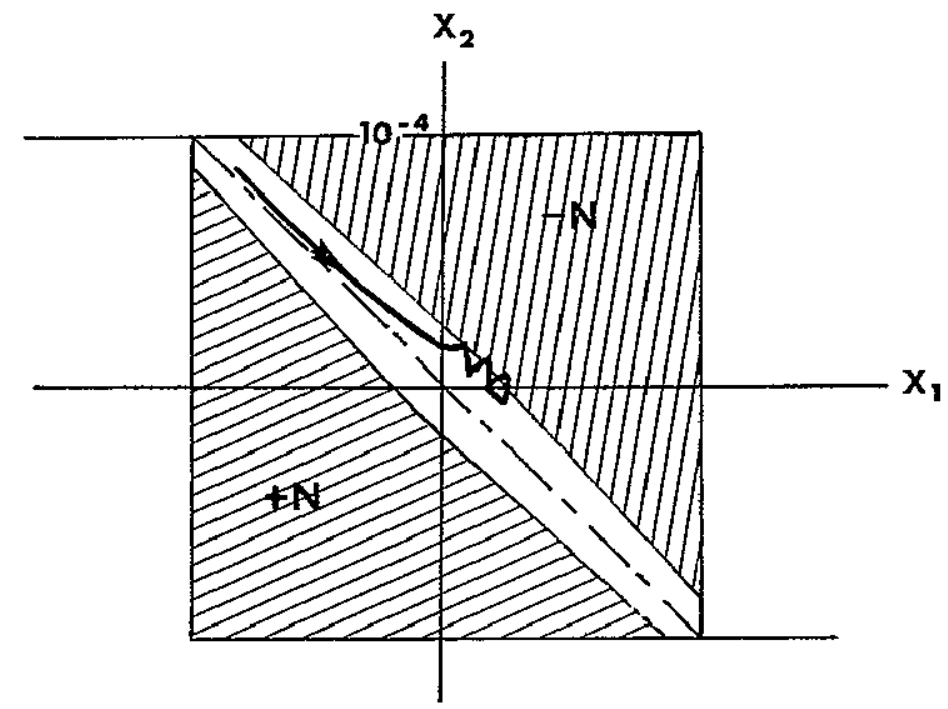

b A Low Cost Control Law which Results in Inmut Cycle Motion
Figure 413 Iow Cost Control Iaws and Trajectorıes, $N=0$ 05, Tume Delay $=01 \mathrm{sec}$


this problem wath

$$
J=\int_{\tau_{0}}^{\tau}\left[\underline{f}_{I}(\underline{x})+|v|\right] d \tau
$$

can be obtained as functions of $\tau^{*}$ as in Appendix $E$ and are given by

$$
\begin{aligned}
& p_{1}\left(\tau^{*}\right)=p_{1 e} \cosh \left(c \Delta \tau^{*}\right)+p_{2 e} c \sinh \left(c \Delta \tau^{*}\right)-F\left(x_{1}\right) c^{-1} \sinh \left(c \Delta \tau_{1}^{*}\right) \\
& +F\left(x_{2}\right)\left[\cosh \left(c \Delta \tau_{2}^{*}\right)-1\right] \\
& p_{2}\left(\tau^{*}\right)=p_{2 e} \cosh \left(c \Delta \tau^{*}\right)+p_{1 e} e^{-1} \sinh \left(c \Delta \tau^{*}\right)+F\left(x_{2}\right) c^{-1} \sinh \left(c \Delta \tau_{2}^{*}\right) \\
& -F\left(x_{1}\right) c^{-2}\left[\cosh \left(c \Delta \tau_{1}^{*}\right)-1\right]
\end{aligned}
$$

where $c^{2}=-a^{2}>0$ (It should be notıced that equatıons ( 4 43) are the "unstable" counterparts of equations (49) whlch are for the "stable" pitch motion )

B. THE STATION-KEEPING CONTROLS - GENERAT ORBTTS

1 Statıon-Keeplng Control of Satellites in a Maxımum Gravitational Torque Orbit

In Section $A$ the orbits were restricted to nearly polar or nearly equatorial orbits which were of sufficient altitude that the aerodynamic torque was insignificant.

If the orbits are not nearly polar or nearly equatorial, the oblateness terms in the gravitatıonal torque can be very significant in the case that high-accuracy earth-pointing is needed. Consider equations (2.17) with the parameters of sateliztes (2) and (3), for example. For all but about one-tenth of an orbyt the terms which contann elther $c_{\theta}$ or $s_{\theta}$ as factors are larger than the other term when $\left|x_{1}\right| \leq 11 \times 10^{-4}$, $I=I, \quad, 6$ Thus, as a lImztIng case the equations of steady-state motion for satellites such as (2) and (3) are 


$$
\begin{aligned}
& x_{1}^{\prime}=x_{2} \\
& x_{2}^{1}=-2 k_{1} A_{3} J\left(r_{E} / r\right)^{2} s_{\delta} c_{\delta} c_{\theta}+v_{1} \\
& x_{3}^{1}=x_{4} \\
& x_{4}^{1}=8 k_{2} A_{3} J\left(r_{E} / r\right)^{2} s_{\delta} c_{\delta} s_{\theta}+v_{2} \\
& x_{5}^{1}=x_{6} \\
& x_{6}^{1}=-A_{2}+v_{3}
\end{aligned}
$$

Since $e=0$ OI in these cases, $A_{3}$ and $\left(r_{E} / r\right)^{2}$ are very nearly constant so that for $\delta=45^{\circ}$ equations ( 4 44) are closely approximated by

$$
\begin{aligned}
& x_{2}^{1}=x_{2} \\
& x_{2}^{t}=E_{1} \cos (\tau+\theta)+v_{1} \\
& x_{3}^{1}=x_{4} \\
& x_{4}^{1}=E_{2} \sin (\tau+\theta)+v_{2} \\
& x_{5}^{1}=x_{6} \\
& x_{6}^{1}=2 e \sin \left(\tau+\theta_{0}\right)+v_{3}
\end{aligned}
$$

where for satelizte (2) $E_{1}=-145 \times 10^{-3}, R_{2}=-505 \times 10^{-3}$ and for satellıte (3) $E_{1}=126 \times 10^{-3}, E_{2}=522 \times 10^{-3}$

In contradistinction to the approximate motions of Section $A$, no equilibrium point exists in the motion described by any one of these three parrs of equatıons (which in this limıting case describe the yaw, roll and pitch motions) In this case there exists no region of stablilty In $S$ (whlch can be acquired with the ald of a minımum fuel control) which is such that no control effort is required to keep the trajectory in $S$ for the remalning lifetime of the satellite

Except for the equations of motion, which have a sine forcing term, the equations of the maximum principle for each pair (4 45) are the same as for $x^{\prime \prime}=v$ The adjount equations in the case of an integral 
constraint on the state variables are (In backwards time) the same as (4 18$)$

Although the sine forcung terms are no longer than 01 , their effects are most Important when $\left|x_{1}\right| \leq 10^{-4}$ so that the optimal feedback statıon-keepıng control law must be highly time varyung This fact and the fact that no equilibrium points and no region of stability in $S$ exıst make the determınation of practical, 1 e , suboptimal minımum-fuel control law improbable However, enough of the characteristics of the optimal control law are known so that a control whlch performs satısfactorlly can be devised

The optimal control must be a "coast function" as given by (4 19) If the time and the states at which the control optimally switches can be found, the optimal feedback control will be known If the NCES are applied to the problem, two characteristics of the minimum fuel control become apparent They are (1) the inctial (and final) values of the adjoint variables, as well as the jump in the adjoint variables at junction points, must be small (about one or less in $p_{2}$ and ten or less in $p_{1}$ ) In most applications for low fuel cost and for minzmum dispersion of the trajectory, (2) the switches in low cost controls occur when the trajectory is near the boundary of the station-keeplng region

In the maximum principle is applied to the minimum-fuel problem of station-lseeping via an integral constralnt on the state or equivalently to the optimal problem with

$$
J=\int_{\tau_{0}}^{\tau}\left[f_{1}(\underline{x})+|v|\right] d \tau
$$

It Is found that for the "best" values of $n_{I}$ and $I_{I}$ the switches in the control occur when the trajectory is near the boundary However, for the values of $n_{1}$ which keep $\left|x_{1}\right| \leq 11 \times 10^{-4}$, the pitch control, $v_{3}$, Is on about $95 \%$ of the time of consideration (The time of consideration was $2 \pi$, the time of one orbit) In this limiting case the controls of the yaw and roll motions are on about $90 \%$ of the time when the "best" values of $n_{1}$ and $\mathbb{N}_{I}$ are used (By reducing the values of 
$n_{1}$ and allowing more error in earth-pointing the fuel cost can be reduced )

Since the solutions obtained from the optimal problem with an integral constraint and from the NCES of the minlmum fuel problem all exhıbıt characterıstıc (2) given above, It Is logical to ask: should successive switches in the control occur when the trajectory is near one edge of the boundary or should successive swztches occur when the trajectory Is alternately near two edges of the boundary? (In the case of the NCES either Is possible, but, In the case of the integral constraint the latter is generally the case) The analysis which follows shows that both methods of control switching result in the same fuel cost over the IIfetime of the satellite

Take, for example, the third pair of equations (4 45) The solution for $x_{6}(\tau)$ is

$$
\mathrm{x}_{6}(\tau)=\mathrm{x}_{60}+2 \mathrm{e}\left(\cos \theta_{0}-\cos \left(\tau+\theta_{0}\right)\right)+\mathrm{v}_{3}\left(\tau-\tau_{0}\right)
$$

where $\tau_{0}, \theta_{0}, x_{60}$ are inftialized after each switch in the control Let $\Delta \tau=\tau-\tau_{0}$ and $\Delta \mathrm{x}_{6}=\mathrm{x}_{6}(\tau)-\mathrm{x}_{60}$. Then, since $\Delta \tau \leq 015$ (and is usually much less), an excellent approximation of (4 46) is

$$
\pm \Delta x_{6} \approx\left(v_{3} \mp 2 e \sin \theta_{0}\right) \Delta \tau
$$

where the upper signs correspond to $0 \leq \theta_{0}<\pi$ and the lower signs correspond to $\pi \leq \theta_{0}<2 \pi$ If the control switches consistantly between off and on when $\mathrm{x}_{6}(\tau)$ Is one of two glven values (e g, both of whych are near $x_{6}=10 \times 10^{-4}$ or $x_{6}=-10 \times 10^{-4}$ or one of whych 1 s near $x_{6}=10 \times 10^{-4}$ while the other Is near $\left.x_{6}=-10 \times 10^{-4}\right)$, then the ratio of the time the control is on to the total time of consideration is found from $(4,47)$ to be

$$
\frac{\Delta \tau_{\mathrm{ON}}}{\Delta \tau_{\mathrm{ON}}+\Delta \tau_{\mathrm{OH}}} \approx \frac{2 \mathrm{e}}{\mathbb{N}_{3}} \sin \theta_{\mathrm{O}}
$$

Thus, for a given control magnitude, $\mathbb{N}_{3}$, the fuel cost depends only on $\theta_{0}$ and $e$ and 1 s Independent of the values of $x_{6}$ at which control swltching occurs so that successive swatches whlch occur when the 
trajectory is near one edge Is no more preferable than successive switches at alternate edges

A similar analysis of the dependence of the optimal switching of the control on $x_{5}$ was made For any glven value of $x_{6},\left|x_{6}\right| \leq 10^{-4}$, no values of $x_{5},\left|x_{5}\right| \leq 10^{-4}$, at which optimal switching should occur were found The reasons for this are considered to be. (1) the rapid changes in the state due to the forcing term, (2) the absence of a preferred point or region to acquire, (3) the periodicity of the forcing terms

In summary it has been found for the limzting case of this part of Section B that at least one of any two consecutive swatches in the minimum-fuel control must occur on the boundary of $S$ and there are no preferred sets of values of $\left(x, x^{3}\right)=\left(x_{1}, x_{2}\right)$ or $\left(x_{3}, x_{4}\right)$ or $\left(x_{5}, x_{6}\right)$ at which the other switch in the minimum-fuel control should occur Thus, for the motion described by any one pair of the three pair of equations (4.45) the control law given in Figure 414 is expected to result in satısfactory steady-state performance The distance $d \neq 0$ is not a consequence of the theory but is an Innovation which is made necessary by the very imperfection in the controller which makes the control law workable - the control time delay For a given $d \neq 0\left(a \leq 10^{-4}\right)$ and a certain size time delay (or control magnitude) there is a maximum value of control magnitude (or time delay) at which chatter with no control-off Intervals will occur If the control magnitude (or time delay) is greater than this maximum value for the given value of $d \neq 0$, fuel 1 s wasted (See Part 4 of this section)

This control law, although simple, also results in satisfactory performance (see Part 5 and Chapter VI) when the periodic exponential forcing function of the aerodynamic torque is dominant as in the ultra hlgh-accuracy earth-polnting of satellite (4) (In this case, as above In the case of the sine forcing term, it is not difficult to show that there are no preferred states in $S$ at which control swltches should occur ) 


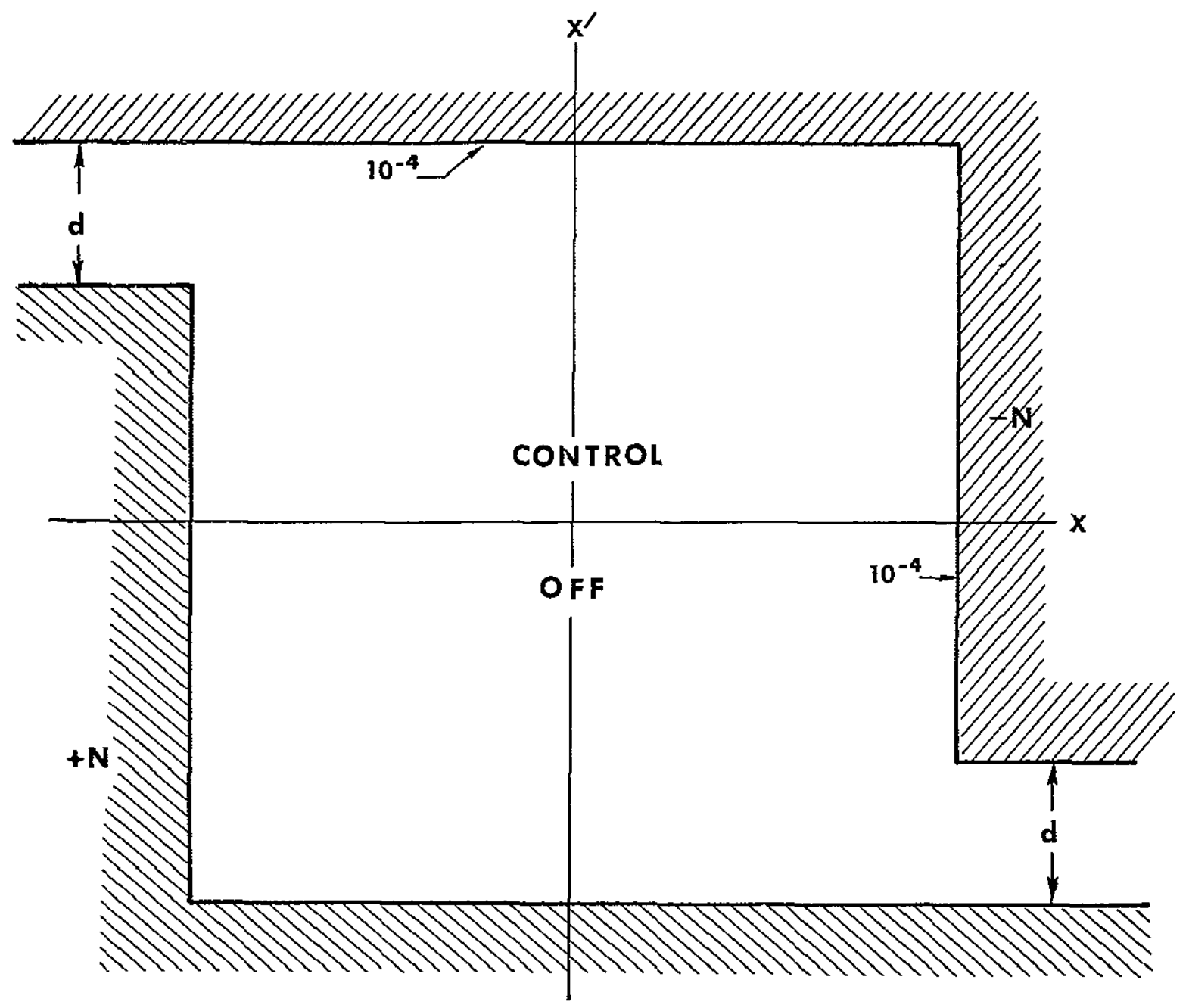

Figure 4 14. A Single-Axıs Station-Keepıng Control Iaw 


\section{Improvement of the Control Law of Part I, Section A}

Although the suboptimal station-keeping control law, equations (4.2) with the second and fourth of equations (4 8) and the second of equations (4 9), was derzved for "stable" satellites in elther polar or equitorial orbits, similar control laws can be derıved for most "unstable" satellites in general orbits All of these control laws are simllar in the terms in which the derıvatıves of the "penalty function", $F\left(x_{1}\right)$, $I=1, \quad 6$, enter These terms are zero when $\underline{x}$ Is in $S$ AII other terms contain the plecewise constant variables, $p_{1 e}, 1=1,6$, whose average values over several orbıts are nearly zero

If $p_{1 e} I=1,6$, are taken as 1 dentıcally zero, the control law Is greatly simplified, and, for the "best" values of $n_{1}$ and $I_{I}$ It $I s$, In each phase plane projection, very nearly the same as In Figure 414 with $d=0$ In comparison, the fuel cost in the case $p_{1 e} \equiv 0$ was found to be $25 \%$ (roll-yaw) to $66 \%$ (pltch) less than when both the full system equations and the full control law was used The largest percentage values correspond to those satellite configurations which require the greatest control effort for earth pointing

\section{The Controls - Approximate Motions}

The control law for single-axis motion which is given in Figure 4.14 is expected to result in the efficient control of the approximate motions of this section and Section $A$ of this chapter Since the most general nearly earth-pointing motions of the satellites consldered here can be approximated (In a least a plecewise sense) by the approximate motions above in this section and in Section $A$, the three-axes control law whose components are as In Figure 414 is expected to result in the efficzent station-keeping control of the general motzon

If the control law given in Figure 414 is used in the control of the motion of $x^{n}+a^{2} x=v, a^{2}>0$, and if a realistic time delay In the control Is assumed, say 01 sec, the trajectories in Figure 415 are typical These trajectories compare well with the optzmal trajectories of Part 3, Section A (See Figure 4.7) ) The distance, d, was taken to be zero, the worst value If $\mathrm{d}=1.0 \times 10^{-4}$, the agreement wath the 


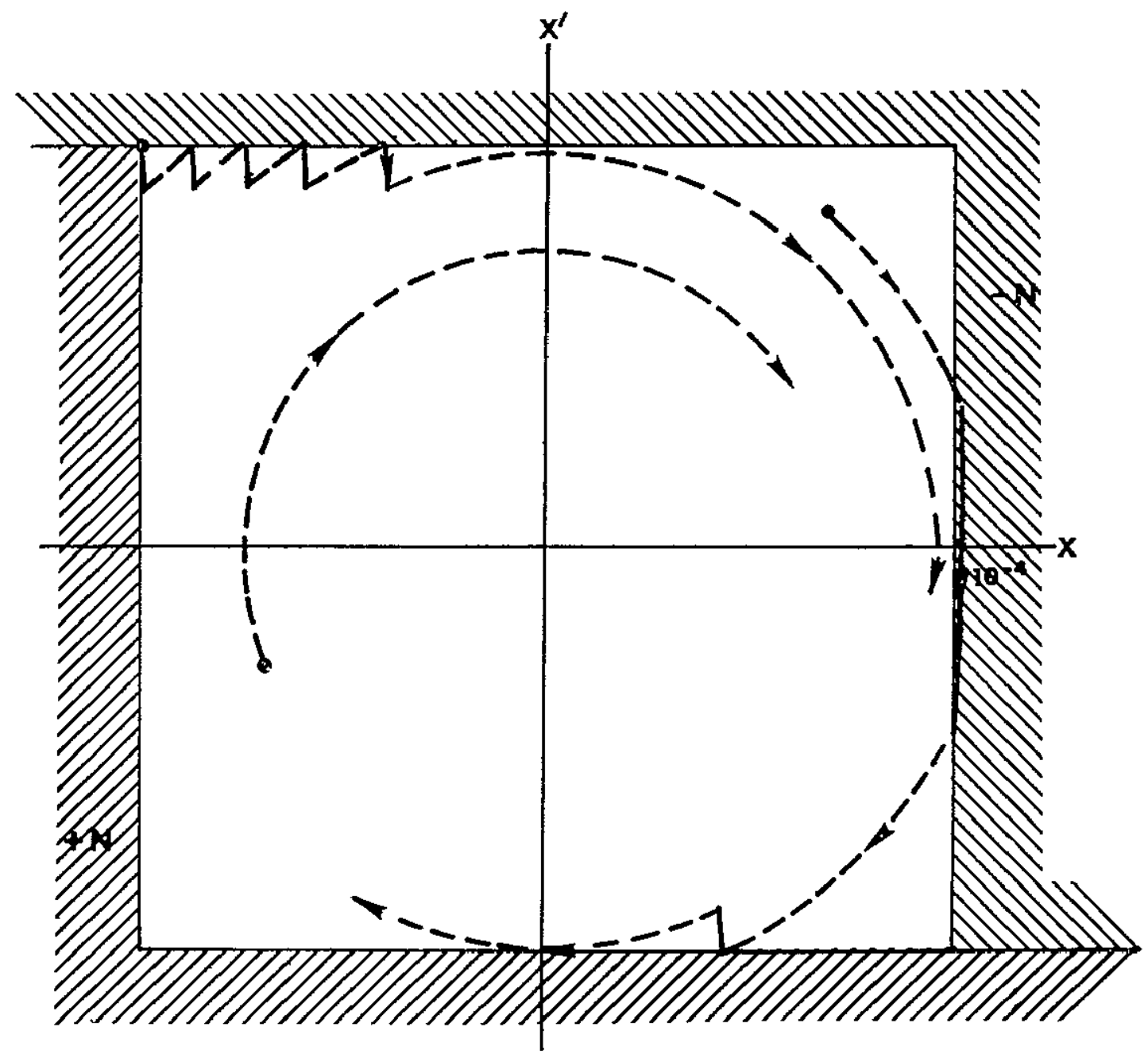

Figure 4 15. The Control of Figure 414 Applied to $x^{13}+a^{2}=v$, $a^{2}=1.0, N=0 I, d=0$ 
optimal trajectories of Part 3, Section A Is even better and the fuel cost is reduced in some cases by as much as $47 \%$ However, if no future control effort is needed, the fuel expenditure is minute even with $a=0$ Consider the motion of $x^{\prime \prime}+a^{2} x=v, a^{2}<0$, when $v$ is as represented in Figure 4.14 If the time delay in the control is 0 I sec, the trajectories in Figure 416 are typıcal in the case $a^{2}=-0.95$ (This value of $a^{2}$ is slightly more realistic for approximating the "unstable" yaw and pitch motions than $a^{2}=-1$ ) The distance, $a$, Is taken Just large enough so that the control (with a time delay of 0 I sec) Is not on all of the time if chatter motzon near the two corners $\left(x, x^{t}\right)=$ $\left( \pm 10^{-4}, \mp 10^{-4}\right)$ occurs For minimum fuel cost d should be as small as possible The fuel cost in this case with $d=10^{-5}$ and $\mathbb{N}=005$ is about

$$
J=\int_{\tau_{0}}^{\tau_{1}}|v| d \tau=3 \times 10^{-4}
$$

per orbzt

4 The Controls - Station-Keeping Motzons of the Sateliztes

The four satellites as described by equations (2.17) or equations (2 18) with the control for each axis as described in Figure 414 were simulated on a PACE TR-48 analog computer (The patching diagrams are gIven In Appendıx F) Some of the results of the many sımulation runs are shown in Figure 417 - Figure 420 as phase plane trajectories (or more precisely, the projection of trajectories into the phase planes) ('The plots were made by an $x-y$ plotter which as directly connected to the computer output ) In all figures the initial point, $P_{1}$, Is outside of $S$ and on the boundary of a region, $S^{+}$, which $I S$ twice the size of $S$ (In maximum dimension). The reason $P_{I_{+}}$Is not taken in $S$ but on the boundary of a newly defined region $\mathrm{S}^{+}$Is given In the acquisition chapter, Chapter $V$ The real time (satellite time) of each run is at least the time of one orbit When more information is obtained from a trajectory corresponding to more than one orbit (for example, the stabilization of the roll-yaw motion of satellite (2)), the 


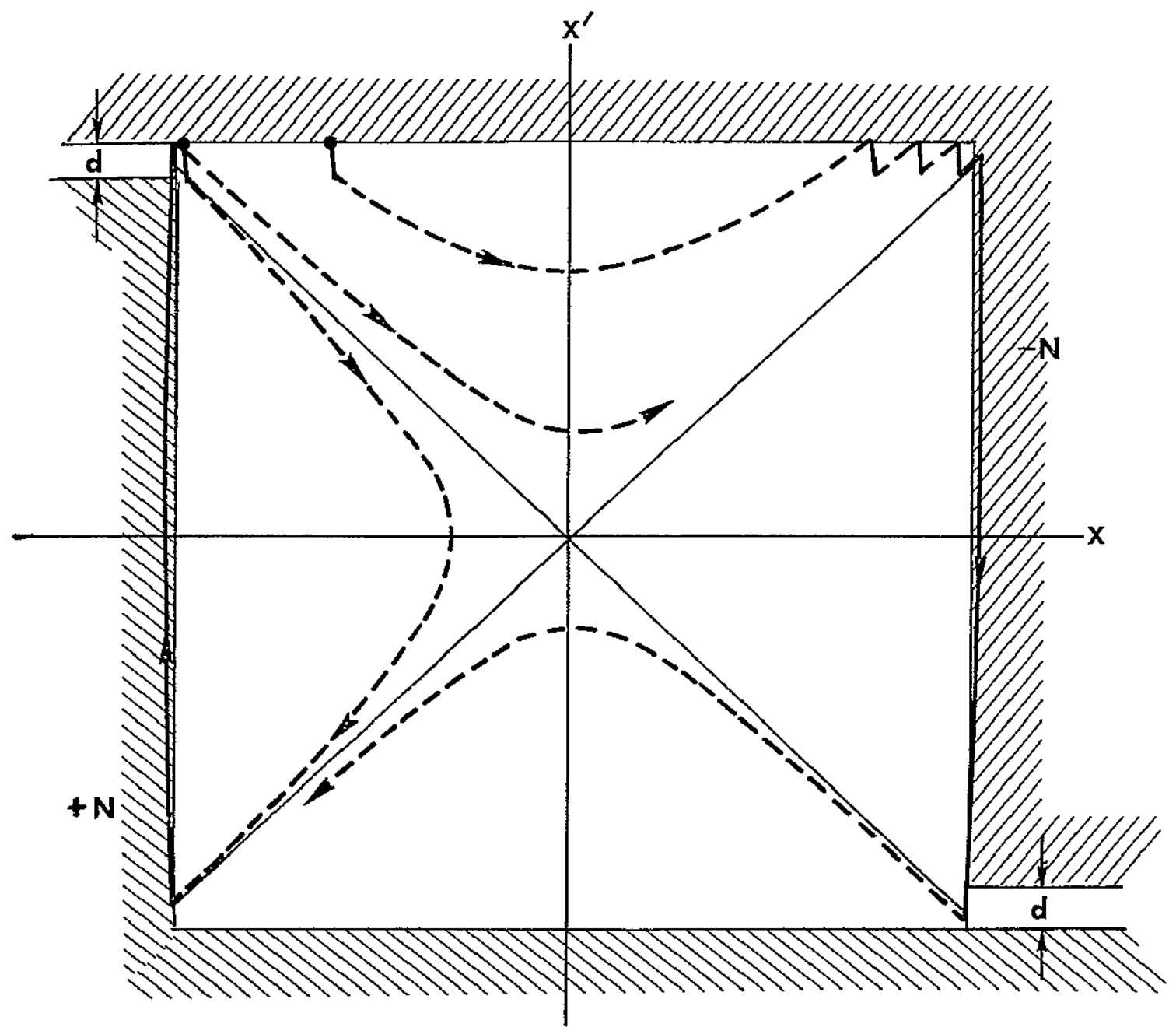

Figure 416 The Control of Figure 414 Applied to $x^{\prime \prime}+a^{2} x=v$, $a^{2}=-095, \mathbb{N}=0.05, a=10^{-5}$ 


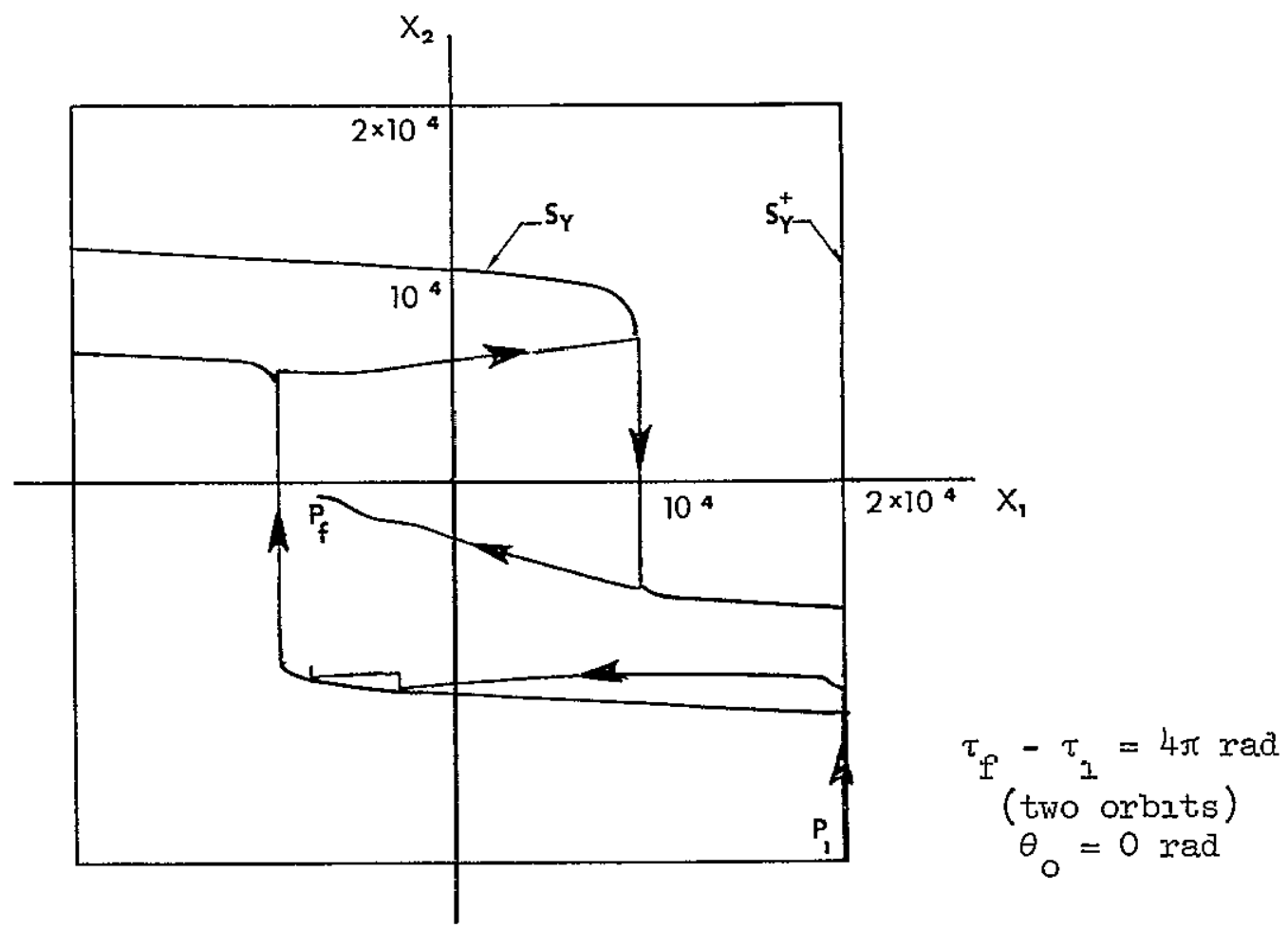

a Yaw Trajectory, $\mathbb{N}_{1}=001, t_{d}^{-}=05 \mathrm{sec}, t_{d}^{+}=125 \mathrm{sec}, d=4 \times 10^{-5}$

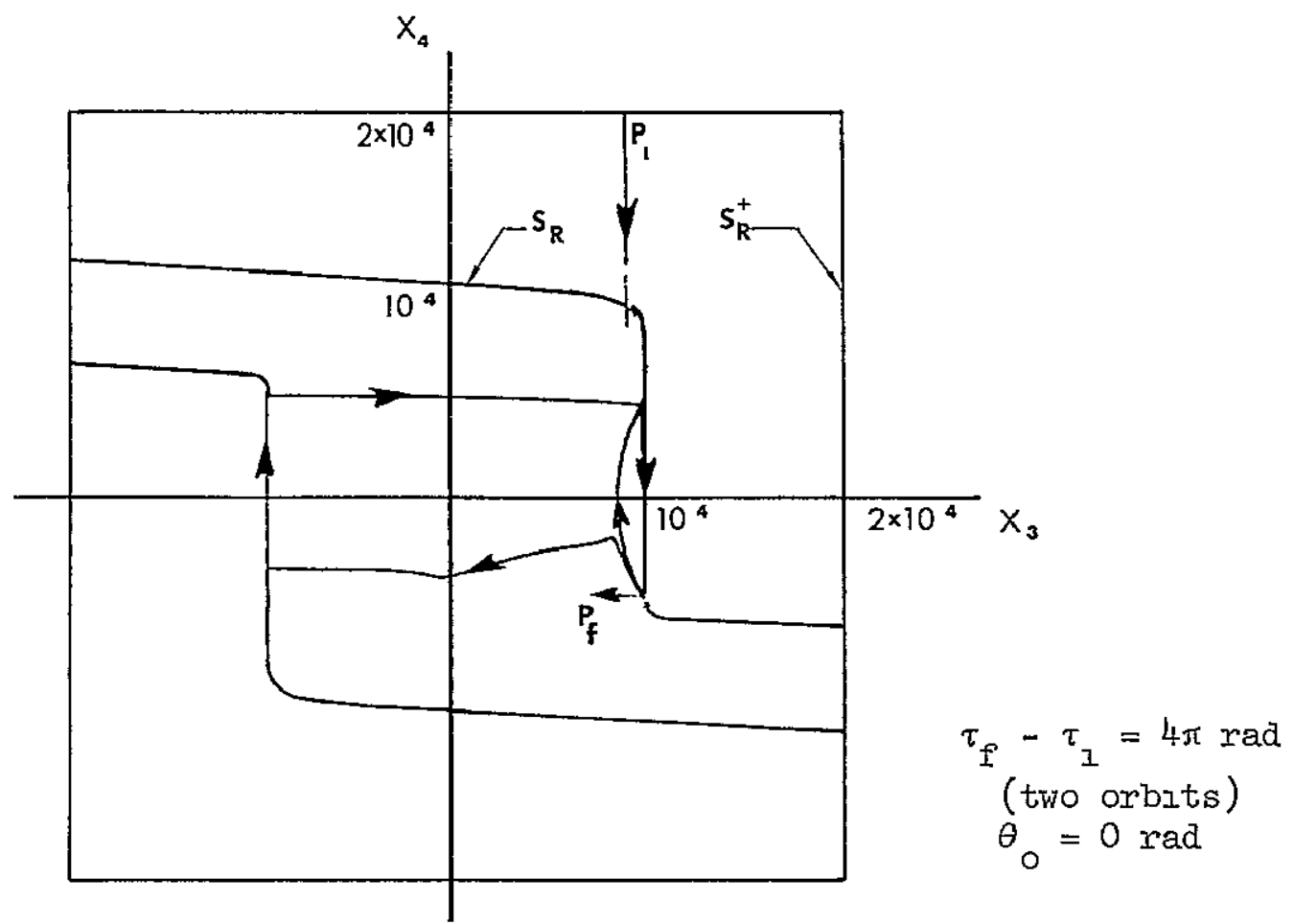

b Roll Trajectory, $\mathbb{N}_{2}=001, t_{d}^{-}=05 \mathrm{sec}, t_{d}^{+}=10 \mathrm{sec}, \mathrm{d}=40 \times 10^{-5}$ Figure 417 Statıon-Keepıng Motıon of Satellıte (1) 


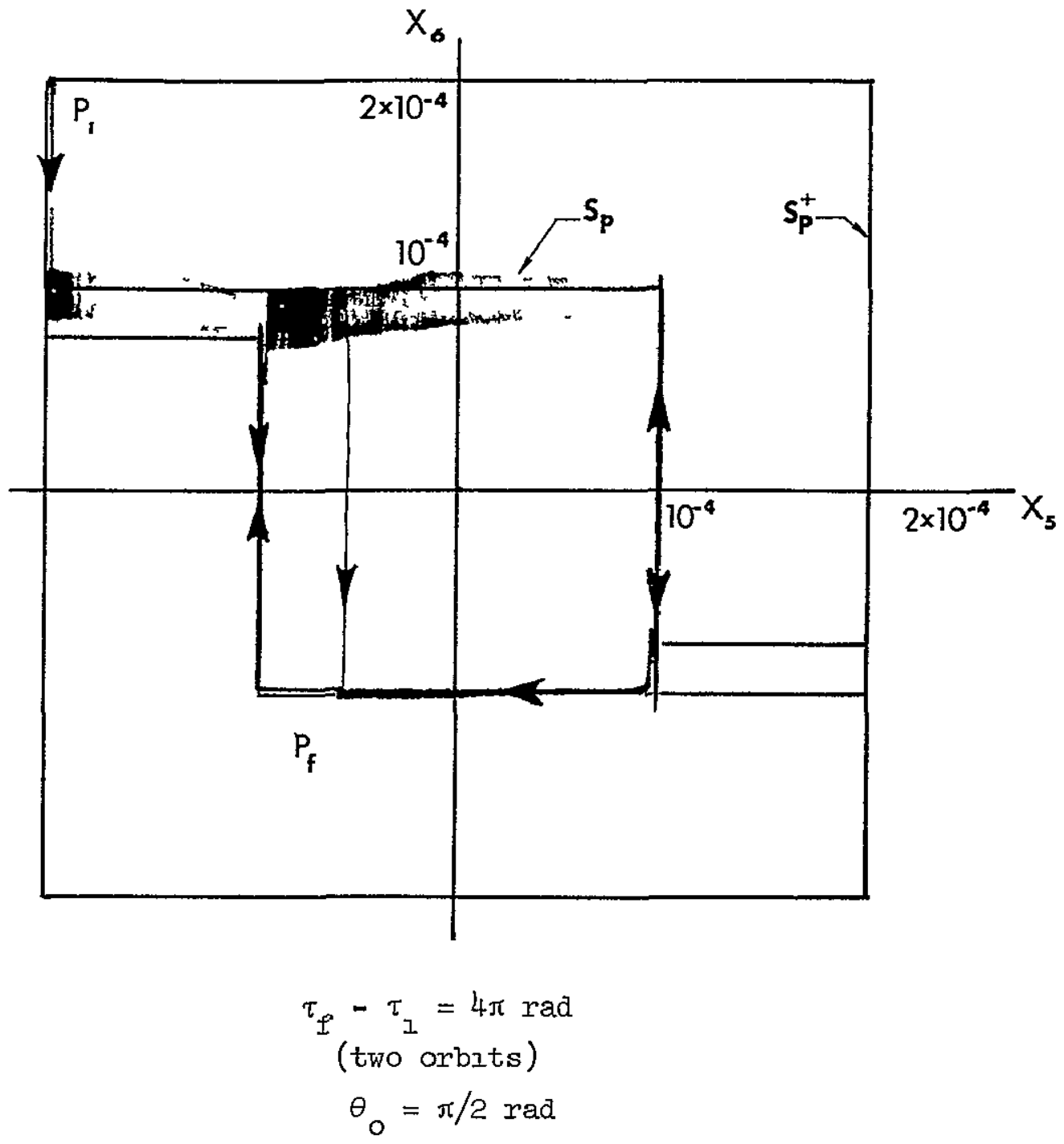

c PItch Trajectory, $N_{3}=02, t_{d}^{-}=005 \mathrm{sec}, t_{d}^{+}=001 \mathrm{sec}$, $\mathrm{d}=25 \times 10^{-5}$

Figure 417 Contınued. 


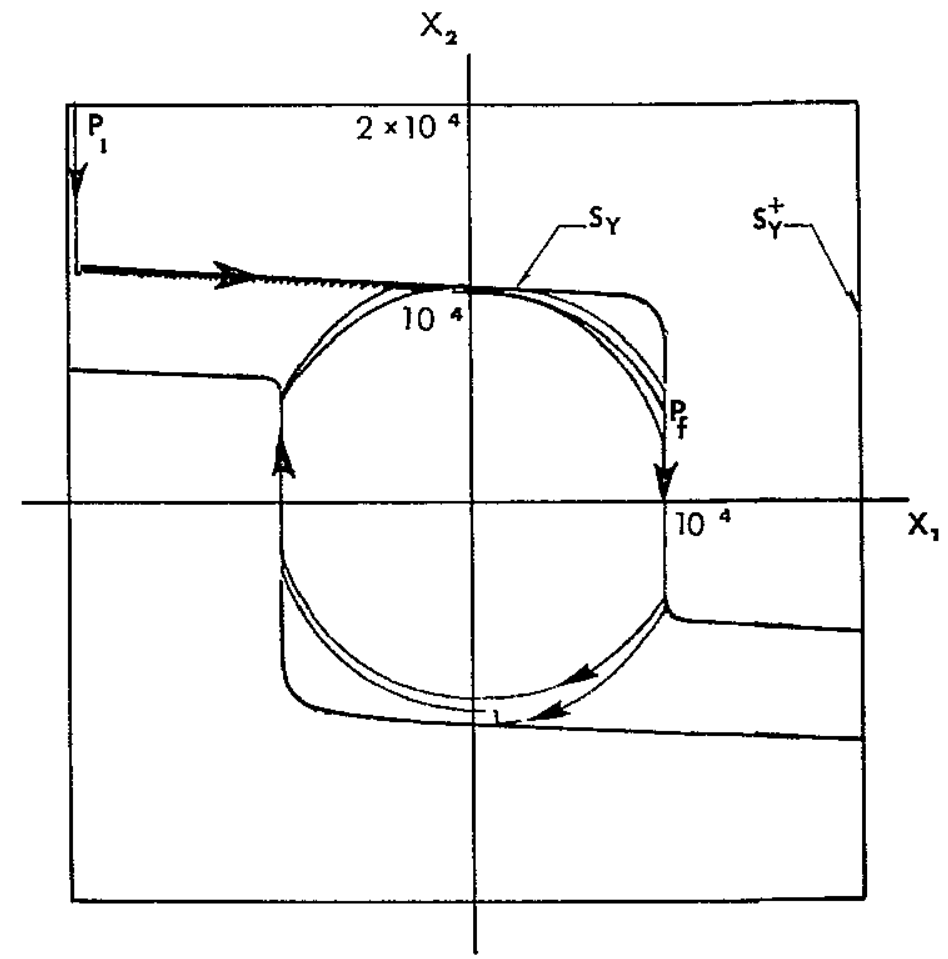

$$
\begin{gathered}
\tau_{f}-\tau_{1}=4 \pi \mathrm{rad} \\
\text { (two orblts) } \\
\theta_{0}=0
\end{gathered}
$$

a Yaw Trajectory, $\mathrm{N}_{1}=002, t_{\mathrm{d}}^{-}=05 \mathrm{sec}, \mathrm{t}_{\mathrm{d}}^{+}=125 \mathrm{sec}$, $\mathrm{a}=4 \times 10^{-5}$

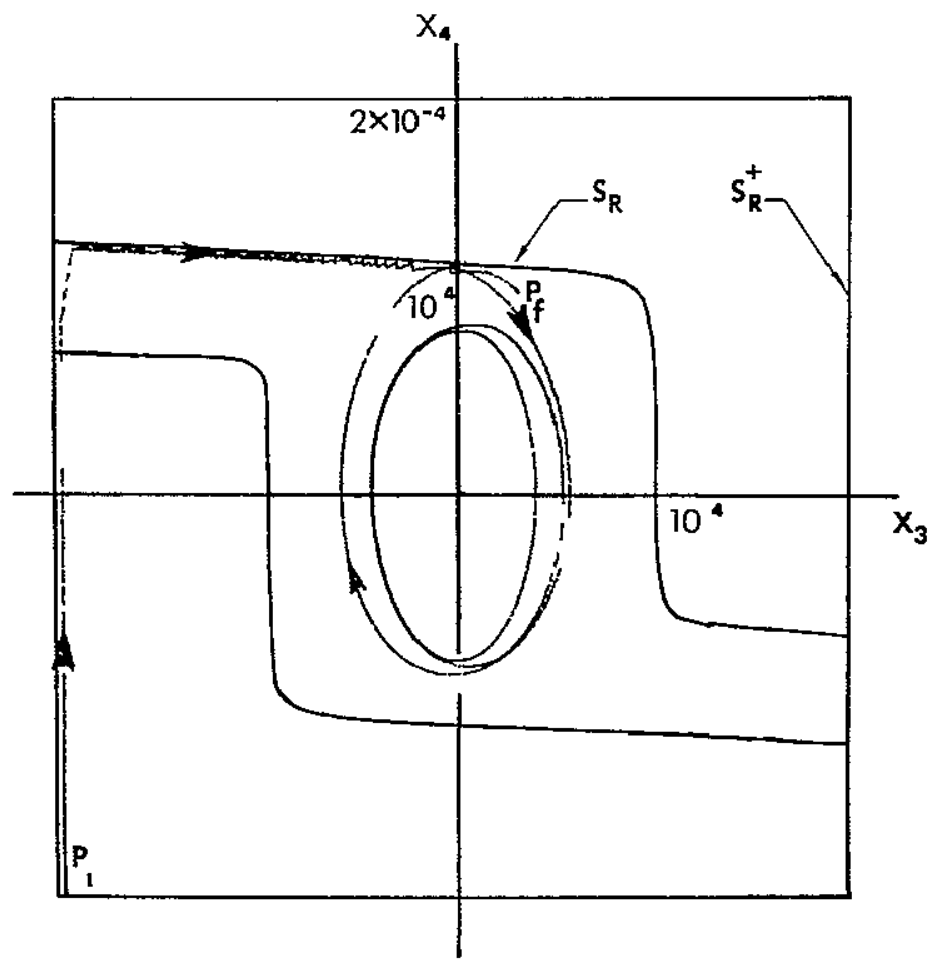

$$
\begin{gathered}
\tau_{f}-\tau_{I}=4 \pi \text { rad } \\
\text { (two orbIts) } \\
\theta_{0}=0
\end{gathered}
$$

b Roll Trajectory, $\mathbb{N}_{2}=002, t_{d}^{-}=05 \mathrm{sec}, t_{d}^{+}=10 \mathrm{sec}$, $\mathrm{d}=4 \times 10^{-5}$

Figure 418 Station-Keepıng Motıon of Satellite (2) 


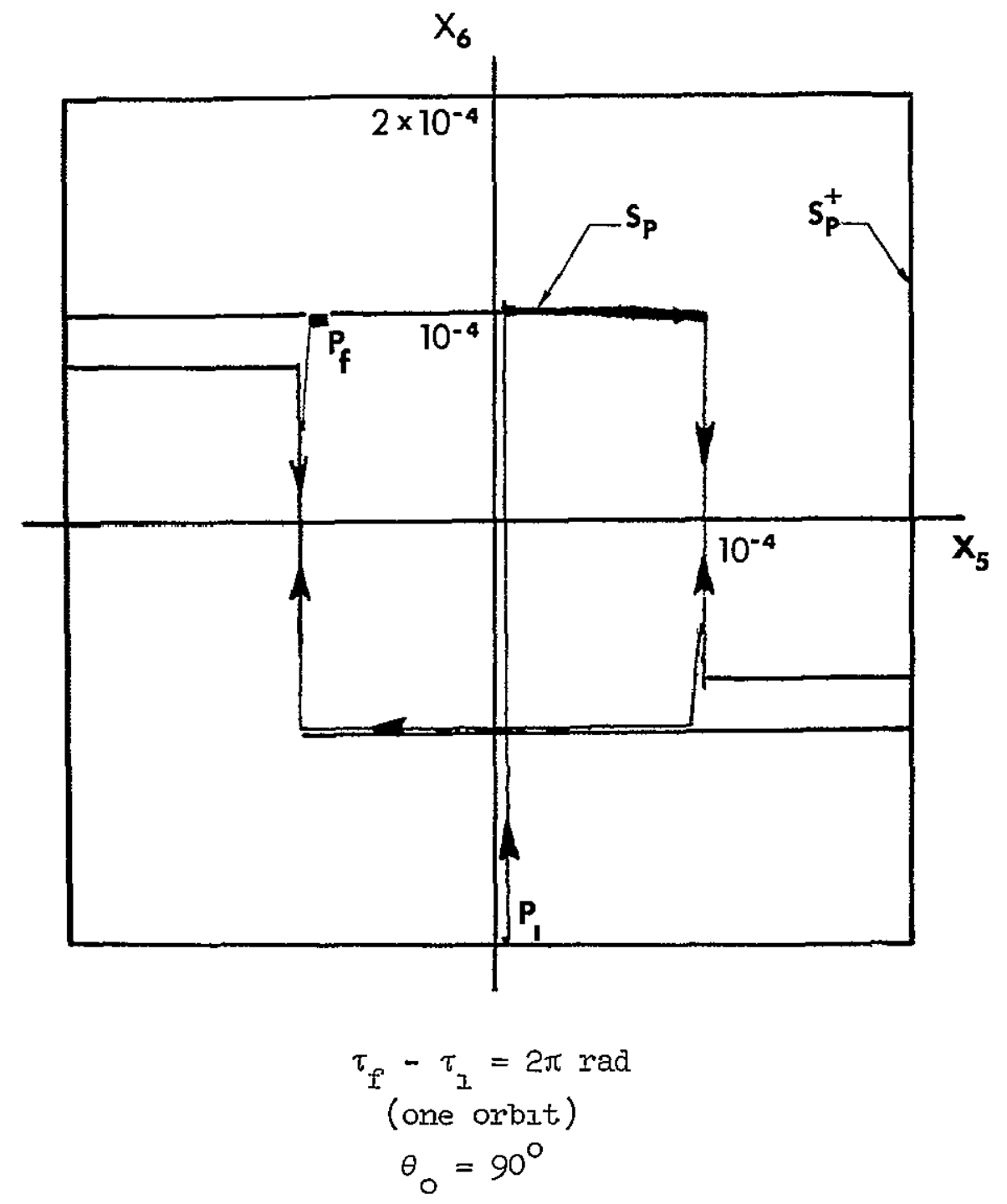

c. Putch Trajectory, $N_{3}=0.03, t_{d}^{-}=02 \mathrm{sec}, t_{d}^{+}=004 \mathrm{sec}$, $a=25 \times 10^{-5}$

Figure 418 Continued. 


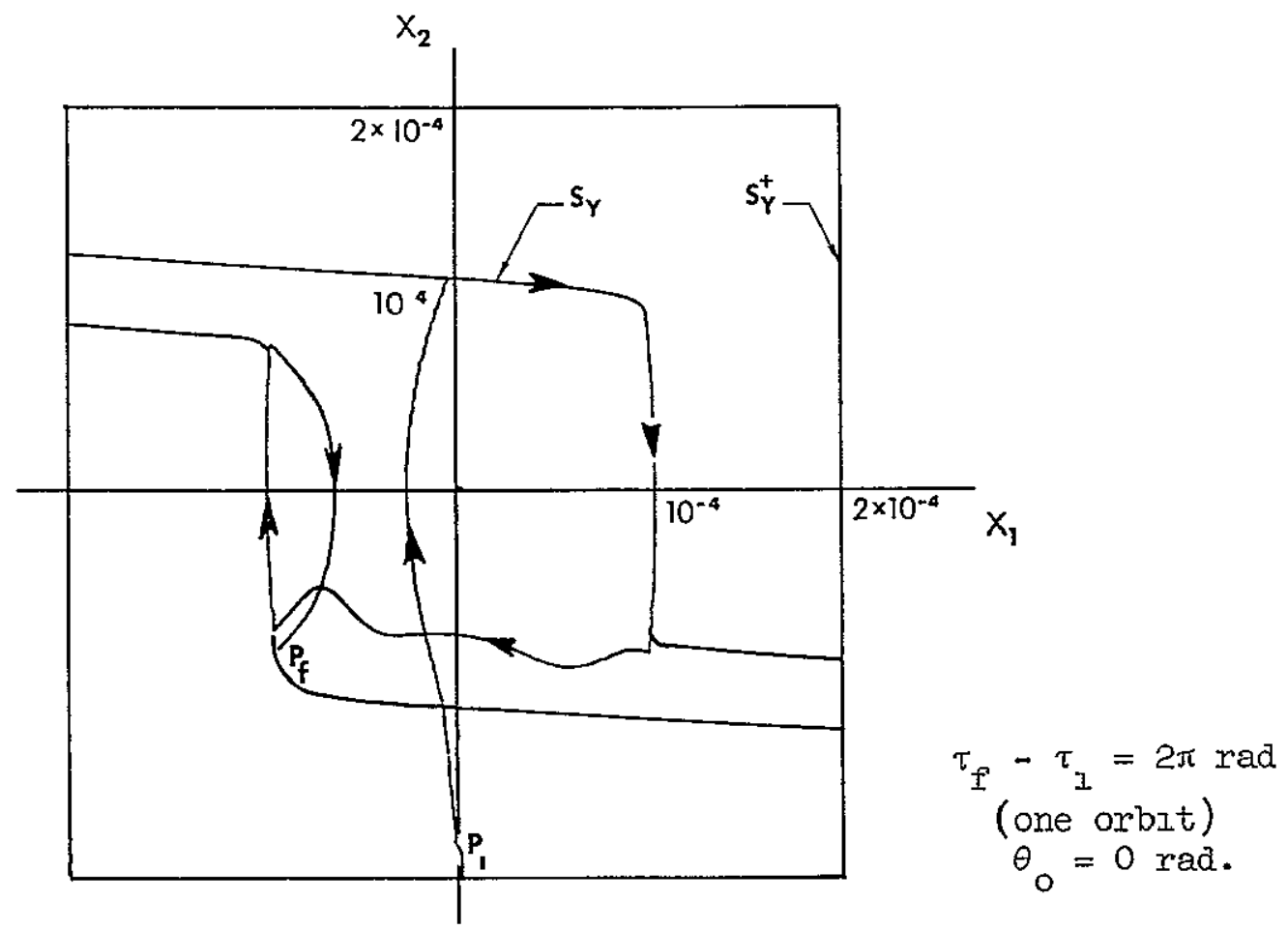

a Yaw Trajectory, $\mathbb{N}_{1}=0001, t_{d}^{-}=05 \mathrm{sec}, t_{d}^{+}=125 \mathrm{sec}$, $a=2 \times 10^{-5}$

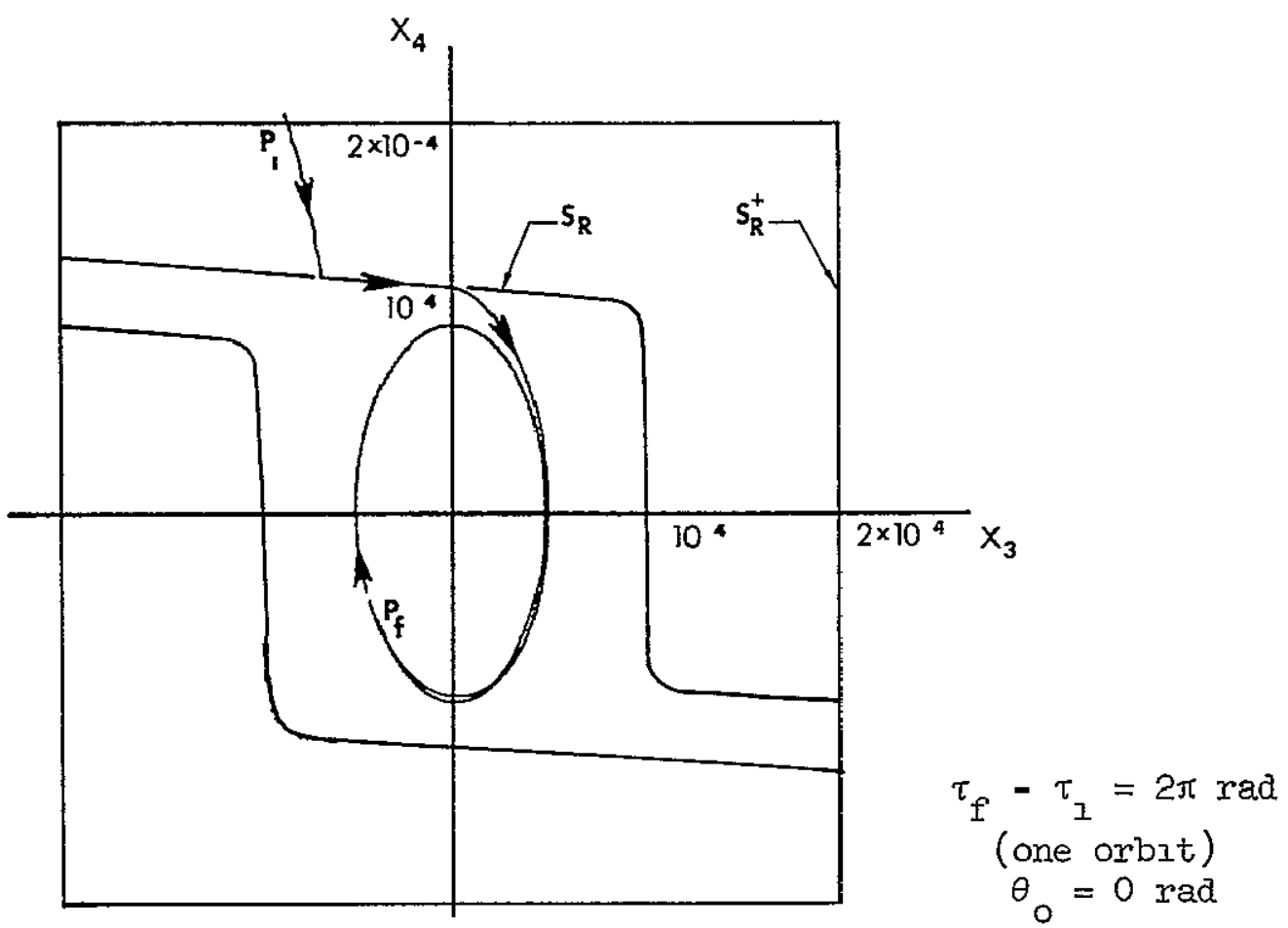

b Roll Trajectory, $N_{2}=0001, t_{d}^{-}=05 \mathrm{sec}, t_{d}^{+}=10 \mathrm{sec}$, $\mathrm{d}=2 \times 10^{-5}$

Figure 419 Statıon-Keepıng Motıon of Satelizte (3) 


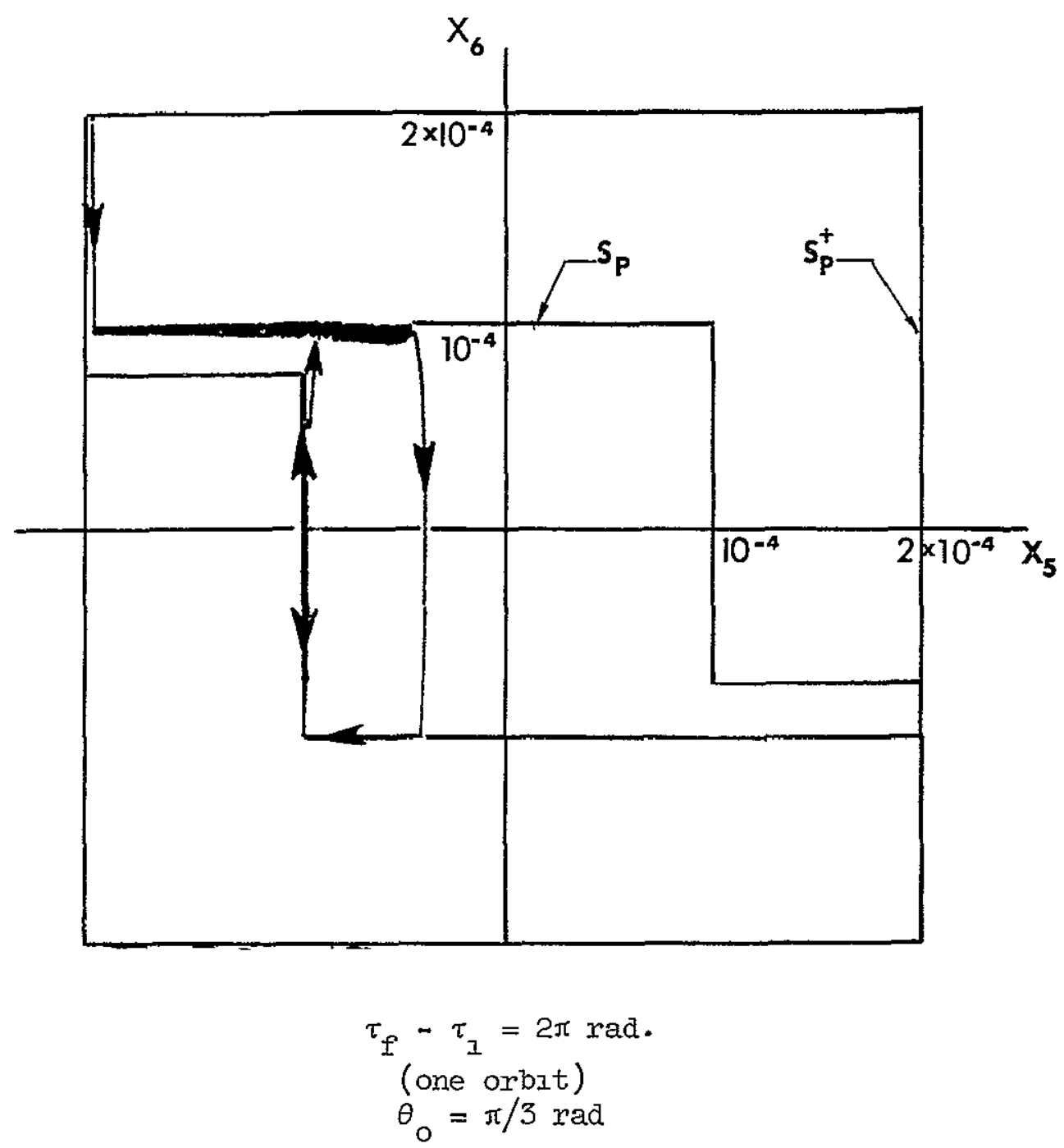

c PItch Trajectory, $\mathbb{N}_{3}=0.03, t_{d}^{-}=02 \mathrm{sec}, t_{d}^{+}=004 \mathrm{sec}$, $\mathrm{d}=25 \times 10^{-5}$

Figure 419 Continued 


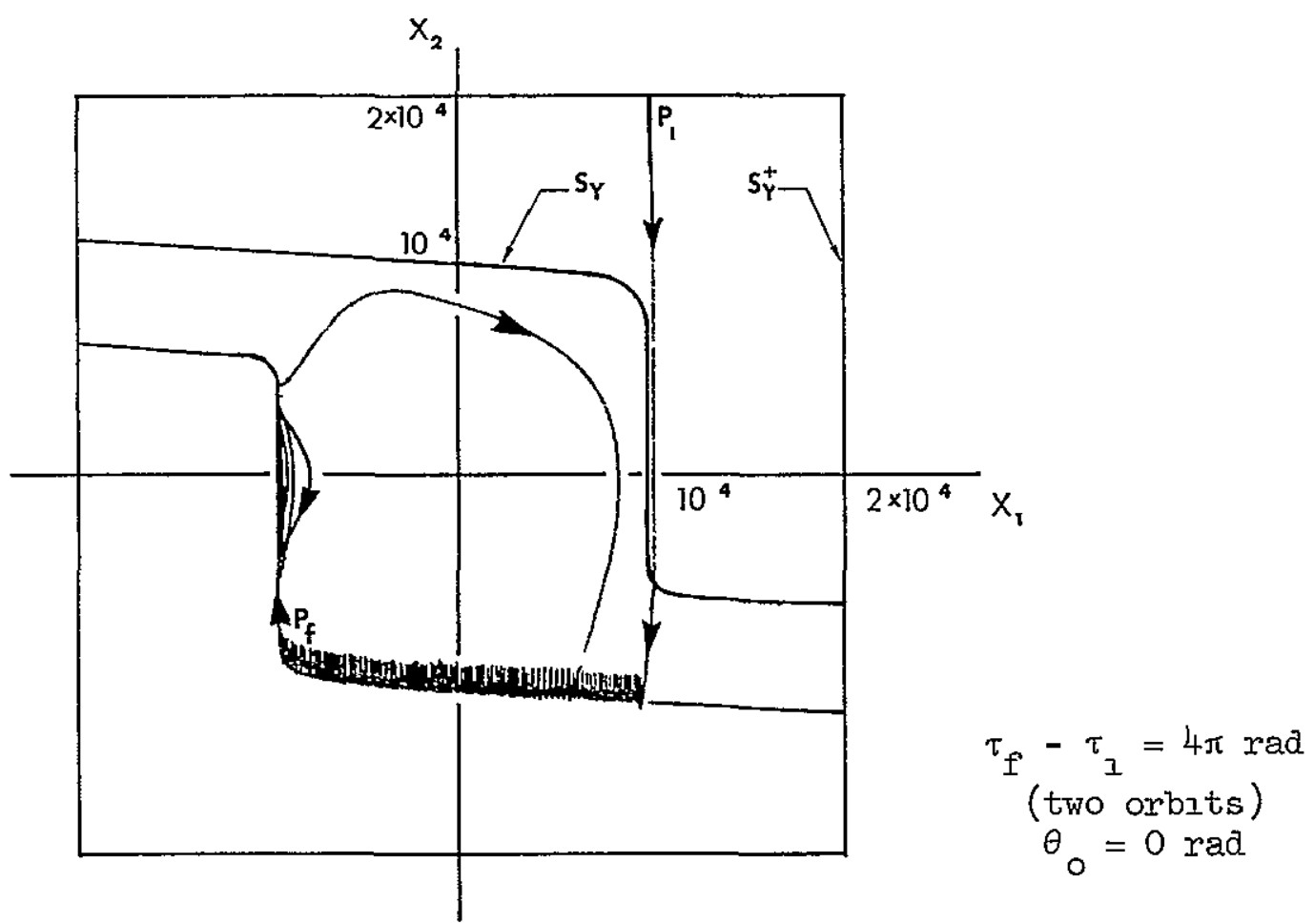

a Yaw Trajectory, $\mathbb{N}_{1}=001, t_{d}^{-}=05 \mathrm{sec}, t_{d}^{+}=125 \mathrm{sec}$, $a=4 \times 10^{-5}$

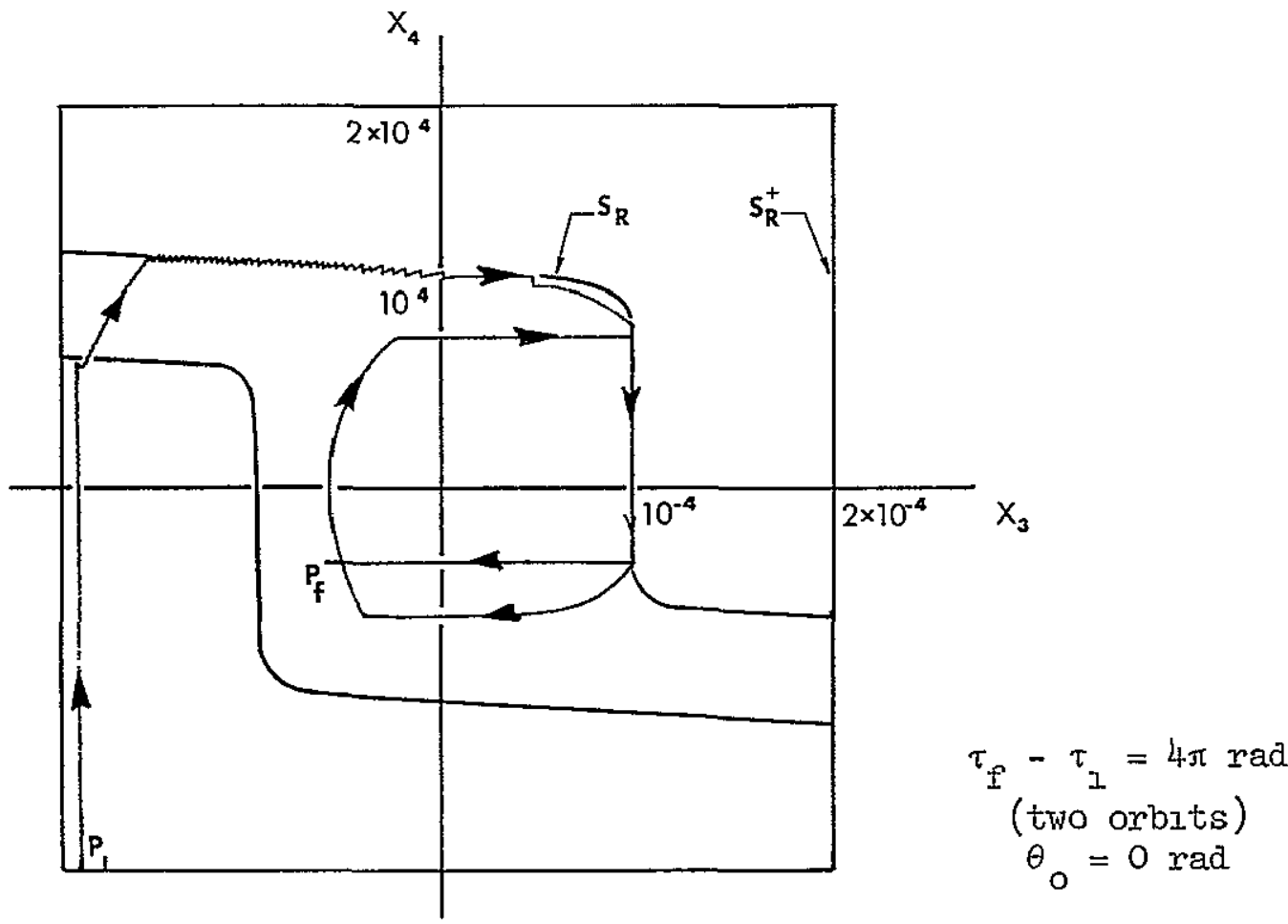

b Rol1 Trajectory, $\mathrm{N}_{2}=001, t_{d}^{-}=05 \mathrm{sec}, t_{d}^{+}=10 \mathrm{sec}$, $\mathrm{a}=4 \times 10^{-5}$

Figure 420 Station-Keeping Motion of Satelizte (4) 


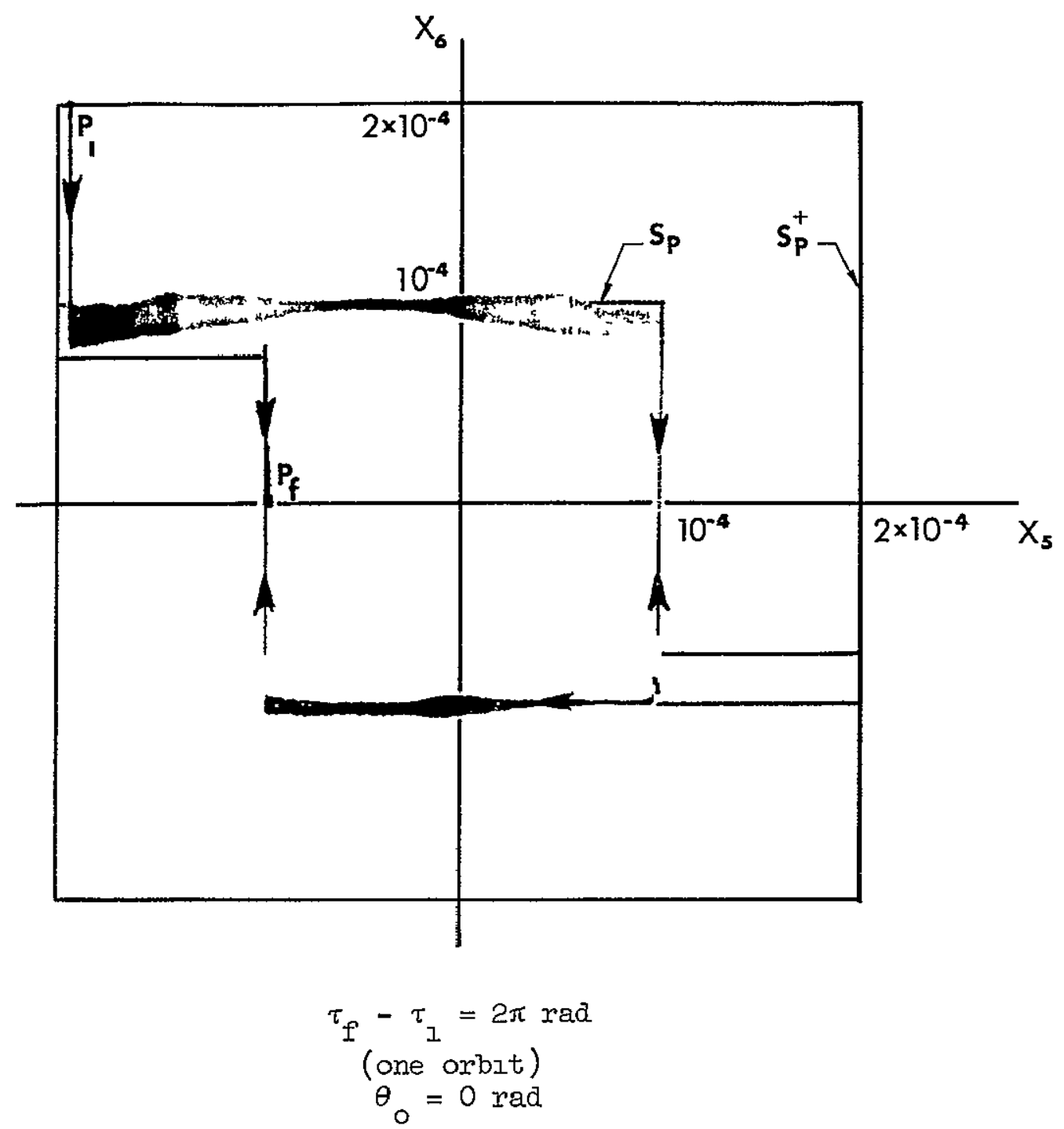

c Pitch Trajectory, $\mathbb{N}_{3}=012, t_{d}^{-}=02 \mathrm{sec}, t_{d}^{+}=004 \mathrm{sec}$, $d=25 \times 10^{-5}$

Figure 420 Continued 
real time is the time of two orbits The point in the orbit correspondIng to the initial time is given by $\theta_{0}$, the angle of the satellite from perigee The time delay in each part of the controllex is given in each figure as $t_{d}^{-}$, whlch corresponds to $-N$, and $t_{d}^{+}$, which corresponds to $+N$ It should be noted in reading the figures that the lightest regions of the rapld chatter parts of the pltch trajectorles generally correspond to the most rapid chatter while the darker parts of the trajectory correspond to slower motion. In Figure $420 \mathrm{a}$ is shown a yaw trajectory of satellite (4) (which Is greatly influenced by the aerodynamic torque) for the time of two orbits. The part of the trajectory corresponding to the second orbit overlaps part of the first orbit trajectory However, the early rapid chatter motion, which occurs when the aerodynamic torque is near Its maximum magnitude, Is light enough for the later less rapld chatter motion to be seen over It. In the roll and yaw parts of Figures $417-$ 420 the boundary IInes of the phase plane projections of $S$ are not perfectly stralght as In Figure 414 These boundaries were created in the analog simulation by an electronic signum function generator which was not perfect, $I \mathrm{e}$, the characteristics of the diodes used were only nearly Ideal The large control magnitudes required in pitch resulted in chatter motion along the nearly vertical parts of the boundary unless these parts of the boundary were stralghtened up somewhat Therefore, for the putch parts of Figure 417 - Flgure 420 the boundary IInes were (electronically) made very strazght by connectıng two dıode sıgnum function generators in series

Table 41 gives the fuel expenditure (nondimensional) for the simulation runs of Figure 4.17 - Figure $420 \quad J_{R-Y}$ and $J_{P}$ are the total fuel expendıtures for the roll-yaw and pitch controls, respectively $J_{R-Y, A C Q}$ for example, Is the cost of acquiring the roll-yaw projection of $S$ from the point $P_{I} \quad J_{P, S S}$, for example, $I S$ the cost of the steady-state pitch motion The fuel expendıture for these runs were typical of all runs of the same duration The average (the Initial points In $S$ and the angle $\theta_{0}$ were varıed) steady-state fuel expenditure for one orbıt differed from the steady-state values in Table 41 by about two or three percent of course, the acquisition part of the fuel expenditure depended greatly on $P_{1}$ and to a lesser extent on $\theta_{0}$ 
TABTE 41 EUEL EXPEIDIIURE FOR THE SIMUIATION RUNS OF FIGURE 4 I7 FIGURE 420

\begin{tabular}{|l|c|c|c|c|}
\hline SATET,IITE & $(1)$ & $(2)$ & $(3)$ & $(4)$ \\
\hline$J_{R-Y}$ & $*$ & $*$ & & $*$ \\
\hline$J_{P}$ & $* 52 \times 10^{-3}$ & $760 \times 10^{-3}$ & $3.71 \times 10^{-3}$ & $788 \times 10^{-3}$ \\
\hline$J_{R-Y, A C Q}$ & $2.05 \times 10^{-1}$ & $603 \times 10^{-2}$ & $752 \times 10^{-2}$ & $1394 \times 10^{-2}$ \\
\hline$J_{P, A C Q}$ & $309 \times 10^{-2}$ & $30 \times 10^{-4}$ & $151 \times 10^{-2}$ & $103 \times 10^{-2}$ \\
\hline $\begin{array}{c}* \\
J_{R-Y, S S}\end{array}$ & $464 \times 10^{-3}$ & $326 \times 10^{-3}$ & $2.46 \times 10^{-3}$ & $584 \times 10^{-3}$ \\
\hline$(t)$ & $* 34 \times 10^{-3}$ & $125 \times 10^{-3}$ & $204 \times 10^{-3}$ \\
\hline$J_{P, S S}$ & $2.74 \times 10^{-1}$ & $603 \times 10^{-2}$ & $601 \times 10^{-2}$ & $1291 \times 10^{-2}$ \\
\hline
\end{tabular}

*Denotes two orbits, otherwise one orbit

NOTE The nondimensional cost va.Iues are translated in Chapter VI Into the number of pounds per orbit (or year) for the example satellytes of Chapter II

$(t)$ RECATI. Satellite (I) Is "mllaly stable" In all axes but the putch motion is strongly forced, satellite (2) is "very stable" in roll-yaw but is "unstable" in pitch with forced motion; satelizte (3) is "unstable" in yaw, "stable" In roll and pitch and pitch has forced motion, satellite (4) Is similar to satellite (1) except that yaw and pitch are "destablizzed" by the aerodynamıc torque. 
(Compare, for example, the value of $J_{P, A C Q}$ for satellite (2) with the value for satellite (I))

From the describing differential equations of controlled motion and the example trajectories of Figure 417 - Figure 420 It is apparent that for all inltial state in $S$ the station-keeping part of the controller can keep the state space trajectory from departing $S$ by a signiflcant amount (except, perhaps, when large unaccounted for dlsturbances overpower the station-keeping part of the controller). Since the minimum fuel expenditure of the station-keeping controller for one orbit is not known, the steady-state fuel cost per orbst obtained in the simulation runs cannot be compared with an absolute minimum However, since from Figure 417 - Figure 420 it is clear that the single-axis satellite motions are approximated, in at least a plecewise sense, by the approximation motions of Section $A$ and this section, (Section $B$ ) the steady-state fuel cost is consıdered to be nearly a minımum Thus, the statıon-keeping part of the controller is considered to perform satisfactorily (In Chapter VI cost, error and other performance measures are evaluated for particular satellites of particular weights There it is found that the weight of fuel used in one year is very small compared to the welghts of the satellites) 


\section{A. EXXPENSIONS OF BUSCH'S SOLUTION}

In Chapter III, Section D, Part 2 It was mentioned that Busch, using PMP and a reverse-time integration method, has found a nearly minimum-fuel optimal feedback control law which for a "stable" satellyte results in acquisition to a region much larger (6.3 $\times 10^{-3}$ radians) than $\mathrm{s}^{+}$(see e g. Figure (4.20)). The control law works well for $x_{1} \leqslant 0.5$ radians, $I=1, \ldots, 6$, but, for some large Inztzal angles (about $60^{\circ}$ ), the coupling between the controlled roll motion and the controlled yaw motion via the controls through the putch angle and the large value of $\cos ^{-1} \theta_{2}$ in the second of Equation (2.14) have a destabllizing effect. The Busch control law results in an acquisition time of about the time of one-half orbit from initial angles of about $25^{\circ}$. Acquisition from larger angles requires much longer acquisition times, and, in some cases when the satelilte is ' unstable" (e.g., satellite (3)) and the lnitial angles are large, acquisition takes a much longer time. (In some cases the motion can become uncontrollable so that acquisition cannot be accomplished.)

Thus, for the controllers of the satellites' motzons to perform satısfactorlly, the Busch control law must be modified so that (1) the region $\mathrm{S}^{+}$can be acquared even if large imperfections exist in the controllers, (2) the time of acquisition from $x_{1} \leqq 15$ radians, $1=1, \ldots, 6$, Is the time of one-quarter orbit or less, and, (3) "unstable" sateliltes such as satelizte (3) are controllable for large inztial angles.

1. Via Phase Plane Techniques

In component form the Busch control law can be written as

$$
\begin{aligned}
& u_{I}=\left(-N_{1}^{\prime} / 2\right)\left(\operatorname{SGN}\left(x_{2}\left|x_{2}\right|+2 x_{1}\right)+\operatorname{SGN}\left(x_{2}+0.1 x_{1}\right)\right) \\
& u_{2}=\left\{\begin{array}{cc}
-N_{2}^{2} \operatorname{SGN}\left(x_{4}\right) & \text { IF } x_{4}^{2}>1.7 \times\left|x_{3}\right| \\
0 & \text { IF } x_{4}^{2}<1.7 \times\left|x_{3}\right|
\end{array}\right.
\end{aligned}
$$




$$
u_{3}=\left\{\begin{array}{cc}
-N_{3}^{\prime} \operatorname{SGN}\left(x_{6}\right) & \text { IF } x_{6}^{2}>2 \times\left|x_{5}\right| \\
0 & \text { IF } x_{6}^{2}<2 \times\left|x_{5}\right|
\end{array}\right.
$$

where $u_{1}, I=1,2,3$, Is the nondimensional acquisition control torque measure numbers, $\mathbb{N}_{I}^{\prime}=1$, and $S G N()$ Is the signum function. Figure (5.1) shows sketches of the two types of control switching curves in the phase planes. It should be noticed that $\mathbb{N}_{I}^{2}, 2=1,2,3$, are all unzty, and, therefore, the parabolic switching curves in the yaw and pitch phase planes are the same as for the manumu-fuel control of $x^{\prime \prime}=u$ when $\left|u_{\max }\right|=1.0$. Thus, if the magnztude of the control components are Increased to shorten the acquisition time, an obvious modification to the Busch control law is the modification of the parabollc switching curves which makes them compatible with the larger values of $\mathbb{N}_{1}^{\prime}, 1=1,2,3$, I.e., In the equation $x^{\prime 2}= \pm a x$, the coefficient $a(=2 \mathbb{N})$ is modified with $\mathbb{N}$. Clearly, $N_{1}=1.0,1=1,2,3$, are too small to glve acquisition from $\left|x_{1}\right|=1.5$ radians, $1=1, \ldots, 6$, in a $\tau$-interval of $1.571 . e$. , in the time of one-quarter orbit. Consider acquisition from $\left(x, x^{2}\right)=$ $(1.5,1.5)$ for $x^{\prime \prime}=u$ in minumum time It Is not difficult to see that for $\left|u_{\max }\right|=\mathbb{N}=10$ the acquisition time Is $\tau_{f}-\tau_{0}=095$. From a study of the minimum-time acquisition of other simple systems $1 . e$. , $x^{t 1}+a^{2} x=u, a^{2}>0, a^{2}<0$, It was found that minumum-time acquisition Is accomplished in $\tau_{f}-\tau_{0}=1.57$ If $N$ was large enough. In particular the required values of $\mathbb{N}$ ranged from a little larger than 2.0 to almost ten (depending on $a^{2}$ ). Thus, It seems that $\mathbb{N}_{1}^{\prime}=10,1=1,2,3$, are nearly lower bounds for the magnztudes of the control components for minimum-time acquisition. For minımum-fuel acquisition $\mathbb{N}_{2}^{2}=10,1=1,2,3$, seem, certalnly, to be lower bounds. Since values of $\mathbb{N}_{1}^{\prime}, 1=1,2,3$, which are much larger than ten (say, one-hundred) can result in very poor performance (such as higher cost and no acquisition to $\mathrm{s}^{+}$) when the usual Imperfections in the controller (e.g. time delays) are present, the inatial value assumed for each of $\mathbb{N}_{1}^{1}, 1=1,2,3$, was taken as ten. (In the next part It Is seen that "splraling in" to $s^{+}$from $x_{1} \approx 0.1,1=1, . ., 6$, should be avolded for low fuel cost. "Spıraling In" Is avolded if 

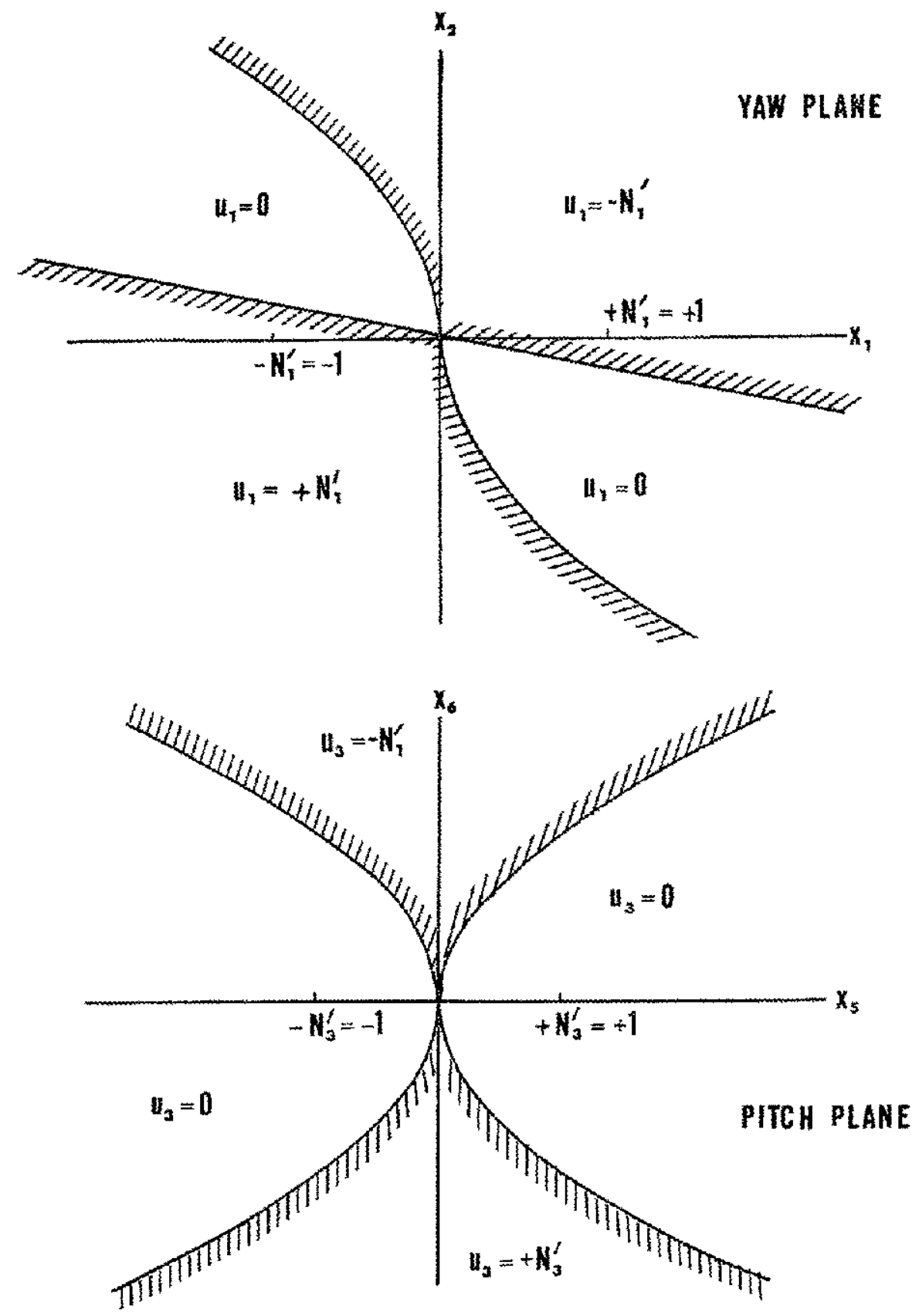

Figure 5.2. Swtching curres of the Buseh Control Iaw in the Taw and Pxteh Planes. 
$\mathbb{N}_{1}^{1}, I=1,2,3$, are large enough $(\geqslant 10)$, since the parabollc switching curves are nearly colncident with the "zeroung" part of a trajectory from a pcint on a parabolıc switching curve with $\left|x_{1}\right| \approx 0.1,1=2,4,6$. )

Since Busch was successful in using a straight line for the other swatching curve in the phase plane of the least "stable" motion and since the switching loglc for such a curve is very simple, stralght lines with various slopes were studied as possible swatching curves. Phase plane methods with the constraints on the time of acquisition and fuel cost were used inztially in the study in the hope of saving computer time. Since the Inztzal values of the state variables considered were no larger than 1.50 radians, the control-on part of the phase plane trajectorzes rary nearly coincided with parts of parabolic curves such as $x_{2}^{2}=2 N_{1}^{1} x_{1}$ If $\mathbb{N}_{1}^{*} \geqslant 10$. Thus, since the behavior of the phase plane trajectories was generally known when the trajectory was in a control-on region, the phase plane analysis was limited mainly to the control-off regions

The phase plane analysis consisted of (1) the calculation of the slopes of control-off trajectories at numerous points in the phase planes by assuming the trajectories in the other two phase planes to be varıous nominal points and (2) for switching lines of various slopes the estimation of the time between control-on intervals with the ald of $\Delta x_{1}=$ $\left(\tilde{x}_{1+1}\right) \Delta \tau_{\text {off }}, 1=1,3,5$, where $\tilde{x}_{1+1}$ Is the (Integral) mean rate value. Equations $(2.14)$ were used for $\left|x_{1}\right| \approx 1.0,1=1, \ldots, 6$, and equations (2.17) and (2.18) were used for $\left|x_{1}\right| \approx 0.1, I=1, \ldots, 6$. The worst possible values $\delta=\pi / 4$ and $\theta_{0}=\pi / 4$ (or $\frac{5 \pi}{4}$ ) were used in each case for each sctellite. The results of this analysis can be summarized as follows (1) the shope of the switching line which gave a maximum controloff time interval of $\Delta_{\tau}$ off $\approx 1.0$ also resulted in most cases in the lowest estimated fuel cost (the total control-on time for acquasition was estimated to be about 20-30\% or the time of acquisition 1.e., $\Delta_{\tau}$ on $\approx$ 0.3-0.5.), (2) if the motion was not very "stable" (e.g. satellite (1)), some of the smaller (In magnitude) slopes tried resulted in chatter motion whlch was very costly and time consuming (especially for $\left|x_{I}\right|<0.01$, $I=1,3,5$, where the sine forcing terms are most influential), and, (3) slopes of the swltching line whlch where much greater (about 10x) resulted In a much hlgher cost estimate (about $200 \%$ hlgher). The slopes of the 
switching lines which are expected to result in a satisfactory acquisition control law are given in Table 5.1. These slopes are given in Table 5 I for each phase plane of each satellite and are generally compromises which are arrıved at by placung the greatest emphasis on fuel economy and simpliclty. For example, the shope of the straight line of the type 2 swltching curves is larger than was estımated as needed for large angles. The estimated values of the slope for pitch of satellites (1), (2) and (4) for large angles ranged from about -0.75 to -1.5 , however, for small angles $\left(\left|x_{1}\right|<0.01,1=1,3,5\right)$ the magnitudes of the slopes were estimated to be about -6.0 . Thus, sance pItch must be "zeroed" faster than roll and yaw to avold detrimental coupling and since other curves which give a variable slope are not as simple, a siope of -2 is a compromise. In the next part of this section the maximum principle is used to check and/or offer modlfications to the control laws of this part.

\section{Vıa Pontryagın's Maxımum Prıncıple}

Using the reverse-time integration method, the maximum principle was applied to the acquisition problem. That is, the equations of motion (with the 'coast function" ovsimal control) and the adjoint equations were written in backwards time and integrated with the ald of the digital computer. (For the program see Appendlx F.) The solutions of the equations of motion were plotted as phase plane trajectorıes (1.e., projections of the trajectories) so that the control switching points in the phase planes could be easıly observed.

Since $\mathrm{S}^{+}$Is small compared to the scale used In the phase plane plots and since, by "smoothing" the corners of $\mathrm{s}^{+}$, the final (forward. tIme) adjolnt vector can span the six-dimensional vector space, the origin of the state space was considered to be the final goal instead of $\mathrm{s}^{+}$. That 1 , since the orlgın of the state space and $s^{+}$are almost equivalent with respect to PMP and since computationally it is simpler to take $\underline{x}\left(\tau_{f}\right)=\underline{0}$, the orıgin was acquired.

The IInearized equations of motion [Equations (2.17) with the aerodynamc torque terms included for satelinte (4)] were used in this application of the maximum principle. The reasons for using the linearized equations are (1) the linear and nonlinear optimal solutions agreed 
TABTE 51 MODIFIED VERSTONS OF BUSCH'S SWITCHING CURVES

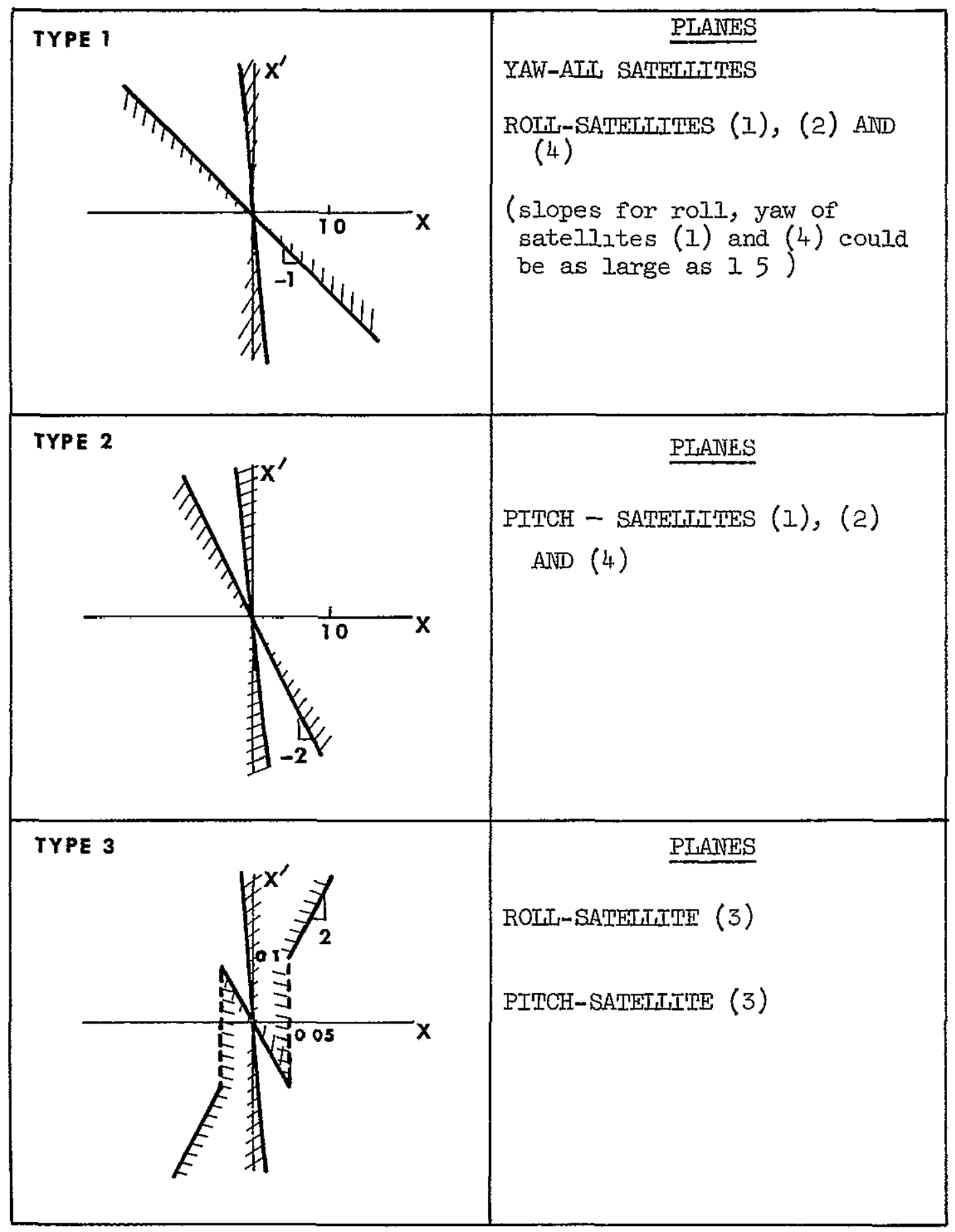


verry well for $\left|x_{1}\right|<0.1,1=1,3,5$, in the cases tested*, (2) for $\left|x_{1}\right|>0.1,1=1,3,5$, the nonlinear equations are highly coupled and result in erratic control switching points (since control switching for one axzs depends on the motzons of the other axes), and (3) the computer time for each solution run of the nonlinear system of equations was too great (about ten minutes) to be practicable (since many solutions were needed).

Some typical solutions of the linear optimal acquisition equations are given in graphical form in Figure 5.2. It should be noted that no trajectorzes "spiral $I n$ " toward the orıgın. "Spıralıng In" Is not a characteristic of an optımal trajectory in the case $\mathbb{N}_{I} \geqslant 10,1=1,2,3$. Indeed, for such large values on $\mathrm{N}_{1}$ three switches in each control component is generally a maximum number in the time interval of $\tau_{f}-\tau_{0}=$ I.57 since the adjolnt variables on which the switches depend generally give (In backward tIme) a short control-on Interval followed by a long control-off interval or with a short control-off interval and then a long control-on interval).

In Table 5.2 are glven some of the data obtalned from the thirtytwo backward time solutions. In particular Table 5.2 presents the range of values for the slopes of the swltching lines whych pass through the origin and the point at which the control swatches from off to on. Also presented are the consensus values (for IInes drawn through the greatest number of switching points) of the slopes and the best values for stablilzation of the motion.

In the next section, Section $B$, the final states of the backward time runs are used as the Inztial states in the solutions of the full nonlinear equations of suboptimally controlled motion. These forward time solutions of the nonlinear equations of suboptimal controlled motion and their fuel costs are compared with optimal linear solutions and their costs in the performance evaluation chapter, Chapter VI.

\section{B. ACQUISITION CONTROL IAWS WHICH PERFORM SATISFACTORIIY}

FAIso, Busch found very good agreement in many comparisons 


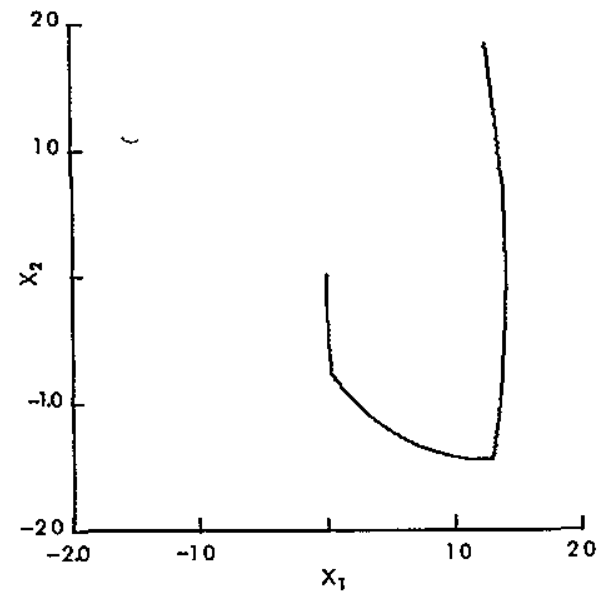

\section{YAW}

ROLL
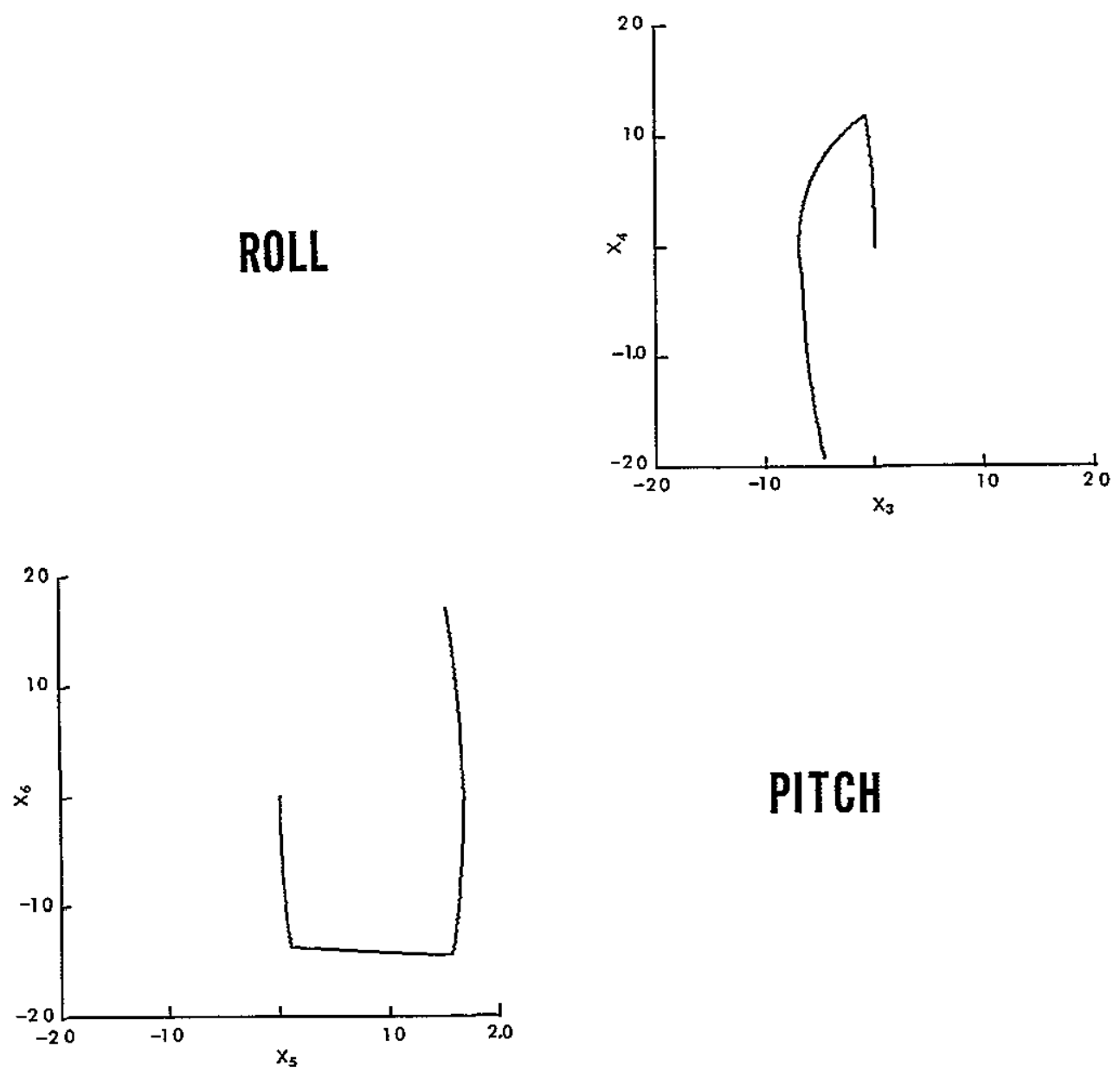

\section{PITCH}

a Satellite (1), $J=819, \tau_{f}-\tau_{0}=142, \theta_{0}=\pi / 4$.

Figure 52 Optimal (IInear) Acquistition Solutions 


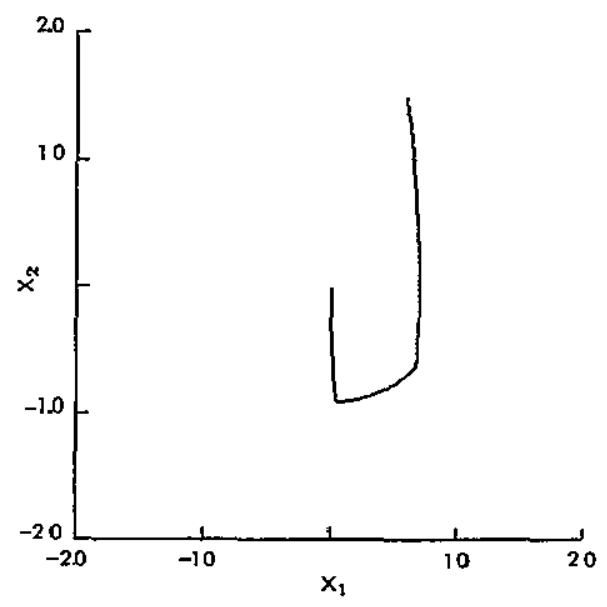

\section{YAW}

ROLL
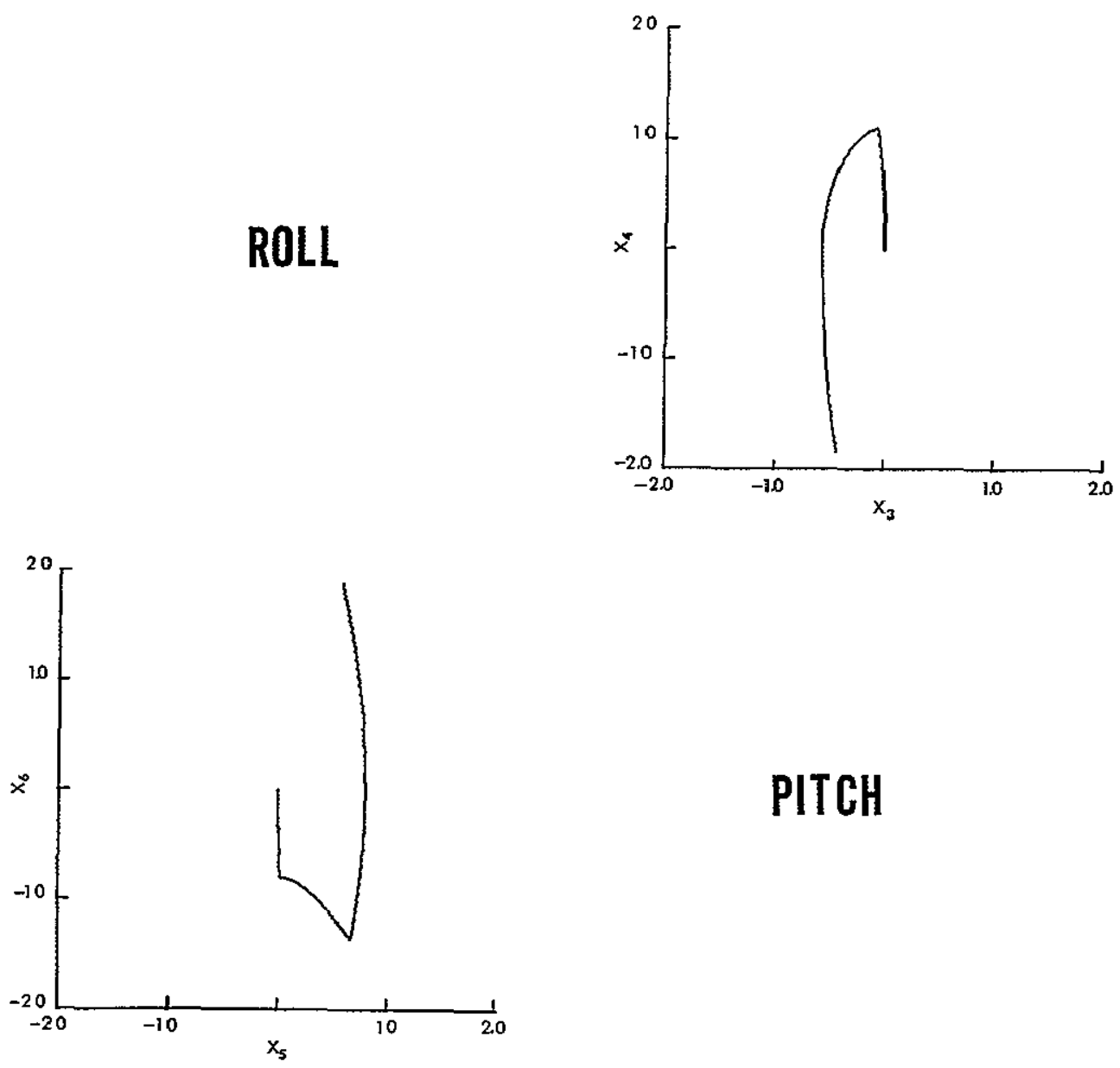

\section{PITCH}

b. Satellite (2), $J=892, \tau_{f}-\tau_{0}=132, \theta_{0}=\pi / 4$.

Figure 52 Contınued 


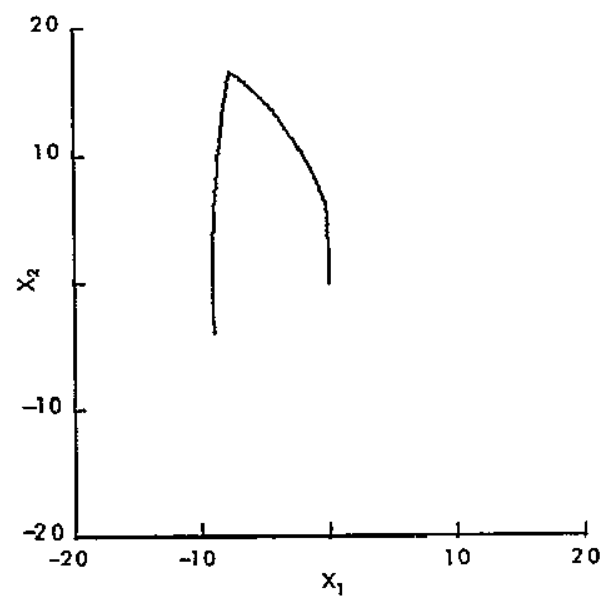

YAW

ROLL
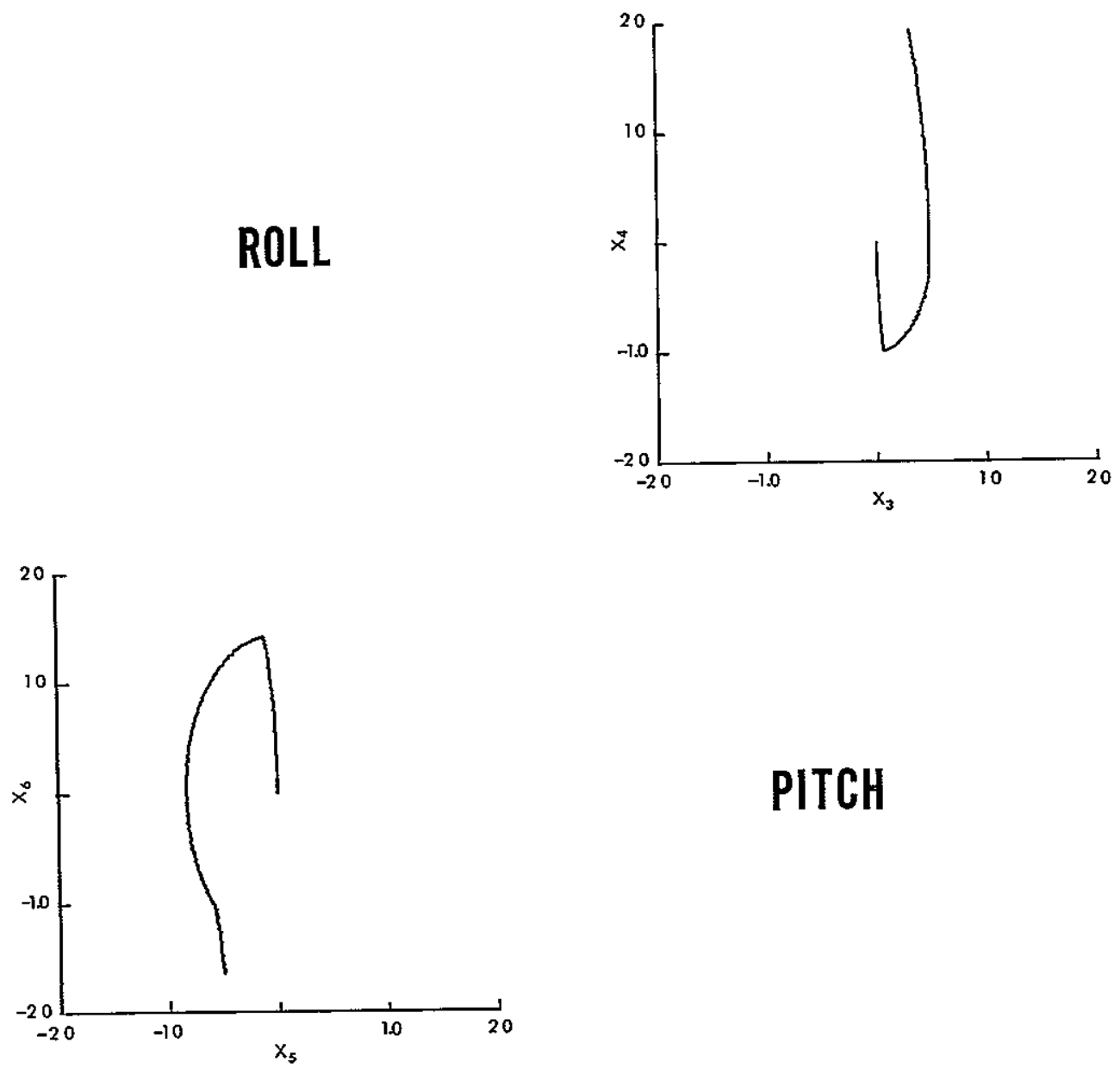

\section{PITCH}

c Satellite (3), $J=603, \tau_{f}-\tau_{0}=146, \theta_{0}=\pi / 4$

Figure 52 Contınued 


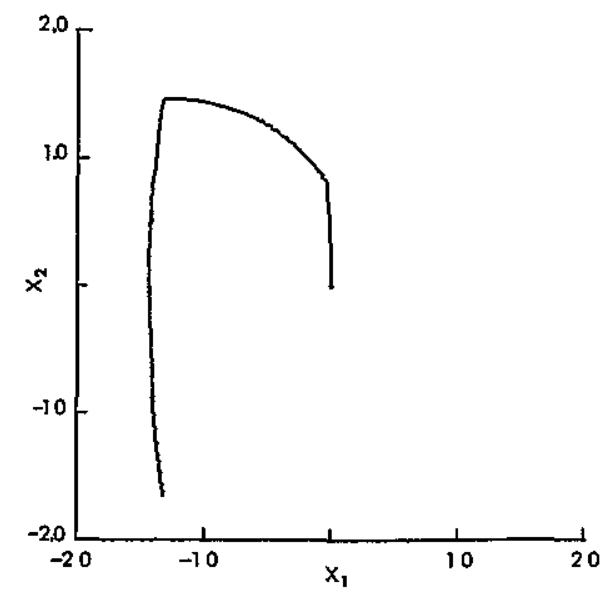

\section{YAW}

ROLL
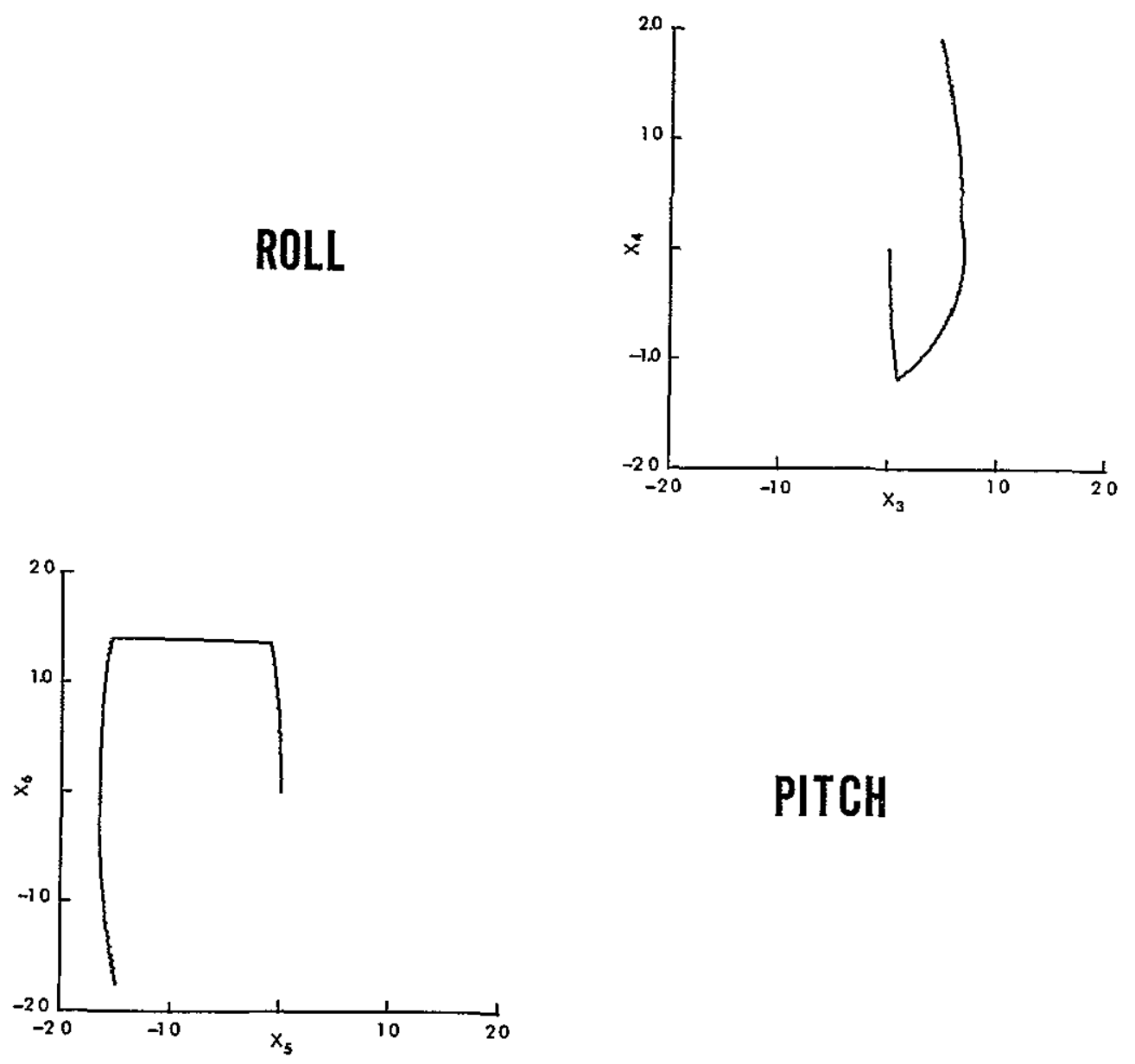

\section{PITCH}

d. Satellite (4), $J=8.73, \tau_{f}-\tau_{0}=1.42, \theta_{0}=5 \pi / 4$

Figure 5 2. (Continued) 


\begin{tabular}{|l|l|l|l|l|}
\hline \multicolumn{2}{|c|}{ TABIE 5 2} & \multicolumn{2}{c|}{ SLOPES FOR THE STRAIGHT IIINE SWITCHING CURVES AS } \\
\hline OBTATNED FROM THE OPTIMAI (IINEAR) SOLUTIONS
\end{tabular}

* Depends on initial condition of adjount variables, but, generally if yaw $\sim-\infty$, then $\operatorname{rol} 11-10$ and vice versa 
In Section A, Part 1 three types of phase plane swltching curves (Table 5.1) were suggested by the phase plane analysis as possible "Improvements" * of the Busch swztching curves In Part 2 of the last section the linear equations for an optimal acquisition solution were Integrated in backward time. Some of the data optalned from these integrations are presented in Table 5.2.

If the consensus values for the slopes of the switching lines (Table 5.2) are compared to the slopes given in the sketches in Table 5.1, good agreement is found in about half of the cases. The exceptions are pitchsatellite (I), roll-satellite (2) pltch-satellıte (4), whlch are each off by nearly a factor of two, and roll or yaw of satellites (1), (3) and (4), whlch are mostly off by a sign. If the best values for stablizzation (the greatest slopes obtalned from the optimal solutions) are compared to the slopes of Table 5.I, the agreement is found to be good in every case.

Of the two types of switching curves, the parabollc curves have the smallest deviation from the optimal. ThIs Is, of course, expected for control magnitudes of ten or greater. From Figure 5.2 it is clear that the parabolıc switching curves will work very well when $\left|x_{1}\right|, 1=1, ., 6$, are small, however, for large angles and rates it is possible that some modificatıons will be needed.

The followng control law was used in the Imitial tests of acquisition of the sateliltes from large angles [using the nonlinear equations of motion, (2.14) - (2.16)]

$$
\begin{aligned}
& u_{1}=\left(-N_{1}^{\prime} / 2\right)\left\{\operatorname{SGN}\left(x_{1+1}\left|x_{1+1}\right|+20 x_{1}\right)+\right. \\
& \left.\operatorname{SGN}\left(x_{1+1}+M_{1} x_{1} \operatorname{SGN}\left(Q_{1}-\left|x_{1}\right|\right)\right]\right\}, I=1,2,3
\end{aligned}
$$

where $M_{1}$, the negative of the slopes, and the "change-In-slope" factor $Q_{I}, 1=1,2,3$, were as gIven in Table 5.3 (If $Q_{I}$ IS Iarge, SGN $\left(Q_{I}-\left|x_{1}\right|\right)$ Is posıtıve for all $x_{I}$ and has essentially no effect ) Using some of the final conditions (backward time) of the optimal

*Busch consldered only one "stable" satellate. Here, conslstent acquisltion to a smaller region from larger angles is obtalned for four ("stable" and "unstable") satellites. 
(IInear) solutions for Inztial conditions, the full nonlinear equations with the control given by (5.2) and Table 5.3 were Integrated with the ald of the digital computer. Since some chatter motion was expected along the stralght swatching lines in some planes, a time delay was built into the control. The time delay was intially simulated by making the control a function of the value of the state at the end of the previous step of Integration. The integration and the plotting (by the Stanford Cal-Comp Plotter) were carried out in two steps so that the small detalls of the phase plane plots could be observed. First, the digltal computer integration proceeded from $\left|x_{1}\right| \approx 15,1=1, \ldots, 6$, down to $\left|x_{1}\right| \leqq 0.02$, $I=1,3,5$. Then, using the final values of the first run, the second. digltal computer run was made down to $\left|x_{1}\right| \leqq 2.0 \times 10^{-4}, 1=1, \ldots, 6$. (Acquisition from $S^{+}$to $S$ vas simulated on the analog computer See Flgures $(4.17)$ - (4.20).)

The inctial runs (for the four sutellites) were quite time consuming and only seven out of the twelve phase plane curves of each run appeared as expected. The trajectories in the phase planes of satellyte (I) did not proceed toward the orıgin as directly as those trajectorıes of Figure (5.2). The reasons for this were considered to be (I) the slope of the switching line in pitch was too small (In magnitude) and caused the acquisition in the pitch plane to be too slow, and, (2) the slow acquisition in pitch resulted in harmful cross-coupling between the roll control and yaw and the yaw control and roll The fuel cost for this run was $J=15.87$ and the tIme $\left(\tau_{p}-\tau_{0}\right)$ of acquisition was greater than 2.0. The inltial integration run of satellite (3) gave an unstable solution 1.e., after a short time the state space trajectory began moving away from the origin and continued untıl there was no hope of acquisition. This unstable behavior proved to depend somewhat on the inftial conditions, however, the main reasons for this bad performance are considered to be the same as the reasons for the poor performance in the initial run of satellite (1). The initial integration run of satellite (2) showed that early chatter motion in roll and yaw occurred. This early chatter motion appeared to be the reason for the cost and acquisition time being greater than expected. The (nondimensional) cost was $J=9.91$ and the (nondim mensional) time was 1.74 . The Initial solution for satelizte (4) was 
TABLE 53 THE PARAMELERS OF THE COIPTROT ILAW FOR THE INITIAL TWST

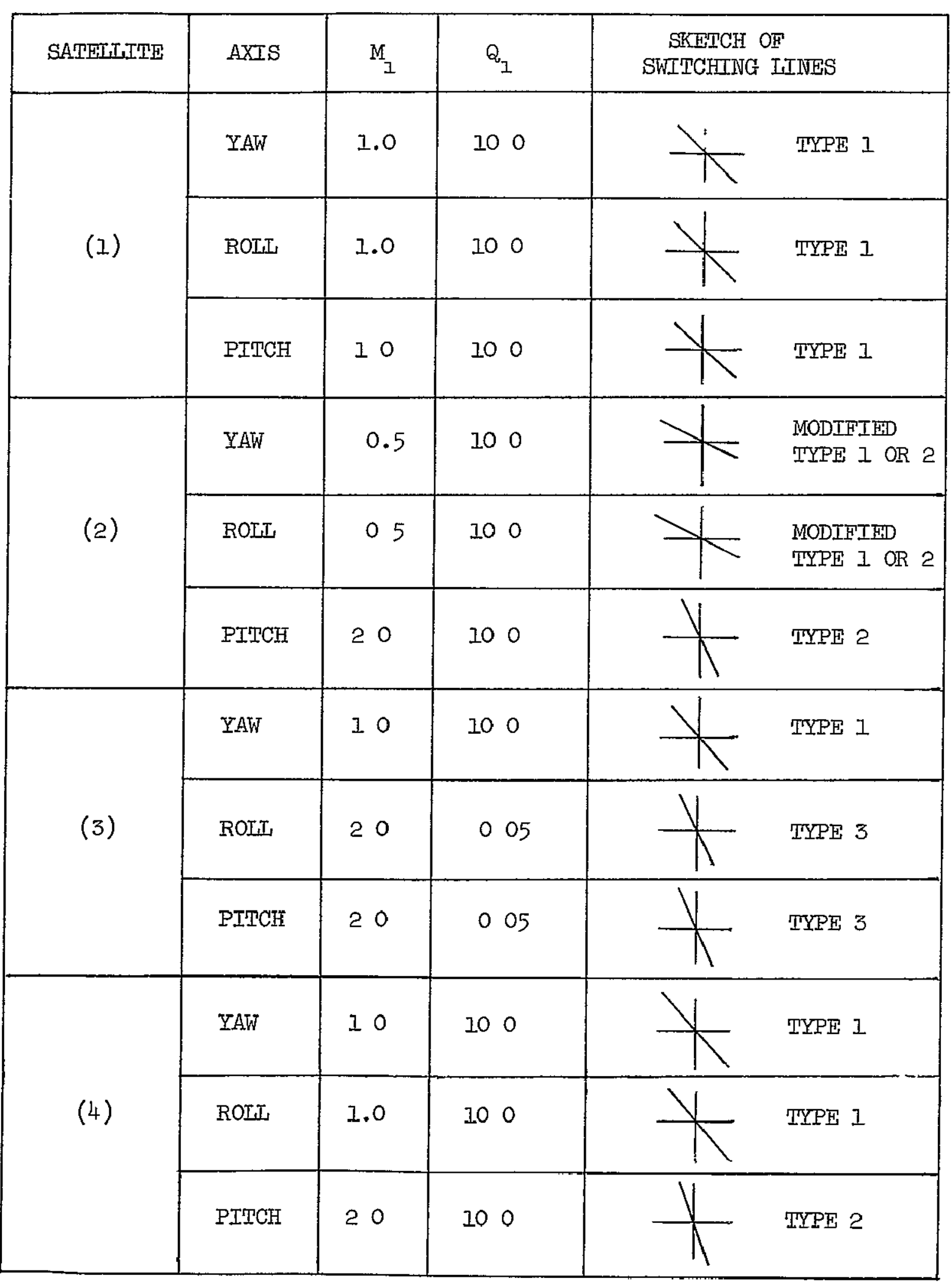


generally as expected except for a little early chatter motion in roll and yaw. The cost and time of acquisition compared very well with the optimal (linear) acquisition cost and time In all of the inltial runs (except the run for satellite (3) which did not result in acquasition) the parabolic control switching curves gave good results with only a slight amount of chatter motion to $\mathrm{S}^{+}$when in one case a "zeroung" part of a trajectory missed $\mathrm{s}^{+}$.

The following changes were made in the phase plane switching lines of satellites (1), (2) and (3), in the hope of improving the performance of their acquisition controls. (The initial run for satellite (4) Indicated that its control resulted in satisfactory performance so that no changes in the control for satellite (4) were made.) The slope of the switching line for pltch-satellite (I) was decreased from -1.0 to -20 In the hope of achieving quicker acquisition in pitch so that the detrimental cross coupling between roll and yaw would be eliminated. The slopes of the switching lines in roll and yaw for satellite (2) were decreased from -0.5 to -1.0 In an attempt to alleviate the early chatter motion in roll and yav and, thus, reduce the fuel cost and time of acquisltion. The slope of the switching line in roll-satellite (3) was reversed In sign for $\left|x_{3}\right| \geqq 0.05$ (by changing $Q_{2}$ to 100 ) and was Increased in slope from -20 to -10 . This modification was made in an attempt to acquire [for the unstable satellite (3)] the region $\mathrm{s}^{+}$(Since pltch for satellite (3) Is so highly "stable", the negatıve slope of the switching IIne in pitch was retalned.) In the remaining simulation runs of the suboptimally controlled nonlinear system the computation time was shortened by removing the fixed time delay and Introducing a more natural but slightly varyıng time delay. This, was accomplished by introducing the stepsize cutting limiter of Part 1, Section A, Chapter IV. For a stepsize of $\Delta_{\tau}=0002$, a time delay of about $t_{d}=0.125 \mathrm{sec}$ was burlt Into the control by limiting the number of cuts to four.* The accuracy was not significantly affected by thls limit The step size was taken as $\Delta_{\tau}=0.0002$ for the second part of each run. This gave an effectrve time delay of about $t_{\mathrm{d}}=0$ Ol sec during this part The smaller FRecall that $\tau$, the nondimens where $n$ is the average orbital rate and $t$ is the real time in seconds 
time delay was required when the trajectory encountered the region $\mathrm{S}^{+}$, since much larger time delays resulted in the overshooting of $\mathrm{S}^{\dagger}$. The larger time delay was used during the first part of each run to save computer time. The large time delay was consıdered a worst case.

The results of the second set of digital computer simulation runs for the four satellites with the new control laws [same as in Table 5.1 except for roll-satellite (3)] and the nev tzme delays showed defunte Improvements. Satelilite (1) acquired the region $\mathrm{S}^{+}$withln the time of one-quarter orblt and the fuel cost was reduced by about $25 \%$. The results for satellite (2) showed an improvement of about $10 \%$ in the fuel cost and a slight Improvement in the acquisition tIme. Satellite (3) was agaln uncontrollable but thls time It took longer for the trajectory to begin moving away from $\mathrm{s}^{+}$. New initial conditions (final conditions of an optimal (IInear) solution) were used in the test of the acquisition control of satellite (4). Agaln, the results for satellite (4) were satisfactory. The fuel cost and time of acquisition compared very well with that of the optimal (IInear).

The pltch control of satellite (3) was agaln modified. The positive slope of the switching IIne (when $\left|x_{5}\right|>0.05$ ) was changed to a negative slope in the hope of reducing the large angle coupling between the yaw control and roll and the roll control and yaw by rapldy reducing the pitch angle. Simulation of the acquisition of satellite (3) with the newly modified control was made for several initial conditions. These simulation runs gave satisfactory results although the fuel costs were 35-67\% greater than the optimal (IInear) fuel costs.

In Figure (5.3) - Figure (5.6) are shown phase plane plots of the phase plane projections of one of the worst case acquisition trajectories for each satellite. These are worst case trajectorles since they show more chatter than others and since the fuel costs and/or times of acquisition are generally greater. The right plot on each page of Figures (5.3) (5.6) Is an enlargement of the orıgın. Of course, these plots do not show all of the acquisition. Once a phase plane projection of $\mathrm{s}^{+}$[see Figure (4 17) - FIgure (4 20)] Is acquired by the phase plane projection of the acquisition trajectory, the station-keeping part of the controller [see FIgure (6.1)] takes over and performs the acquisition form near the 


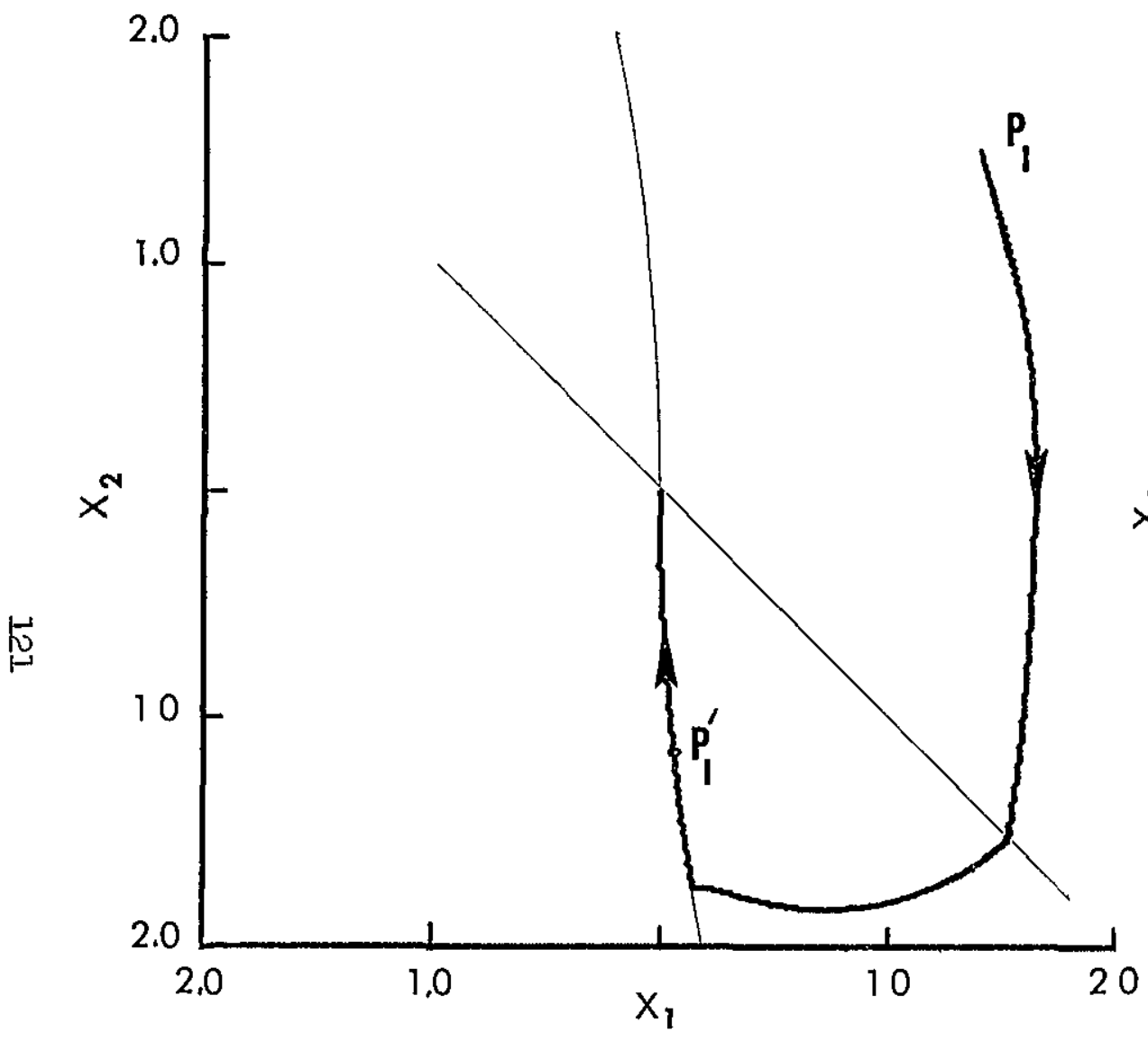

a. Large Yaw Angles

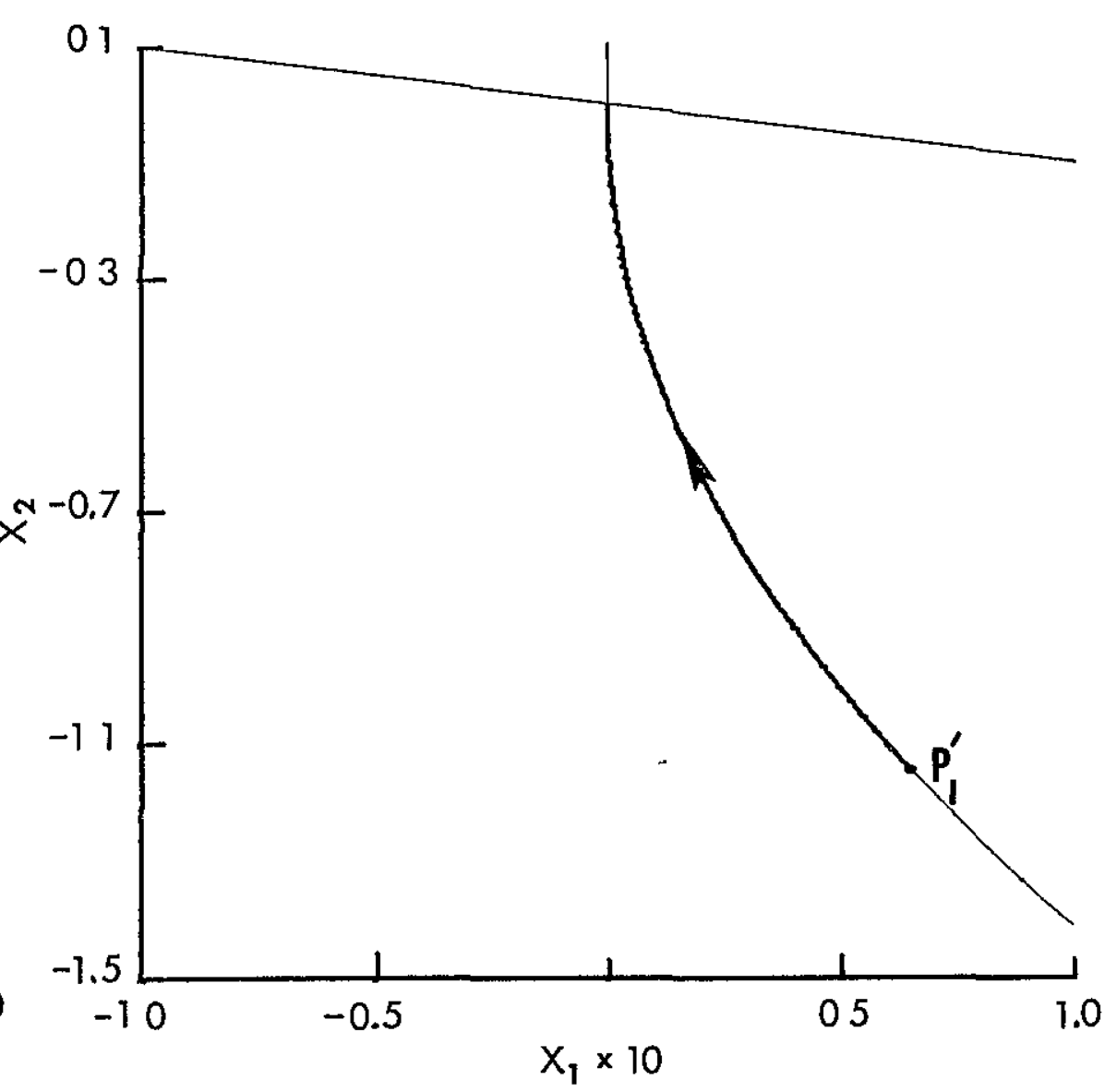

b Small Yaw Angles

Figure 53 Suboptimally Controlled Acquisition Motion of Satelizte (I), $J=1266, \tau_{f}-\tau_{0}=142, \theta_{0}=\pi / 4$ 


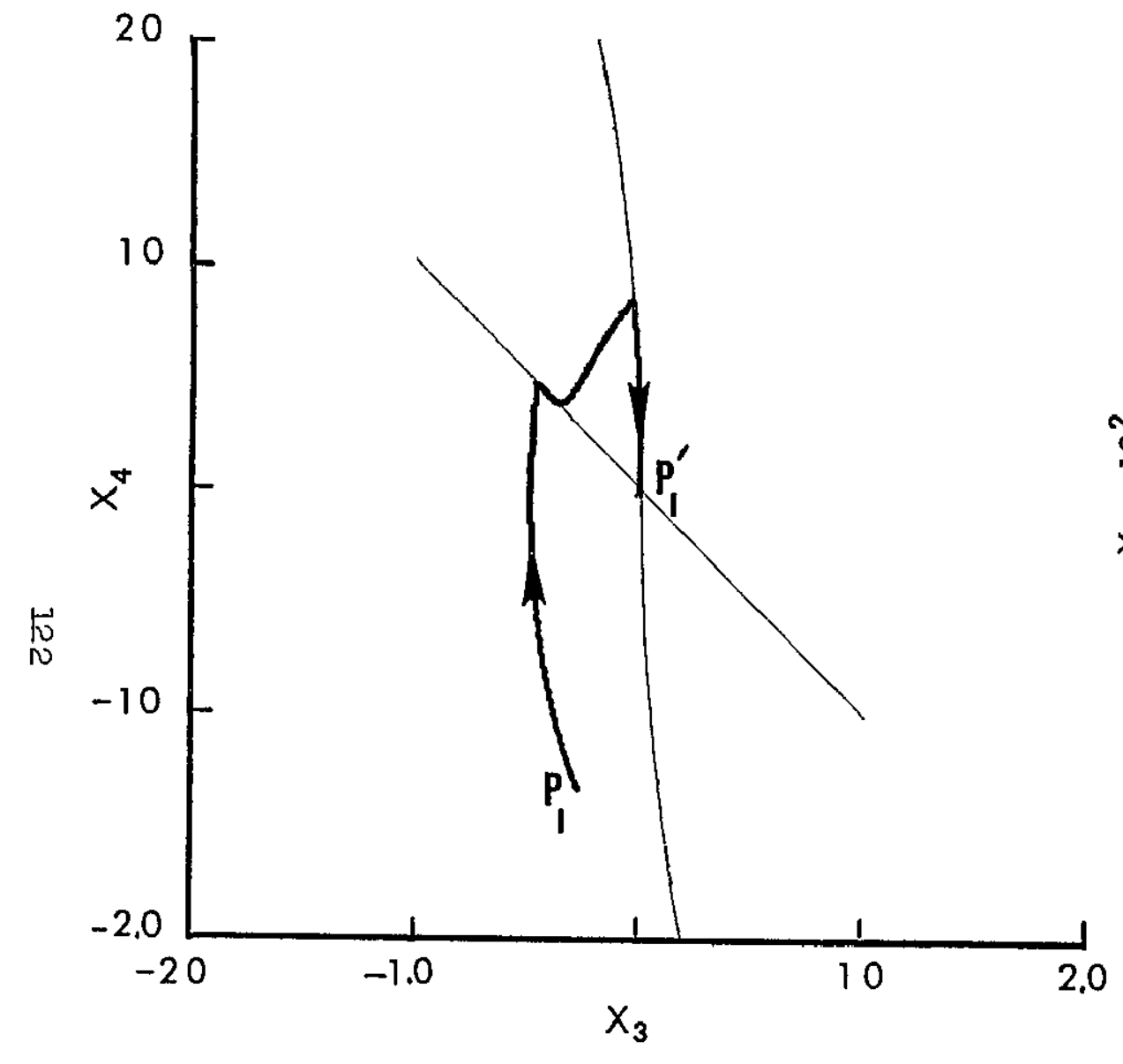

c Iarge Roll Angles

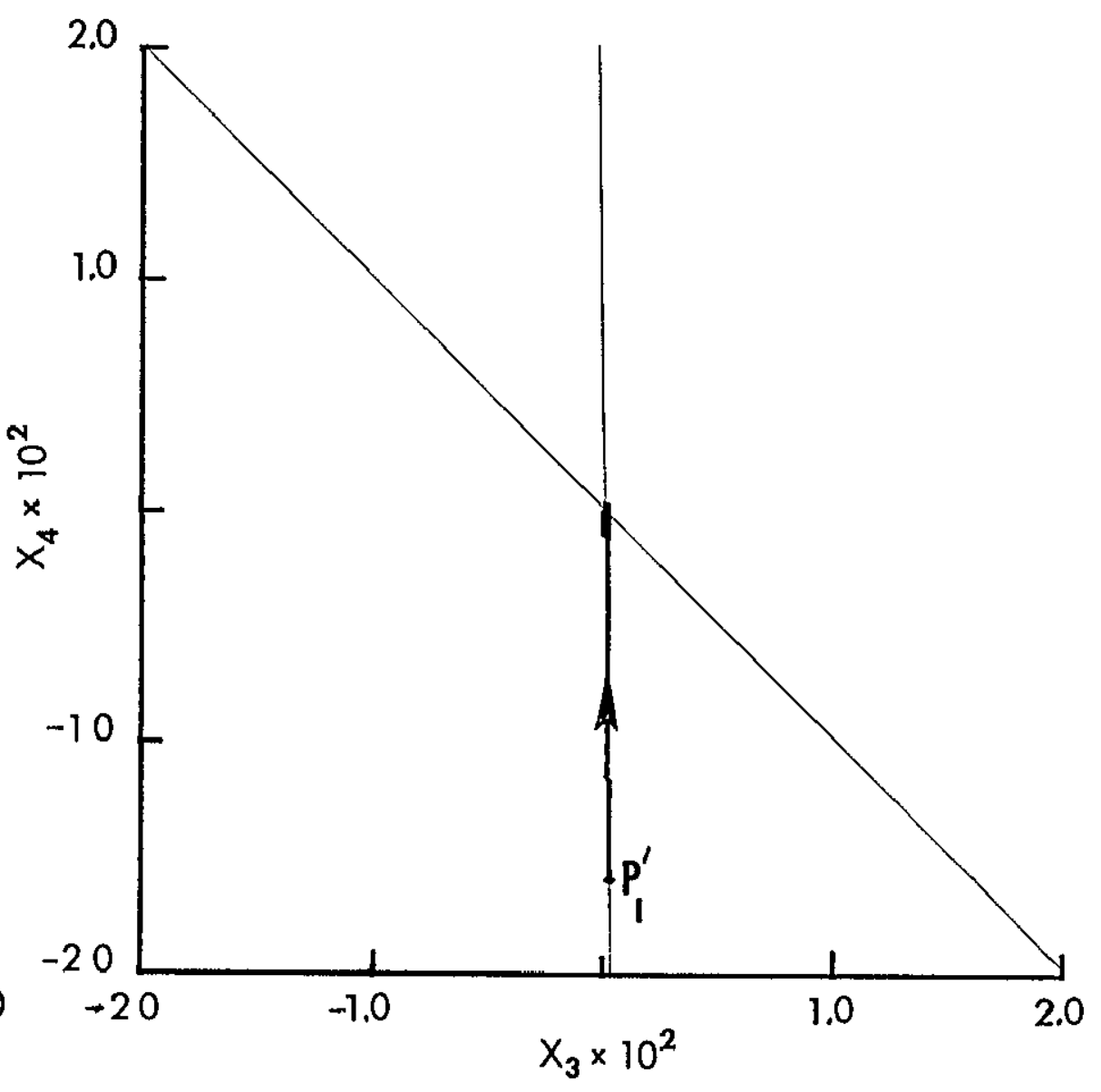

d Small Roll Angles

Figure 53 . Continued 


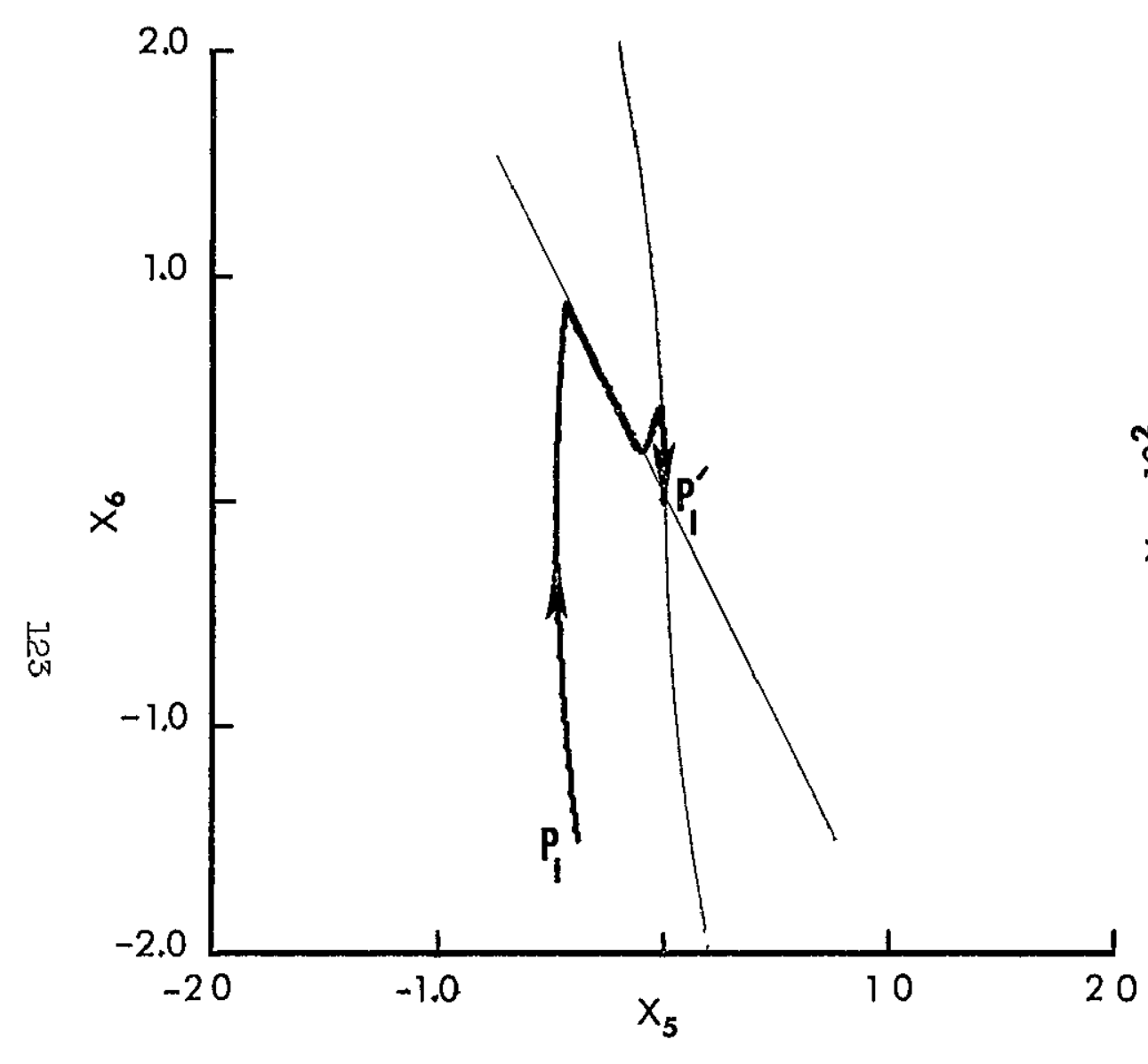

e Iarge Pitch Angles

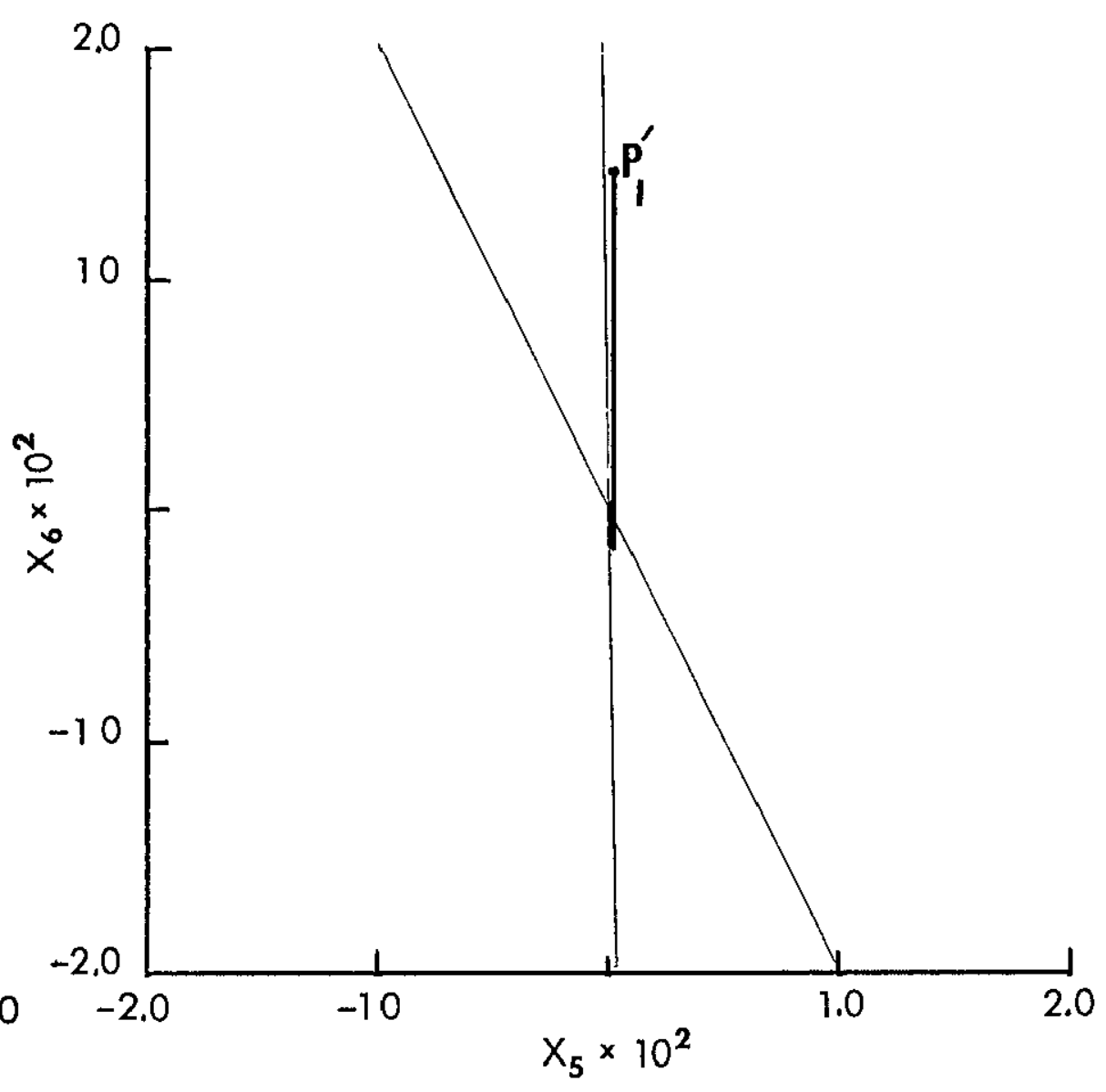

$f \quad$ Small PItch Anlges

Figure 5.3. Continued 


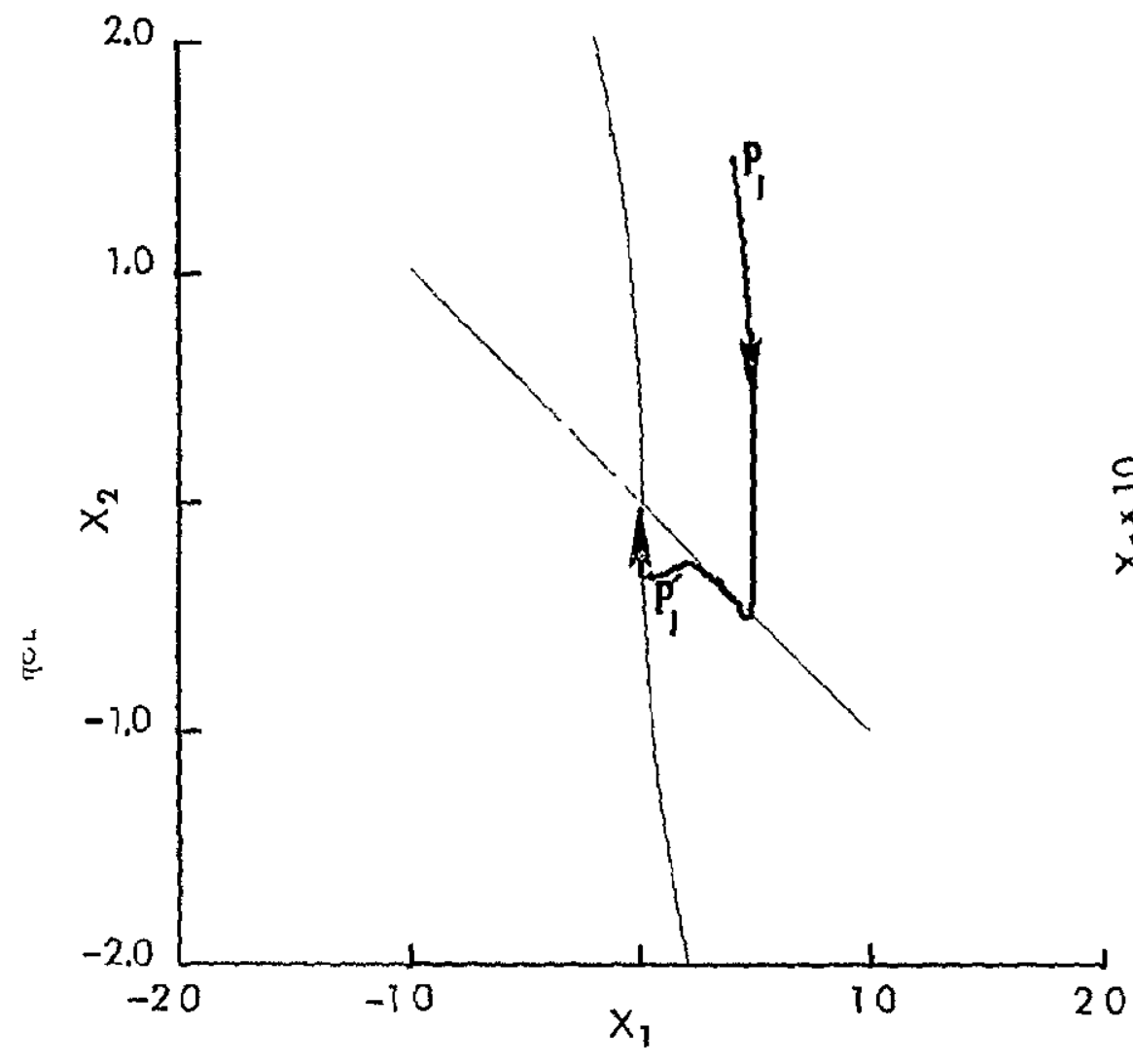

a. Iarge Yaw Angles

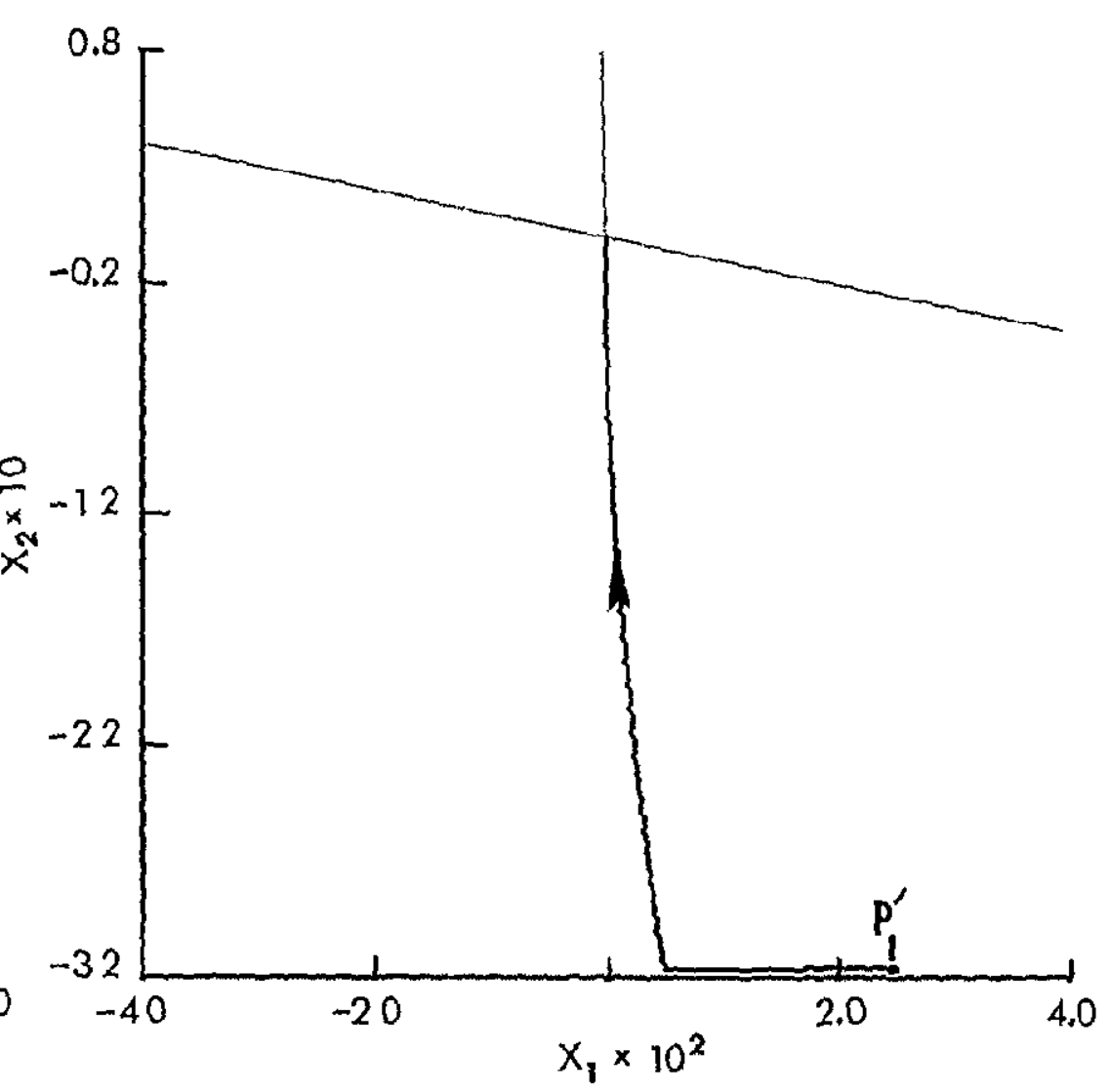

b SmaI1 Yaw Angles

Figure 5.4 Suboptimaliy Controlied Acquistition Motion of Satelizte (2), $J=9.07, \tau_{f}-\tau_{0}=169, \theta_{0}=\tau / 4$. 


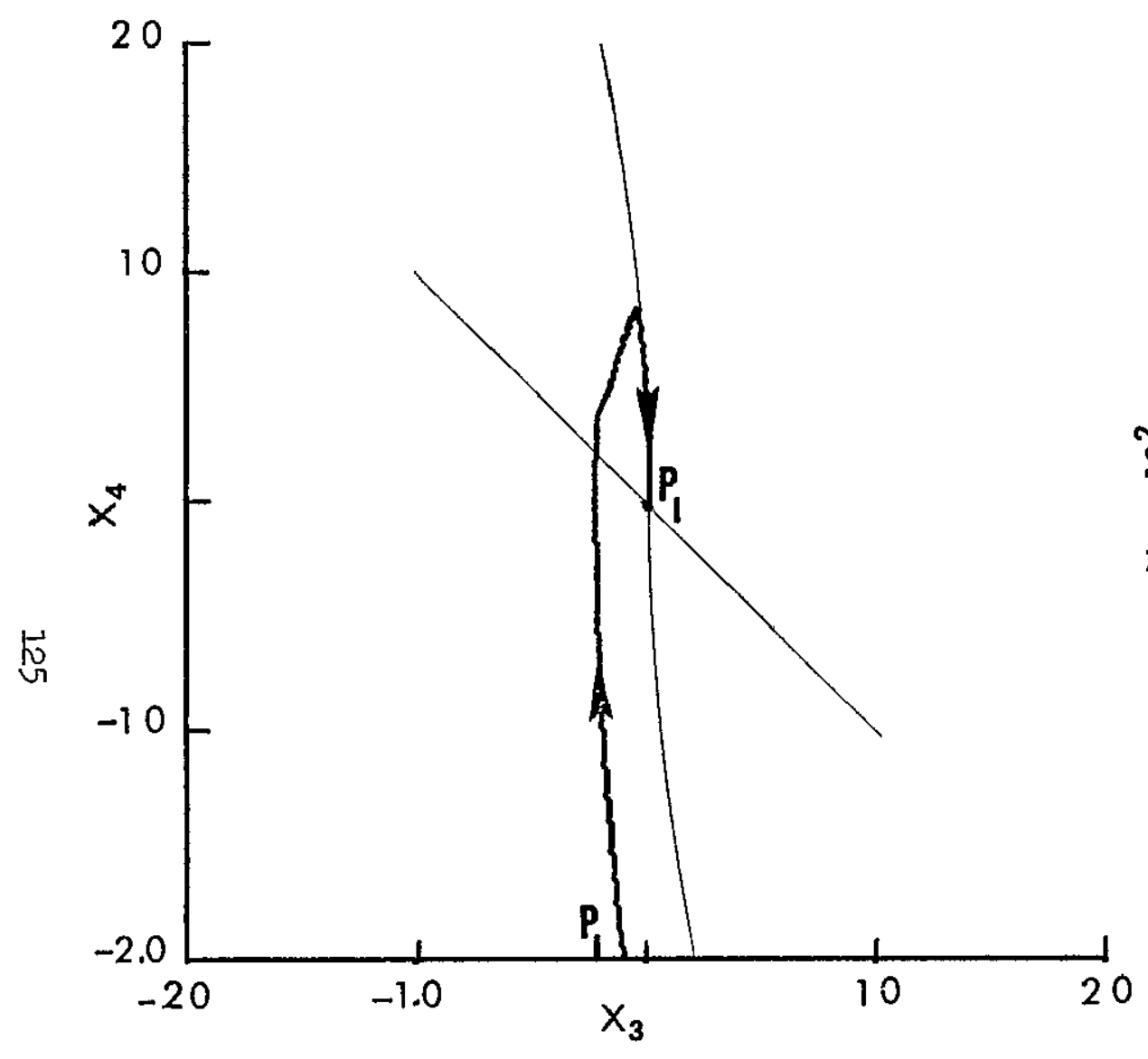

c. Large Roll Angles

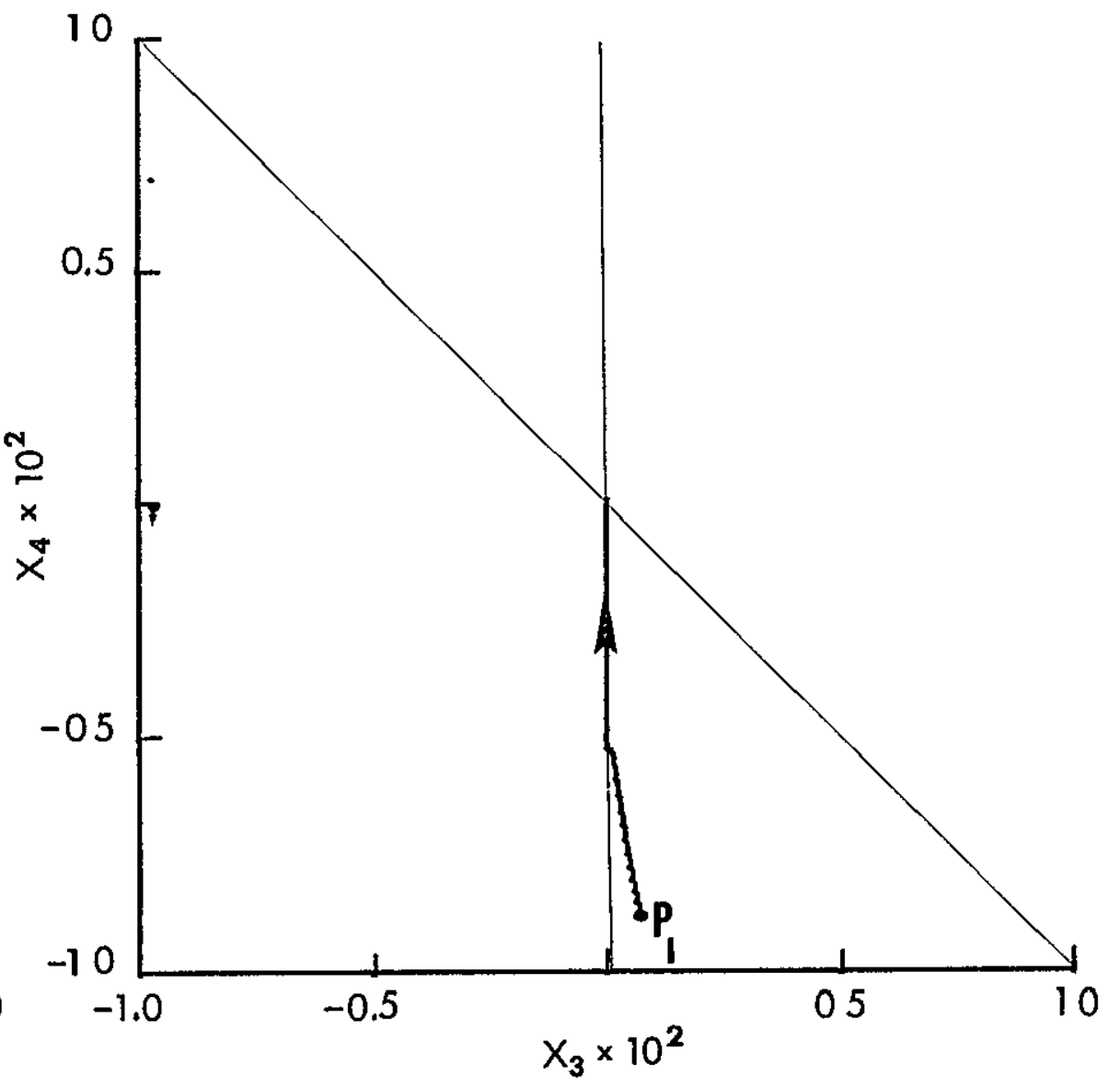

d. Small Roll Angles

Figure 54 Continued. 


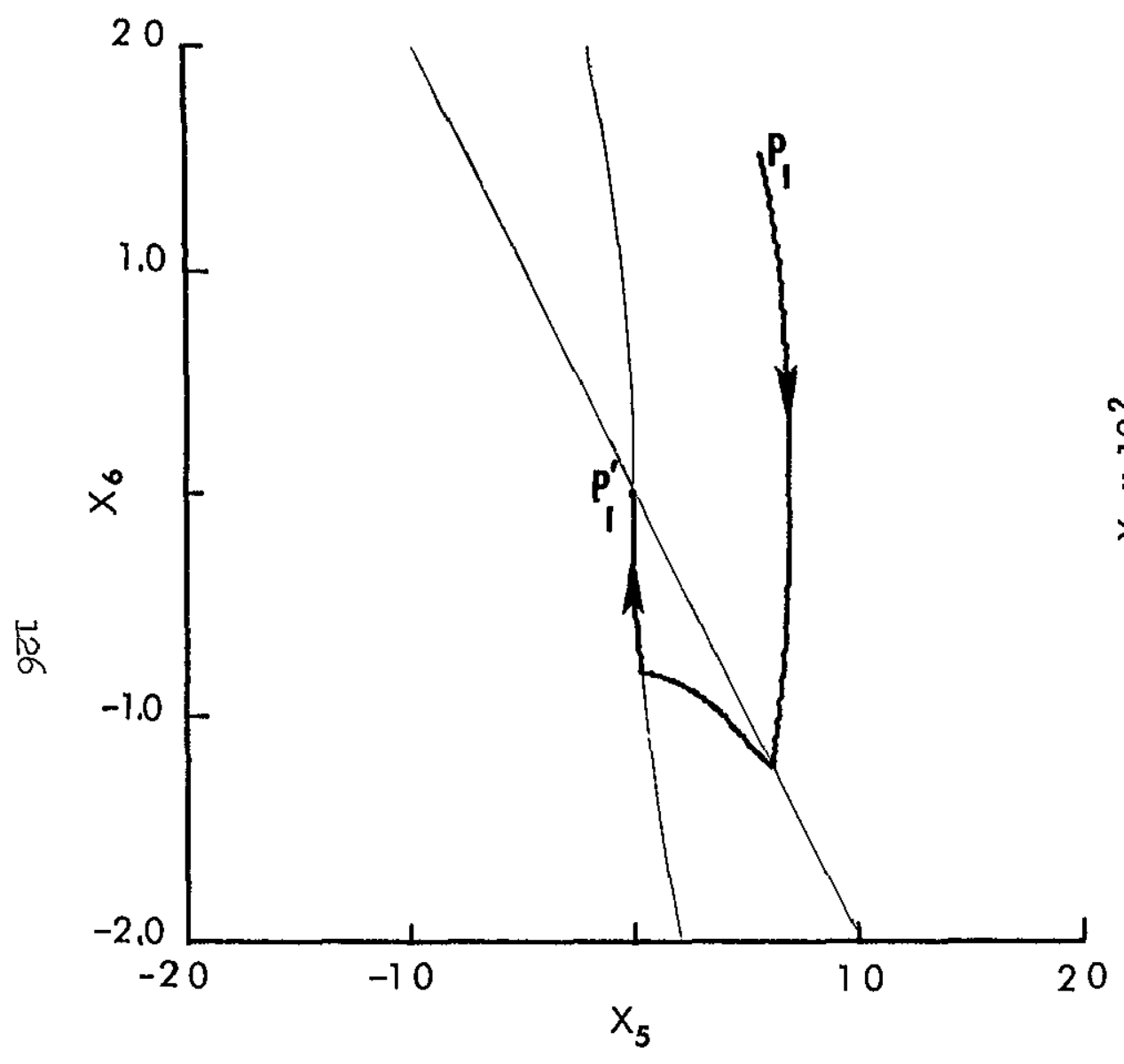

e Iarge Pltch Angles

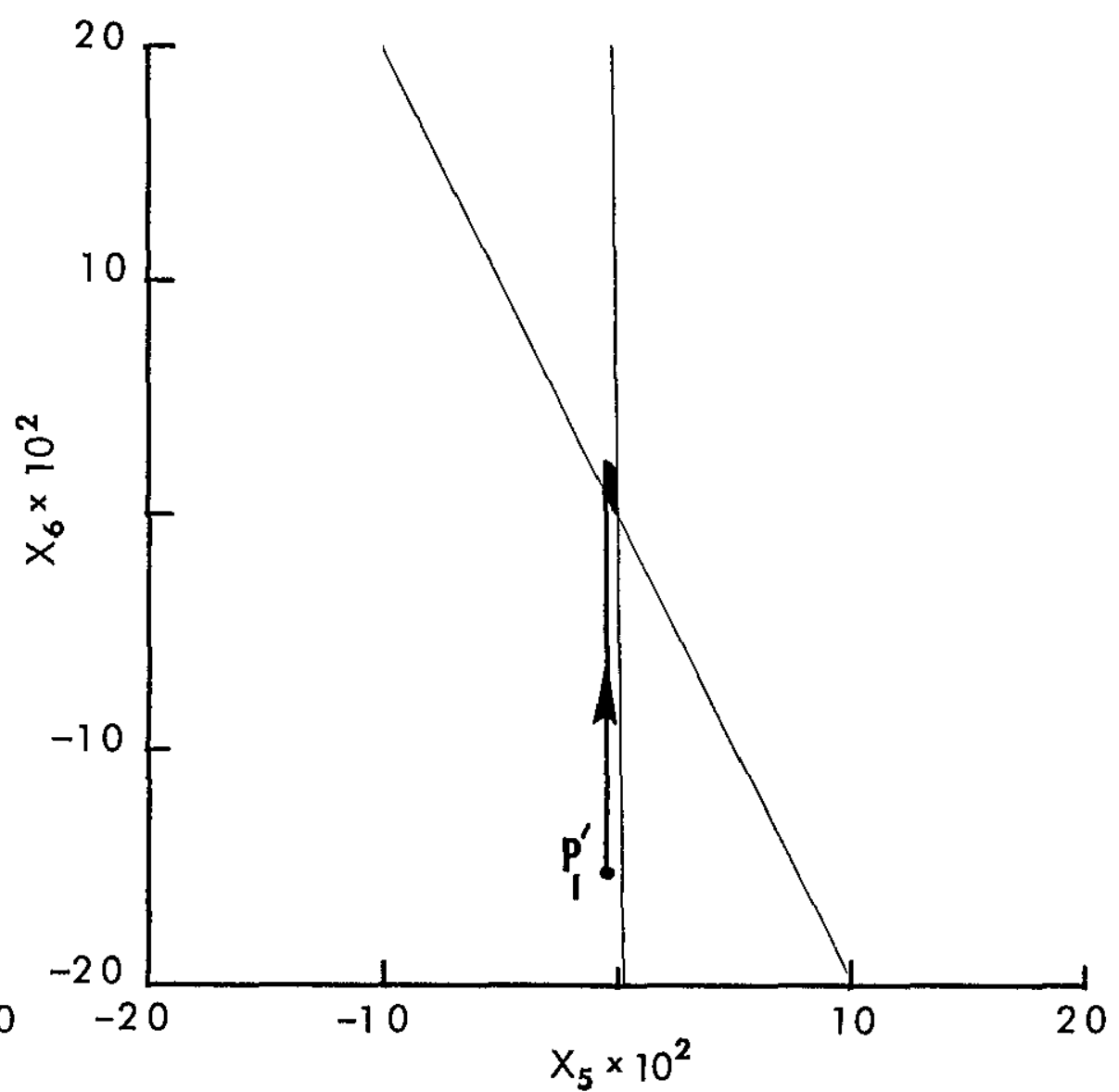

f Small Pytch Angles

Figure 54 Contınued 


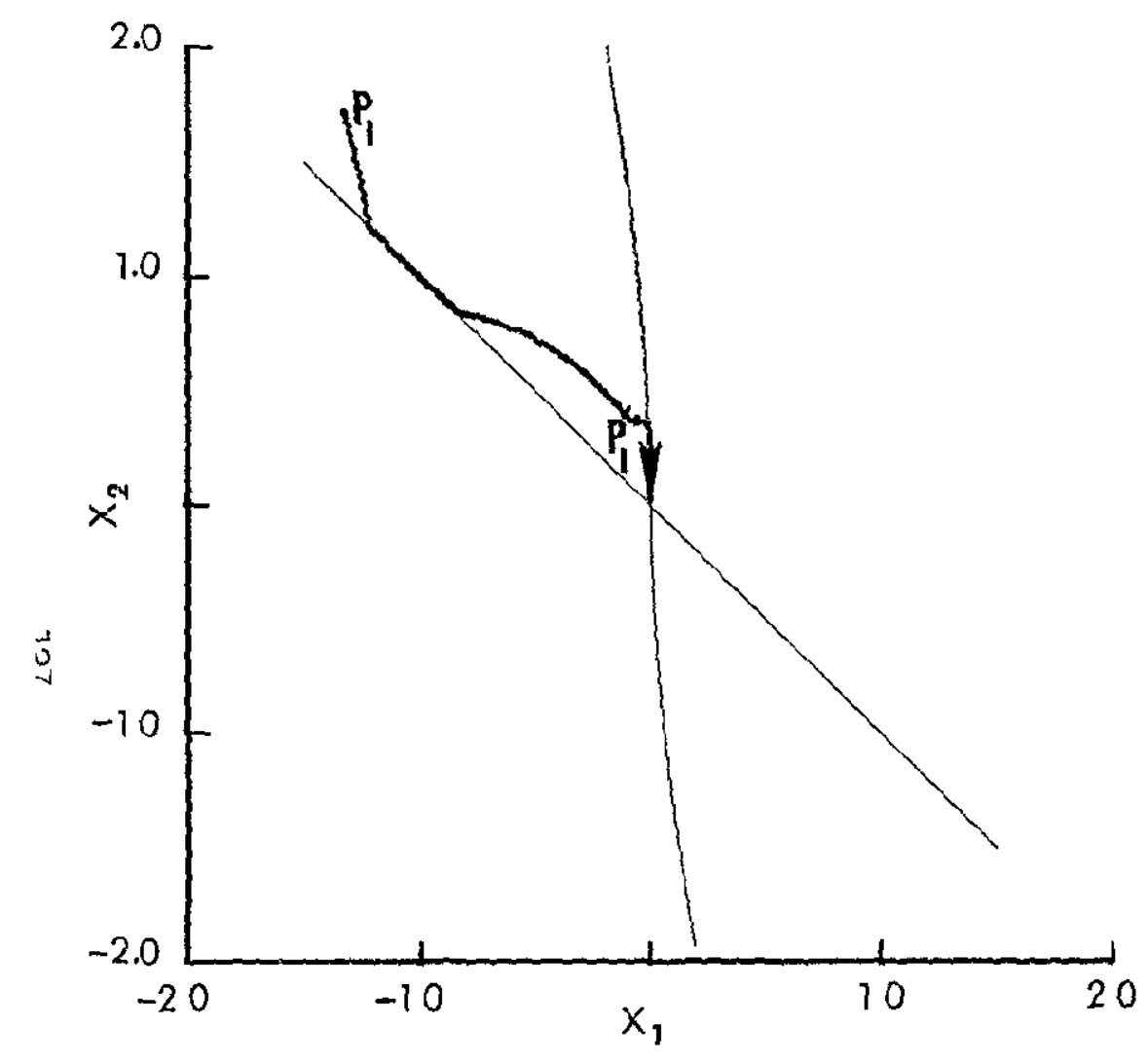

a. Iarge Yaw Angles

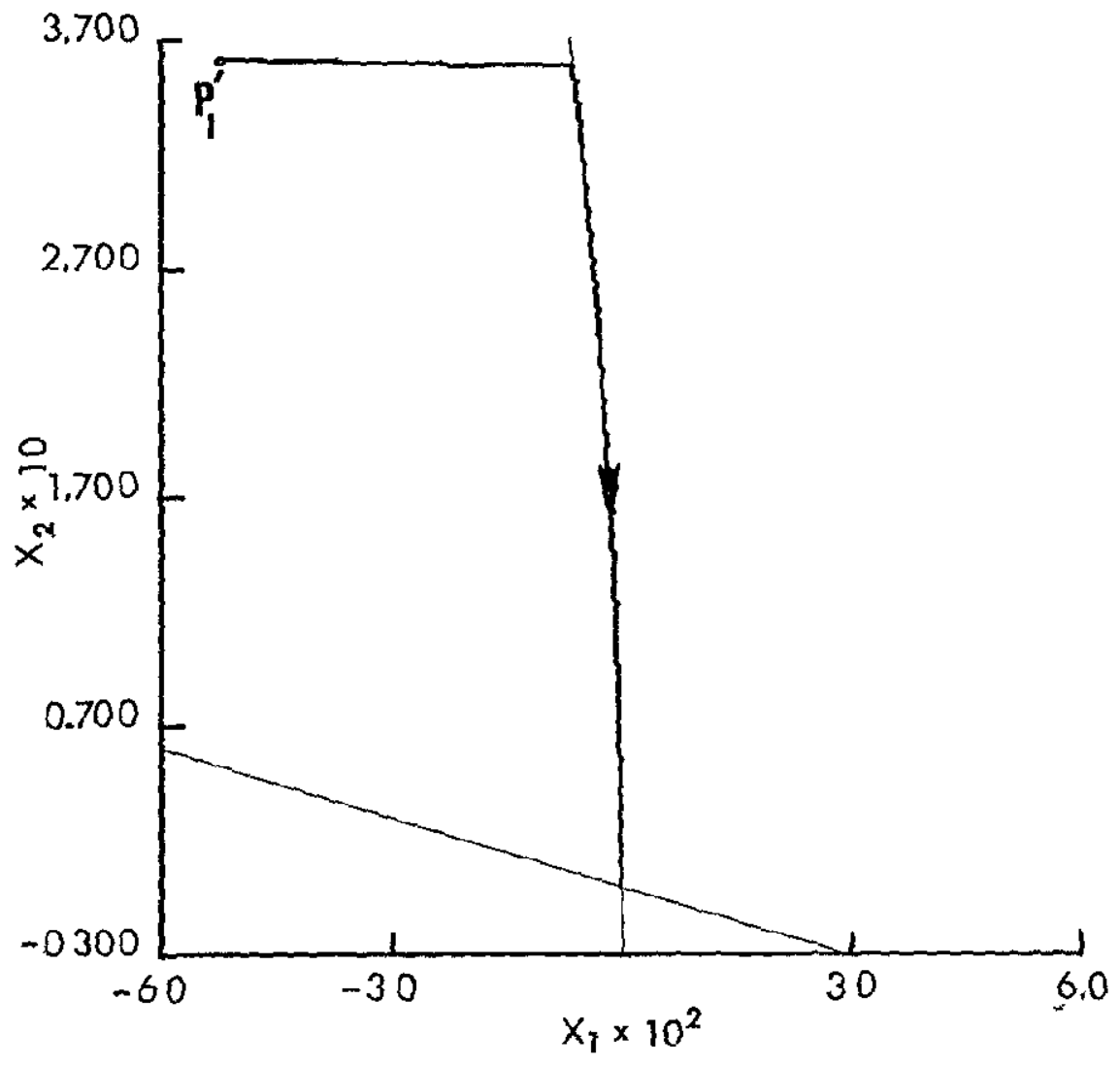

b Small Yaw Angles

Figure 55 Suboptzmally Controlled Acquisition Motzon of Satellite (3), $J=9.75, \tau_{\infty}-\tau_{-}=1.63, \theta_{-}=\pi / 4$ 


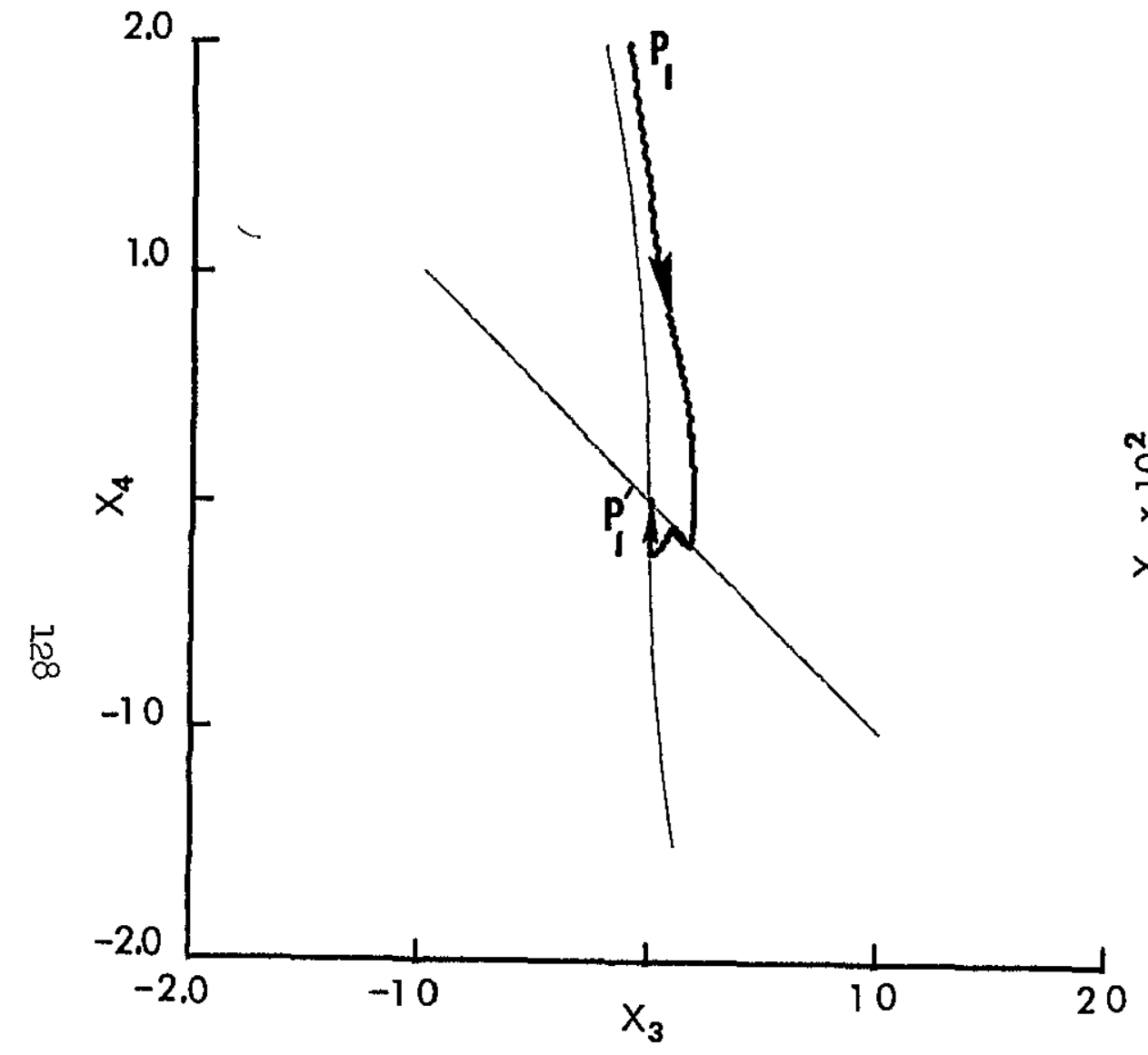

c. Iarge Roll Angles

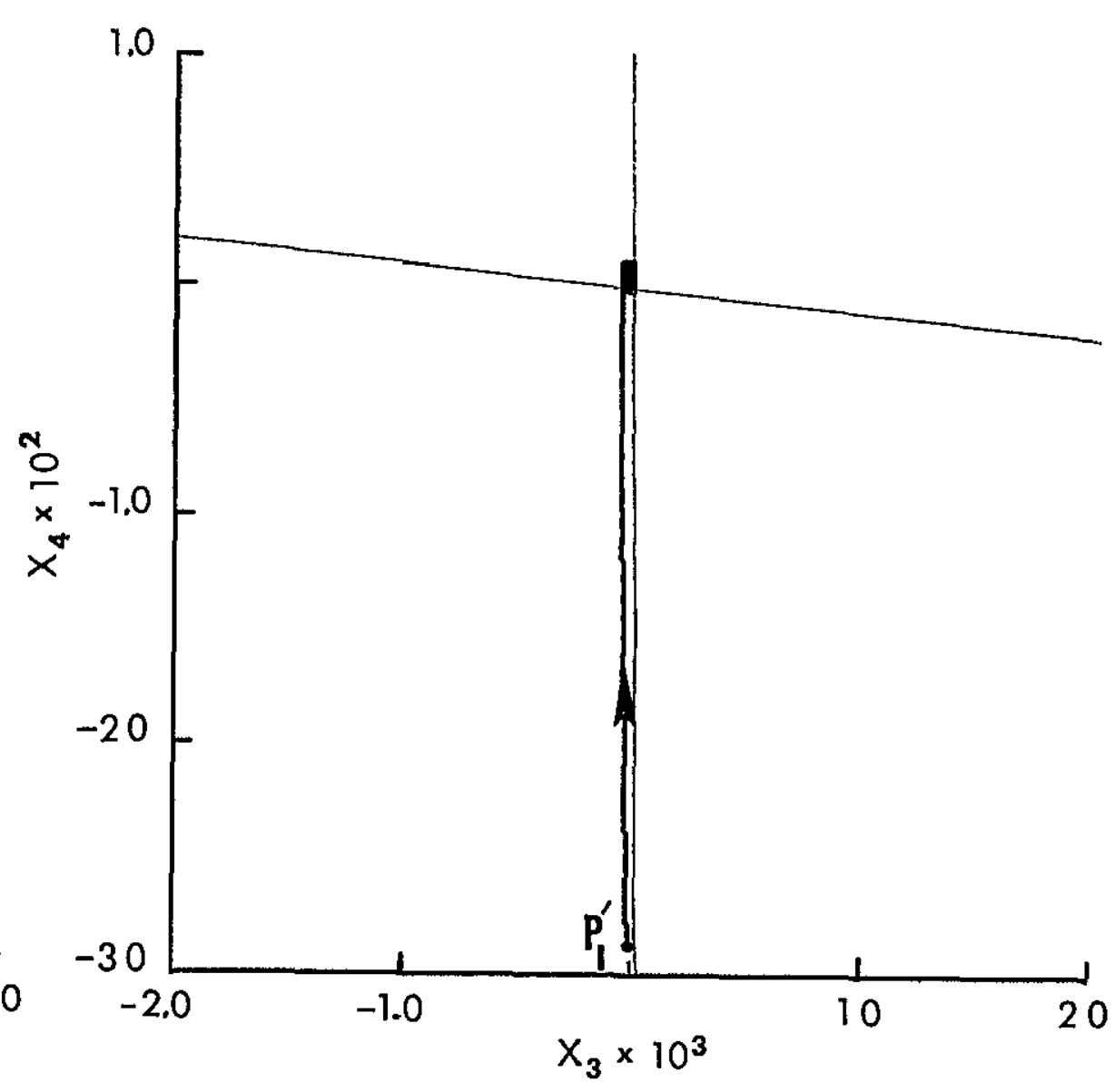

d. Small Roll Angles

Figure 55. Continued. 


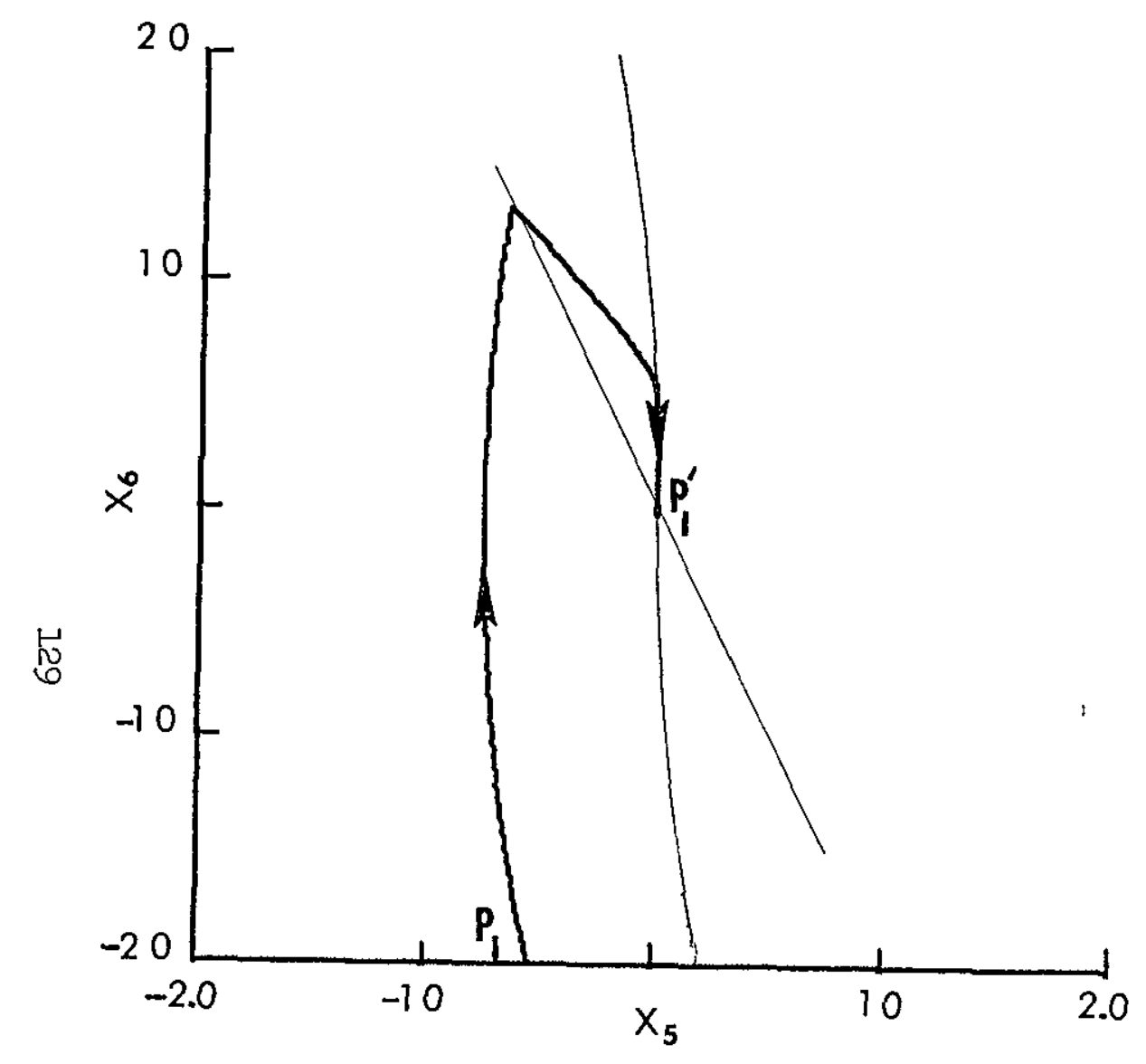

e Iarge Pltch Angles

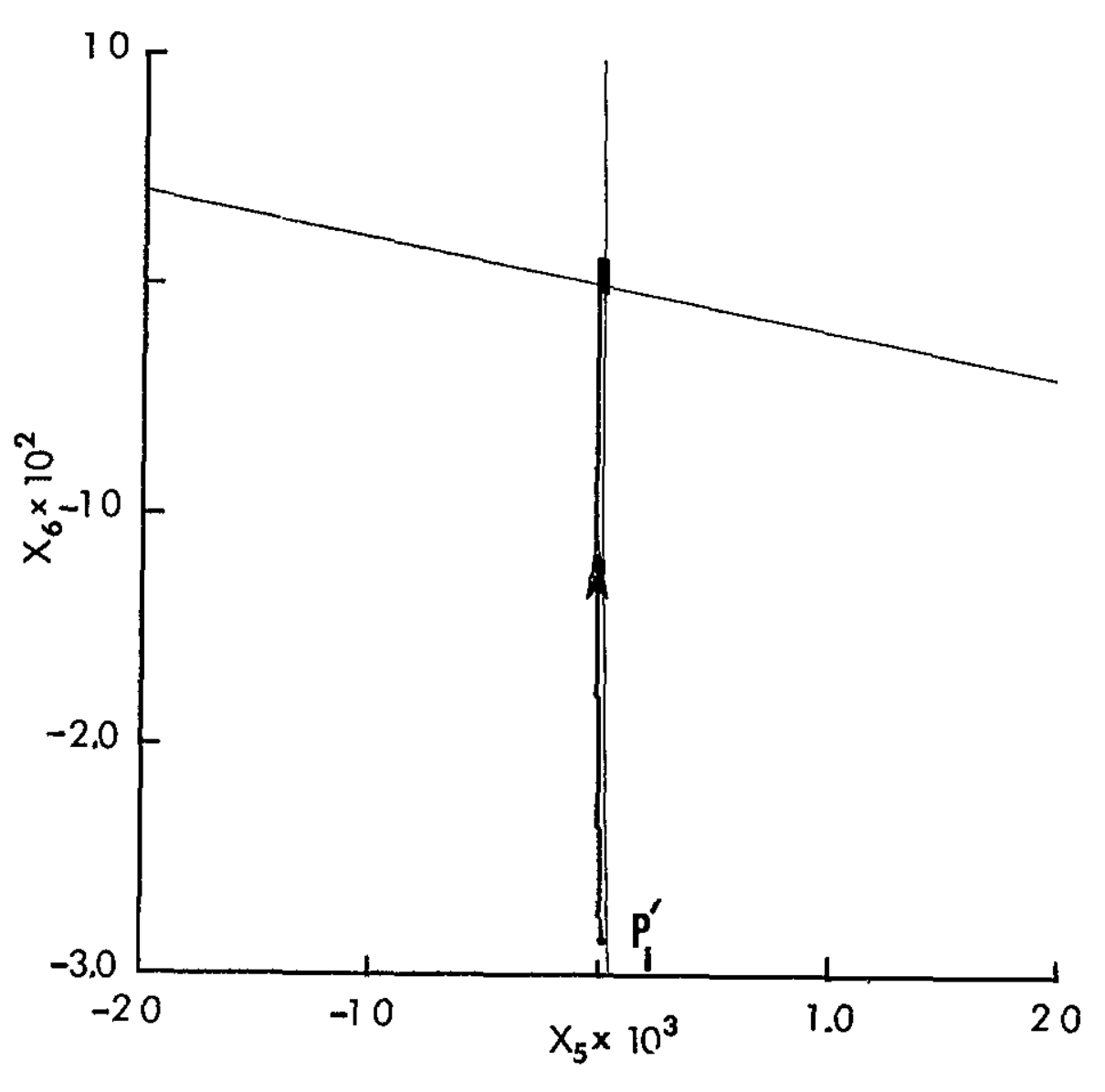

$f \quad$ Small Putch Angles

Figure 55 Continued 


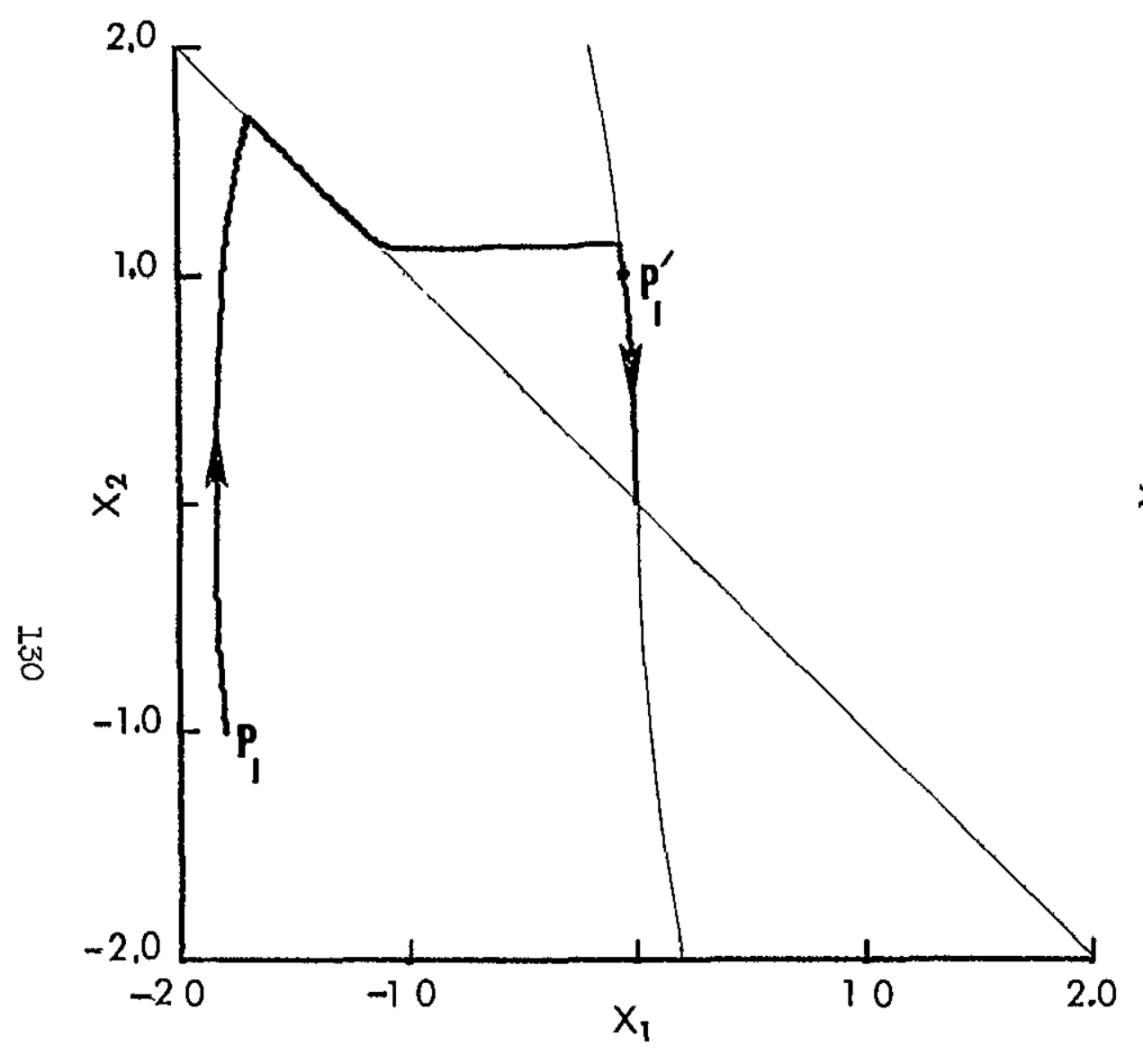

a. Iarge Yaw Angles

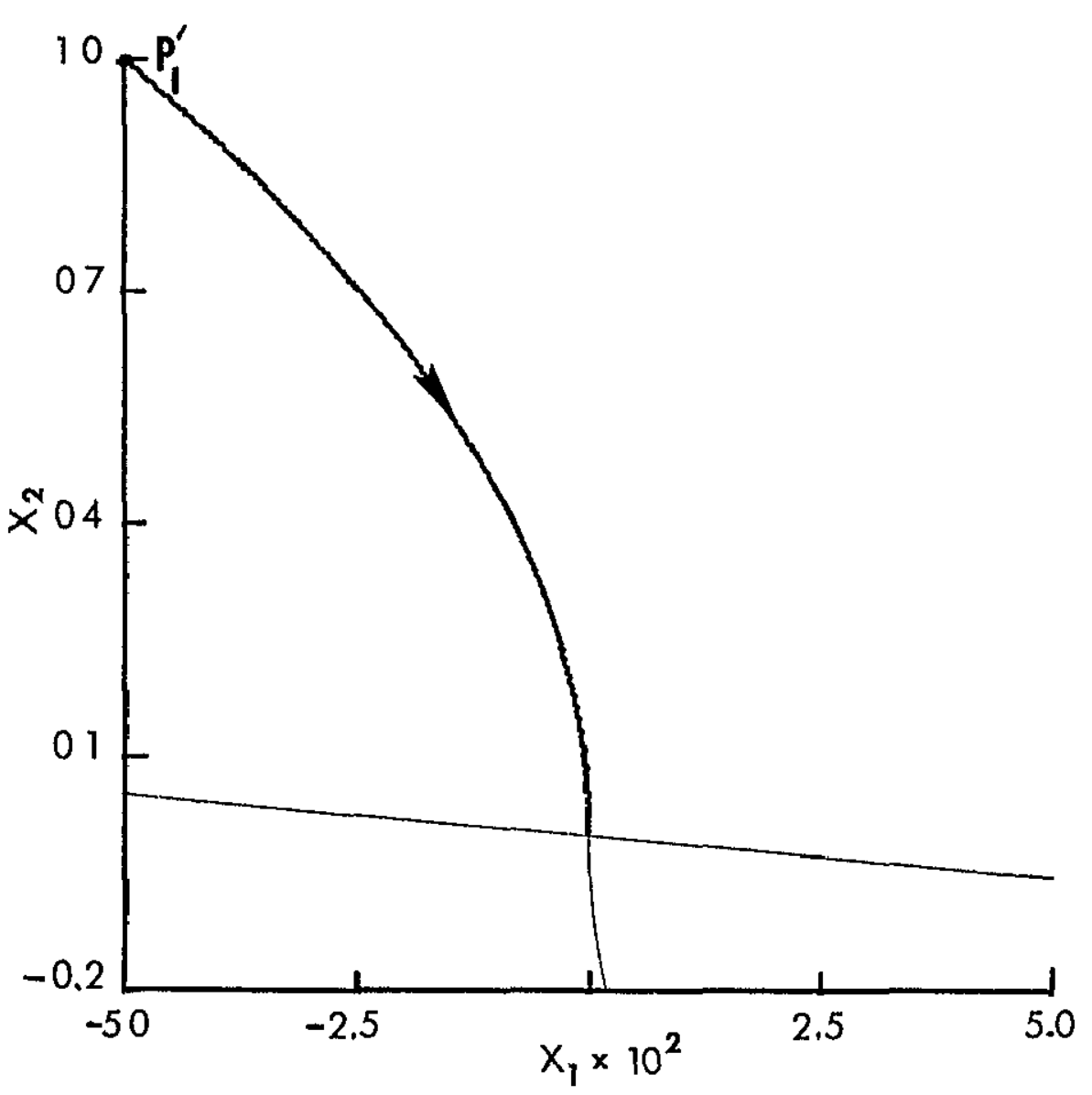

b Small Yaw Angles

Figure 56. Suboptimally Controlled Acquisition Motion of Satellite (4), $J=8.37, \tau_{f}-\tau_{0}=1.69, \theta_{0}=7 \pi / 4$ 


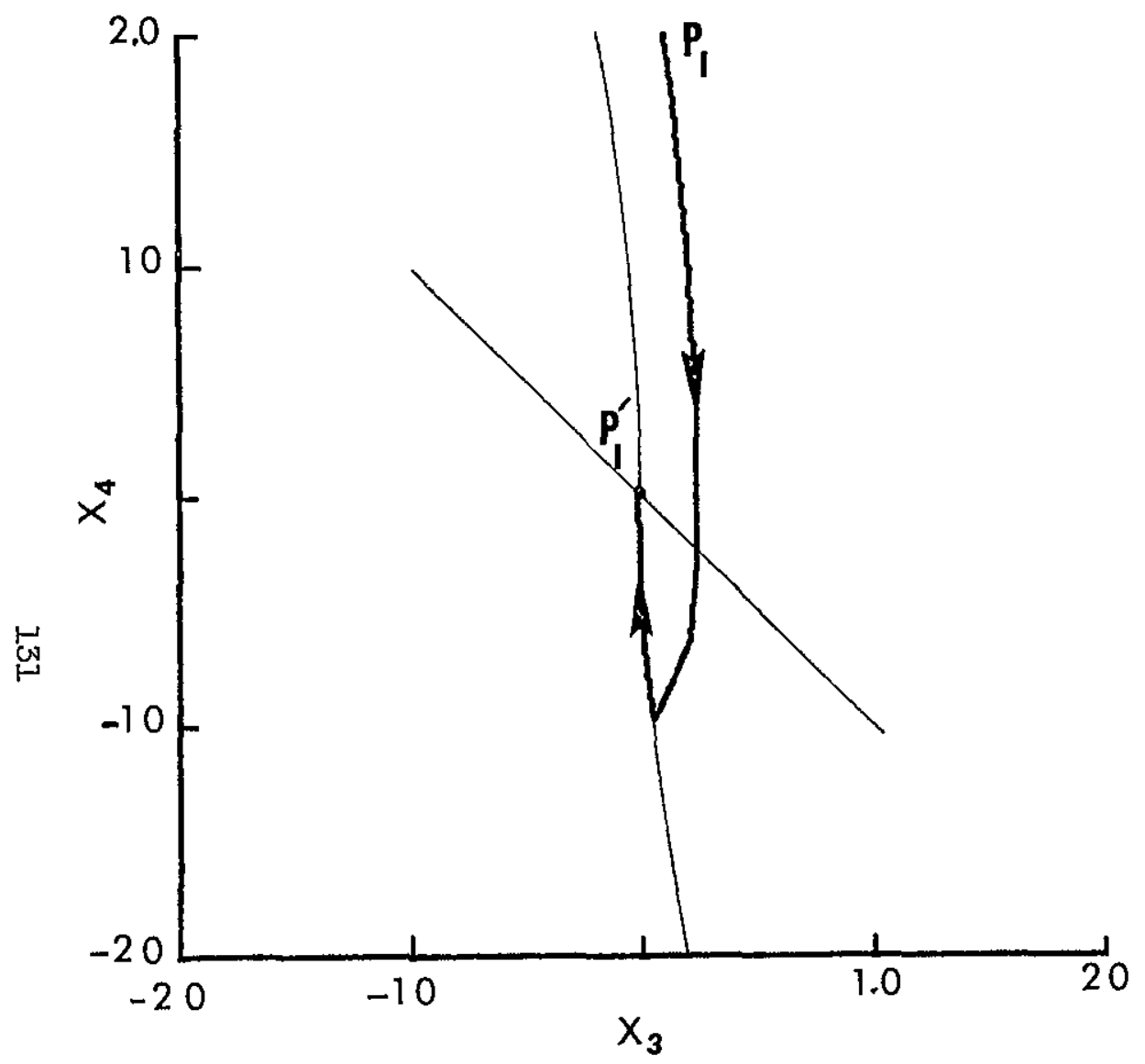

c Iarge Roll Angles

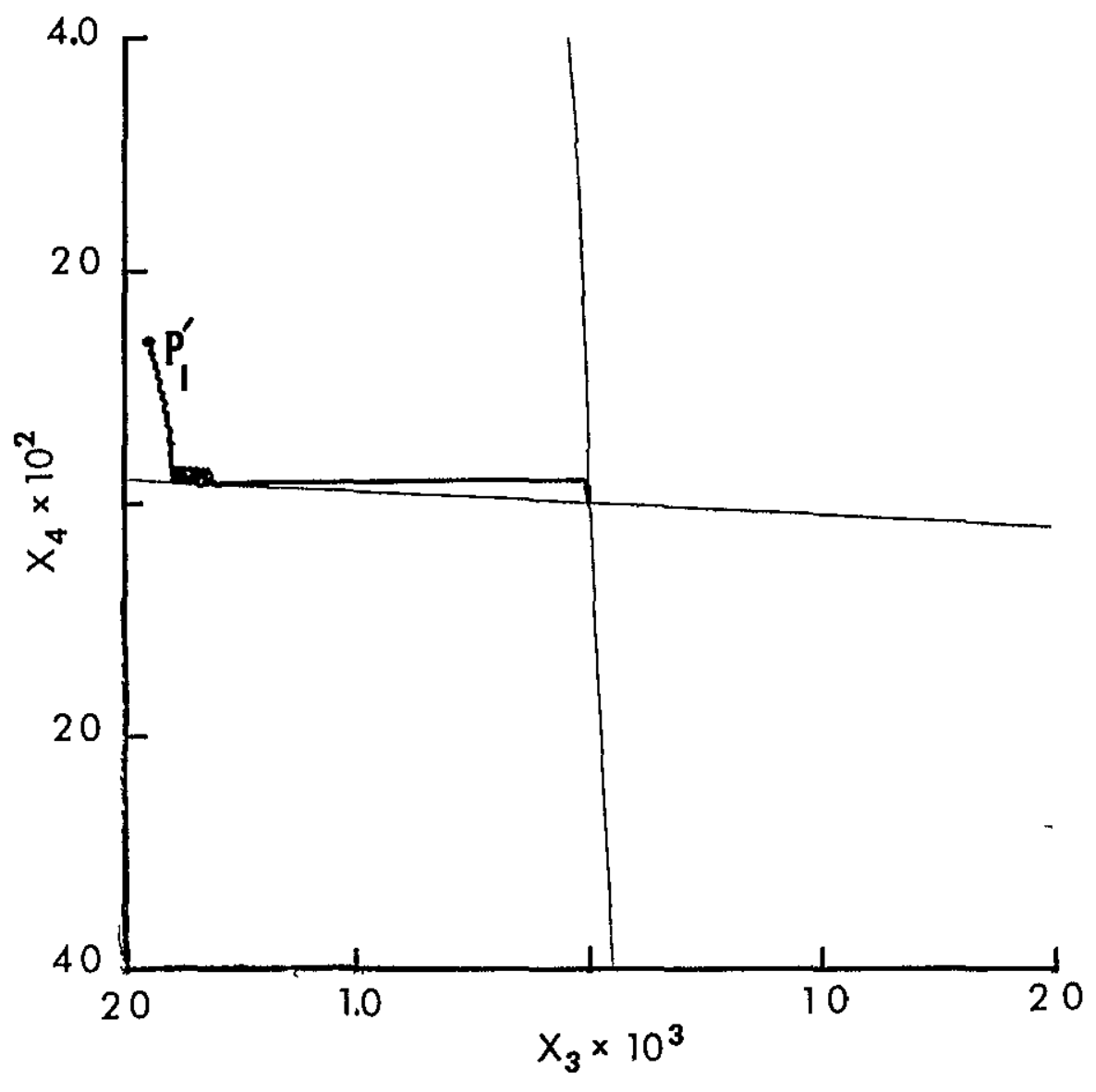

d. Small Roll Angles

Figure 5.6 Contınued. 


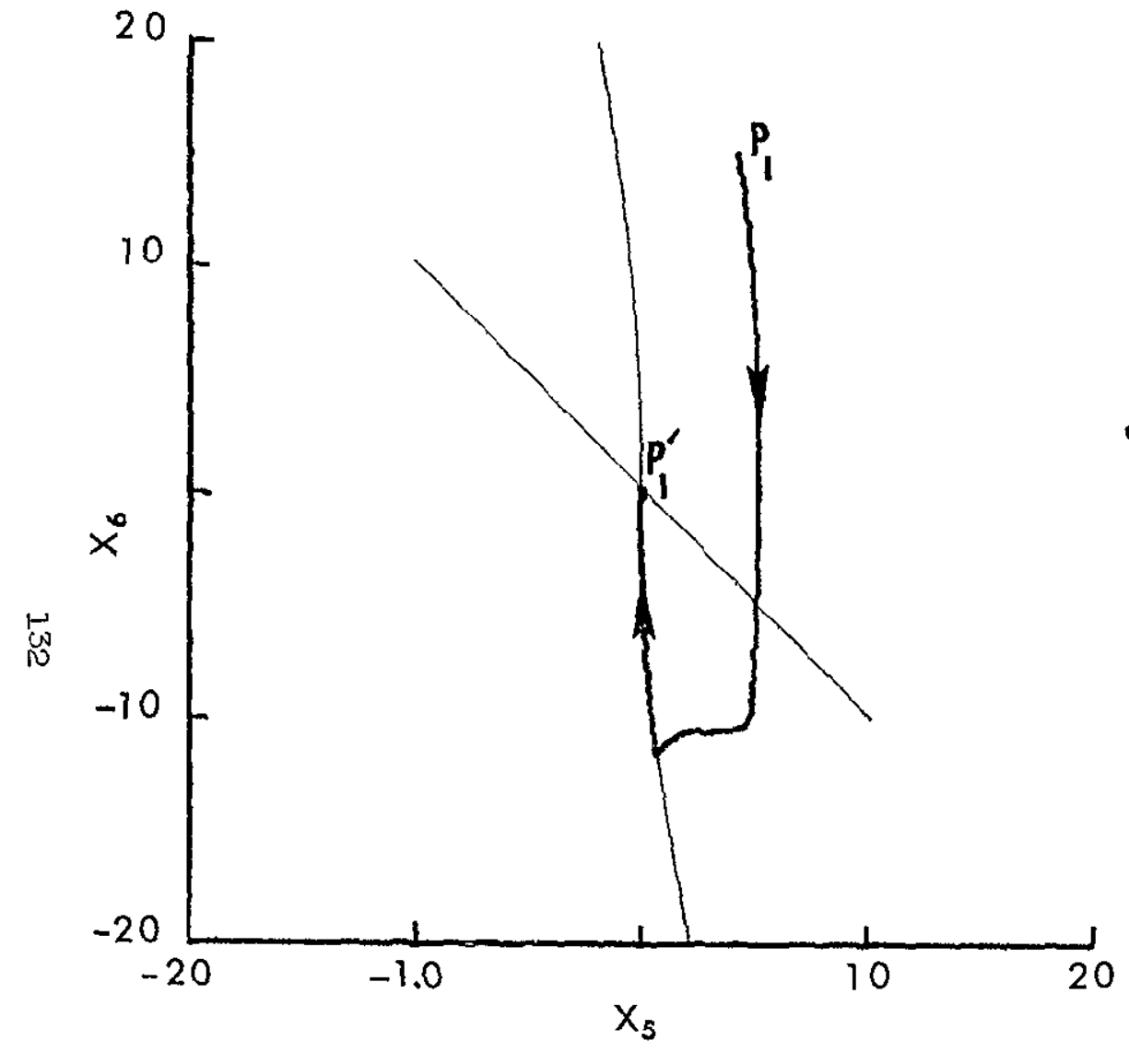

e. Large Prtch Angles

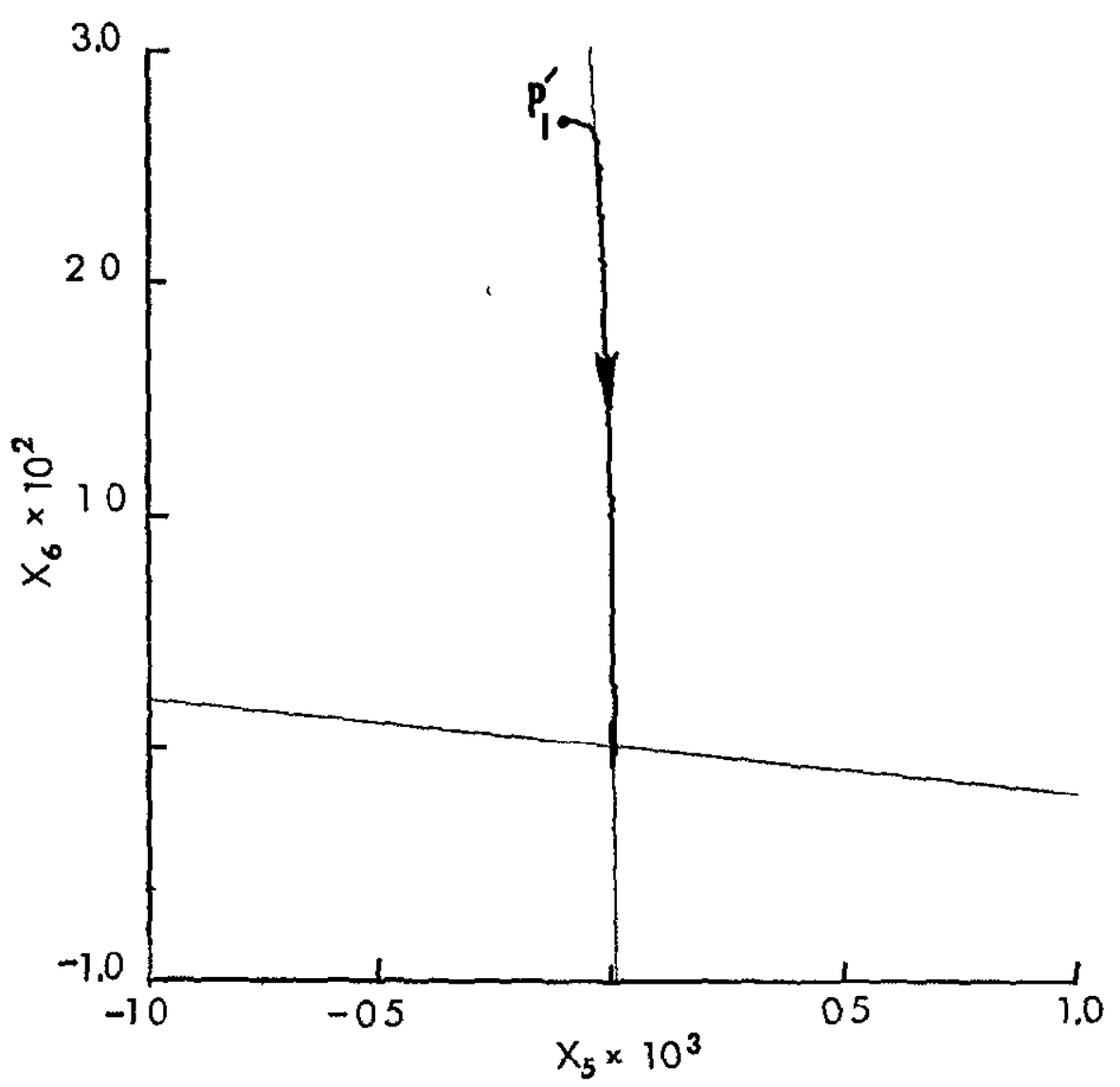

$f \quad$ Small PItch Angles

Eigure 5 6. Continued. 
projected boundary of $\mathrm{S}^{+}$to the projection of $\mathrm{s}$. (Since two widely different levels of control torque are needed for satisfactory performance In acquisition and station-keeping, the region $S^{+}$was acquired by the acquisition part of the controller. Otherwzse, rapld chatter motion and wasted control effort result from the control torque being too large for the region of station-keepzng. See the data of Chapter VI on the fuel cost versus the size of $N_{1}, 1=1,2,3$, and the size of $\mathrm{s}$.) 
VI. COMPLETE AITITUDE CONIROI AID PERFORMANCE EVALUATION

The complete attitude control system consisting of the stationkeeping controls derıved in Chapter IV and the acquisition controls derıved in Chapter $V$ are considered to give satısfactory performance A block diagram of this complete attıtude control system is given in Figure (6.1).

In the remaznder of this chapter the performances of the two parts of the complete control system are evaluated in terms of the performances of other systems and In terms of the weight of fuel required for a year of control as compared to the weight of the satellite. Also, presented here are performance limitatıons Imposed by Imperfections.

A. ACQUISITION CONTROL COMPARED TOO OPITMAI (IINEAR) ACQUISITIONY CONTROI

In Section $B$ of Chapter V, the selected acquisition control system was tested and found to perform satisfactorlyy, however, a thorough comparison of the fuel costs found in the test runs with the optimal (IInear) fuel costs was not made. Although the optimal (Iinear) fuel costs are probably very conservatıve, they are considered to be a lower bound which is large enough for the comparison to be meaningful

The average nondimensional fuel cost for the acquisition simulation runs of satellite (1) was $J=12.4$. For satellites (2), (3) and (4) the average fuel costs were 10.2, 14.1 and 13.2, respectively. These average costs differed from the average optımal (IInear) fuel cost by $34 \%, 15 \%$, $43 \%$ and $36 \%$ for satellites (1), (2), (3) and (4), respectively. The percent differences of the average costs seem quite high, however, considering the strong cross coupling which occurs when the angles are large $\left(\geqslant 60^{\circ}\right)$, the fact that a simple fixed switching logic control is used and the fact that the optimal (IInear) cost is not a greatest lower bound, these percent differences are not unsatisfactory.

Several simulation runs of the nonlinear acquisition system were made for small angles $\left(\approx 5^{\circ}\right)$ from the flnal conditions (backward time) of optimal (linear) runs. The percent differences for the small cases were about $15 \%$.

The varzation in the percent difference for each individual run was 


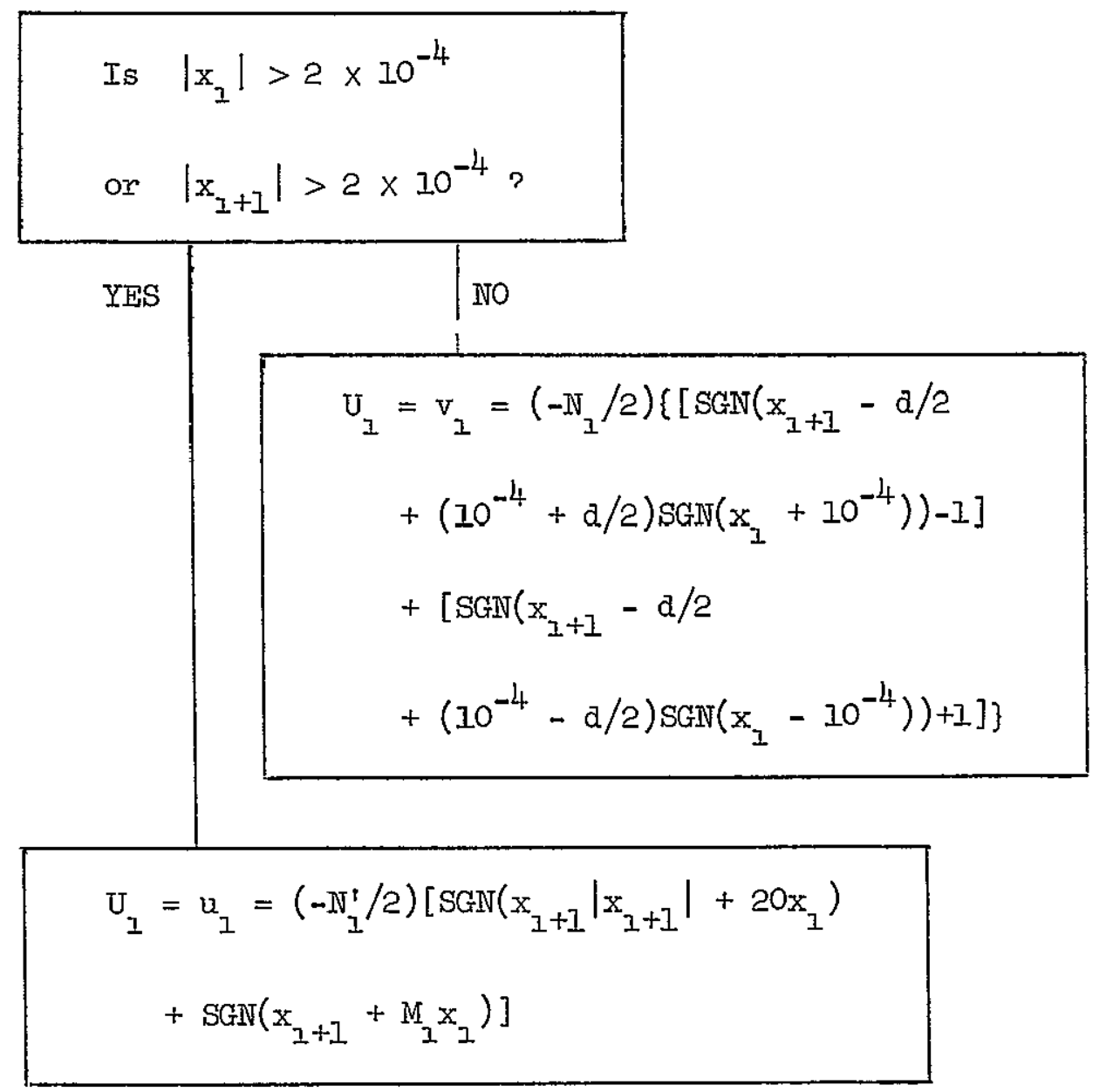

NOTES: (1) The Index $I=1,2,3$ for yaw, roll and pitch, respectively

(2) $M_{1}=1.0, M_{2}=10$ and $M_{3}=20$

(3) The drstance d (see Section B, Chapter 4) depends on the satellite, the strength of station-keeping control and on the controllers time delay

(4) $U_{1}, 1=1,2,3$, are the nondimensional control components (eIther acquisition or steady-state)

Figure 6 I Block Diagram of the Complete Attitude Control System 
from $-4.1 \%$ to $+62 \%$. The extreme percent differences belonged to the large angle runs. The suboptimal system had an advantage of $41 \%$ over the optimal system in one of the runs for satellite (4), however, the time of acquisition for the suboptimal was almost $20 \%$ greater than that of the optzmal. The maximum percent idfference of $62 \%$ was for the run of satellite (3) which was given in Figure (5.5).

One of the mann reasons for the greater fuel cost of the suboptimal system is the chatter motion whjch occurs during acquisition from some Inltial conditions. This chatter motion can be avolded, even with a fixed swltching logic control, by increasing the values of $M_{I}$ (the negative values of the slopes of the stralght line switching curves). If the values of $M_{1}$ are increased until no (or little) chatter motion occurs, the time of acquisition generally decreases, but, the fuel cost increases. However, unless the slopes are increased untll no (or little) chatter motion occurs (about a factor of ten), the costs do not generally increase by more than $100 \%$.

The nondimensional fuel cost values can be translated for particular satellites into the welght of fuel used in, say, pounds. If, whlle a gas jet is on, It is assumed that the gas flow rate and exhaust velocity are constant, the welght-flow for a gas jet couple Is given by

$$
\dot{w}_{I}=\frac{\mathbb{N}_{I}^{\prime} I_{1} n^{2}}{2 l_{1}} \frac{g}{v}, I=1,2,3 \text {, }
$$

where $2 b_{1}$ is the moment arm distance, $g$ Is the acceleration of gravity and $v$ Is the magnitude of the exhaust velocity. If both sides of (6.I) are multiplied by $n^{-1} \triangle_{\tau}$ (recall that $\tau=n t$ ), the result is

$$
\mathrm{w}_{1}=\dot{\mathrm{w}}_{I} \Delta t=N_{I}^{2} \Delta_{\tau} \frac{I_{I} \mathrm{n}}{2 l_{1}} \frac{g}{v}=J_{I} \frac{I_{I}}{2 l_{I}} \mathrm{n} \frac{\mathrm{g}}{\mathrm{v}}
$$

which Is the weight of fuel used in the time interval, $\Delta t$, that the gas jet couple is on.

The ratio $\mathrm{v} / \mathrm{g}$, whose reciprocal is a factor in (6.2), is usually referred to as the specific impulse, $I_{\mathrm{sp}}$. A realistic value for $v$ is $1500 \mathrm{ft} . / \mathrm{sec}$. so that a reasonable specific Impulse Is $I_{\mathrm{sp}}=46.5 \mathrm{sec}$. 
In thrs case $\mathrm{g} / \mathrm{v}=2.15 \times 10^{-2} \mathrm{sec}^{-1}$. The values of $\mathrm{n}$ for the satelIItes considered in this investigation range from $0.95 \times 10^{-3}$ to $1.13 \times$ $10^{-3}$. In the following calculations of the weight of fuel used, the worst case value of $n=1.13 \times 10^{-3}$ is used. The typical sateliztes referred to are those of Section D, Chapter II. Since the typical satellites are sperical or cylindrical and since the lever arm distance, $2 l_{1}$, Is usually half the length of an axis, the ratio $I_{1} / 2 b_{1}$ can be approximated by $1 / 5 \mathrm{~m} l_{1}$, If the satellite $1 \mathrm{~s}$ spherical, by $1 / 4 \mathrm{ml}$ for the longltudinal axıs and by $1 / 6 \mathrm{ml}$ for the transverse axıs, if the satellite is cylindrical. ( $m$ is the satellite's mass. For satellite (1) $m=1,860$ slugs. For satellites (2), (3) and (4) $m$ Is 1550 slugs, 1550 slugs and 310 slugs, respectively.)

Now the nonalmensıonal average acquisıtion fuel cost for each satelIIte can be translated Into pounds welght. The values of $J$ (given earlier in this section) for satellites (1), (2), (3) and (4) are 12.4, 10.2, 14.1 and 13.2, respectively. Therefore, the approximate (worst) weights of fuel used on the average for acquisition by sateliztes (1), (2), (3) and (4) are $0.88 \mathrm{Ibs} .\left(l_{1}=7 \mathrm{ft.}\right), 1.28 \mathrm{Ibs} .\left(l_{1}=15 \mathrm{ft.}\right)$, $1.78 \mathrm{lbs} .\left(l_{I}=15 \mathrm{ft}.\right)$ and $0.10 \mathrm{Ibs} .\left(l_{I}=45 \mathrm{ft}.\right)$, respectIvely

B. STATION-KEHEPING CONTROL

In Part 4, Section B of Chapter IV the statzon-keeping control system was simulated on the analog computer and found to perform satisfactorlly. In this section the performance of the station-keeping control is evaluated by comparing it to the hybrid station-keepıng control system of Busch (whinh contains a reaction wheel) and by evaluating fuel costs changes with varzous parameters of the system.

1. Comparıson with Busch's Solution

Busch obtalned station-keeping control in roll and yaw simply by leaving small $\left(6.3 \times 10^{-3}\right.$ radians $)$ clrcular regions of no control about the origin in the roll and yaw phase planes of the acquisition phase plane switching logic. This performed well for the "stable" satellite considered by Busch. (The steady-state cost per orblt for roll and yaw was about $J=10^{-3}$.) 
Since the pitch motion was forced by a sinusoldally varying term and sunce neither of the switching curves were of a "stablinzing" type, Busch's pitch acquisition control could only achieve complete acquisition in pitch perıodically and the error in pitch grew periodically to about 0.1 radians. The fuel cost for this periodic reacquisition in pltch was high. To gain greater accuracy in pitch and to reduce the weight of the fuel used, Busch supplemented the putch part of the control system with a reaction wheel.

If the environmental torques acting on the satellite are nearly sinusoldal, the power required for "pushıng" against the reaction wheel Is nearly zero, so that, except for the welght of the reaction wheel and supporting components the welght of the pitch part of the controller is negliglble. However, since the environmental torques are not sinusoldal but have the character of a nearly constant forcing term with some periodic variations, the reaction wheel must be continuously "pushed" against in such a way that the wheel speed Is continously Increased. Since Busch used gas jets to produce the torque to hold the satellite steady whlle slowng the reaction wheel once it reached Its saturation speed, his steadystate fuel consumption was increased by $21.9 \%$, (This Increase was due to slowing the reaction wheel when only cross coupling caused the wheel speed saturation $1 . e$, all forcing terms were consldered as purely sınusozdal.)

The weight of the fuel used for statzon-keeping can be compared (for the same size satellite) to the welght required by Busch's system for station-keeping control. Consıder the "stable" satellite (2) Busch suggests a reaction wheel moment of inertia of $I_{\mathrm{w}}=10^{-5} \times I_{3}=1.21$ slugs-ft. ${ }^{2}$. If the reaction wheel is a brass cylinder with a diameter of $1.5 \mathrm{ft}$. and a helght of one foot, the welght of the reaction wheel Is 138 Ibs. From Table 4.1 It is found that the cost of the steady-state pitch control for satellite (2) Is $J_{p, s s}=6.03 \times 10^{-2}$ per orbit. The cost for a year (about $5.6 \times 10^{3}$ orbits) of putch steady state control Is $J=337$. From Equation (6.2) the welght of fuel used in pitch for a year of station-keepıng is found to be $8.47 \mathrm{Ibs}$. ( $l_{1}=3 \mathrm{ft}$.). In the same manner the wezght of the fuel used for roll-yaw station-keeping is found to be $113 \mathrm{lbs}$. ( $\left.l_{1}=15 \mathrm{ft}.\right)$ per year which 1 s about the same as 
Busch's roll-yaw control used for the 50,000 Ib. satellite.

Clearly, the welght of the fuel used for station-keeping by the control of Section B, Chapter IV Is much less (about 94\%) than the weight required by Busch's station-keepıng control system.

2. Fuel Fxpenditure Per Orbit For Values of Varıous Parameters

The fuel cost for station-keepung varies with the values of parameters such as eccentriclty $(e)$, Inertıa parameters $\left(k_{1}\right)$, strength of the control $\left(N_{I}\right)$, size of $S\left(s_{1}\right)$ and the peak voltage of sensor noise. Simulation runs (as in Section B, Chapter IV) were made to determne the effect of the variation of these parameters on the fuel cost. (The results of the runs also offer a check on the behavior predicted for the satellites by the analysıs of the simple motions of chapter IV.)

To test the effect of eccentricity on the fuel cost, simulation runs were made for the inertia parameters of satellite (3) which Is "unstable" in yaw but "stable" in roll and pitch. From these runs It was found that the roll-yaw fuel cost varıed by only $3 \%$ for a variation In $e$ from 0.0 to 005 , however, the putch fuel cost varied directly as the eccentricity Figure (6.2) shows the pltch fuel cost as a function of eccentricity.

To test the effect of the inertia parameters on the fuel cost per orbit, five sets of values of $k_{1}, 1=1,2,3$, (whlch correspond to five satellites whose earth-polnting motions range from highly "unstable" to highly "stable") were used in the simulation runs. The change in the putch fuel cost was negliglble when $e=0.05$ was used. A second set of runs was made with $e=0.01$ in the hope that the reduction of the size of the relatively large forcing term would result in noticeable changes In the pitch fuel cost with changes in $\mathrm{k}_{3}$, however, the results were the same for this set of runs. The changes in the roll-yaw fuel cost with changes in $k_{1}$ and $k_{2}$ were quite significant (a maximum increase of $172 \%$ ) These changes are represented in the chart of Figure (6.3) for $N_{1}=N_{2}=0.01, e=0.05$ and $d=3 \times 10^{-5}$.

Satellites (2) and (3) were simulated in the investigation of the effect of the strength of control on the fuel cost. (These two satellites were chosen for this investigation since satelizte (2) Is 


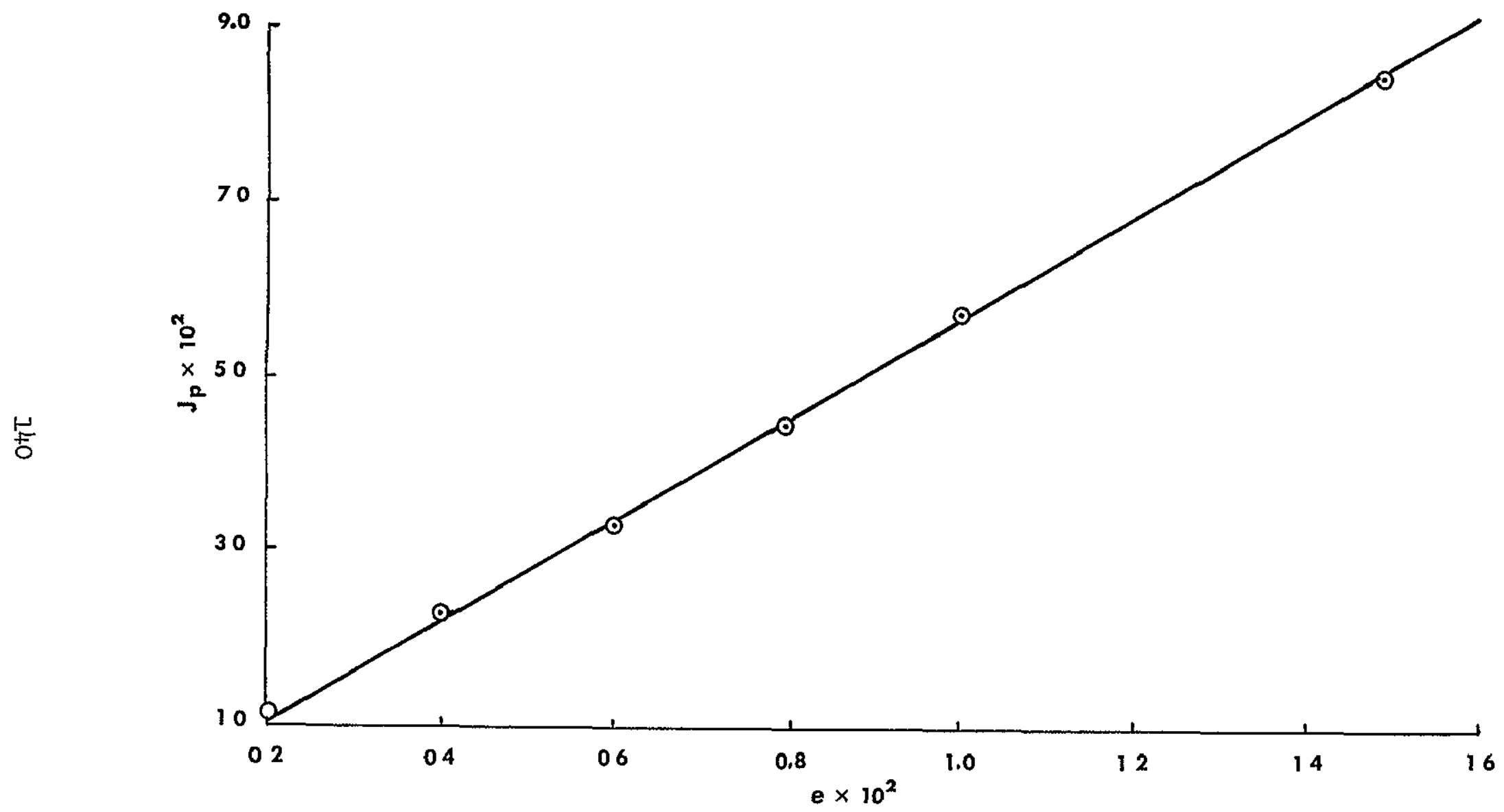

Figure 6.2 Pitch Fuel Cost Per OrbIt vs. Eccentricity, $\mathbb{N}_{3}=0035, k_{3}=0.99, d=0$ 


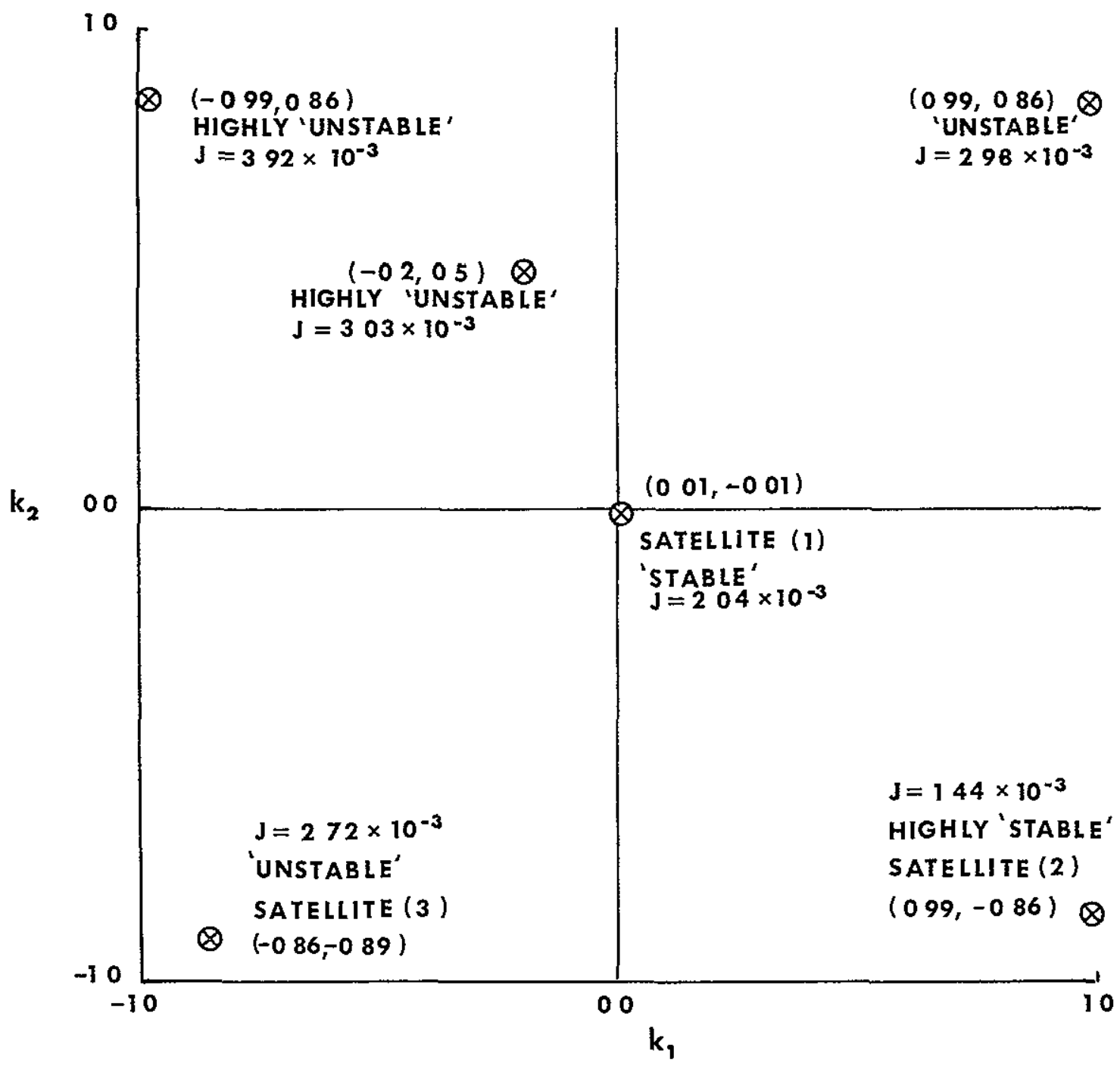

Figure 6.3. Roll-Yaw Fruel Cost for Varıous Values of $\mathrm{k}_{1}$ and $\mathrm{k}_{2}$, $\mathbb{N}_{1}=\mathbb{N}_{2}=0.01, \mathrm{e}=0.05, \mathrm{~d}=3 \times 10^{-5}$. 
"unstable" in pitch and satellite (3) is "unstable" in yaw.) The distance d was taken as $2.0 \times 10^{-5}, 2.5 \times 10^{-5}$ in the pitch control and as $2 \times 10^{-5}$ and $4.5 \times 10^{-5}$ In both the roll and yaw controls. Recall from Chapter IV that in pltch, when the sinusoldal forcing term is most significant, the distance d should be large enough to insure a controloff interval in any interval which contains two consecutive control swatches to $\pm \mathbb{N}_{3}$. Also, recall that for "stable" single-axis motions (e.g those of $x^{\prime \prime}+a^{2} x=v$ ) the fuel cost should decrease wath increases In $d\left(\leqq 10^{-4}\right)$. For "unstable" single-axis motzons (e.g. those of $x^{\prime \prime}+$ $\left.a^{2} x=v, a^{2}<0\right)$ the fuel cost should increase with $a\left(\leqq 10^{-4}\right)$, however, a must be just large enough to insure a control-off interval in any Interval which contalns two consecutive control switches to $\pm N$ Figure (6.4a) shows the roll-yaw fuel cost per orbit of satellites (2) and (3) plotted as a function of the control strength for the various values of $d$. Since the putch fuel cost varıes Insigniflcantly with the inertia parameters, only the pitch fuel cost per orbit of satellite (3) Is shown plotted in FIgure 6.4b. The points on the curves of Figure 6.4b marked "overshoot" correspond to the values of $\mathbb{N}_{3}$ (for a time delay of about 0.5 sec.) for which control-on pitch trajectories overshoot the small strips (of width $d$ ) in the pitch phase plane. For $\mathbb{N}_{3}$ greater than these values the values of $d$ are not large enough to insure a control-off interval in any interval which contains two consecutive control swatches to $\pm_{\mathrm{N}_{3}}$.

The effect of the size of the region $S$ on the fuel cost per orbit was investigated for satellite (2). The results of this investigation are given if Figure 6.5. The point $(0.0,0.0)$ alded in the construction of the curve for roll-yaw. (ThIs was possible since the origin of the roll-yaw state space is an equilibrium point.)

To test the effect of sensor nozse on the error and fuel cost per orbit a Iow frequency (100 cps) Gaussian nolse generation was used. The nolse was added to the state varıables as they entered the controller. Runs were made for satellite (3) with $\mathbb{N}_{1}=0.04$ and $d=25 \times 10^{-4}$. The peak nolse voltages used were 0.05, 01 and 0.2 tImes the peak state varlable voltage of 1.0 volt. The error and fuel cost of each run with nolse were compared to the error and fuel cost of the nolseless run. 


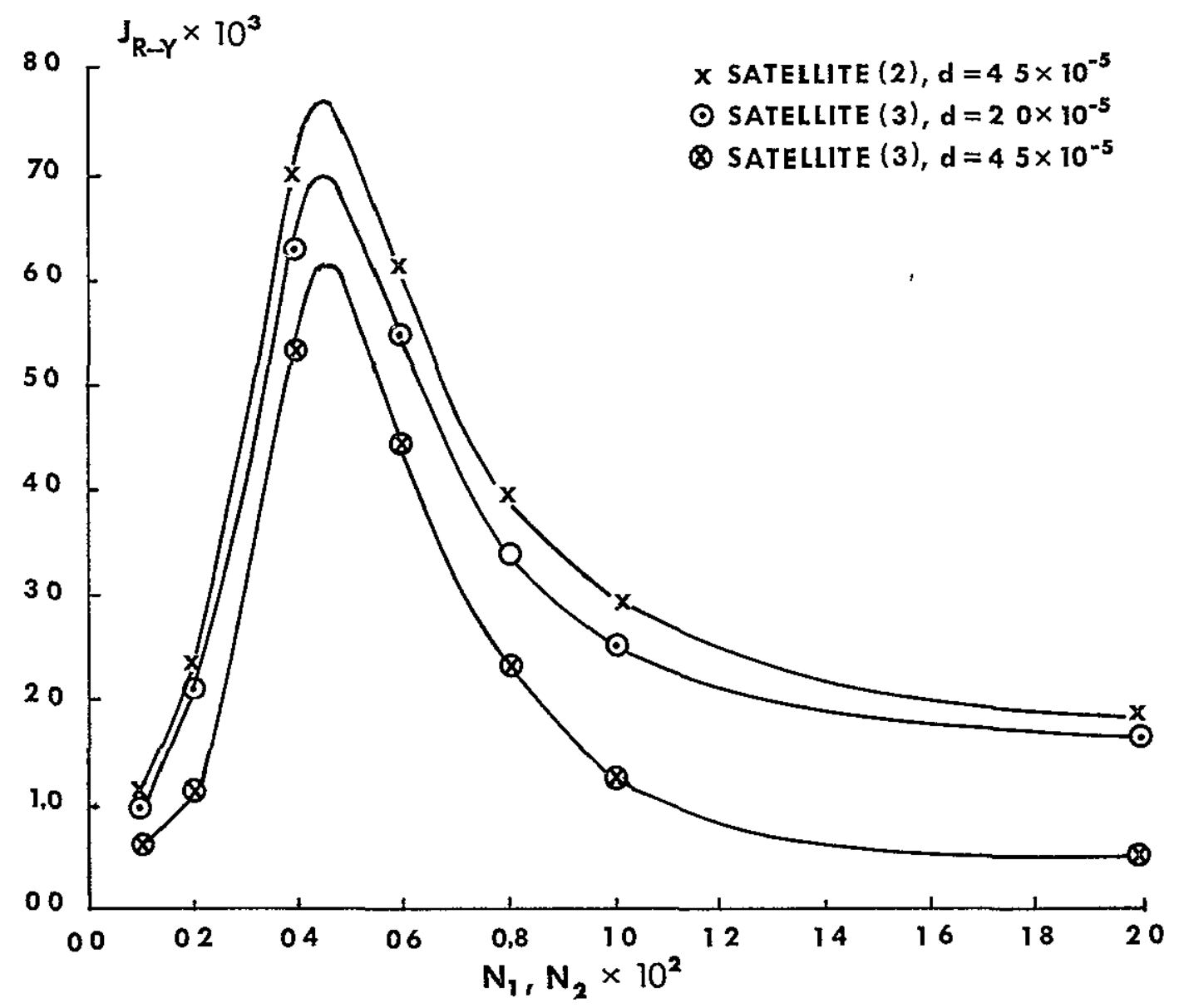

a. Roll-Yaw of Satellites (2) and (3)

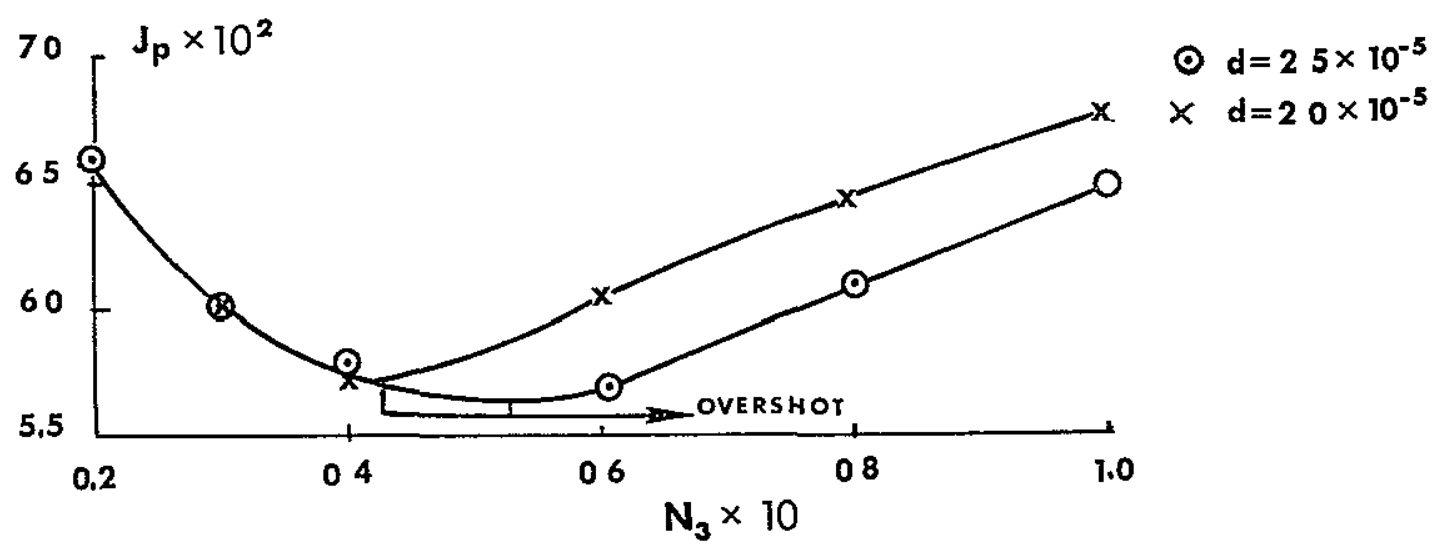

b Pltch of Satelinte (3)

Figure 6.4 Fuel Cost Per Orbit vs Control Strength. 


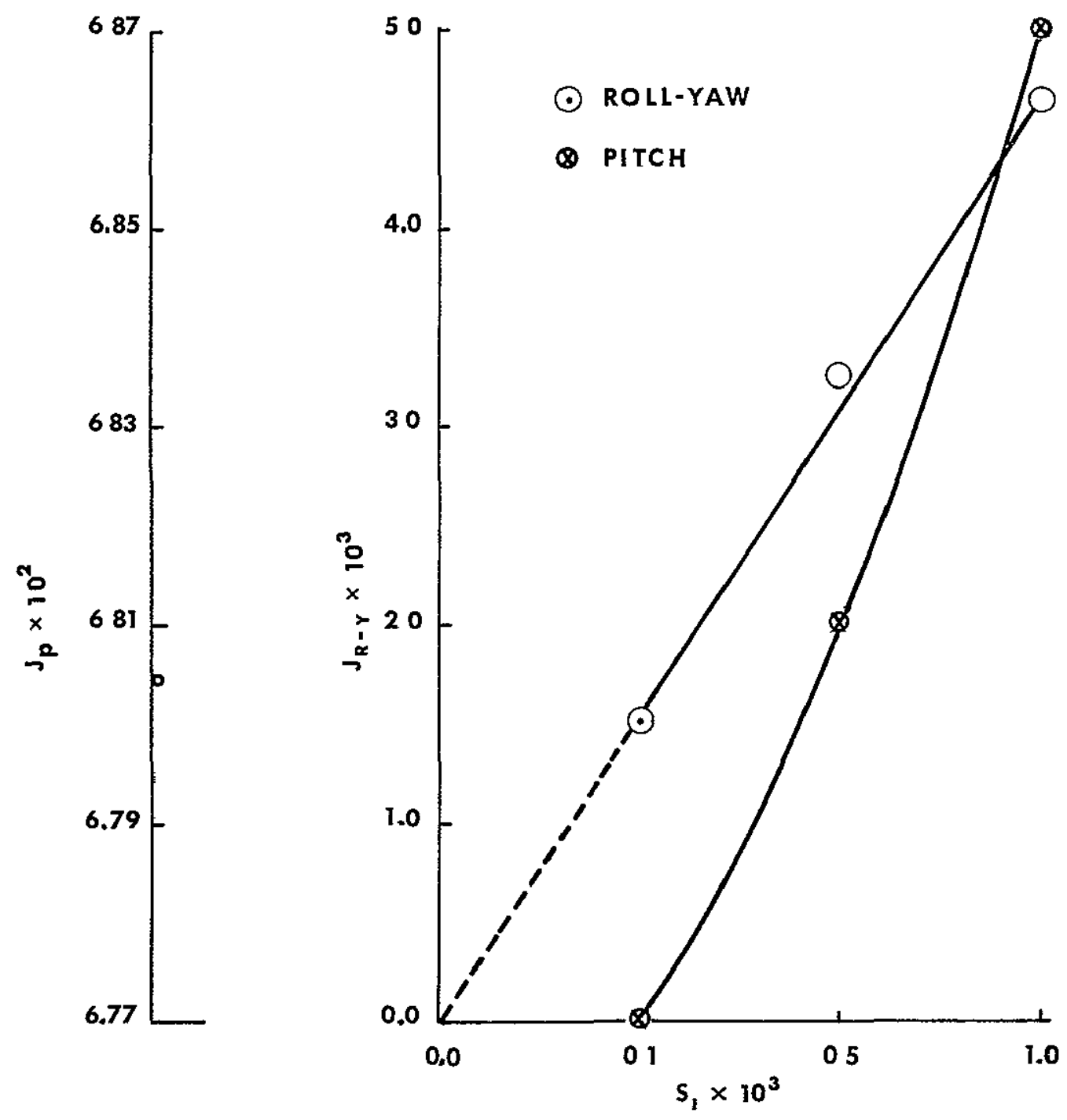

Figure 6 5. Fuel Cost Per Orbit vs Size of the Region S - Satellite (2), $\mathrm{d}=20 \times 10^{-5}, \mathrm{~N}_{1}=\mathrm{N}_{2}=0.01, \mathrm{~N}_{3}=0.1$ 
The fuel cost was found to increase slightly (less than $2 \%$ ) whlle the error was at most $0.5 \times 10^{-5}$ radians or $5 \%$.

C. IMPERFECTIONS IN THE MODEU AND THE ULTIMATE ABEITITY TO EARTH-POINT

1. Nonrigidity of the Satellites

The mathematical satellite models were made on the assumption that the satellites are rigid. This, of course, is not precisely the case, however, for the satellite configurations considered in this investigation, the effects of the various causes of nonrigidity can be made acceptably small Contributors to nonrigidity include the silght deformation of the satellite structure in the small force environment (The largest gas jet required for acquisition gives only 0.17 Ibs. of tinrust.), the motion of the valves of the gas jets and the gaseous fuel

In the steady-state mode, the deformation of the satellites should be Insignificant when, for example, an attached camera is to be aligned very accurately for earth-pointing to withln $10^{-4}$ radians. For the satellites considered here the deformation is generally much smaller than the best machining tolerance avallable today and Is, therefore, Insignificant

The motion of the gas jet valves is very rapld so that the valves are opened or closed in just a fer milliseconds. Thus, the gas valve must attann a speed of the order of $100 \mathrm{In} . / \mathrm{sec}$ from rest (with respect to the satellite). After attalning this speed the valve must aga.n be brought to rest. The forces required to accelerate the values and to bring them to rest can cause a significant torque (about 0.1 ft.lbs.) unless care is taken in their design.

Since the pressure due to a completely gaseous fuel is (for all practical purposes) uniformly distributed over the inner surface of the fuel container, the torque due to the pressure forces is essentially zero (regardless on the containers shape or its position in the satelizte). Therefore, the third contrubutor to the satellyte's state of nonrıgldity has an insigniflcant effect on the satelizte's earth-pointing performance.

2. Gas Jet Misalignment

Each gas jet pair was assumed to be alıgned such that the torque 
of the couple was "about" a principal axis of inertia for the mass center. In practzce the orientations of the principal axes are known to wathin only about 0.01 radians. Hence, when a gas jet palr is on, It is probable that a torque with a magnitude of about 0.01 of the gas jet palr's torque Is applied about the other principal axes. It is most inkely that these misalignment torques wlll not improve the control systems performance, however, their effects on the accuracy are considered to be insignificant but they can result in as much as a $12 \%$ increase in the fuel cost.

\section{Sensors and Error}

In this investigation It is assumed that the state of the attitude motion is avallable from sensors. In the last section, Section $B$, It was found that low frequency (100 cps) nolse added to the swate variable signals from the sensors has almost no effect on the performance (even if its peak voltage is 0.2 of the sensor's output voltage). However, If there is a bias error of $10 \%$, say from the misalignment of the sensors, the earth-pointing accuracy will suffer by $10 \%$ at tames and the fuel cost wall generally increase.

\section{Others}

The mathematical satellite models used in this investigation do not account for very large forces such as those due to the motion of a man on board and the collision of the satellite with a very high momentum, but "non-fatal" meteorold.

Calculations based on $\Delta \mathrm{x}_{1+1} \approx \mathrm{Nm}_{2} \Delta_{\tau}, 1=1,2,3$, and on $\mathrm{n}^{2} I_{I} \mathrm{Nm} \mathrm{m}_{I} \Delta_{\tau} \approx z_{I} \mathrm{~m}_{\mathrm{m}} \Delta v, I=1,2,3$, where $\mathrm{Nm}_{I}$ Is the effectIve value of the $I_{\text {th }}$ component of the nondimensional meteorold torque, $m_{m}$ is the meteorold's mass, $b_{I}$ Is the moment arm for the $I^{\text {th }}$ axis and $\Delta v$ is the change In the magnitude of the meteorold's velocity, showed that (for $\Delta 0$ between 20,000 ft./sec. and 60,000 ft./sec. and for $l_{1}$ between $1.0 \mathrm{ft}$. and 15 ft.) the station-keeping control should be able to easily accommodai e meteorolds with masses up to about $5 \times 10^{-5}$ Ibs. several times per orbit. (Accommodation of meteorolds of this size is considered to occur rarely. See Section $F$, Chapter II.) The acquisition control, which acts like a back-up station-keeplng control with some decrease in accuracy, 
should be able to accommodate meteorozds up to about 0.05 Ibs. (with little loss of accuracy).

A man in motion aboard the satelilte can exert forces on the satellite which cannot be compensated for by the station-keeping control. (The force on the satellite due simply to the man casually ralsing his arm above his head Is about 10 lbs.) The acquisition control cannot compensate for these forces unless (for the satelintes considered in this Investigation) the nondimensional control magnitudes, $N_{1}, I=1,2,3$, are increased to about 10,000 and the tıme delays are reduced to about IO microseconds. (Of course, if the satellites are much more massive than those considered here, say about 1000 tons, the values of $\mathbb{N}_{1}$ and of the tzme delays do not need to be so extreme.) 


\section{CONCLUSION}

A feedback control system for efficiently controlling the attitude motions of satellites in elliptic orbits about an oblate earth with an atmosphere was devised The criterıa used for efficient (or "satısfactory") performance were (1) high-accuracy (10-4 radians) In earth-pointing after the acquisition of the earth-pointing mode has been accomplished within the time of one-quarter orbyt from large angles $\left(\geqslant 60^{\circ}\right)$, (2) minimum fuel expenditure, and, (3) practicality of the system. Although four particular satellıte conflgurations ("stable" and "unstable") were assumed in the derivation, the devised control system performed well for a wide varlety of satellite shapes, orbits and parameters of the control. (See Chapter VI.)

The derivation of the control system proceeded In two steps. Furst, in Chapter IV the station-keeping part of the controlier was devised. Pontryagın"s maximum principle, the "jump conditions" and the guidelines obtalned from the minlmum-fuel station-keeping controls devised for single-axis systems were used in this derıvation. The maximum principle was applied to (1) the minimum-fuel problem which was considered as a problem in the theory of optimal processes with bounded phase coordinates and (2) the minimum-fuel problem with an integral constraint on the state (of the attıtude) for malntaining hlgh-accuracy earth-pointıng.

In Chapter $V$ the acquisition part of the controller was devised. Pontryagin's maxımum principal and phase plane methods were used to extend the Busch acquisition control to glve (1) acquistion for a wider range of satellites (Including "unstable" satellites), (2) higher accuracy and (3) acqusiztion from larger angles in the more realistic time of one-quarter orbit。

Two avenues of future research related to this Investigatiun are considered to be (I) the theory (sufficiency conditions) for the longtime optimal control of hlghly forced systems with bounded phase coordinates and (2) the high-accuracy and efficient control of the attitude motion of a manned satellite (by, perhaps, devices other than gas jets). 
REFHERENCES

1. Athans, M, "Fuel-Optimal Control of a Double Integral Plant with Response Time Constraints", IEEE Transactions on Applications and Industry, Vol. 83, July 1964.

2. Bandeen, W. R., and Manger, W. P., "Angular Motion of the SpIn Axıs of the TIros I Meteorological Satellite Due to Magnetıc and Gravitatıonal Torques", J. of Geophysıcal Research, Vol. 65, No. 9, September 1960

3. Breakwell, J V., "The Optimızatıon of Trajectorıes", J. Soc Ind Appl. Math., Vol. 7, No. 2, June 1959.

4 Breakwell, J V., and Koehler, I., "Ellıptıc Orbıts Infetımes", Advances in Astronautical Sciences, Plenum Press, New York, 1962.

5 Bryson, A. E., Denham, W. F., and Dreyfus, S. E., "Optımal Programming Problems with Inequalıty Constraints", AIAA Journal, Vol。 I, iNo 11, November 1963.

6. Busch, R., "The Attztude Control of a Satellite in an Fillzptic OrbIt", Stanford Ünıversıty Ph.D Thesıs, 1966, SUDAAR No. 261.

7. Chang, S. S. I., "Optimal Control In Bounded Phase Space", Automatıca, Vol. I, 1962. ‘

8. Christman, D. R., and McMillan, A. R., Journal of Environmental Sciences, Vol. 9, February 1966.

9. Cloutıer, G J., "Attztude Perturbatıon of Space Vehıcles by Meteorold Impact", Journal of Spacecraft and Rockets, Vol. 3, AprıI 1966.

10. Craıg, A., and FIügge-Lotz, I., "Investıgatıon of Optımal Control with a Minimum-Fuel Consumption Criterion for a Fourth-Order Plant with Two Control Inputs, Synthesis of an Efficient Suboptimal Control", ASME Journal of Basıc Englneerıng, Vol. 87, Serıes D, No 1, March 1965 
11. DeBra, D. B., "The Iarge Attztude Motıons and Stabllity Due to Gravity, of a Satellite with Passive Damping in a Orbit of Arbitrary Eccentrıcıty About an Oblate Body", Stanford Unıversıty Ph D. Thesıs, May 1962, SUDAER Report No. 126.

12. Flügge-Lotz, I., Dascontznuous and Optımal Control, McGran-Hzll Book Co, New York (New book to appear sprıng, 1968).

13. Flügge-Iotz, I, and Marbach, H., "The Optzmal Control of Some AttItude Control Systems for Different Performance Cruterza", ASME Journal of Basıc Englneerıng, Vol. 85, Serıes D, June 1963.

14. Foy, W. H., "Fuel Minimization in Flight Vehıcle Attıtude Control", IFHE Transactions on Automatic Control, Vol. AC-8, April 1963.

15. Haefner, K. B., "Attztude Control and Stabllizatzon System for an Orbıtıng Vehıcle", AFFDL-TR-64-165, May 1965

16. Hales, K. A., "Minzmum-Fuel Control of a Sixth-Order Nonlinear Plant by an Fxtended Method of Steepest Descent", Stanford Unבversity Ph.D. Thesıs, January 1966, SUDAAR No 257

17 Halkzn, H., "On the Necessary Condztıon for Optimal Control of NonIInear Systems", Technlcal Report No. 116, Applied Mathematics and Statzstıes Laboratory, Stanford Unıversıty, June 13, 1963.

18. Hayes, W. D., and Probsteln, R. F., Hypersonzc Flow Theory, AcademIc Press, New York, 1959.

19. Horwztz, H. P., and Ianning, W. C., "Precision Attztude Control Usıng Pulse WIdth Modulatıon", Control Engıneerıng, Vol. 13, June 1966.

20. Huston, R. I., "Twבn-Gyro Attıtude Control System", Journal of Spacecraft and Rockets, Vol. 3, July 1966.

21 Johnson, F. S., "Atmospherıc Structure", Satellite Environment Handbook, Stanford Unıversıty Press, Stanford, Calıformia, 1961.

22. Kane, T. R., Force and Energy (The second of three parts of a preIIminary edition from a forthcoming text on dynamies), Holt, Rinehart and Winston, New York, 1966 
23. King-Hele, D, Theory of Satellite Orbits in an Atmosphere, ButterWorth, Iondon, 1964.

24. Lee, E. B., "An Approximation to Innear Bounded Phase Coordinate Control Problems", Journal of Mathematical Analysis and Application, Vol. 13,1966

25. Marbach, $\mathrm{H}$, "The Optzmal Control of Innear Systems for a Minimum Control-Effort Performance Cruterıon", Stanford Unzversıty Ph.D. Thesis, 1963, SUDATR Report No. 153.

26. McElvain, R. J., "Effects of Solar Radiatzon Pressure on Satellite Attitude Control", Guzdance and Control (Progress in Astronautics and Rocketry), Vol. 8, Academzc Press, New York, 1962.

27. Medıtch, J. S., "On MinımaI-Fuel Satellite Attıtude Control", IEEE Transactions on Applicatzons and Industry, Vol. 83, No 71, March 1964

28 Nichol, K. C., "Research and Investigation on Satellite Attıtude Control, Parts I and II", AFFDI-TR-64-168, June 1965.

29. Pontryagin, I. S., et al., The Mathematical Theory of Optımal Processes, Edıted by L. W. Neustadt, Interscience Publishers, New York, 1962.

30. Rozonoer, I. I., "Pontryagin's Maximum Principle in the Theory of Optımal Systems - Parts I and II", Automatzka I Telemekhanıka, VoI. 20, 1962.

31. Russell, D I., "Penalty Functions and Bounded Phase Coordinate Control", Honeywell MPG-Report 1541-TR7, I6 January 1964.

32 Schwartz, I., "On innzmum-Energy Attıtude Acquisition Usıng Reaction Wheel Control", Journal of Spacecraft and Rockets, Vol. 3, JuIy 1966.

33. Sterne, T. E., An Intxoduction to Celestza1 Mechanics, Interscience Publishers, Inc., New York, 1960. 
34. Wheeler, P. C., "Magnetıc Attztude Control of Rigld Axıally Symmetric Spinning Sateliztes in Circular Farth Orbits", Stanford University Ph.D. Thesis, Aprıl 1965, SUDAER Report No. 224.

35. Whipple, F. I., "Environment in Space-Dust and Meteorıtes", Astronautzcs, Vol. 7, No. 8, August 1962. 
APPENDIX A. THE GRAVITATIONAL TORQUE

DeBra [11] has shown that the gravitational torque for $\mathrm{B} *$ (the $\mathrm{cm}$ of the satellite) due to an oblate earth is surtably given by

$$
\begin{aligned}
& \underline{T}_{\mathrm{g}}=\left(3 \mu / x^{3}\right) \underline{n}_{\mathrm{R}_{1}} \times \underline{I}_{\mathrm{R}_{1}} \\
& +\left(5 \mu J r_{E}^{2} / r^{5}\right) \underline{n}_{R_{1}} x I_{R_{1}}\left(1-7 \cos ^{2} \gamma\right) \\
& -\left(2 \mu J r_{E}^{2} / r^{5}\right) \underline{N} \times I_{\mathbb{N}} \\
& +\left(10 \mu \mathrm{Jr}_{\mathrm{E}}^{2} / \mathrm{r}^{5}\right) \cos \left(\underline{n}_{\mathrm{R}_{1}} \times \underline{I}_{\mathrm{N}}+\underline{N} \times I_{\mathrm{R}_{1}}\right)
\end{aligned}
$$

where $J=3 / 2\left(I_{p}-I_{E}\right) / m_{E} r_{E}^{2}=163 \times 10^{-3}, \mu=m_{E} G, I_{p}$ and $I_{E}$ are the polar and equatorial principal moment of inertia for $\mathrm{E}^{*}$ (the $\mathrm{c} \mathrm{m}$ of the earth) $m_{E}$ Is the earth's mass, $r_{E}$ Is the earth's equatorial radius, $G$ Is the universal gravitation constant, $\underline{n}_{\mathrm{R}}$ is a unit vector directed from $E^{*}$ to $B^{*}$, N Is a unit vector which is parallel to the earth's axis, $\gamma$ Is the angle between $\underline{N}$ and $\underline{n}_{R}$, and $\underline{I}_{R l}$ and $I_{N}$ are second moment vectors of the satellite, $B$, relative to $B^{*}$ for $\underline{n}_{R}$ and $\underline{N}$, respectıvely Kane [22] shows that $I_{N}$, for example, can be written as

$$
\underline{I}_{N}=\sum_{I=1}^{3} \sum_{j=1}^{3} b_{I} I_{I J} \underline{n}_{J}
$$

where $\underline{n}_{1}, I=I, 2,3$, are mutually perpendlcular unlt vectors, $b_{I}=\underline{N}$. $\underline{n}_{1}, I=1,2,3$, and $I_{I J}, 1, J=1,2,3$, are moments and products of inertia of $B$ relative to $B^{*}$ for $\underline{n}_{1}$ and $\underline{n}_{j}$

Suppose $\underline{n}_{1}, 1=1,2,3$ are parallel to principal axes of inertia of $B$ for $B^{*}$ (see Flgure $2 I$ ) Then $I_{I J}=0$ for $I \neq j$. If $\underline{n}_{I}, 1=1,2$, 3 , are right handed unzt vectors and $a_{1}=\underline{n}_{R_{1}} \underline{n}_{1}, 1=1,2,3$, then with the ald of $A .2$ and a simllar relation for $I_{R_{I}}$ the terms which appear as vector products in A.I can be written as 


$$
\begin{aligned}
\underline{n}_{1} \times \underline{I}_{R_{1}} & =a_{3} a_{2}\left(I_{3}-I_{2}\right) \underline{n}_{1}+a_{1} a_{3}\left(I_{1}-I_{3}\right) \underline{n}_{2} \\
& +a_{2} a_{1}\left(I_{2}-I_{1}\right) \underline{n}_{3}
\end{aligned}
$$

where ' $I_{I}=" I_{1 J}, 1=J=1,2,3$

Now the gravitational torque as given by A I can be written with the ald of equations A.3 in the desired component form A more useful expression for the torque is obtalned If $a_{1}$, and $b_{1}, 1=1,2$, 3 , are written as functions of the attitude angles $\theta_{I}, I=1,2,3$, and of the parameters of the orbit of the satellite, $\delta, \theta, \theta_{p}$ (see Figure A.1) ThIs will be done before equations A.3 are substituted into A.I.

It Is not difficult to conclude with the ald of Bigure A.I and trigonometry that

$$
\underline{N}=\sin \delta\left[\sin \left(\theta+\theta_{p}\right) \underline{n}_{R_{I}}+\cos \left(\theta+\theta_{p}\right) \underline{n}_{R_{2}}\right]+\cos \delta n_{R_{3}}
$$

where $\underline{n}_{R_{1}}$ is the unit vector given above, $\underline{n}_{R_{3}}$ is a unit vector which is normal to the orbit plane wath lts sense given by the right hand rule for increasing $\theta, n_{R_{2}}$ is a unit vector which together whth $\underline{n}_{\mathrm{R} I}$ and $\underline{n}_{\mathrm{R}}$ form a set of right-handed mutually perpendicular unIt 


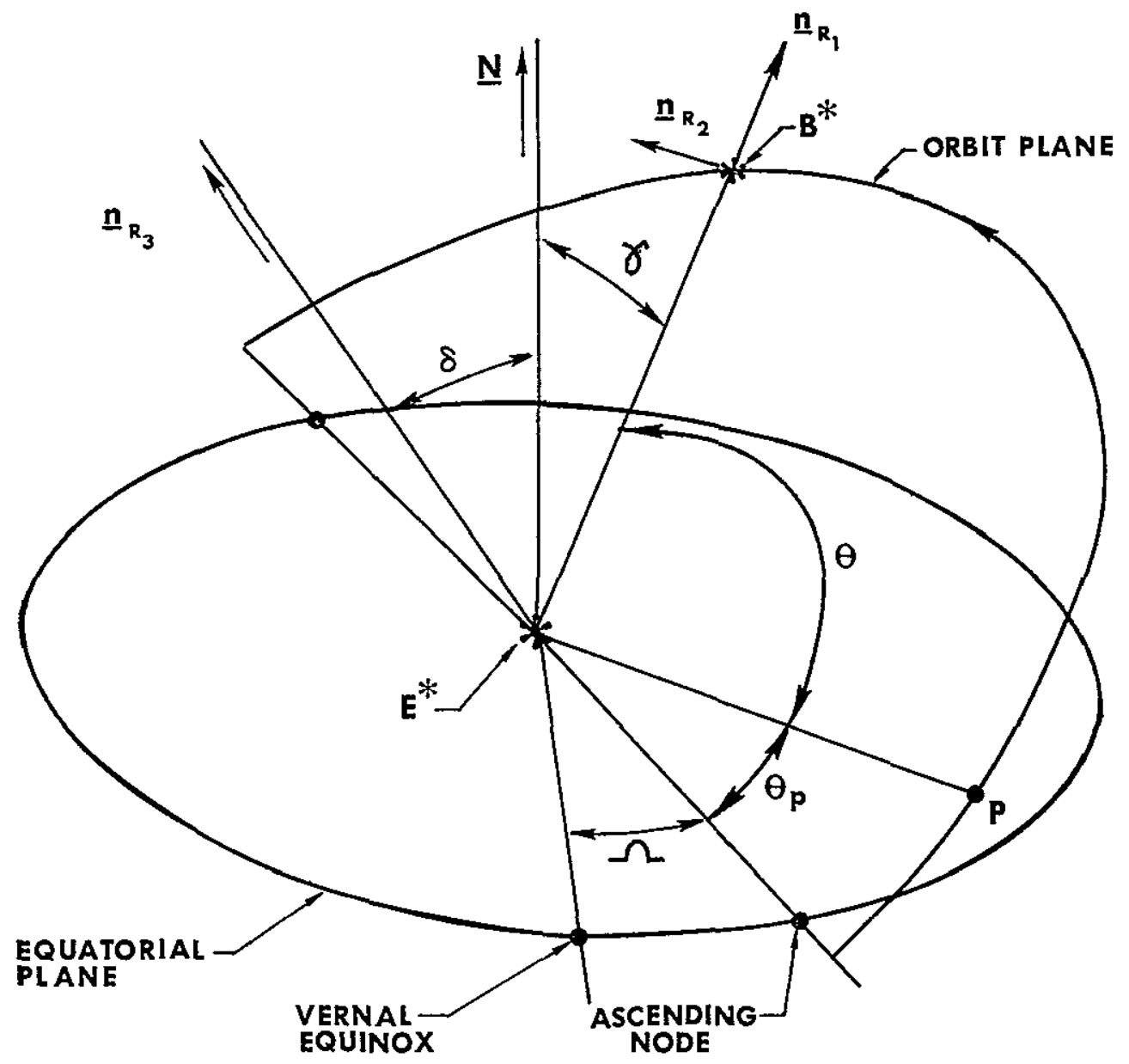

Figure A I Unzt Vectors and Parameters of the Orbit 
vectors and $\theta_{p}$ Is the angle between the ascending line of nodes and the line between $E^{*}$ and the perıgee pount of the orbit.

Now, If $\underline{n}_{R_{1}}, 1=1,2,3$, are written in terms of $\underline{n}_{1}, I=1,2$, 3 , and If these expressions are substituted into $A 4$, then the coefficients of $\underline{n}_{1}, 1=1,2,3$, in the resulting expression will be $b_{1}$, $1=1,2,3$, respectively The coefficients of $\underline{n}_{1}, 1=1,2,3$, 1 n the expression for $\underline{n}_{R_{1}}$ are $a_{1}, I=1,2,3$, respectively

If the three-axes Euler angles, $\theta_{1}, \theta_{2}, \theta_{3}$, are used as in Busch [6], It can be concluded that

$$
\begin{aligned}
& \underline{n}_{R_{1}}=c_{2} c_{3} \underline{n}_{1}-c_{2} s_{3} \underline{n}_{2}+s_{2} n_{3} \\
& \underline{n}_{R_{2}}=\left(s_{1} s_{2} c_{3}+c_{1} s_{3}\right) \underline{n}_{1}+\left(c_{1} c_{3}-s_{1} s_{2} s_{3}\right) \underline{n}_{2}-s_{1} c_{2} \underline{n}_{3} \\
& \underline{n}_{R_{3}}=\left(s_{1} s_{3}-c_{1} s_{2} c_{3}\right) \underline{n}_{1}+\left(s_{1} c_{3}+c_{1} s_{2} s_{3}\right) \underline{n}_{2}+c_{1} c_{2} \underline{n}_{3}
\end{aligned}
$$

where $c_{I}=\cos \theta_{1}, s_{1}=\sin \theta_{1}, 1=1,2,3$

From the first of $A$ It 1 s observed that

$$
a_{1}=c_{2} c_{3}, \quad a_{2}=-c_{2} s_{3}, \quad a_{3}=s_{2}
$$

and from $A 4$ and $A$ It 1 s observed that

$$
\begin{aligned}
& b_{1}=s_{\delta} s_{\theta} c_{2} c_{3}+s_{\delta} c_{\theta} c_{1} s_{3}-c_{\delta} c_{1} s_{2} c_{3}+s_{\delta} c_{\theta} s_{1} s_{2} c_{3}+c_{\delta} s_{1} s_{3} \\
& b_{2}=s_{\delta} c_{\theta} c_{1} c_{3}+c_{\delta} s_{1} c_{3}-s_{\delta} s_{\theta} c_{2} s_{3}+c_{\delta} c_{1} s_{2} s_{3}-s_{\delta} c_{\theta} s_{1} s_{2} s_{3} \\
& b_{3}=c_{\delta} c_{1} c_{2}+s_{\delta} s_{\theta} s_{2}-s_{\delta} c_{\theta} s_{1} c_{2}
\end{aligned}
$$

where, for example, $c_{\delta}=\cos \delta$ and $s_{\theta}=\sin \left(\theta+\theta_{p}\right)$

Now with A.3, A 6 and A 7 the gravitational torque, which is given by A.I, can be expressed in a form whlch Is convenlent for studying Its effect on the attitude motion of earth-pointing satellites The sub- 
stitution of $A_{0} 3$ Into $A .7$ results in $T_{g}=T_{g l} \underline{n}_{1}+T_{g 2} \underline{n}_{2}+T_{g 3} \underline{n}_{3}$ where

$$
\begin{aligned}
T_{g 1} & =\left(\mu / r^{3}\right)\left(I_{3}-I_{2}\right)\left\{3 a_{3} a_{2}+5 J\left[r_{E} / r\right]^{2}\left[1-7 \cos ^{2} \gamma\right] a_{3} a_{2}\right. \\
& \left.-2 J\left[r_{E} / r\right]^{2} b_{3} b_{2}+10 J\left[r_{E} / r\right]^{2} \cos \gamma\left[a_{2} b_{3}+a_{3} b_{2}\right]\right\} \\
T_{g 2} & =\left(\mu / r^{3}\right)\left(I_{1}-I_{3}\right)\left\{3 a_{1} a_{3}+5 J\left[r_{E} / r\right]^{2}\left[1-7 \cos ^{2} \gamma\right] a_{1} a_{3}\right. \\
& \left.-2 J\left[r_{E} / r\right]^{2} b_{1} b_{3}+10 J\left[r_{E} / r\right]^{2} \cos \gamma\left[a_{3} b_{1}+a_{1} b_{3}\right]\right\} \\
T_{g 3} & =\left(\mu / r^{3}\right)\left(I_{2}-I_{1}\right)\left\{3 a_{2} a_{1}+5 J\left[r_{E} / r\right]^{2}\left[1-7 \cos ^{2} \gamma\right] a_{2} a_{1}\right. \\
& \left.-2 J\left[r_{E} / r\right]^{2} b_{2} b_{1}+10 J\left[r_{E} / r\right]^{2} \cos \gamma\left[a_{1} b_{2}+a_{2} b_{1}\right]\right\}
\end{aligned}
$$

In the terms of equations A.8 the factors which Involve only $a_{1}$ and $b_{1}, 1=1,2,3$, are given by

$$
\begin{aligned}
a_{3} a_{2} & =-c_{2} s_{2} s_{3}, a_{1} a_{3}=c_{2} s_{2} c_{3}, a_{2} a_{1}=-c_{2}{ }^{2} c_{3} s_{3} \\
b_{3} b_{2} & =s_{\delta} c_{\delta} c_{\theta} c_{1}{ }^{2} c_{2} c_{3}+s_{\delta}{ }^{2} c_{\theta} s_{\theta} c_{1} s_{2} c_{3}-s_{\delta}{ }^{2} c_{\theta}^{2} c_{1} s_{1} c_{2} c_{3} \\
& +c_{\delta}{ }^{2} c_{1} s_{1} c_{2} c_{3}-c_{\delta} s_{\delta} s_{\theta} c_{1} c_{2}{ }^{2} s_{3}+\left(\text { terms In } s_{1}^{2}, \ldots, s_{1}^{4}\right) \\
b_{1} b_{3} & =s_{\delta} c_{\delta} s_{\theta} c_{1} c_{2}{ }^{2} c_{3}+s_{\delta}{ }^{2} s_{\theta}{ }^{2} c_{2} s_{2} c_{3}-s_{\delta}{ }^{2} s_{\theta} c_{\theta} s_{1} c_{2}{ }^{2} c_{3} \\
& \left.+s_{\delta} c_{\delta} c_{\theta} c_{1}{ }^{2} c_{2} s_{3}-c_{\delta}{ }^{2} c_{1}{ }^{2} c_{2} s_{2} c_{3}+\text { (terms In } s_{1}{ }^{2}, s_{1}{ }^{3}\right)
\end{aligned}
$$

157 


$$
\begin{aligned}
& b_{2} b_{1}=s_{\delta}^{2} s_{\theta} c_{\theta} c_{1} c_{2} c_{3}^{2}+s_{\delta} c_{\delta} s_{\theta} s_{1} c_{2} c_{3}^{2}-s_{\delta}{ }^{2} s_{\theta}{ }^{2} c_{2}{ }^{3} c_{3} s_{3} \\
& +s_{\delta}{ }^{2} c_{\theta}{ }^{2} c_{1}{ }^{2} c_{3} s_{3}-s_{\delta} c_{\delta} c_{\theta} c_{1}{ }^{2} s_{2} c_{3}^{2}+\left(\text { terms in } s_{1}^{2}, \ldots, s_{1}{ }^{5}\right) \\
& a_{2} b_{3}+a_{3} b_{2}=c_{8} c_{1} c_{2}\left(s_{2}-c_{2} s_{3}\right)+\left(\text { terms in } s_{1}^{2}, \ldots, s_{1}^{4}\right) \\
& a_{3} b_{1}+a_{1} b_{3}=c_{\delta} c_{1} c_{2}^{2} c_{3}+2 s_{\delta} s_{\theta} c_{2} s_{2} c_{3}-s_{\delta} c_{\theta} s_{1} c_{2}{ }^{2} c_{3} \\
& +\left(\text { terms In } s_{1}^{2}, s_{1}^{3}\right) \\
& a_{1} b_{2}+a_{2} b_{1}=s_{\delta} c_{\theta} c_{1} c_{2} c_{3}^{2}-2 s_{\delta} s_{\theta_{2}} c^{2} c_{3} s_{3}+c_{\delta} s_{1} c_{2} c_{3}^{2} \\
& +\left(\text { terms in } s_{1}^{2}, s_{1}^{3}\right)
\end{aligned}
$$

From $A_{0} 4$ It is found that $\cos \gamma=\underline{N} \cdot \underline{n}_{R_{1}}$ is given by

$$
\cos \gamma=\sin _{\delta} s_{\theta}
$$


APPEIVDIX B。 THE AERODYNAMIC TORQUE

If a satellite $1 \mathrm{~s}$ in orbit 100 mlles or more above the earth's surface, then the ratıo of the speed of $B^{*}$ to the most probable random speed of the arr molecules is of the order of $10^{3}$. At these altitudes the mean free path of the molecules greatly exceed the maximum IInear dimension of the satellite Hayes and Probsteln [18] have shown for bodies in such free molecular flow that the pressure and shear Is given by

$$
\begin{aligned}
& p=\left(2-f_{n}\right) \rho V^{2} \cos \psi \\
& \tau=f_{t} \rho V^{2} \sin \psi \cos \psi
\end{aligned}
$$

where $f_{n}$ and $f_{t}$ are the normal and tangential accommodation coefficients, $\rho$ is the density of the aur, $v=\left|\underline{v}^{p / a}\right|$ where $\underline{v}^{p / a}$ Is the velocity of a point $P$ of the element of surface area of $B$ relative to the free-stream velocity of the air near the satellite and $\psi$ is the angle between the vector $\mathrm{v}^{\mathrm{p} / \mathrm{a}}$ and a line normal to the surface element.

For the satelizte attitude motzons considered in this thesis the angular velocity of $B$ in inertial space is such that error in taking $\underline{v}^{p / a}=\underline{v}^{B^{*} / a}$ Is at most $0.0001 \%$. In the following derivation $V$ wlll be assumed to be $\left|\underline{\mathrm{v}}^{\mathrm{B} / \mathrm{a}}\right|$.

The accommodation coefficients are defined by $f_{t}=\left(\tau_{I}-\tau_{\underline{r}}\right) / \tau_{I}$ and $f_{n}=\left(\underline{p}_{1}-p_{r}\right) /\left(p_{1}-p_{b}\right)$ where, for example, $p_{b}$ Is the normal momentum component of the molecules which are re-emctted from the surface with a Maxwellian distribution at the surface temperature $\mathrm{T}_{\mathrm{b}}$ and the subscripts $I$ and $r$ denote incident and reflected. Hayes and Probstein conclude from the results obtained by experimentalists that $f_{t}$ lies in the range between 08 and 1.0 and $f_{n}$ is about uncty

If $\underline{n}$ denotes a unt vector normal to the element of surface area, say ds, and Is directed out of $B$ and if $\underline{n}$ is such that $\underline{v}^{B * / a}=V_{n}$, then the force on ds is given by

$$
d \underline{E}=-\rho V^{2} \cos \psi\left[\left(2-f_{n}\right) \cos \psi \underline{n}_{n}-f_{t} \sin \psi \underline{n}_{t}\right] d s
$$


where $\underline{n}_{t}$ is a unzt vector in the direction of the projection of $\underline{n}$ onto ds.

For a spherical satellite the Integration of (B.I) over the half of the surface in the flow gives

$$
\underline{F}=-C_{D} S \rho V^{2} / 2 \underline{n}
$$

where $C_{D}=2-f_{n}-f_{t}$ and $S$ is the projected area so that the force vector is parallel to $\underline{\mathrm{v}}^{\mathrm{B} / \mathrm{a}}$ and is a drag force.

If $f_{n}=f_{t}=1$ in $(B .1)$, then $\underline{d F}$ is paraliel to $\underline{v}^{B^{*}}$ for an element of a satellite of arbitrary shape. Thus, the sum $\underline{F}$ will be a drag force only for any satelizte if $f_{n}=f_{t}=1$.

If $f_{n}=I$ and $f_{t}=0.80$, the lowest value given above, then in (B.I), the term In parentheses can be written as

$$
\underline{n}+0.2 \sin \psi\left(\cos \psi \underline{n}_{\ell}-\sin \psi \underline{n}\right)
$$

where $\underline{n}_{\ell}$ is perpendicular to $\underline{n}$ and is directed maximally away from dsi. Examnation of this term shows that a "IIft" component of the force is possible for some orientations of some sateliztes. For a cylindrical satellite with elther circular or elliptic cross section in a nearly earth-pointing orientation, say $10^{-3}$ radians, the term which contributes to the lift is smaller than $10^{-3}$ times the drag component for both lateral and end surfaces so that the "IIft" component of the resultant force $\mathrm{W} I l$ be insignificantly small. For all other orlentations of any satellite the ratıo of "Ilft" to "drag" is still less than 0.12.

The aerodynamic force used in the calculation of the aerodynamic torque for $B^{*}$ wI,I be that given by (B.2).

$\mathrm{K}$ Ing-Hele [23] considers the error to be less than 5\% when $C_{D}$ Is taken to be 2.2 for both spheres and cylinders $(\ell / d>1)$ if $C_{D}$ is based on the mean area, $s$, perpendicular to the direction of motion.

The atmospheric density $\rho$ has been determined experimentally and theoretically in resent years for altitudes above $100 \mathrm{mlles}$. It has been found (see KIng-Hele [23] and Johnson [21]). that $\rho$ decreases a.most logarithmlcally with altitude between about $150 \mathrm{mlles}$ and about 500 miles. If this be the case then 


$$
\rho=\rho_{p} \exp \left[-K\left(r-r_{p}\right)\right]
$$

where the subscript $p$ denotes perigee, $K$ Is a constant to be determined from the data and $r$ is the distance from $E^{*}$ to $B^{*}$. The atmospheric density data Is usually plotted on sem-log graph paper so that $K$ can be read from the plots directly From these plots it is observed that $K$ should be about 002 miles $^{-1}$ from an altitude of 200 mlles and should be about 0 OI miles ${ }^{-1}$ from an altztude of 500 miles Also, it is observed that due to changes in the sun's influence between day-tıme and nIght-time, the density changes by a factor of about two at an altitude of 200 miles and by a factor of about ten at an altztude of 500 miles. The maximum values occur in the daytime. If it is desired to $f \mathrm{fx} \rho_{p}$ and $K$ for any one orbit without regard to day and night, then for the most nearly correct values of $\rho$ over the range of altitudes of the orbit and over the time Interval of days it is best to pick the day-time value of $\rho_{p}$ and the value of $K$ which corresponds to day-time values of $\rho$ near perıgee. This is done in the thesis for a height of perigee of 200 miles In this case the density, $\rho$, as given by $(B)$ Is considered to be too large during night-time by a factor of two at $200 \mathrm{mlles}$ and by a factor of ten at $500 \mathrm{mlles}$. It Is considered to be too small by a factor of 0.7 durıng day-tıme at 500 miles and to be correct during day-time at 200 miles

The torque of the aerodynamic forces acting on the elements of surface area of a spherıcal or high-accuracy earth-pointing cylindrical satellite is given by

$$
\underline{\underline{T}}=\underline{\ell} \times \underline{\underline{F}}
$$

where $\&$ Is the distance vector from $B^{*}$ to the geometrical centrold (GC) of the satelinte.

In Appendix A, Figure A I, the orbiting reference axes with unit vectors $\underline{n}_{R 1}, \underline{n}_{R_{2}}, \underline{n}_{R_{3}}$ were defined The unit vectors $\underline{n}_{1}, 1=1,2,3$, are defined in Section A of Chapter II (see Figure (2.I)).

Since the GC Is fixed in $B$, it is convenient to write

$$
\underline{l}=\ell_{1-1} \underline{n}_{1}+\ell_{2-2} \underline{n}_{2}+\ell_{3} \underline{n}_{3}
$$


where $\ell_{1}=\underline{\ell} \quad \underline{n}_{1}, 1=1,2,3$ If $\underline{n}$ Is written in terms of $\underline{n}_{1}$, $I=1,2,3$, then with the use of (B 5) $\underline{T}_{a}$ wIII be In.terms of $n_{1}$, $1=1,2,3$, as desired.

Since $\underline{v}^{B^{*} / a}=\underline{v}^{B^{*}}-\underline{v}^{a}=\underline{V}$ and sunce $\underline{v}^{B^{*}}=\dot{r}_{R_{1}}+r \theta \underline{n}_{R_{2}}$ and $\underline{\mathrm{v}}^{\mathrm{a}}=\underline{\omega}^{\mathrm{E}} \times \underline{r n}_{\mathrm{R}_{I}}=\dot{\theta}_{\mathrm{E}} r\left(\underline{\mathbb{N}} \times \underline{\underline{n}}_{\mathrm{R}_{I}}\right)$ where $\theta_{\underline{E}}$ Is the angular speed of the earth and $\mathbb{N}$ Is given in Appendix $A$, then

$$
\underline{n}=\frac{\stackrel{r}{r}}{v} \underline{n}_{R_{1}}+\frac{r\left(\dot{\theta}-\theta_{E} c_{\delta}\right)}{v} \underline{n}_{R_{2}}+\frac{r \dot{\theta}_{E} s_{\delta} c_{\theta}}{v} \underline{n}_{R_{3}}
$$

where $s_{\delta}, c_{\theta}$ are defined in Appendıx A.

From (B.6) It is seen that

$$
v^{2}=\dot{r}^{2}+r^{2} \dot{\theta}^{2}+r^{2}\left[\dot{\theta}_{E}^{2}\left(c_{\delta}^{2}+s_{\delta}^{2} c_{\theta}^{2}\right)-2 \theta_{E} \theta c_{\delta}\right]
$$

WIth the ald of (C 7)-(C 9) equation (B 7) can be written as

$$
v^{2}=\frac{h^{2}\left(1+e^{2}+2 e c \theta\right)}{a^{2}\left(1-e^{2}\right)^{2}}-2 h \theta_{E} c_{\delta}+r^{2} \dot{\theta}_{E}^{2}\left(c_{\delta}^{2}+s_{\delta}^{2} c_{\theta}^{2}\right)
$$

where $c \theta=\cos \theta$.

If $e \leq 005$, then the expression for $v$ differs from

$$
\mathrm{V}=(\mathrm{h} / \mathrm{a})(1+2 e c \theta)^{1 / 2}=r \dot{\theta}
$$

only in the third significant figure.

The substitution of (A.5) Into (B 6) and the results of this substitution into (B 2) produces an expression for the force, $F$, which is in terms $n_{1}, 1=1,2,3$. If this expression for the force 1 s substituted Into (B 4) with (B 5) and if the vector product Is carried out, the result is $\underline{T}_{a}=T_{a 1} \underline{n}_{1}+T_{a 2}-2+T_{a 3}-3$ where

$$
\begin{aligned}
& T_{\text {aI }}=-\frac{C_{D} S p V}{2}\left\{\dot{r}\left(l_{2} s_{2}+\ell_{3} c_{2} s_{3}\right)-r\left(\theta-\theta_{E} c_{\delta}\right)\left[l_{2} s_{1} c_{2}\right.\right. \\
& \left.\left.+b_{3}\left(c_{1} c_{3}-s_{1} s_{2} s_{3}\right)\right]+r \dot{\theta}_{E} c_{\theta} s_{8}\left[b_{2} c_{1} c_{3}-b_{3}\left(s_{1} c_{3}+c_{1} s_{2} s_{3}\right)\right]\right\} \\
& T_{a 2}=-\frac{c_{D} S \rho V}{2}\left\{\dot{r}\left(b_{3} c_{2} c_{3}-b_{1} s_{2}\right)+r\left(\theta-\theta_{E} c_{8}\right)\left[l_{3}\left(s_{1} s_{2} c_{3}+c_{1} s_{3}\right)+b_{1} s_{1} c_{2}\right]\right.
\end{aligned}
$$




$$
\begin{aligned}
& \left.+r \theta_{E} c_{\theta} s_{\delta}\left[b_{3}\left(s_{1} s_{3}-c_{1} s_{2} c_{3}\right)-b_{1} c_{1} c_{2}\right]\right\} \\
T_{23} & =-\frac{C_{D} S \rho V}{2}\left\{-r\left(l_{1} c_{2} s_{3}+l_{2} c_{2} c_{3}\right)+r\left(\theta-\dot{\theta}_{E} c_{\delta}\right)\left[l_{1}\left(c_{1} c_{3}-s_{1} s_{2} s_{3}\right)\right.\right. \\
& \left.-l_{2}\left(s_{1} s_{2} c_{3}+c_{1} s_{3}\right)\right]+r \dot{\theta}_{E} c_{\theta} s_{\delta}\left[l_{1}\left(s_{1} c_{3}+c_{1} s_{2} s_{3}\right)\right. \\
& \left.\left.-l_{2}\left(s_{1} s_{3}-c_{1} s_{2} c_{3}\right)\right]\right\}
\end{aligned}
$$

The quantztzes $\rho$ and $v$ in (B.9) are assumed to be suztably given by (B.3) and (B 8) The quantities $r, r$, and $\dot{\theta}$ are given as functions of time in Appendix $C$ The quantities $C_{D}, S, l_{1}, 1=1,2,3$, pertain to a glven satellıte, and, the quantıties $h, a, c_{\delta}, s_{\delta}, \theta_{p}, r_{p}, K$ and $\rho_{p}$ pertain to a given orbıt. Except for $C_{D}$, which is taken as $C_{D}=22$, given values of these quantitıes were chosen in Chapter II The angular speed of the earth Is $\theta_{\mathrm{T}}=73 \times 10^{-5} \mathrm{rad} / \mathrm{sec}$.

The error in the torque components, (B 9), are considered to be caused primarily by the error in $\rho$ and the exror in the product $C_{D} S$. These errors were discussed above The total error in each of Tas", $I=1,2,3$, Is considered to be between $2000 \%$ to large (night-time at $500 \mathrm{mlles}$ ) and $50 \%$ too small (day-tıme at $500 \mathrm{mlles}$ ) Generally, this means that the magnitudes of the components of $\underline{T}_{2}$ are between $I / 2$ and 20 times the correct values

For the purpose of determining a feedback control law whych wIll result in sultable attitude motion, when this motion is influenced by the atmosphere, this inaccuracy is Insignificant of course, performance measures such as fuel cost can be 1 n ersor as much as $T_{a I}, 1=1,2,3$, are in error, but, generally, this depends on the magnitudes of the components of the other torques which influence the attitude motion. 


\section{APPENDTX C THE PARAMETERS OF THE ORBIT}

\section{AS FUNCTIONS OF TTME}

KIng-Hele [23] and Sterne [33] have derived expressions for the rates of change of $a, e, \Omega, \delta$, and $\theta_{p}$ of a Kepler orbut due to the primary perturbing sources which are the earth's oblateness and the earth's atmosphere. For the orbits considered in this investigation the changes are less than 10 miles per day in a, $2 \times 10^{-4}$ per day in e, $7^{\circ}$ per day in $\Omega, 1^{\circ}$ per day in $\delta$ and $10^{\circ}$ per day in $\theta_{p}$ For any one orbit these changes cause only an insignificant change in the terms In the attitude equations of motion Thus, since the equations of motıon are perıodically tıme varyıng, they need to be integrated for a single orbit only so that for any one integration $a, e, \Omega, \delta$ and $\theta_{p}$ can be assumed constant.

The angle $\theta$ varıes from zero to $2 \pi$ radians For a Kepler orbut $\theta$ is related to $r$ by

$$
r=\left(h^{2} / \mu\right)(1+\text { ec } \theta)^{-1}
$$

where $\mu=\mathrm{m}_{\mathrm{E}} G, c \theta=\cos \theta^{-\alpha}$ and $h$ Is a constant such that $r^{2} \theta=h$ Thus,

$$
\begin{aligned}
& \underline{\mu}_{3}=n^{2}(1+e c \theta)^{3} \\
& \dot{\theta}=n(1+e c \theta)^{2}
\end{aligned}
$$

and

$$
\frac{1}{r^{2}}=\frac{(1+e c \theta)^{2}}{a^{2}\left(1-e^{2}\right)^{2}}
$$

* For convenzence $c \theta=\cos \theta$, but generally $c \theta=\cos \left(\theta+\theta_{0}\right)$. 
where $n=\mu^{2} / h^{3}$ and $a\left(1-e^{2}\right)=h^{2} / \mu$

The differentiation of $C .3$ with respect to time and the substitution of $\mathrm{C} 3$ into the differentiated expression gives

$$
\dot{\theta}=-2 n^{2} e s \theta(1+e c \theta)^{3}
$$

The angle $\theta$ can be written as an approximate function of $t$ so that the right hand sides of equations C I - C 5 can be written as approximate functions of $t$

In the thesis $e$ is assumed to be less than or equal to 0.05 In this case the function $(1+e c \theta)^{-2}$ can be expanded in a rapldiy converging power series in $e$ so that the integral of $\mathrm{C} 3$ can be written as

$$
\int_{0}^{\theta}\left(1-2 e c \theta+3 e^{2} c^{2} \theta-[\text { REMAINDER] }) d \theta=n \int_{0}^{t} d t\right.
$$

where (REMAINDER) $=4 e^{3}\left[\left(\cot +e c^{2} \theta\right)^{3} /(1+\operatorname{ec} \theta)^{8}\right]_{e=x}$ for $0 \leq x \leq 0.05$. If the maximum absolute value of the REMAINDER Is used, then

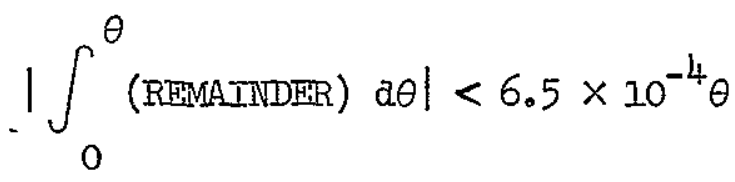

so that

$$
\Omega t=\theta\left(1+3 / 2 e^{2}\right)-2 e \sin \theta+3 / 4 e^{2} \sin 2 \theta
$$

with an error less than $0.06 \%$ or

$$
n t=\theta-2 e \sin \theta
$$


with an error only in the third significant figure (except at $\theta=0$ where the error is zero)

Equations C 1 - C.5 are approxımately glven by

$$
\begin{aligned}
& r=\left(h^{2} / \mu\right)(1-e c \theta) \\
& \frac{\mu}{r^{3}}=n^{2}(1+3 e c \theta) \\
& \theta=n(1+2 e c \theta) \\
& r^{-2}=a^{-2}(1+2 e c \theta) \\
& \dot{\theta}=-2 n^{2} \operatorname{es} \theta(1+3 e c \theta)
\end{aligned}
$$

With the approximation only in the third significant figure The use of $\mathrm{c} .6$ and trigonometric ldentities results in

$$
c \theta=\cos n t \cos (2 e \sin \theta)-\sin n t \sin (2 e \sin \theta)
$$

and

$$
s \theta=\sin n t \cos (2 e \sin \theta)+\cos n t \sin (2 e \sin \theta)
$$

The expressions for $c \theta$ and $s \theta$ given in $c 12$ and $c .13$ differ from exact values by less than 0.01 . (This Is easily seen by plotting $[\cos \theta-\cos (\theta \pm \epsilon)]$ and $[\sin \theta-\sin (\theta \pm \epsilon)]$ as a function of the error, $\epsilon \leq \mathrm{O}$ OI $(\epsilon>0)$, for varıous values of $\theta)$ Thus, if $\mathrm{C} 12$ and $\mathrm{C} 13$ are substituted into $\mathrm{C} .7-\mathrm{C} 11$, then $\mathrm{C} .7$ - C $10 \mathrm{w} 11$ be in exror only in the fourth significant figure and $C 11$ wlll be in error by less than $1 \%$ for most of the orbit. In $\mathrm{C}$ - C 11 the factors $(1-\operatorname{ec} \theta),(1+2 e c \theta),(1+3 e c \theta)$ and $\operatorname{se}(1+3 e c \theta)$ can be written with the ald of $\mathrm{C} I 2$ and $\mathrm{C} 13$ as 


$$
\begin{aligned}
(1-e c \theta)=1 & -e \cos n t \cos (2 e \sin \theta) \\
& +e \sin n t \sin (2 e \sin \theta) \\
(1+2 e c \theta)=1 & +2 e \cos n t \cos (2 e \sin \theta) \\
& -2 e \sin n t \sin (2 e \sin \theta) \\
(1+3 e c \theta)=1 & +3 e \cos n t \cos (2 e \sin \theta) \\
& -3 e \sin n t \sin (2 e \sin \theta)
\end{aligned}
$$

$$
\begin{aligned}
\operatorname{se}(1+3 e c \theta) & =\sin n \tau \cos (2 e \sin n)+\cos n t \sin (2 e \sin \theta) \\
& +3 e \cos n t \sin n t\left[\cos ^{2}(2 e \sin \theta)-\sin ^{2}(2 e \sin \theta)\right] \\
& +3 e\left(\cos ^{2} n t-\sin ^{2} n t\right) \sin (2 e \sin \theta) \cos (2 e \sin \theta)
\end{aligned}
$$

S.nce $e \leq 0.05$, then $|\sin (2 e \sin \theta)| \leq 2 e \leq 0.1$ and $\mid \cos (2 e$ $\sin \theta) \mid=1.00$. Thus, $\mathrm{C} .14-\mathrm{C} .16$ can differ from

$$
\begin{aligned}
& (1-e c \theta)=1-e \cos n t \\
& (1+2 e c \theta)=1+2 e \cos n t \\
& (1+3 e c \theta)=1+3 e \cos n t
\end{aligned}
$$

only in the third signlficant figure and

$$
\begin{aligned}
& \begin{aligned}
\operatorname{si} \theta(1+3 e c \theta) & =\sin n t+\cos n t \cdot 2 e \sin \theta+3 e \cos n t \sin n t \\
& +3 e\left(\cos ^{2} n t-\sin ^{2} n t\right) \cdot 2 e \sin \theta
\end{aligned} \\
& \text { Is } 1 n \text { error by less than } 1 \% \text {. Since } \sin \theta=\sin n t+2 e \sin \theta \cos n t \\
& \text { (from C.13) with less than } 1 \% \text { error for most of the orblt, then } C .21
\end{aligned}
$$
can be written as 


$$
\operatorname{se}(1+3 e c \theta)=\sin n t+5 e \cos n t \sin n t
$$

or

$$
\operatorname{s} \theta^{2}(1+3 e c \theta)=\sin n t+5 / 2 e \sin 2 n t
$$

with a total error of less than $1 \%$ for most of the orbit. (Actually, the difference in the exact values and the values given by $C .22$ Is less than 0.01 for the entire orbit, but the percent error becomes unbounded as the exact value approaches zero).

Now the substitution of $\mathrm{C.18}-\mathrm{C.20}$ and $\mathrm{C} .22$ Into $\mathrm{C.7}-\mathrm{C} .1 \mathrm{l}$ results in

$$
\begin{aligned}
& r=r_{p}[1-e(\cos n t-1)] \\
& \frac{\underline{\mu}_{3}}{r^{3}} \underline{n}^{2}(1+3 e \cos n t) \\
& \dot{\theta}=n(1+2 e \cos n t) \\
& r^{-2}=a^{-2}(1+2 e \cos n t) \\
& \ddot{\theta}=-2 n^{2} e(\sin n t+5 / 2 e \sin 2 n t)
\end{aligned}
$$

where in C.7 $h^{2} / \mu$ has been replaced by $a\left(1-e^{2}\right)=r_{p}(1+e)$ and terms in $e^{2}$ omitted. The results in equations $c .23$ - 0.26 differ from the exact values in the third or higher significant figure, and, the values for $\ddot{\theta}$ which are given by C.27 are in error by less than 0.01 parts in one for most of the orbit. If $c .6$ Is used, then $s \theta$ and $c \theta$ can be written approximately as 


$$
\begin{aligned}
\sin \left(\theta+\theta_{0}\right) & =\sin \left(n t+\theta_{0}\right) \\
& +2 e \cos \left(n t+\theta_{0}\right) \sin n t(1+2 e \cos n t) \\
\cos \left(\theta+\theta_{0}\right) & =\cos \left(n t+\theta_{0}\right) \\
& -2 e \sin \left(n t+\theta_{0}\right) \sin n t(1+2 e \cos n t)
\end{aligned}
$$

The order of approxzmation in $\mathrm{C.28}$ and $\mathrm{C.29}$ is the same as in C 12 and C.13. 


\section{APPENDIX D THE STATE-SPACE REGION OF STATION-KEEPING}

The region of station-keepıng, $S$, was defined in Section $A$ of Chapter III Since It is clear that at least parts of the boundary of S must be swltchnng surfaces for a feedback control law, the cholce of the region $S$ from possible station-keeping regions should be a best cholce. The criteria used for a best cholce are small error, a minimum fuel expenditure and simplicity.

If the angle, $\varphi$, between the local vertical and the satellitefluxed IIne $I_{1}$ [see Figure (2 l)] and Its rate, $\varphi^{*}$, are required to be small, say $|\varphi| \leq s,\left|\varphi^{\prime}\right| \leq r$, then the requlrements on $\theta_{1}, I=2,3$, and their rates are

$$
\begin{aligned}
& |\varphi| \approx \sqrt{\theta_{2}^{2}+\theta_{3}^{2}}=\sqrt{x_{3}^{2}+x_{5}^{2}} \leqslant s \\
& \left|\varphi^{t}\right| \approx \frac{\left|\theta_{2} \theta_{2}^{\prime}+\theta_{3} \theta_{3}^{\prime}\right|}{\sqrt{\theta_{2}^{2}+\theta_{3}^{2}}}=\frac{\left|x_{3} x_{4}+x_{5} x_{6}\right|}{\sqrt{x_{3}^{2}+x_{5}^{2}}} \leqslant r
\end{aligned}
$$

For near earth-pointing, the yaw angle and Its rate must also be restricted to small values so that the requirements on $\theta_{1}$ and $\theta_{I}$ are $\left|\theta_{1}\right| \leq s_{1},\left|\theta_{1}^{\prime}\right| \leq s_{2}$. This region of station-keeplng is not sufflclent to avold exceedingly large values in elther $\theta_{2}^{\prime}$ or $\theta_{3}^{\prime}$ Also, the switching $\log I$ c for a controller based on such a region is not simple.

Generally, the station-keeping region should be closed region of the state-space which encloses the orıgin Thus, in any phase-plane projection of the region, the projection of its boundary should be a closed curve which encircles the origin Circles, ellipses, parts of parabolas, parts of straight lines, etc can be used for constructing the closed curves However, If parts of curves such as circles, parabolas, etc., which are analytically described with squares of the state variables, are used, the error in the state variable signal from the sensors is compounded. Thus, the region which encloses the orIgin should be constructed with linear functions unless such a regıon results 
In a significant fuel cost increase The region $S$, as given, is one such region. The dependence of the size of the region on fuel cost is discussed in Section B, Chapter VI 
APPENDIX E. AN APPROXIMATE SOLUTION OF THE ADJOINT FQUATIONS

For satellites which are "stable" In roll-yaw, the approximate solution of the adjoint equations for

$$
J=\int_{\tau_{0}}^{\tau_{f}}\left[f_{1}(\underline{x})+\sum_{I}^{3}\left|v_{1}\right|\right] d \tau
$$

which is derived below is in excellent agreement with the digital computer solutions.

Iet $\tau_{e}, \tau_{0}^{*} \leq \tau_{e} \leq \tau_{i}^{*}$, denote the time at which the roll-yaw (pitch) trajectory re-enters the roll-yaw (pitch) projection of $S$ if the trajectory has departed the projection of $S$ Otherwise, let $\tau_{e}=\tau_{0}^{*}$. With this fixed (after each encounter with the boundary of $s$ ) time, the piecewise IInear equations, (4.4) and (4.6) with (4.7), can be approximated by plecewise constant equations by replacing $\tau^{*}$ with $\tau_{e}$ In $A_{1}, A_{2}$ and $A_{3}$.

Iet $\tau_{1}, \tau_{0}^{*} \leq \tau_{1} \leq \tau_{1}^{*}, I=1, \ldots, 6$, Denote the time at whIch the projected trajectory, $x_{1}\left(\tau^{*}\right)$, exits the $x_{1}$-projection of $s$. Then, since $F\left(x_{1}\right)$ is $10^{n_{1}},-10^{n_{1}}$ or zero and since $A_{1}, A_{2}$ and $A_{3}$ are now constants, equations $(4.4)$ and $(4.6)$ can be laplace transformed as follows

\section{yaw-rol1}

$$
\begin{aligned}
& s P_{1}-p_{1 e}=\frac{-F\left(x_{1}\right)}{s} \exp \left(-\tau_{1} s\right)-k_{1} A_{1}^{2} P_{2}+A_{2} P_{4} \\
& s P_{2}-p_{2 e}=\frac{F\left(x_{2}\right)}{s} \exp \left(-\tau_{2} s\right)+P_{1}-K_{2} A_{1} P_{4} \\
& s P_{3}-p_{3 e}=\frac{-F\left(x_{3}\right)}{s} \exp \left(-\tau_{3} s\right)-A_{2} P_{2}+k_{2}\left(3 A_{3}+A_{1}^{2}\right) P_{4} \\
& s P_{4}-p_{4 e}=\frac{F\left(x_{4}\right)}{s} \exp \left(-\tau_{4} s\right)+K_{1} A_{1} P_{2}+P_{3}
\end{aligned}
$$




\section{Prtch}

$$
\begin{aligned}
& s P_{5}-p_{5 e}=\frac{-F\left(x_{5}\right)}{s} \exp \left(-\tau_{5 s}\right)-3 k_{3} A_{3} P_{6} \\
& s P_{6}-p_{6 e}=\frac{F\left(x_{6}\right)}{s} \exp \left(-\tau_{6} s\right)+P_{5}
\end{aligned}
$$

where $p_{I e}=p_{1}\left(\tau_{e}\right), I=1, \ldots, 6$, and $P_{1}=P_{1}(s)$ Is the Iaplace transform of the variable $p_{1}(\tau *), I=1, \ldots, 6$.

If equations $(E I)$ are solved for $P_{I}, I=1,4$, and equations (E.2) are solved for $P_{1}, I=5,6$, the results are

$$
\begin{aligned}
& P_{1}=\left\{p_{1 e^{s}} s^{3}-\left(T_{1}+p_{2 e} B_{1}+p_{4 e} B_{5}\right) s^{2}+\left[p_{1 e}\left(B_{4}-B_{3}\right)-p_{2 e} B_{4} B_{5}\right.\right. \\
& \left.-p_{3 e} B_{5}+p_{4 e} B_{1} B_{2}-B_{1} T_{2}-B_{5} T_{4}\right]_{s}+p_{1 e} B_{2} B_{5}+p_{2 e}\left(B_{1} B_{3}-B_{5}^{2}\right) \\
& +p_{3 e} B_{1} B_{2}+\left(B_{3}-B_{2} B_{4}\right) T_{1}-B_{4} B_{5} T_{2}+B_{5} T_{3}+B_{2} T_{4} \\
& \left.-\left[B_{5} B_{2} T_{1}+\left(B_{1} B_{3}-B_{5}^{2}\right) T_{2}-B_{1} B_{2} T_{3}\right] s^{-1}\right\} / \Delta \\
& P_{2}=\left\{\underline{p}_{2 e^{s}} s^{3}+\left(p_{1 e}-B_{2} p_{4 e}+T_{2}\right) s^{2}-\left(p_{2 e} B_{3}+p_{3 e} B_{2}+p_{4 e} B_{5}\right.\right. \\
& \left.+T_{1}+B_{2} T_{4}\right)_{s}-\left(p_{1 e} B_{3}+p_{3 e} B_{5}+B_{3} T_{2}-B_{2} T_{3}+B_{5} T_{4}\right) \\
& \left.+\left(B_{3} T_{1}+B_{5} T_{3}\right) s^{-1}\right\} / \Delta \\
& P_{3}=\left\{p_{3 e} s^{3}+\left(B_{5} p_{2 e}-B_{3} p_{4 e}-T_{3}\right)_{s}^{2}+\left[p_{1 e} B_{5}+p_{2 e} B_{3} B_{4}\right.\right. \\
& \left.+p_{3 e}\left(B_{1}+B_{2}\right)+p_{4 e} B_{5} B_{2}+B_{5} T_{2}-B_{3} T_{4}\right]_{s}+p_{1 e} B_{3} B_{4} \\
& +p_{3 e} B_{4} B_{5}+p_{4 e}\left(B_{1} B_{3}+B_{5}^{2}\right)-B_{5} T_{1}+B_{3} B_{4} T_{2}-\left(B_{1}+B_{2} B_{4}\right) T_{3} \\
& \left.\left.\left.-B_{2} B_{5} T_{4}\right]-\left[B_{3} B_{4} T_{1}-B_{4} B_{5} T_{3}+\left(B_{5}^{2}-B_{1} B_{3}\right) T_{4}\right]\right]^{-I}\right\} / \Delta \\
& P_{4}=\left\{p_{4 e} s^{3}+\left(p_{2 e} B_{4}+p_{3 e}+T_{4}\right) s^{2}+\left(p_{1 e} B_{4}+p_{2 e} B_{5}+p_{4 e} e_{1}\right.\right. \\
& \left.+B_{4} T_{2}-T_{3}\right)_{s}+p_{1 e} B_{5}+p_{3 e} B_{1}=B_{4} T_{1}+B_{5} T_{2}+B_{1} T_{4} \\
& \left.-\left(B_{5} T_{1}+B_{1} T_{3}\right) s^{-I}\right\} / \Delta
\end{aligned}
$$




$$
\begin{aligned}
& P_{5}=\left(p_{5 e} s-p_{6 e} B_{6}-T_{5}-B_{6} T^{s}{ }^{-1}\right) /\left(s^{2}+B_{6}\right) \\
& P_{6}=\left(p_{6 e} s+p_{5 e}+T_{6}-T_{5} s^{-1}\right) /\left(s^{2}+B_{6}\right)
\end{aligned}
$$

where $T_{1}=F\left(x_{1}\right) \exp \left(-\tau_{1} s\right), 1=1, \ldots, 6, \Delta=s^{4}+\left(B_{1}-B_{3}+B_{2} B_{4}\right) s^{2}$ $+B_{5}\left(B_{2}-B_{4}\right)_{s}+B_{5}^{2}-B_{1} B_{3}$ and $B_{1}=k_{1} A_{1}^{2}, \quad B_{2}=K_{2} A_{1}, \quad B_{3}=k_{2}\left(A_{1}^{2}+3 A_{5}\right)$, $B_{4}=K_{1} A_{1}, \quad B_{5}=-A_{2}$ and $B_{6}=3 k_{3} A_{3}$ w1th $A_{1}, 1=1,2,3$, evaluated at $\tau^{*}=\tau_{\mathrm{e}}$

Iet $B_{1}-B_{3}+B_{2} B_{4}=2 a, B_{2}-B_{4}=b$ and $B_{5}^{2}-B_{1} B_{3}=c$. Then $\Delta$ can be written as

$$
\Delta=s^{4}+2 a s^{2}+B_{5} b s+c
$$

If the characteristic equation, (E.5), has roots which do not change type, e.g., from type Imaglnary to type complex, with tıme, then equations $(\mathrm{E} .3)$ and $(\mathrm{E} .4)$ can be Inverted once-and-for-all to give the approximate solution of (4.4) and (4.6) for the entire time of one orbit. This is the case if $B_{5} b$ Is zero or very small.

For satellites (1) and (2) $B_{5}{ }^{b}$ varies periodically from about $3.10^{-4}$ to $-10^{-4}$ and the roots of (E.5) have real parts less than 0.1 in magnitude Thus, the exponential factors in the solution due to these real parts are nearly unity for solution times $1 . e$. , the time intervals between two successive encounters with the boundary of $s$, less than unity (In Chapter IV It Is seen that dozens of encounters occur in the time of one orbit, which takes about six time units to complete.)

If the term in ( $\mathrm{E} .5$ ) with $\mathrm{B}_{5} \mathrm{~b}$ as a factor is omitted, then (․5) can be written as $\Delta=\left(s^{2}+\omega_{1}^{2}\right)\left(s^{2}+\omega_{2}^{2}\right)$ where $\omega_{1}^{2}=a+\sqrt{a^{2}-c}$ and $\omega_{2}^{2}=a-\sqrt{a^{2}-c}$. If this expression of $\Delta$ is substituted into equations (E.3) and If, on Inverting (E.3) and (E.4) for positive and real values of $\omega_{1}, \omega_{2}$ and $B_{6}$, the functions sin $y$ and $\cos y$ are replaced by $y$ and $1-y^{2}$, respectively, then the approximate solution of equations $(4.4)$ and $(4.6)$ Is 


$$
\begin{aligned}
& p_{1}=p_{1}\left\{1-\left[\left(B_{3}-B_{4}\right)+\left(\omega_{1}^{2}+\omega_{2}^{2}\right)\right]\left(\Delta \tau^{*}\right)^{2}\right\}-p_{2}\left[B_{1} \Delta \tau^{*}\right. \\
& \left.+\mathrm{B}_{4} \mathrm{~B}_{5}(\Delta \tau *)^{2}\right]-\mathrm{p}_{3 \mathrm{e}} \mathrm{B}_{5}\left(\Delta \tau^{*}\right)^{2}-\mathrm{p}_{4 \mathrm{e}}\left[\mathrm{B}_{5} \Delta \tau^{*}-\mathrm{B}_{1} \mathrm{~B}_{2}\left(\Delta \tau^{*}\right)^{2}\right] \\
& -F\left(x_{4}\right) B_{5}\left(\Delta \tau_{4}^{*}\right)^{2}-F\left(x_{1}\right) \Delta \tau_{1}^{*}-F\left(x_{2}\right) B_{1} \Delta \tau_{2}^{*}
\end{aligned}
$$

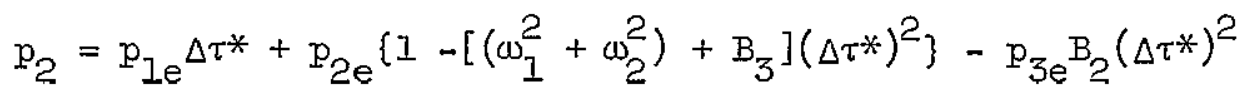

$$
\begin{aligned}
& -\underline{p}_{4 e}\left(B_{2} \Delta \tau^{*}+B_{5} \Delta \tau^{*^{2}}\right)+F\left(x_{2}\right) \Delta \tau_{2}^{*}-F\left(x_{1}\right)\left(\Delta \tau_{1}^{*}\right)^{2}-F\left(x_{4}\right) B_{2}\left(\Delta \tau_{4}^{*}\right)^{2} \\
& p_{3}=p_{1 e} B_{5}\left(\Delta \tau^{*}\right)^{2}+p_{2 e}\left[B_{5} \Delta \tau^{*}+B_{3} B_{4}(\Delta \tau *)^{2}\right]+p_{3 e}\left\{1-\left[\left(\omega_{1}^{2}-\omega_{2}^{2}\right)\right.\right. \\
& \left.\left.+\left(B_{1}+B_{2}\right)\right]\left(\Delta \tau^{*}\right)^{2}\right\}-p_{4 e}\left(B_{3} \Delta \tau^{*}+B_{2} B_{5}\left(\Delta \tau^{*}\right)^{2}+F\left(x_{2}\right) B_{5}(\Delta \tau)^{*}\right)^{2} \\
& -F\left(x_{3}\right) \Delta \tau \frac{\pi}{3}-F\left(x_{4}\right) B_{3}(\Delta \tau)_{4}^{2} \\
& p_{4}=p_{1 e^{B_{4}}}(\Delta \tau *)^{2}+p_{2 e}\left[B_{4} \Delta \tau^{*}+B_{5}(\Delta \tau *)^{2}\right]+p_{3 e} \Delta \tau^{*} \\
& +p_{4 e}\left\{1-\left[\left(\omega_{1}^{2}+\omega_{2}^{2}\right)+B_{1}\right]\left(\Delta \tau^{*}\right)^{2}\right\}+F\left(x_{4}\right) \Delta \tau \psi_{4}^{+}-F\left(x_{3}\right)\left(\Delta \tau \frac{+}{3}\right)^{2} \\
& +F\left(x_{2}\right) B_{4}\left(\Delta \tau \frac{\pi}{2}\right)^{2}
\end{aligned}
$$

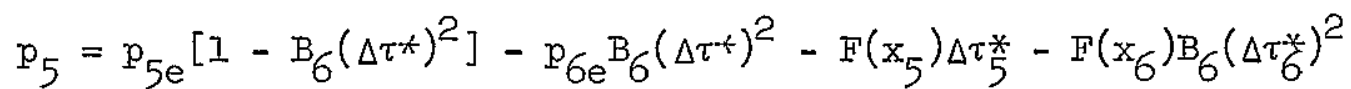

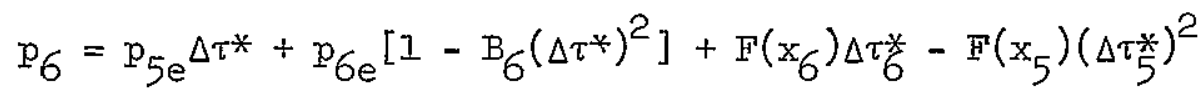

where $\Delta \tau^{*}=\tau^{*}-\tau_{\mathrm{e}}$ and $\Delta \tau_{1}^{*}=\tau^{*}-\tau_{1}, I=1, \quad, 6$

An approximate solution of the adjolnt equations for "unstable" satellites can be derived in a similar manner However, instead of sine and cosine functions (which can be replaced by simplier functions) appearing in the equations, the equations contain the exponential function and are much more complicated in yaw-roll In Section A, Part 3 of Chapter IV an approximate solution ls presented for "unstable" pitch motion 
In Flgures F 1, F 2, F 5 and F 6 are given listings of the digltal computer programs. These are given in the order in which they are used In the text The word "clock" which appears in the digltal computer program is an ALGOI procedure This procedure was used to determine the elapsed time required for the execution of certain parts of the programs so that measures could be taken to reduce excessive computation times The symbols used in the differential equations (DE) procedures are not the same as in the differential equations in the text since these symbols were reserved for the plot routıne. However, the equivalences are given In the comments

In Flgures $F 3$ and $\$ 4$ are given simplifled analog computer programs which were used to simulate the acquisition motions from $S^{+}$to $S$ and the steady-state motion for the suboptimal steady-state control. The time delays required in these simulations were obtalned from the time delays in the comparators by time scaling 


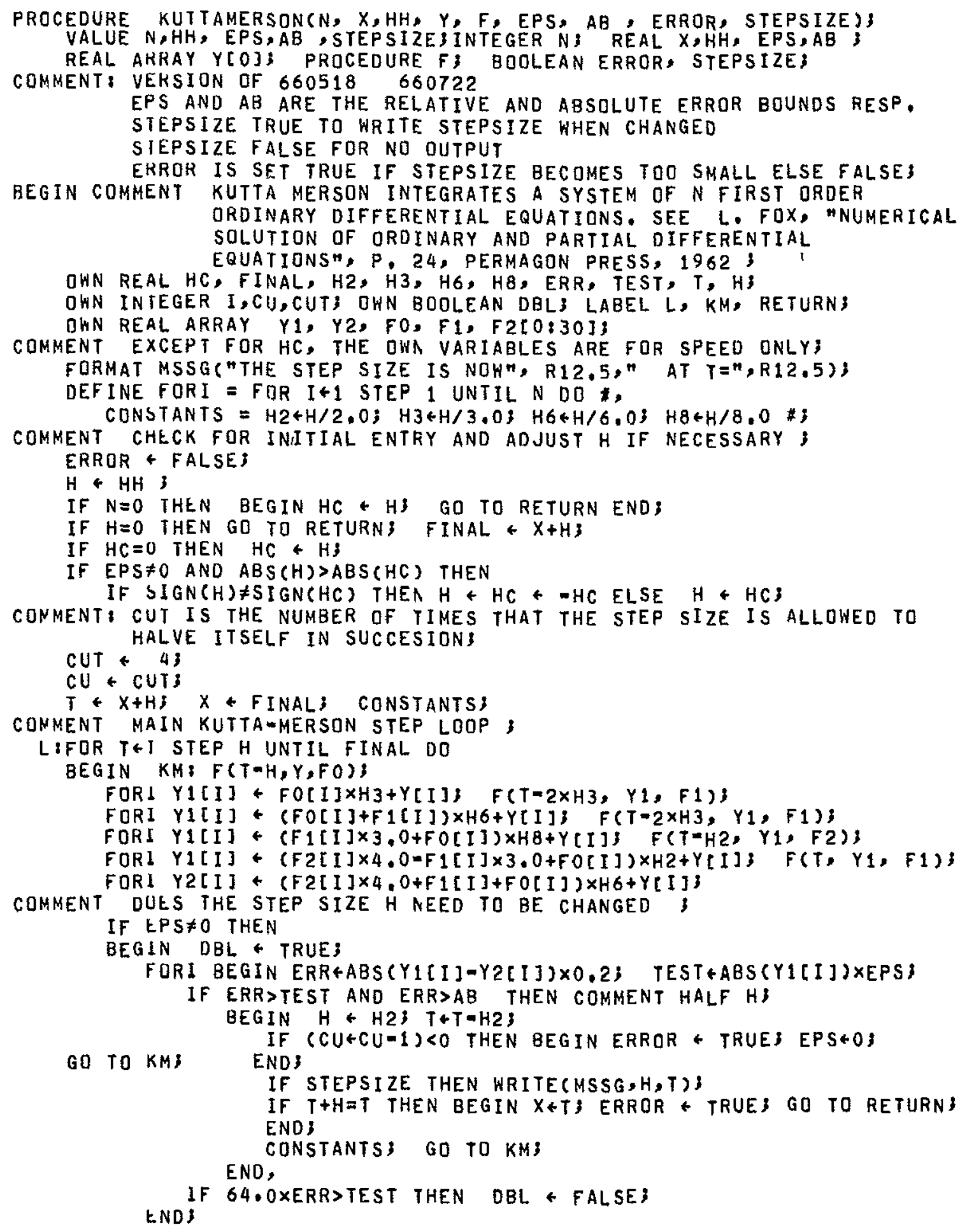

Figure F 1. Solution of Approximate, Mnnmum-Fuel Optimal, StationKeeping Equations [(4 3) and (4 4)] for Roll-Yaw. 


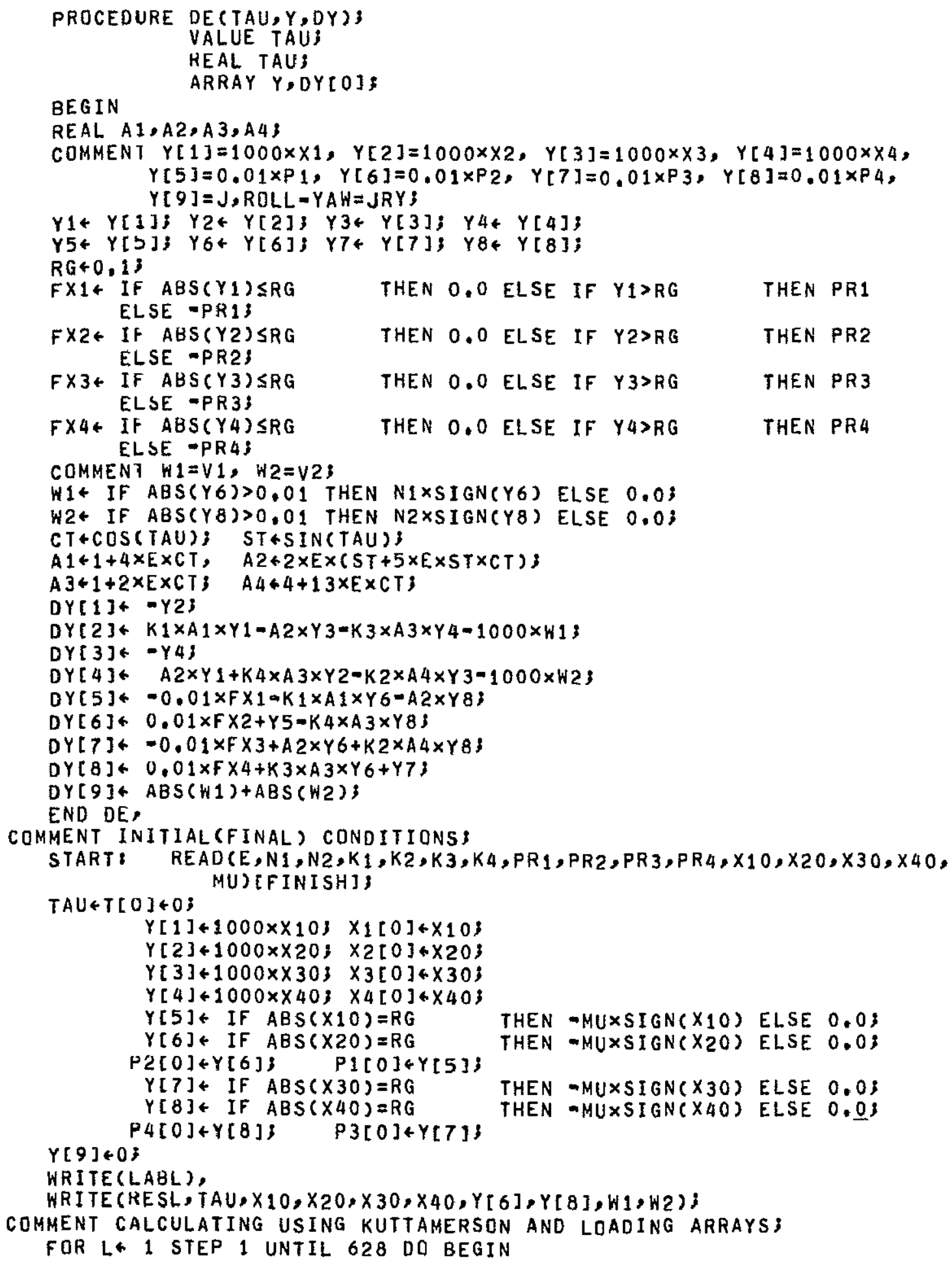

Figure F.I Contınued. 


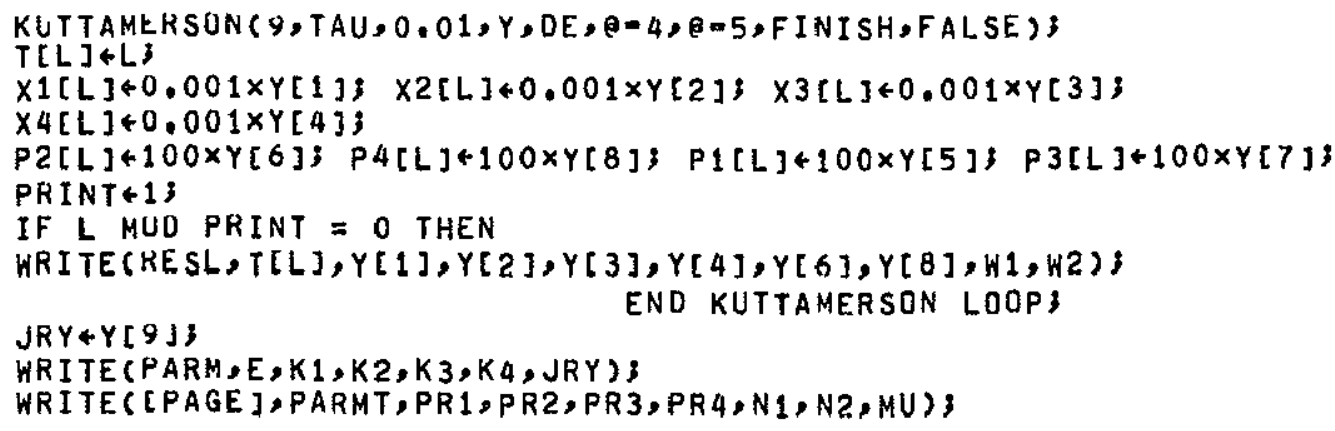

Figure F 1 Continued. 


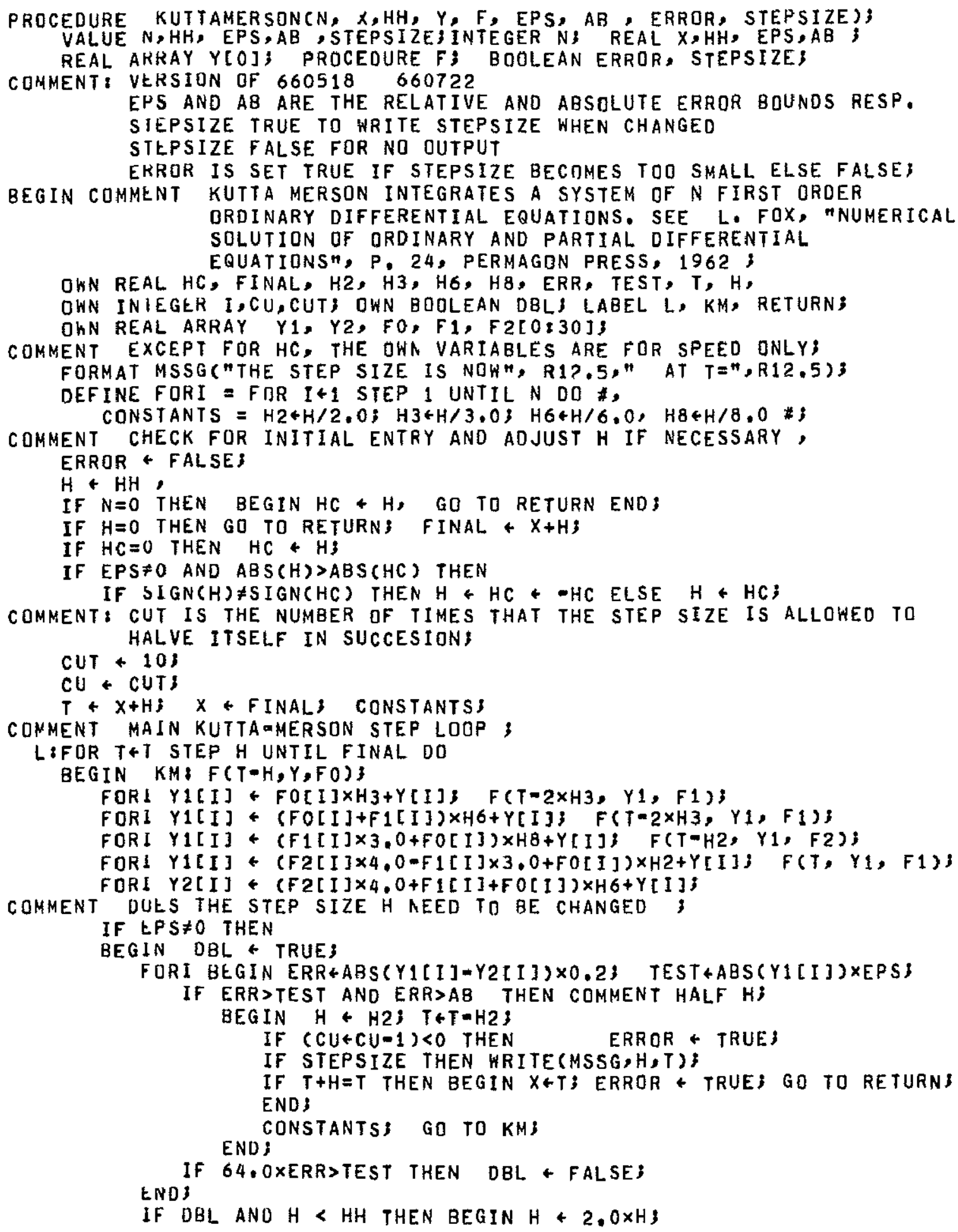

Figure F 2 Solution of Approximate, Minimum-Fuel Optimal, StationKeeping Equations [(4.5) and (4.6)] for Pltch 


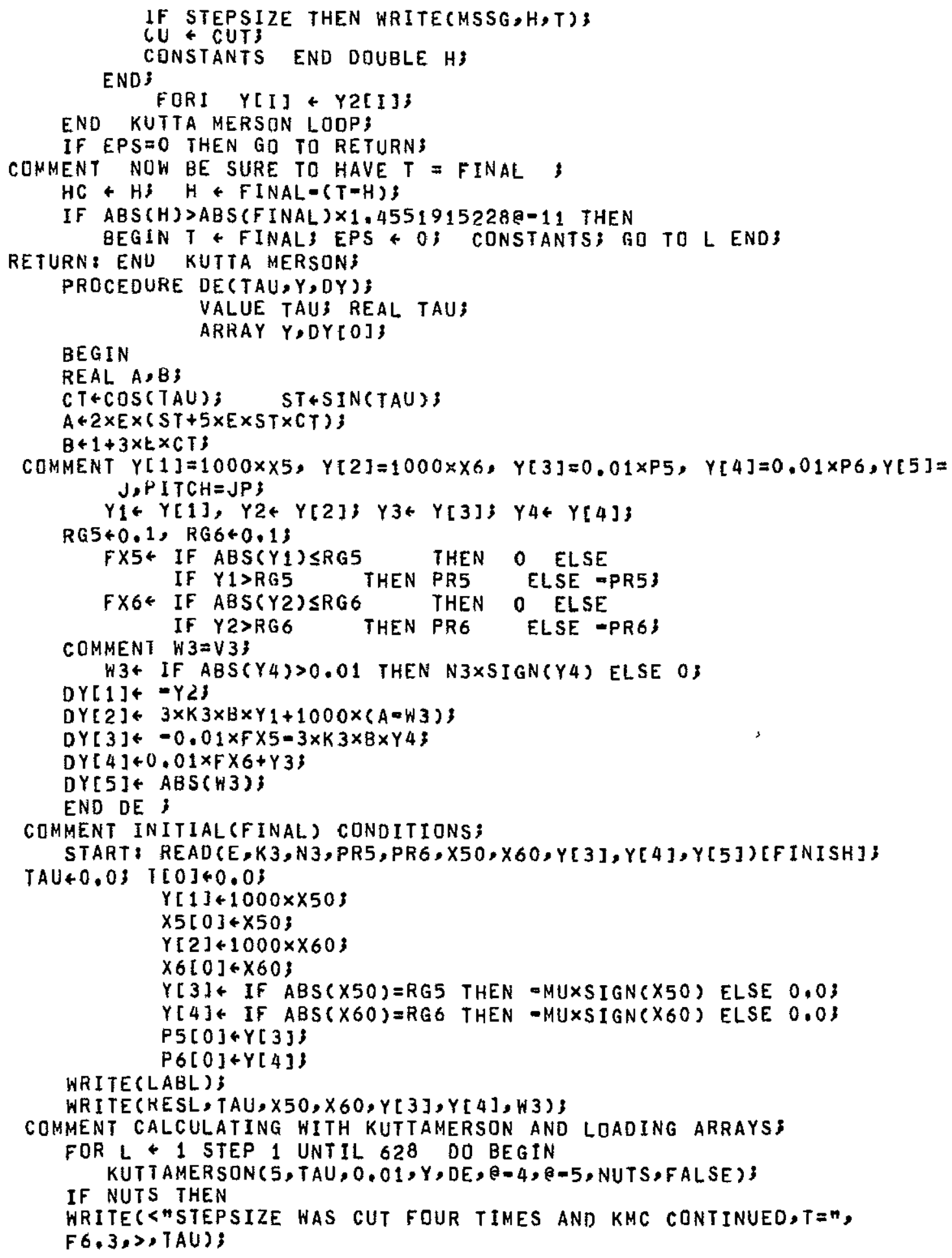

Fugure F.2. Continued. 


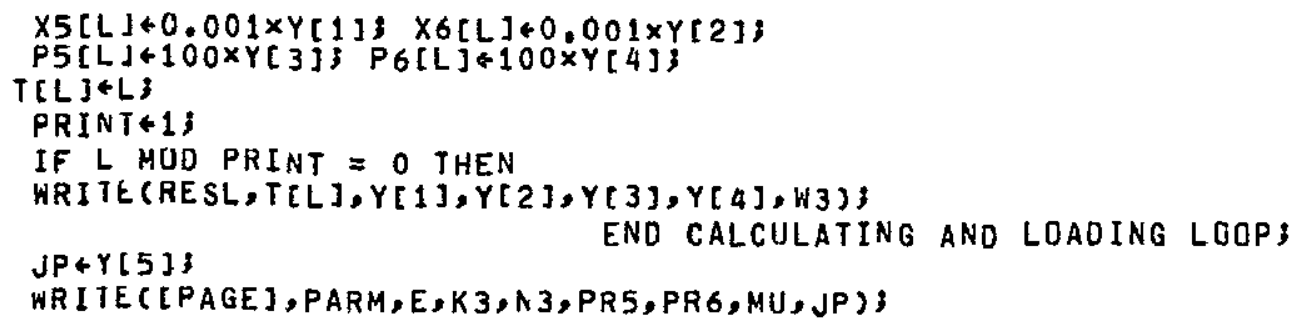

Figure F 2 Continued. 
$\overbrace{}^{2 e c a_{0}^{-1}}$

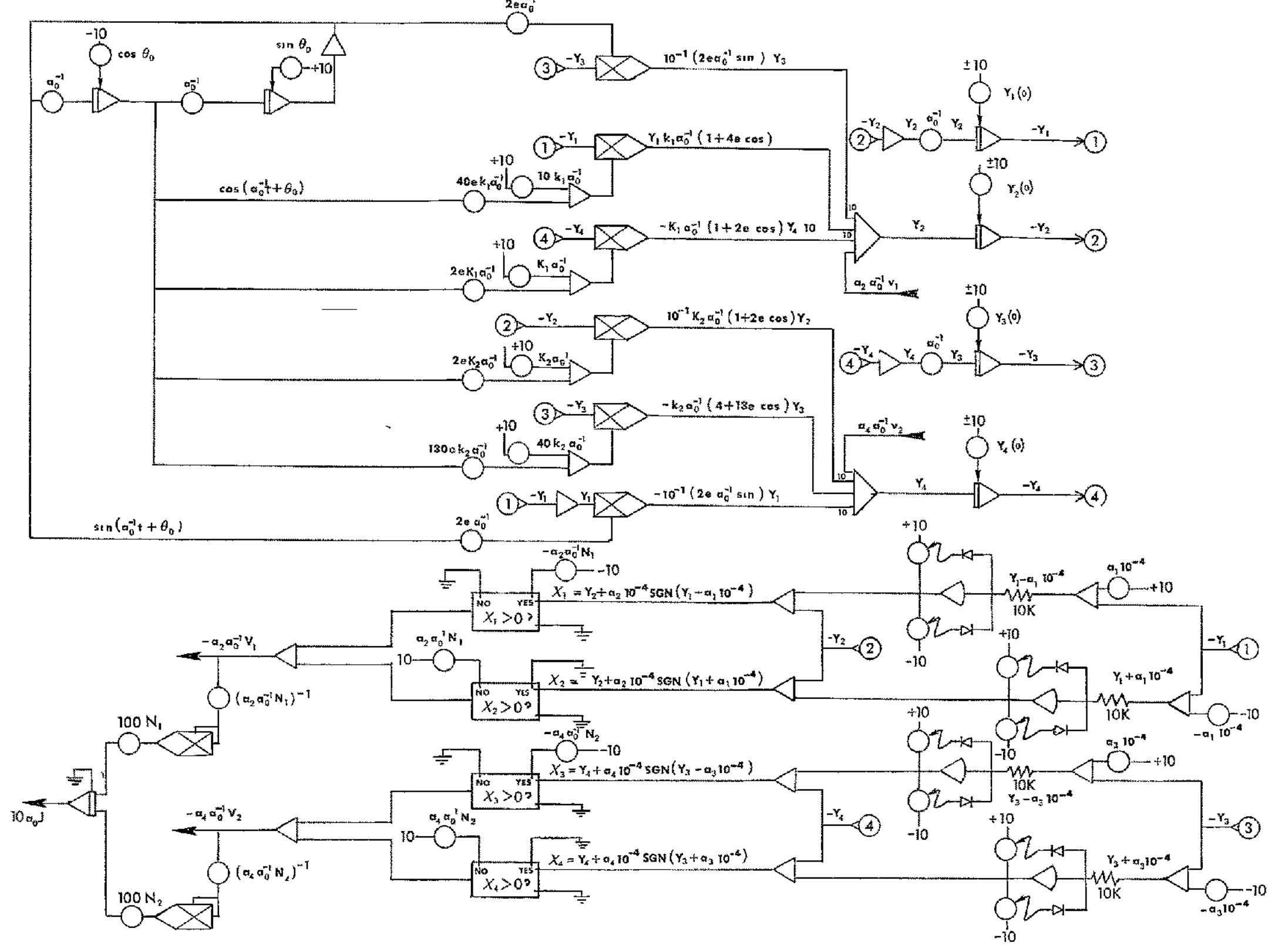

Fugure if 3 Analog Computer Program for Roll-Yaxy (Cenerator of Aerodynamze Torque Terms Ilot Shown) 


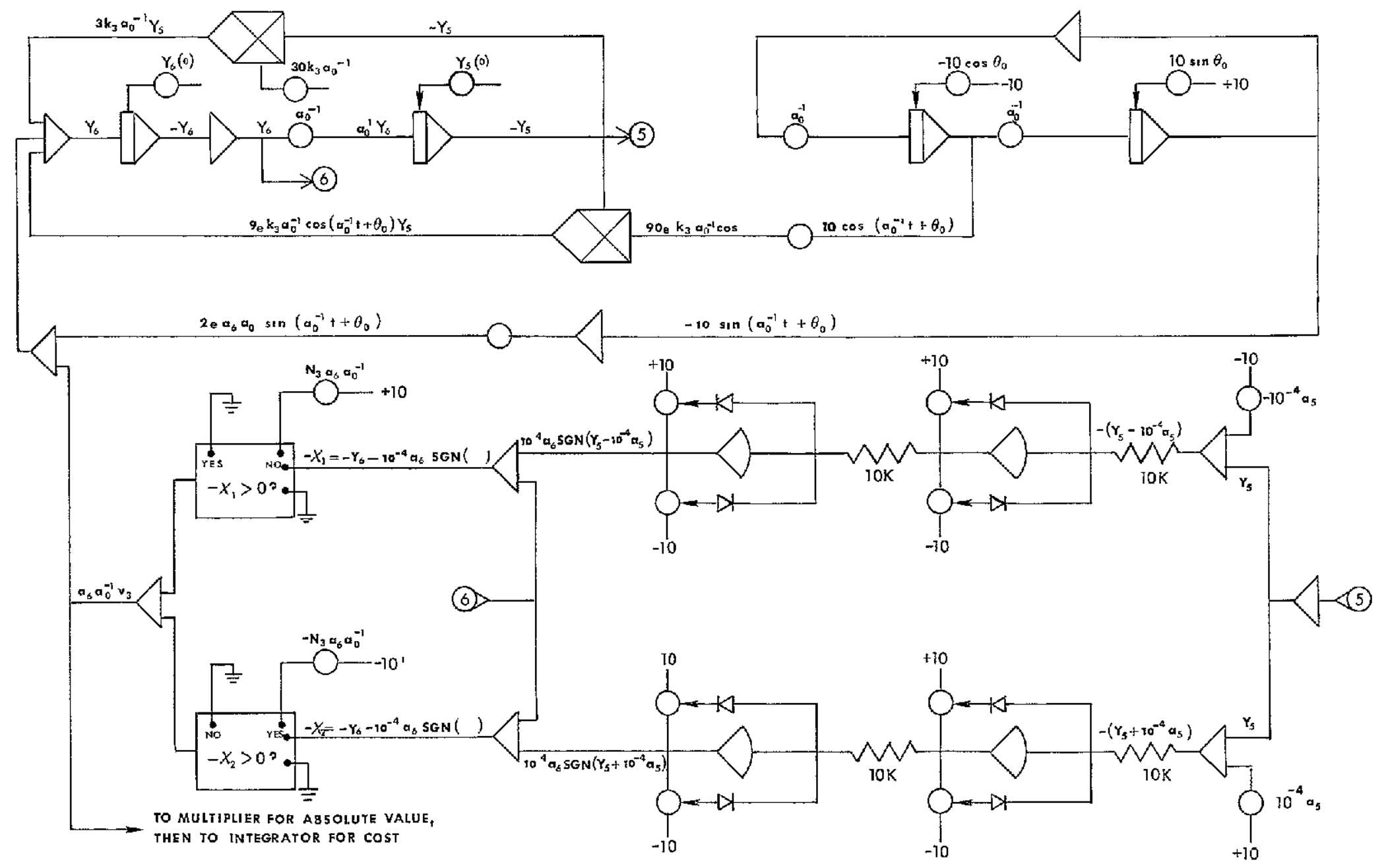

Figure 54 Analog Computer Program for Pltch (Generator of Aerodynamic Torque Term Not Shown) 
PROCEDURE KUTTAMERSON(N, X, H, Y, F, EPS, AB, ERROR, STEPSIZE);

VALUE $N$, $H$, EPS, AB , STEPSI2E; INTEGER N; REAL $X$, H, EPS, AB;

REAL ARRAY Y[O]; PROCEDURE F; LABEL ERROR; BOOLEAN STEPSIZE;

COMMENT EPS AND AB ARE THE RELATIVE AND ABSOLUTE ERROR BOUNDS RESP. STEPSIZE TKUE TO WRITE STEPSIZE WHEN CHANGED, FALSE FOR NO OUTPUT;

BEGIN COMMENT KUTTA MERSDN INTEGRATES A SYSTEM OF N FIRST ORDER ORDINARY DIFFERENTIAL EQUATIONS. SEE L. FOX, "NUMERICAL SOLUTION DF ORDINARY ANO PARTIAL DIFFERENTIAL EQUATIONS", P. 24, PERMAGON PRESS, 1962 ;

OWN REAL HC, FINAL, H2, H3, H6, HB, ERR, TEST, T;

DWN INTEGER I; OWN BODLEAN DBL, LABEL L, KM, RETURN,

OWN REAL ARRAY Y1, Y2, FO, F1, F2[0:30];

COMMENT EXCEPT FOR HC, THE OWN VARIABLES ARE FOR SPEED ONLY;

FORMAT MSSG("THE STEP SIZE IS NOW", E18.11))

DEF INE FORI = FOR I+1 STEP 1 UNTIL N DO *, CONSTANTS $=\mathrm{H} 2+\mathrm{H} / 2,0 ; \mathrm{H} 3+\mathrm{H} / 3,0 ; \mathrm{H} 6+\mathrm{H} / 6.03 \mathrm{H} 8+\mathrm{H} / 8.0 \# ;$

CONMENT CHECK FOR INITIAL ENTFY AND ADJUST H IF NECESSARY;

If $N=0$ THEN BEGIN HC *H; GO TO RETURN END;

If $H=0$ THEN GO TO RETURN; FINAL $\leftarrow X+H$;

IF $\mathrm{HC}=\mathrm{O}$ THEN $\mathrm{HC} \leftarrow \mathrm{H}$;

IF EPS $\neq 0$ AND ABS $(H)>A B S(H C)$ THEN

IF $S I G N(H) \neq S I G N(H C)$ THEN $H \leftarrow H C \&-H C E L S E H \leftarrow H C$;

$T \leftarrow X+H, \quad X+F I N A L ; \quad$ CQNSTANTS;

COMMENT MAIN KUTTA MERSON STEP LOOP;

L:FQR T\&I STEP H UNTIL FINAL DO

BEGIN KM: $F(T-H, Y, F O)$;

FORI YI[I] FO[I] $\times H_{3}+Y[I] ; \quad F(T=2 \times H 3, Y 1, F 1) ;$

$F O R I Y 1[I] \leftarrow(F O[I]+F I[I]) \times H 6+Y[I] ; F(T=2 \times H 3, Y 1, F 1)$,

FORI YI[I] (FI[I] $] 3,0+F O[I]) \times H 8+Y[I] 3 \quad F(T-H 2, Y 1, F 2) ;$

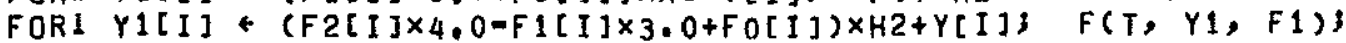

FORI YZ[I] $*(F 2[I] \times 4,0+F 1[I]+F O[I]) \times H 6+Y[I]$,

COMMENT DOES THE STEP SIZE H NEED TO BE CHANGED;

IF EPS $\neq 0$ THEN

BEGIN DBL + TRUE:

FORI BEGIN ERR \&ABS(Y1[I]-Y2[I]) $\times 0.2 ; \quad$ TEST\&ABS(Y1[I]) XEPS;

IF ERR $>$ TEST AND ERR>AB THEN COMMENT HALF H3

BEGIN $\mathrm{H} \leftarrow \mathrm{H} 2$; $T \leftarrow \mathrm{T}-\mathrm{H} 2$;

IF STEPSIZE THEN HRITE(EDBL], MSSG, H) 3

IF $T+H=T$ THEN BEGIN $X+T \&$ GO TO ERROR END;

END;

CONSTANTS; GO TO KM;

END;

IF $64.0 \times E R R>T E S T$ THEN DBL \& FALSE;

IF DBL THEN BEGIN $H+2 \times H$;

IF STEPSIZE THEN WRITE([DBL], MSSG, H) ;

END;

CONSTANTS END DOUBLE H?

FOKI Y[I] 4 Y $2[\mathrm{I}] 3$

END KUITA MERSUN LOQP;

IF EPS $=0$ THEN GQ TO RETURN;

COMMENT NOW BE SURE TO HAVE T = FINAL;

$H C+H 3 \quad H \leftarrow F I N A L=(T-H) 3$

If $A B S(H)>A B S(F I N A L) \times 1.45519152280-11$ THEN

BEGIN T FINAL; EPS 40 , CONSTANTS; GO TO L END;

RETURN : ENU KUTTA MERSON

Flgure F.5 Solution of Nonlinear, Suboptimal Acquisition Equations

$$
[(214)-(216) \text { and }(52)]
$$




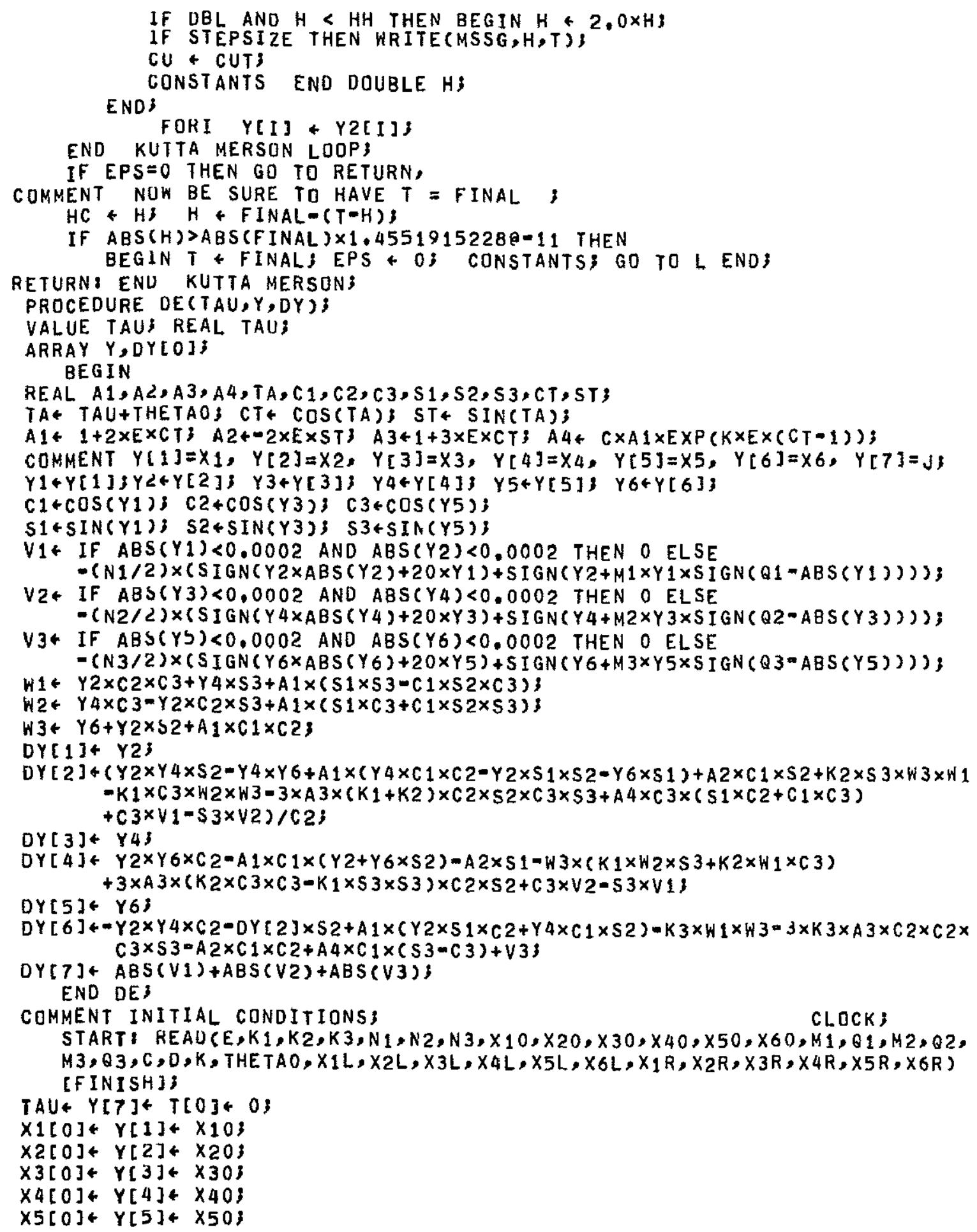

Figure F 5 Continued. 


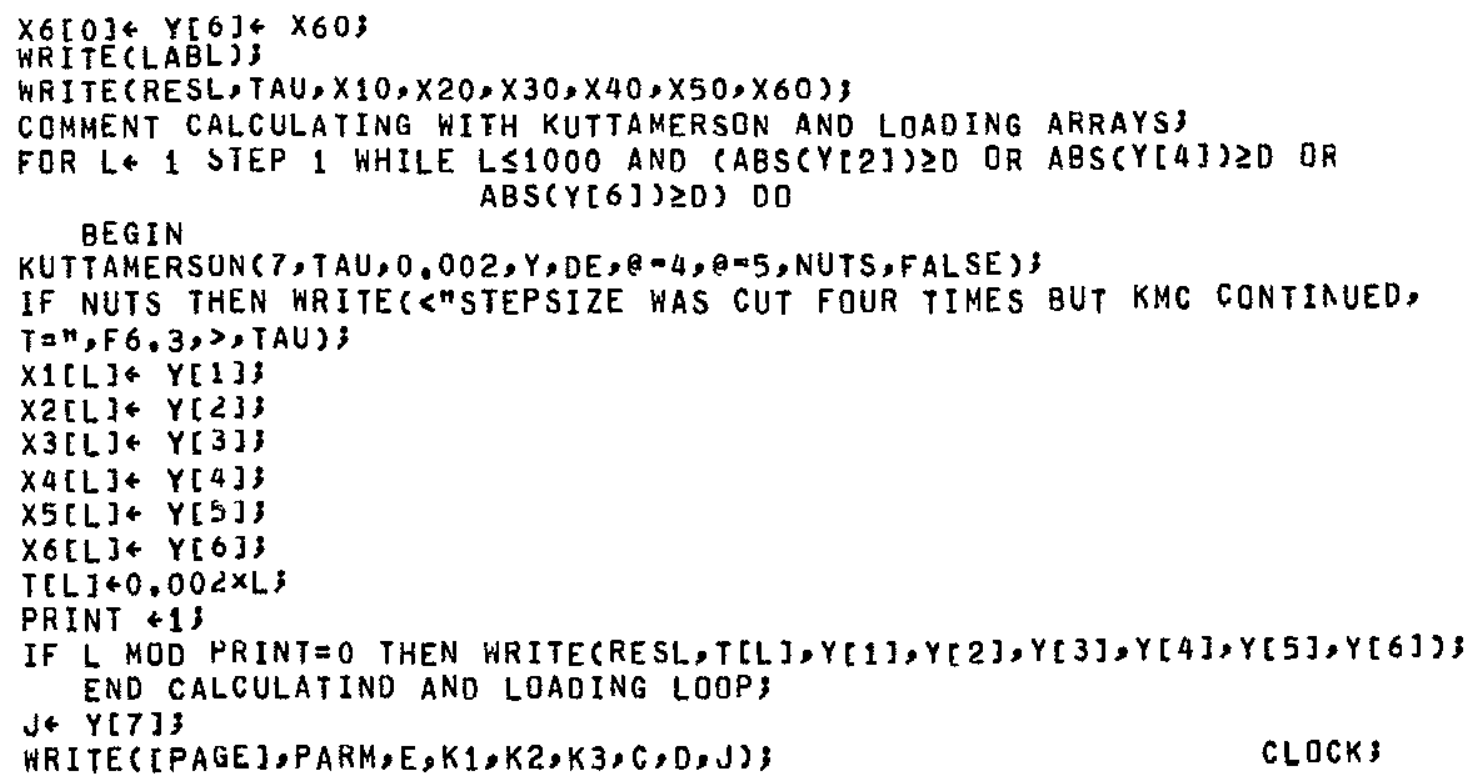

Figure F.5. Continued 


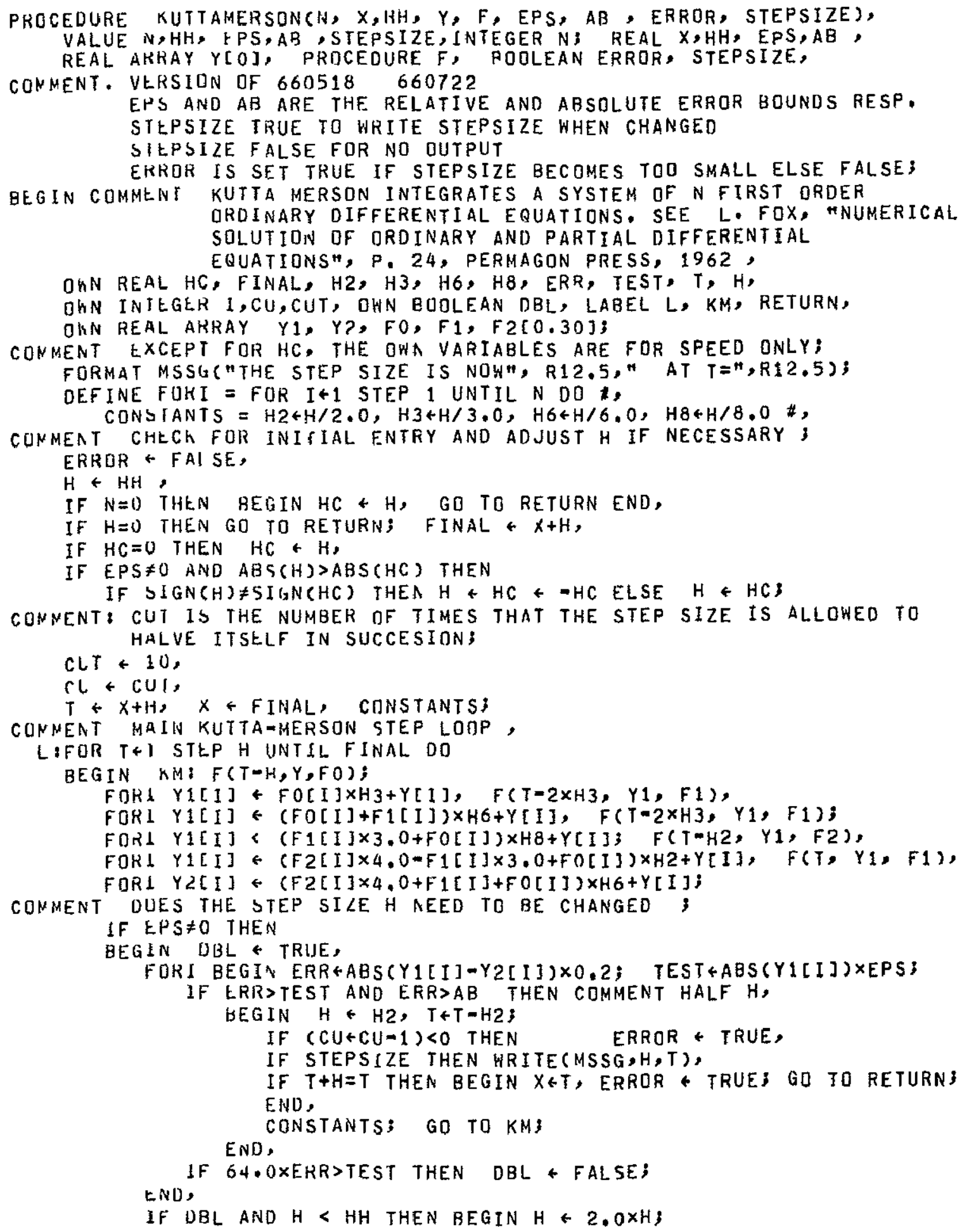

\section{a Roll-Yaw}

Figure F 6. Solution of Optimal Innear Acquisition Equations in Backward Tame 


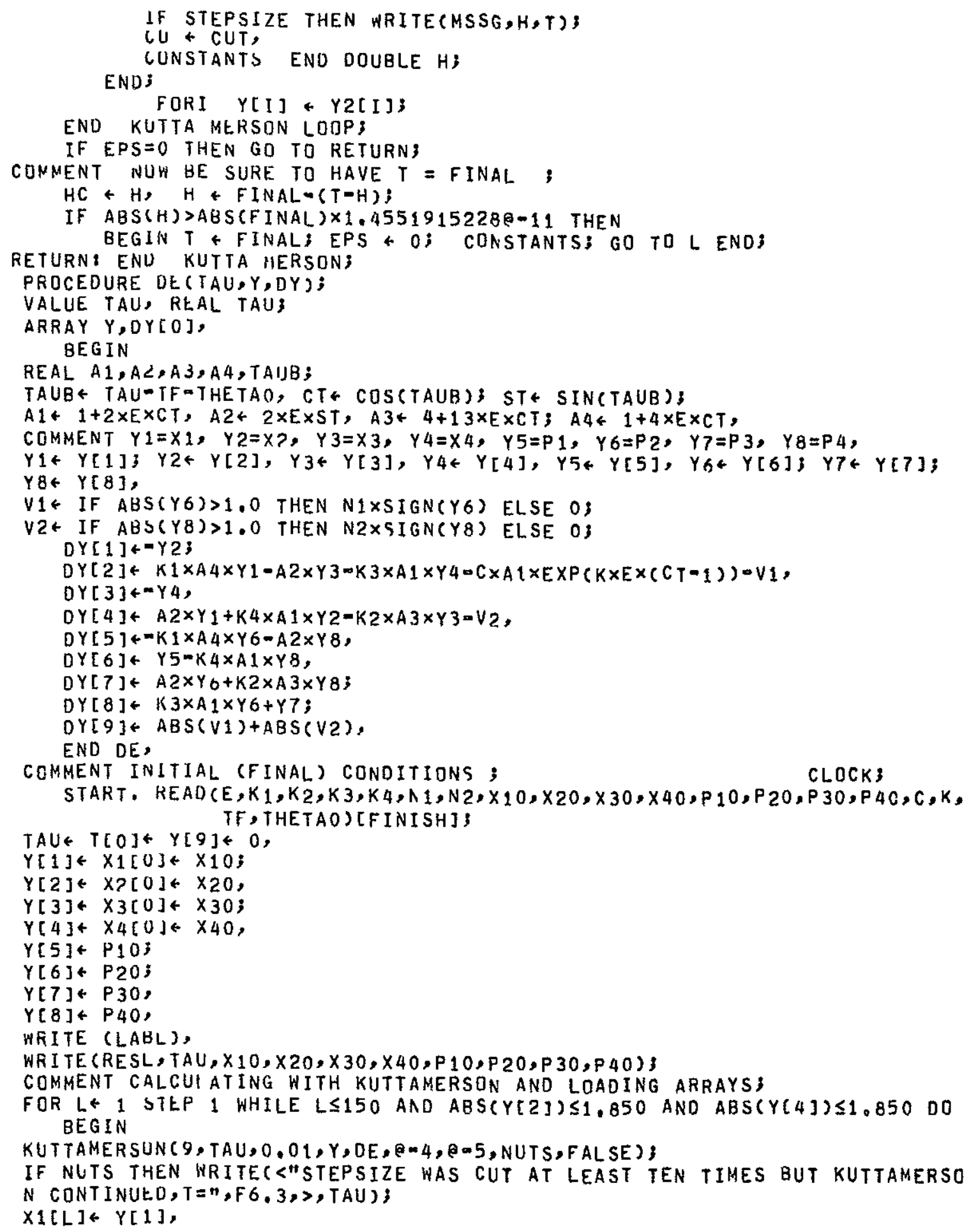

Figure $F$ 6. Continued. 


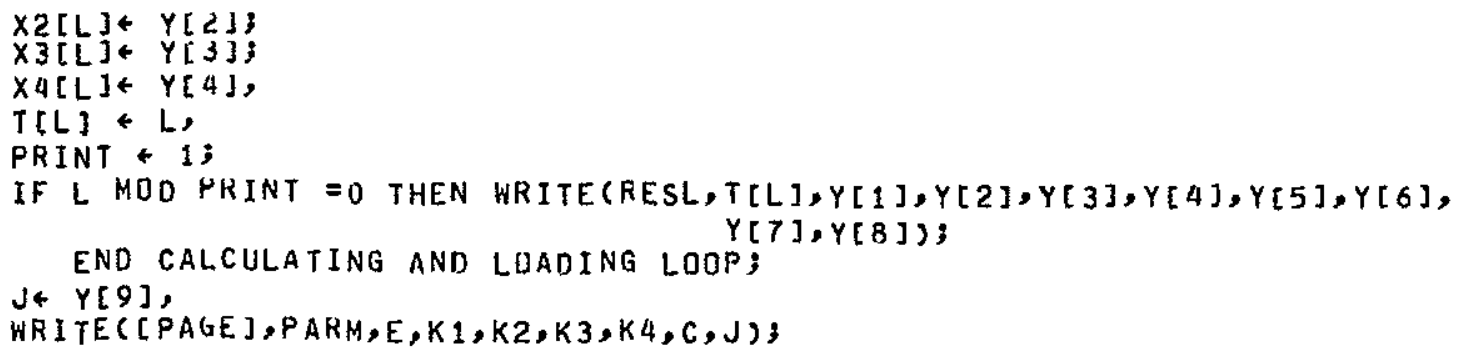

Figure F.6 Continued, 

SAVE BEGIN COMMENT OPTIMAL PITCH ACQUISITION IN BACKWAROS TIME,

FILE OUT PLOTTER 2(1,765);REAL ARRAY A[0:1022], A2[0:2,0:2],C[0.9], SYMA[0 $: 112]$, SYMB $[-15 \cdot 63], A B C D[0: 2]$, REAL OLTH,

PROCEDURE PLOT $(X, Y, I C)$;VALUE $X, Y, I C$;REAL $X, Y$; INTEGER IC;BEGIN STREAM PRO CEDURE WRIT(FIL,IFL, A);BEGIN SI+A; DI+IFL; $17(60(S I+S I+2, D S+6 C H R))$; RELEASE (FIL);END WRIT; OWN INTEGER TT, I, NPX,NPY, BA, T, WIDX, PEN;OWN BOOLEAN BUDL, I NTEGER J, K, DX,DY,IY,NR,NT,NC,II2, NA, LABEL FINSH, ON,L13FORMAT TORMC $1022 A 6$ ); IF ABS (IC)>3THEN BEGIN BA+0, WIDX+IF IC<-3THEN 2Q2ELSE 182; PEN 2 , A $[0] \leftarrow "$ 444444"; A $[1]+" 444433 ", A[2]+" 333332 ", G O$ TO FINSH;END, IF ABS(IC) APEN THEN GO ON;PEN+5-PEN;A[I]+(IF BOOL THEN"666661"ELSE TT+24955)+PEN+PEN;BOQL+TR UE,FOR K+9XPEN STEP-1UNTIL 1500 BEGIN ALI+I+1]+"666606"; IF I I 1018THEN BE GIN A[ 1019$]+" 340000 "$, WRIT (PLOTTER, PLOTTER(O), A[O]), I \&3;GO ON;END, END, ON: $N A+R E A L(D X+-N P X+(N P X+W I D X X X) \geq 0)+R E A L(D X>0) ; I Y+R E A L(D Y+-N P Y+(N P Y+W I D X X Y) \geq$ $0)+R E A L(D Y>0)$, IF $A B S(D X) \geq A B S(D Y) T H E N \quad B E G I N N R+A B S(D Y)$, NC\&NT+ABS(DX); I I $2+$ $\triangle 2[N A, 1] E N D$ ELSE BEGIN NR+ABS(DX);NC+NT+ABS(DY); II2+AZ[1, IY]END; IY+AZ[NA - IYJ, NA+NT DIV 2 ; NT +NT-NR, $L 1$ - IF $(N C+N C-1) \geq 0 T H E N$ BEGIN IF NA $\geq N T$ THEN BEGIN $T+I Y, N A+N A-N T$; END ELSE BEGIN T\&II2;NA\&NA+NR END;IF BODL +NOT BOOL THEN B EGIN A[I]+T+TT, IF $(I+I+1) \geq 1019 T H E N$ BEGIN A[1019]+"340000"; WRIT (PLOTTER, PL OTTER(0), A[0]), I+3, END; GO TO L1, END,TT\&"006006" \&T[15.33:9];GO TO LI;END; IF IC<OTHEN BEGIN IF BDOL THEN I+I-IELSE A[I]\&TT+"000660"; A[I+I+1]+" 3400 00", WR I TE (PLOTTER, TORM, FOR K+OSTEP IUNTIL I DO A[K I), FINSH - WR I TE (PLOTTER -TORM, "444444","444433","333331",C[(BAF(BA+1)MOO 100)MOD 10]8C[BA DIV 10 ] [24:36:12],"133333","334444",FOR K+OSTEP IUNTIL 70DO"444444"\}, BOOL \&TRUE , NPX $+N P Y+O, I+3 ; E N D ; E N D$,

PROCEDURE SYMBOL ( $X O, Y O, H G T, B C D, T H E T A, N)$, VALUE $X_{O}, Y O, H G T$, THETA, N, INTEGER $N$; REAL $X_{O}, Y O, H G T$, THETA ALPHA ARRAY BCDCO],BEGIN REAL BINX, AC,W, OSC, AINX, $I$, OSTS, MnV $1, H I, I I, M_{0} V_{2}, W C, C C, L P, X_{A}, Y A, X A G, Y A 6, O W_{N}$ REAL CTH, STH; LABEL LOA DB, DEF INE A=SYMA\#, $B=S Y M B \#, I F$ THETAZOL TH THEN BEGIN OL TH+THETA;CTH+COSCTH ETA THETAX.01745329251); STH+SIN(THETA), END;HI+HGTX.142857142857, XA+CTHXH

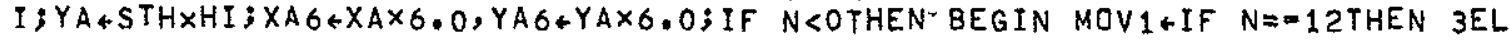
SE $2 ; \times O+X O-M O V 1 \times(X A+Y A), Y O+Y O-M O V 1 \times(X A-Y A), B I N X+N, G O$ TO LOADR;END;AC+WC+ $C C+0 ; W+B C D[0]$; WHILE $A C+A C+1 \leq N$ DO BEGIN IF $C C+C C+1 \geq 7$ THEN BEGIN $W+B C D[W C+W$ $C+1] ; C C+1 E N D ; B I N X+W .[12: 6], W+0 \& W[12.18: 30], L O A D B: 0 S C+B[B I N X] .[33: 5], 0 S T S$ $+A[A I N X+B[B I N X],[39: 9]], L P+3 ; I I+0 ; F D R$ I+ISTEP IUNTIL OSC DO REGIN IF II+ II +1 $\geq 8$ THEN BEGIN II+1; OSTS+A[AINX+AINX+1] END;MOV $1+0 S T S,[6: 3] ; M O V 2+0 S T S$. [ $9 \cdot 3]$; DSTS + O\&OSTS[6:12:36], IF MOV $1=7$ THEN LP+3ELSE BEGIN PLOT (XO+MOV $1 \times X A=M$ $O V 2 \times Y A, Y O+M O V 1 \times Y A+M O V 2 \times X A, L P), L P+2$, END, END; $X 0+X O+X A G ; Y O+Y O+Y A G, E N D$, END;

PROCEOURE NUMBER ( $X, Y, H G T, F L T, T H E T A, N)$; VALUE $X, Y, H G T, F L T, T H E T A, N$; INTEGER $N$; REAL $X, Y, H G T, F L T, T H E T A, B E G I N$ REAL FRAC,BOOLEAN $B, L A B E L$ SWORD; REAL STRE AM PROCEDURE CV(XO); VALUE XO;BEGIN SI+LOC XO;DI +LOC CV,DI +DI+2, DS $+60 E C E$ ND, REAL STREAM PROCEDURE LZRO $V N, B)$, VALUE VN, $B, B E G I N$ LABEL $M$; $S I+L O C V N, D$ $I+L O C$ LZRO;DS +WDS, SI+SI-6;DI+DI-6;5 (IF SC="0"THEN BEGIN DS+LIT" "SI+SI+ 1END ELSE JUMP OUT TO M),M.SI LOC $B$, SKIP 47 SB, IF SB THEN BEGIN DI+OI-1,D $S+L$ IT" $=$ "END;END LZRO;FRAC + IF $N \leq O T H E N$. 5ELSE IF $N=1$ THEN, 05ELSE IF $N=2$ THEN. 005 ELSE IF $N=3$ THEN.0005ELSE IF $N=4$ THEN.00005ELSE.000005, B \& FLTS-FRAC; IF $F$ $L T+A B S(F L T)+F R A C \geq 100000 T H E N$ IF FLT $10000000 R$ B THEN BEGIN ABCD[0]*"***** *",GO TO SWORD END, ABCD[O]+LZRO(CV(FRAC+ENTIER(FLT)), B); IF N - SYMBOL $(X, Y, H G T, A B C D$, THETA, 6) ELSE BEGIN ABCDL 1 I +CV(ENTIER( $(F L T=F R A C) \times 100$ $000))+", 00000 "$, SYMBOL $(X, Y, H G T, A B C D$, THETA, IF N $\leq 5$ THEN N+7ELSE 12 ), FNN: IND,

b Pltch (Complete Program)

Figure $F 6$ Continued. 
PROCEDURE AXIS(X,Y,BCD,NC,SIZE, THETA,YMIN,DY), VALUE X,Y,NC,SIZE,THETA, YM IN,DY;REAL $X, Y$, SIZE, THETA, YMIN, DY; INTEGER NC, ALPHA ARRAY BCD[O], BEGIN RE $A L T H, C T H, S T H, I, X B, Y B, X A, Y A, I C T H, I S T H, Y M A X, A B S V, E X P P$; LABEL L $50 ; T H+T H E T A X$ $0.017455 ; I C T H \& C T H+C O S(T H)$, ISTH\&STH+SIN $(T H), X R+X, Y B \leftarrow Y$, IF THETASOTHEN BEGI $N$ ICTH+-ICTH; ISTH+-ISTH END, PLOT (XA+X- .1XISTH,YA+Y+.1XICTH, 3);FOR I $1 S T E$ $P$ 1UNTIL SIZE DO BEGIN PLOT (XB,YB,2); PLOT $(X B+X B+C T H, Y B+Y B+S T H, 2), P L D T(X A$ $+X A+C T H, Y A+Y A+S T H, 2)$, END, IF NC<OTHEN GO TO L50, YMAX+YMIN+SIZEXDY; IF ABSV $+A B S(Y M I N)<A B S(Y M A X) T H E N$ ABSV+ABS(YMAX), EXPP $+0 ; I+1$; WHILE ABSV>9999.999D0 BEGIN ABSV+ABSVX.1, I+IX.1; EXPP +FXPP=1END, WHILE ABSV $00.999 D 0$ BEGIN ABSV $A B S V \times 10,0, I+I \times 10,0 ; E X P P+E X P P+1 E N D, D Y+D Y \times I ; Y M A X+Y M A X \times I, X A+X B=.15 \times I S T H=.53$ $X C T H, Y A+Y B+.15 \times I C T H-.53 \times S T H, F O R$ I + SIZE STEPMIUNTIL ODO BEGIN IF ABSCYMAX $2 \geq 0.001 T H E N$ NUMBER $(X A, Y A=0.1, Y M A X, T H E T A, 3) 3 Y M A X+Y M A X=D Y ; X A+X A=C T H, Y A+Y A=$ STH END, I IF EXPP=0THEN NC ELSE NC+7;YA+( (SIZE+SIZEX.5)-.06XI) XSTH+.33XI $C T H+Y ; X A+(S I Z E=.06 \times I) \times C T H=.33 \times I S T H+X ; S Y M B O L(X A, Y A, .14, B C D, T H E T A, N C), I F E$ $X P P=0$ THEN GO TO $L 50, I+(I-6) \times, 12, X A+I X C T H+X A, Y A+I \times S T H+Y A ; A B C D[O]+\| \times 10 " 1 "$ ; SYMBOL $(X A, Y A, .14, A B C D$, THETA, 6), IF EXPP=1THEN GO TO L5O;XA $4 X A+.25 \times C T H=.0$ $7 \times S T H, Y A+Y A+.25 \times S T H+.07 \times C T H ; N U M B E R(X A, Y A, .07$, EXPP, THETA,O0):L50:END,

PROCEOURE LINE $(X, Y, N, K)$, VALUE N,INTEGER $N$;BOOLEAN K; ARRAY $X, Y[O]$;BEGIN I NTEGER I, I $3, A, B, C$, IF $K$ THEN BEGIN $A+0, B+1, C+N-1, E N D$ ELSE $B E G I N A+N-1 ; B+-$ 1; $C+0, E N D ; I 3+3 ; F O R$ I $+A$ STEP B UNTIL C DO BEGIN PLOT $(X[I], Y[I], 13) ; I 3+2 E N$ $\mathrm{N}, \mathrm{K}+\mathrm{NOT} \mathrm{K}, \mathrm{END}$;

PROCEDURE SCALE (A,N,K,L, YMIN,DY); VALUE $N, L, K, I N T E G E R ~ N, K, R E A L$ L,DY,YMIN; REAL ARRAY A[O], BEGIN REAL YMAX, INTEGER I, NMK, YMIN+YMAX 4 TK $[K-1], N M K+N-K, F$ OR I+K+K-1STEP K UNTIL NMK DO IF A[I]>YMAX THEN YMAX+A[I]ELSE IF A[I]<YM IN THEN YMIN\&A[I],DY\&(YMAX-YMIN)/L,FOR I+K-1STEP K UNTIL NMK DO A[I]+(A[ IJ-YMIN $/ D Y, E N D$,

PROCEDURE SETPLOTTER, BEGIN PLOT $(0,0,0,0,-1019)$, ABCD[0]\&"START ", ABCD[1]+ "CALIBR"; ABCD[2]\&"ATION ", SYMBOL $(0.0,5.0,0.28, A B C D,-90,0,18) ; A B C D E O] \leftarrow " Y=$ $0 \quad "$, SYMBOZ $(0.0,=0.14,0.28, A B C D, 0.0,3), P L O T(0.8,0.0,3), P L 0 T(7,0,0,0,2)$, ABCD[0]+"SET $X "$, SYMBOL $(6,7,0,5,0,28, A B C D, 90,0,5)$, PLOT $(7,0,0,0,3), P L O T(7$ $.0,28,0,2)$; PLOT $(1.0,28.0,2), A B C D[0]+" Y=28$ ", SYMBOL $(0,0,27.84,0,28, A B C 0$, $0.0,4), P L O T(10.0,0.0,-3), E N D$,

FILL C[*]WITH OCT040404040404,0CTO40404040405, DCTO40404040406,0CTO404040 $40407,0 \mathrm{CTO} 40404040504,0 \mathrm{CTO} 40404040505,0 \mathrm{CTO} 40404040506,0 \mathrm{CTO} 40404040507,0 \mathrm{C}$ T040404040604, OCT040404040605, FILL A2[0,*]WITH OCT50500,0CT50600,0CT5070 C,FILL A2[1, *]WITH OCT60500, OCT60600,0CT60700,FILL A2[2,*]WITH OCT70500, OCT70600, OCT70700,FILL SYMAL * ]WITH OCT10304146371706,OCT1100000000000,0C T $10302027160000,0 \mathrm{CT} 40000144463717$, OCT $6050000000000,0 \mathrm{CT} 01103041433414,0 \mathrm{CT}$ 34454637170600,0 CT 43033730204000,0 CTOOO000000000000, OCTO1103041433404,0CT 7470000000000,0 CT0 3143443413010, OCT 1061737460000, OCTO6074721200000, OCT34 434130100103 , DCT 14344546371706, OCTO5140000000000, OCTO1103041463717, 0CT60 41333440000, OCT 11151404141202 , OCT42323135344404, OCT40100105164655, OCT514 24435251412, OCT21314200000000, OCT 10112120107022, OCT23454637170600, OCT 111 22221117014,0 CT 15252414000000,0 CTO2440600000000, OCTO1417006440200,0CT212 52303430000, OCTOOO34346371706, DCT3434000000000, OCTO4OT3746453404,0CTO304 $143340000,0 \mathrm{CT} 42413010010617$, OCT $37464500000000,0 \mathrm{CT} 00073746413000,0 \mathrm{CT} 47070$ 434040040, OCT 47070434040000, OCT $33434130100106,0 \mathrm{CT} 17374645000000,0 \mathrm{CTO} 0070$ $444474000,0 \mathrm{CT} 10302027173700,0 \mathrm{CT} 00011110000000,0 \mathrm{CT} 40202747000000,0 \mathrm{CT} 36271$

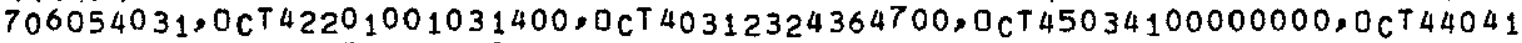
513040000,0 CT01452305410000, OCTO1103041470000, OCTO0070347254000,0CTO7004 000000000,0 CT00072347400000, OCT00074047000000, DCT $10304146377036,0 \mathrm{CT} 47703$

Figure F 6. Continued 
717060110, OCTO0073746453404, OCT 10010617374641, OCT 30107022400000,0 CTO0073 746453404, OCT 34434000000000 , OCT02324334140516, OCT46262720000000, OCT01452 305412303 , OCT 43232521000000 , OCTO 3430000000000, OCTO0112324160700,OCT10212 212112170, OCT24251514240000, OCTO 1417042044600, OCTO0000000000000, OCTOO470 000000000 , OCT01103041433414, OCT 05061737460000 , DCT20270747000000,OCTOTO11 030414700, OCTO7204700000000, OCTO7002440470000, OCTO0477007400000, 0CTO7244 724200000, OCT 07470040701434, OCTOONC 0000000000, OCT 10212313122200,0 OT 00477 016060717 , OCT 16704131304041 , OCT 02463545053513, OCT 3430000000000 , OCTO 24270 04440000 , DCT07272000000000, OCT 14167036340000 , OCTO0404404000424, OCT220000 00000000 ,OCT 00442204402200 ,OCTOO40C044044422, DCTOO400444002200, OCT243443 41301001,0 CT 3142422000000 , OCT24422002242200, กCT 20224422042200 , OCT2224220 0000000 , OCT24014124220000, OCT24024224202200, OCT44331304131100,OCT1131403 1332200 , OCT 10365004641070 , OCT 22220000000000 , OCTO2422220242200, OCTO044044 0220000, OCT 00442224202204, OCT 40220242220000, F ILL SYMBL * ]WITH OCT 30157 , OC T12156, OCT14155, OCT22153, OCT32151, OCT14150, OCT12147, OCTO6146, OCT14145, OC T14144, OCT26142, OCT14141, OCT16140,OCT14137, OCT20135, OCT22000, OCT12002, OC T22003, OCT32005, OCT14007, OCT22011, OCT30013, OCT12015, OCT40016, OCT30021, OC T 34023 , OCT 42025, OCT $32030,0 \mathrm{CT} 20032$, OCTO6034, OCT1 4035, OCT 12036, OCT24037, OC

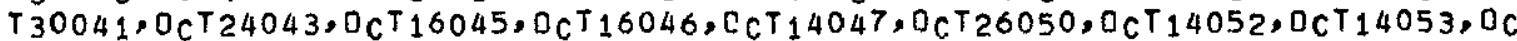
T12054, OCT10055, OCT32056, OCT14060, CCTO6061, OCT12062, OCT12063, OCT12064, OC T14065, OCT06066, OCT 12067, OCT 10070, CCT 34071, OCT 16073, OCT 30074, OCT 24076, OC T26100, OCT26102, OCTO4104, OCT14105, OCT 30106, OCT14110, OCTO0111, OCTO4112, OC T30113,OCT10115, OCT14116, OCTO6117,OCT12120,OCT12121, OCT12122,OCT16123, OC T14125, OCT34126, OCT22130, OCT12132,OCT10133, OCT12134;0LTH\&Q10;

PLOT $(0,0,1019) ;$

BEGIN

REAL CT,ST, X,TAU, TF, THETAO,E,K3,N3,V3,X50,X60,P50,P60, J,C,K, $Y 1, Y 2, Y 3, Y 4, X 5 M I N, X 6 M I N, D X 5, D X 6$,

INTEGER L,PRINT,

ARRAY Y $[0: 5], T, X 5, \times 6[0: 500]$,

BODLEAN NUTS;

LABEL START, FINISH,

ALPHA ARRAY HOZ, VER[0:1];

FORMAT LABL ("TAU", X3,"X5",X5, "X6", X5,"P5",X5,"P6"),

FORMAT RESL(I $3,4(X 2,55,2))$,

FORMAT PARM("E=",F5,2, X2,"K3=",F6,3,X2,"C=",E10,2,X2,"J=",F5.2);

PROCEDURE KUTTAMERSON (N, $X, H H, Y, F$, EPS, AR, ERROR, STEPSIZE);

VALUE $N, H H$, EPS, AB , STEPSIZE;INTEGER N; REAL $X, H H, E P S, A B$;

REAL ARRAY Y[0], PROCEDURE F; BDOLEAN ERRDR, STEPSIZE;

COMMENT: VERSION OF 660518 66072?

EPS ANO AB ARE THE RELATIVE AND ABSOLUTE ERROR BOUNDS RESP.

STEPSIZE TRUE TO WRITE STEPSIZE WHEN CHANGED

STEPSIZE FALSE FOR ND OUTPUT

ERROR IS SET TRUE IF STEPSIZE BECOMES TOO SMALL ELSE FALSE;

BEGIN COMMENT KUTTA MERSON INTEGRATES A SYSTEM OF N FIRST ORDER OROINARY DIFFERENTIAL EQUATIONS. SEE L. FOX, "NUMERICAL SOLUTION OF ORDINARY AND PARTIAL OIFFERENTIAL EQUATIONS", P. 24, PERMAGON PRESS, 1962 ;

OWN REAL HC, FINAL, H2, H3, H6, H8, ERR, TEST, T, H;

OWN INTEGER I, CU, CUT; OWN BOOLEAN BBL; LABEL $L$, KM, RETURN;

OWN REAL ARRAY Y1, Y2, FO, F1, F2[0:30];

COMMENT EXCEPT $F O R$ HC, THE OWN VARIABLES ARE FOR SPEED ONLY;

FORMAT MSSG("THE STEP SIZE IS NOH", R12.5," AT T=",R12.5);

DEFINE FORI = FOR I 1 STEP 1 UNTIL N DO \#,

CONSTANTS $=\mathrm{H}_{2}+\mathrm{H} / 2, \mathrm{O}, \mathrm{H} 3+\mathrm{H} / 3.0 ; \mathrm{H} 6+\mathrm{H} / 6.0 ; \mathrm{H}^{8}+\mathrm{H} / 8.0 \#$;

Figure F 6 (Continued) 


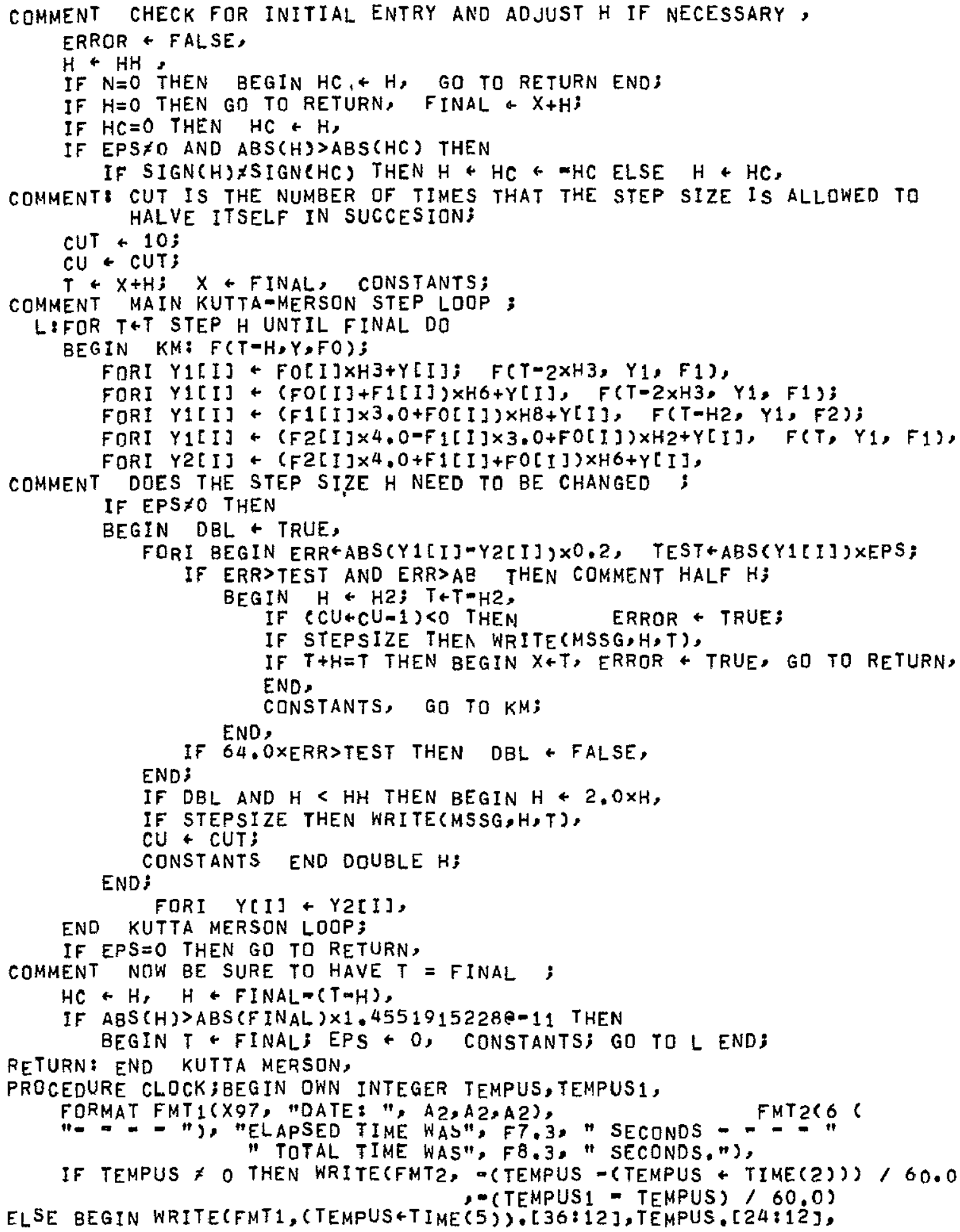

Figure $F 6$ Continued, 


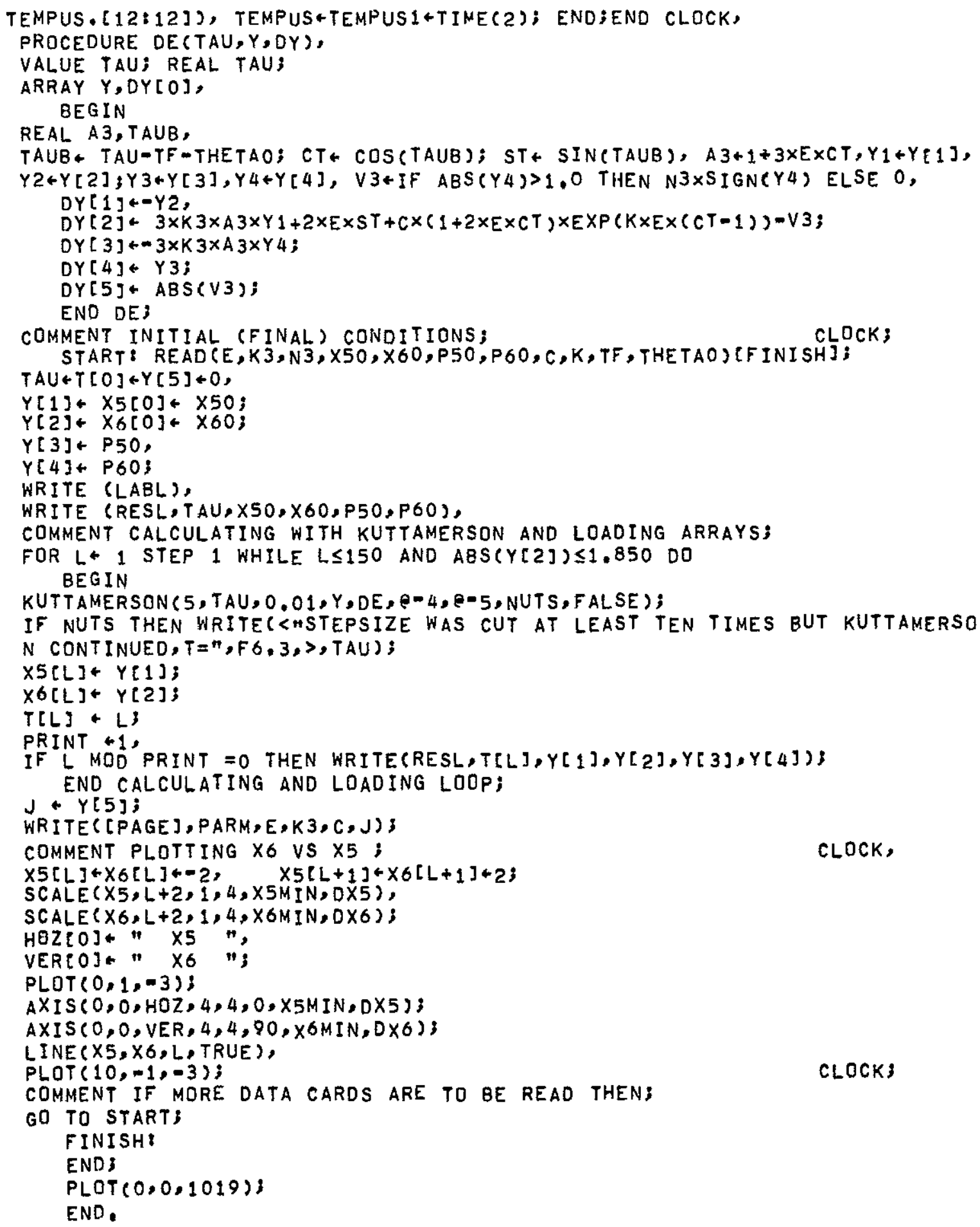

